
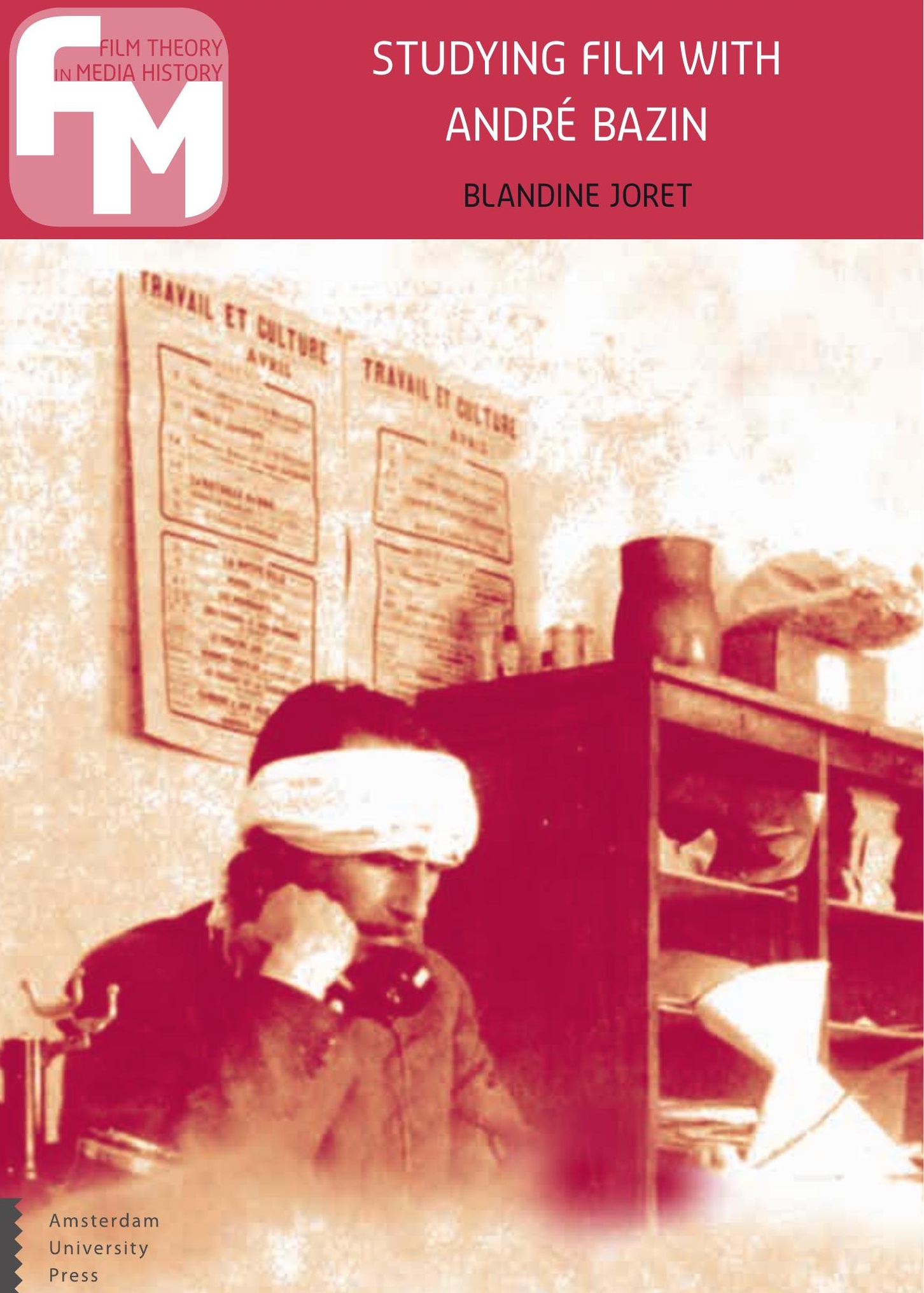
Studying Film with André Bazin 


\section{Film Theory in Media History}

Film Theory in Media History explores the epistemological and theoretical foundations of the study of film through texts by classical authors as well as anthologies and monographs on key issues and developments in film theory. Adopting a historical perspective, but with a firm eye to the further development of the field, the series provides a platform for ground-breaking new research into film theory and media history and features high-profile editorial projects that offer resources for teaching and scholarship. Combining the book form with open access online publishing the series reaches the broadest possible audience of scholars, students, and other readers with a passion for film and theory.

\section{Series editors:}

Prof. Dr. Vinzenz Hediger (Goethe University Frankfurt, Germany), Weihong Bao (University of California, Berkeley, United States), Dr. Trond Lundemo (Stockholm University, Sweden).

\section{Editorial Board Members:}

Dudley Andrew, Yale University, United States

Raymond Bellour, CNRS Paris, France

Chris Berry, Goldsmiths, University of London, United Kingdom

Francesco Casetti, Yale University, United States

Thomas Elsaesser, University of Amsterdam, the Netherlands

Jane Gaines, Columbia University, United States

Andre Gaudreault, University of Montreal, Canada

Gertrud Koch, Free University of Berlin, Germany

John MacKay, Yale University, United States

Markus Nornes, University of Michigan, United States

Patricia Pisters, University of Amsterdam, the Netherlands

Leonardo Quaresima, University of Udine, Italy

David Rodowick, University of Chicago, United States

Philip Rosen, Brown University, United States

Petr Szczepanik, Masaryk University Brno, Czech Republic

Brian Winston, Lincoln University, United Kingdom

Film Theory in Media History is published in cooperation with the Permanent Seminar for the History of Film Theories. 


\section{Studying Film with André Bazin}

Blandine Joret 
Cover illustration: Bazin at work, 1948 (Paris, photographer unknown).

Cover design: Suzan Beijer

Lay-out: Crius Group, Hulshout

Amsterdam University Press English-language titles are distributed in the US and Canada by the University of Chicago Press.

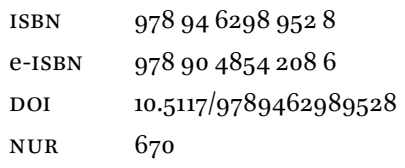

\section{(c) $(1) \Theta$}

Creative Commons License CC BY NC ND

(http://creativecommons.org/licenses/by-nc-nd/3.o)

@ B. Joret / Amsterdam University Press B.V., Amsterdam 2019

Some rights reserved. Without limiting the rights under copyright reserved above, any part of this book may be reproduced, stored in or introduced into a retrieval system, or transmitted, in any form or by any means (electronic, mechanical, photocopying, recording or otherwise).

Every efffort has been made to obtain permission to use all copyrighted illustrations reproduced in this book. Nonetheless, whosoever believes to have rights to this material is advised to contact the publisher. 
In loving memory of my parents, Anne Eeckelaert and Paul Joret. 
This book is the result of several years of research, first as a fellow at the Amsterdam School for Cultural Analysis, then as a lecturer in Media Studies at the University of Amsterdam. I'm grateful to my former supervisors as well as the members of my jury for their attentive reading and often argumentative comments on my work. My acknowledgments also go to the editors and reviewers at Amsterdam University Press. I thank my colleagues and students at the UvA, and my friends here in the Netherlands and abroad. Finally, I'm grateful to my brothers and sisters, and most of all to Thomas. 


\section{Table of Contents}

Preface

1. Studying Film 17

1.1. Young Art, Old Critics 19

1.2. In Search of a Method 29

1.3. Bazin's Mayonnaise Theory 37

2. The Art of Reality 47

2.1. Paradox: The Existence of Film 48

2.2. Integral Realism: Reality and Cinema 'Ultimately Equal' 60

2.3. Bazin's Wager $\quad 75$

3. Film and the Other Arts 89

3.1. Debates on Contemporary Art: Bazin, Marcel and Portmann 91

$\begin{array}{lr}\text { 3.2. Cinema and Painting } & 107\end{array}$

3.3. Case Study: Van Gogh's Ear $\quad 116$

3.4. Recreation: The Language of Film $\quad 126$

4. A Matter of Form 135

4.1. Form + Content 137

4.2. Perspectives on 3-D 149

4.3. Bazin Put to the Test: Godard and Wenders $\quad 161$

4.4. VR: Complete Film, or Total Cinema? 169

$\begin{array}{ll}\text { Epilogue: Unknown Arts, New Media } & 181\end{array}$

$\begin{array}{lr}\text { About the Author } & 187\end{array}$

$\begin{array}{lr}\text { Index } & 189\end{array}$ 



\section{Preface}

This book is not so much a study on André Bazin as it is a study with him on film. Deceased in 1958 at the age of forty, his ideas and theories have been praised, criticized, defended and appropriated to the point where much scholarship on him is either antagonistic or apologetic. Whereas the following pages are invested in testing the relevance of his work for contemporary film and media studies, I do not aim to defend nor appropriate Bazin. Instead, I wish to make his criticism (the metaphors, the references, the paradoxes) reverberate with contemporary perspectives and thereby extend the potential of his lineage today.

Studying film... Bazin's time as a film critic in the 1940 s and 1950s, spanning from the Nazi occupation of France into the post-war era in which film culture started to flourish in Paris, was marked not only by the gradual institutionalization of film studies at universities but also by the emergence of the first comprehensive film history books. Established at the Sorbonne right after the Second World War, the Filmology movement can be said to have initiated the 'serious' study of cinema, leaning on academic methodologies that were anthropological, sociological, psychological or philosophical in nature. With their laboratories set up to perform cognitive and behavioural experiments; their books, lectures, and conferences on cinema; and - let's not forget - a theater for screenings, the university embarked on a rigorous analysis of film. And, as the seventh art started to outgrow its critics, there was a real necessity to document its evolution in film histories. Bazin, though a passionate teacher and supportive of film books (historical or other), was not a film historian nor was he a scholar. As the other visionary French critic Serge Daney puts it, 'Bazin, educator, would never become professor. He became more than that: an initiator.'.

... with Bazin. To him, education and cinema were inextricably linked, but rather than finding place in the sterile laboratories or lecture halls at the Sorbonne, his work was socially oriented. By the time of the Liberation, he had brought film clubs to factories, farming communities and literary as well as student societies, on a national and international level. Around 1945, along with the immense amount of written criticism he would produce for newspapers, weekly and monthly magazines, he became responsible for the film programs at Travail et culture, an organization involved in popular education. There, for Bazin, lay the potential of cinema: a popular 
art capable of educating and integrating the people. Reading through his notes on preparing film screenings and discussions, one could easily conclude that Bazin in fact invented film analysis as it is taught in every single film program today. The photograph on the cover of this book was taken during this time. He is in his office which had become a cinephile hub in Paris attracting, among others, Alain Resnais and Chris Marker, the experimental pedagogue Fernand Deligny, as well as François Truffaut, at that time a delinquent teenager whose life would be forever altered by Bazin and cinema. ${ }^{2}$ In 1951, he co-founded Cahiers du cinéma, still associated with its famous yellow cover and with Bazin. An initiator he certainly was, and still is today.

After Bazin. Dedicated to the memory of Bazin, Truffaut's first feature film, 400 Blows (1959), marks the beginning of Bazin's afterlife. In an interview at its premiere in Cannes, Truffaut implicitly describes the film's famous direct address and freeze frame: 'My film ends there, where I first met Bazin. ${ }^{3}$ Without resolution, this shot must reverberate, expand and extend in the minds of whoever is watching: we, the spectators, are its reverse shot. The same principle applies to Bazin's texts, which are never set in stone but imply the reader's interpretation. Decades later, facing an entirely different film culture, Daney adds to this:

When we reread Bazin, it's something else that moves us. The quality of his style, his carefully phrased remarks, his measured tone, everything which qualified his work at the time as "constructive criticism" - something that has disappeared today. 4

As he points to the many changes in the evolution of film, from Bazin's realist discourse to advertising aesthetics of the digital image, Daney continues: 'it is in this manner that Bazin, ad absurdum, remains present.'5 If not Bazin's most comprehensive interpreter, Daney is his most imaginative reader: he reinvents Bazin by putting his reasoning to work, to test it. Though the primary sources of this study are Bazin's texts, I occasionally return to these names - Truffaut, Deligny, Daney - as well as others, to include the influence

2 On Bazin's as well as Deligny's intimate connection with Truffaut, see Dudley Andrew's 'Every Teacher Needs a Truant: Bazin and L'Enfant sauvage' in A Companion to François Truffaut (2013). From their involvement in popular education, the chapter beautifully traces the triangular relation between cinephilia, education and rebellion.

3 Truffaut, 1959.

4 Daney, 1983a, p. 45.

5 Ibid. 
they have had either on Bazin or his afterlife. As a scholar, furthermore, I hope this book contributes in its own way to an already established and still growing body of research on Bazin's role in film and media studies.

\section{Intellectual Justification}

Reading Bazin today almost certainly means testing him. As a cultural critic of his time, he was sensitive to the cultural/political/industrial landscape that both shapes and is shaped by the media (film in particular, but also $\mathrm{TV}$, radio and advertising). In other words: flexibility, evolution and change are cornerstone themes in his work. About the dependency of film theory on the actual evolution of film techniques, for example, Bazin wrote:

There are great silent films and there are great sound films. We already know masterpieces in colour, and tomorrow we might have excellent ones in $3 \mathrm{D}$. Let us not repeat the same mistake that film theorists of the silent period made, who spent all their time decrying the advent of sound, to no avail. ${ }^{6}$

His concepts, too, were not fixed but formed by specific film analyses. Of realism, Bazin had said during a film club debate that it is 'an empty concept, which we will try to fill up by analysing this film'.7 Bazin's way of thinking is pervaded by a need for flexibility, which is the benefit of being a film critic more than a theorist. That said, this flexibility resulted not only in an immensely diverse but also an inherently fragmented and ambiguous oeuvre, which complicates theoretical studies intending to either generalize or scrutinize his work.

The two very first posthumous studies on Bazin, published in the honorary issue of Cahiers du cinéma in 1959, already address these complementary premises. Eric Rohmer maintains that Bazin's so-called 'Summa' can be structured around basic principles ('ontology and language', 'film and other arts', 'film and sociology', 'neo-realism') that form 'an a priori plan rather than an arrangement after the fact'. ${ }^{8}$ Georges Sadoul argues that 'the thousands of pages he wrote and published have been, following a

6 Bazin, 1953c, EC p. 1238; Transl. Andrew, 2014, p. 289.

7 Bazin, 1947e, EC p. 310.

8 Rohmer, 1959, p. 37. 
phrase he liked, an enormous work in progress. ${ }^{9}$ Whether or not there is a methodical coherence in Bazin's work has remained a much-debated topic up to this day. Jean Ungaro, for example, writes that: 'Bazin is inevitably a theoretician, he has the taste and the preoccupation for abstraction and generalization', yet continues with: 'I am not sure whether there is one theory of Bazin because these theorizations lack that which would unify them in a coherent system.' ${ }^{10}$ And in "The Structure of Bazin's Thought" (1972), Brian Henderson argues that Bazin's writing in fact develops around a dichotomous structure of critical historical work on the one hand, and an ahistorical ontological theory on the other: 'Despite its realist terminology, the history system is not assimilable to the ontology system. ${ }^{11}$ This statement in fact summarizes the major critiques on Bazin throughout the second half of the twentieth century: with an emphasis on the Ontology essay, his entire oeuvre would be deemed 'ahistorical', in other words outdated. The critiques are manifold, but generally run along these lines: if cinema is a realist art form, and this realism is grounded in the photographic image of film, then Bazin's 'theory' could never account for the many changes in technology, aesthetics or politics of the past decades.

Throughout this book, I maintain that Bazin's criticism surpasses the dichotomy between a realist theory and historical criticism. Like many previous comprehensive studies on Bazin, my starting point is his affirmation of cinema as a fundamentally realist art form; unlike many of them, however, I approach Bazin's realism from the perspective of myth rather than ontology. Notwithstanding the canonical importance of 'The Ontology of the Photographic Image' (1945), Bazin's examination of ontology is more or less sparse, whereas the presence of myth in his work by far exceeds the scope of a single study like 'The Myth of Total Cinema' (1946). Theoretically speaking, myth in Bazin stands for a cinema that is 'not yet invented'; ${ }^{2}$ applied in his criticism, it functions as masquerade each time film shows one of its many faces, from Chaplin's comedy to Stalin's propaganda. This flexibility inherent in myth, then, comes closer to the open concept of realism itself, and ultimately to the immense variety in Bazin's critical work: Tom Gunning's detailed study of the Myth essay rightfully concludes that 'Bazin himself has not yet been invented. ${ }^{13}$ If Bazin has been a "negative fetish," 
a foil reminiscent of the crucifix in a vampire movie, for a predominantly structuralist and semiotic film theory in the mid-sixties, ${ }^{14}$ today the tide has turned. With several scholars rereading his texts, first in archives and now finally published integrally, a multi-faceted Bazin capable of commenting on today's media landscape is slowly but surely surfacing. Some try to outline a Bazin 2.0 by moving beyond Bazin, while others provide new insights in previously unknown texts. The combination of realism (Bazin the theorist) and myth (Bazin the critic) in this book, then, enables me to do both simultaneously: to show that his most fundamental concept, realism, is and always had to be continued.

Each chapter in this book is centered on a specific theme: film criticism versus theory (Chapter 1: Studying Film), realism (Chapter 2: The Art of Reality), impurity (Chapter 3: Film and the Other Arts) and evolution (Chapter 4: A Matter of Form). Starting from such key topics in Bazin's discourse, I then work through a series of implied paradoxes, derived either from his own body of work or from the actualization of his criticism in a contemporary context: if one technique can change the foundations of film theory, can we still have theory? How much realism is too much? Can a painting, following Bazin's logic, be cinematographic? Are 3-D and Virtual Reality the negation of his discourse? Following Daney's directive, then, I paired my analyses of Bazin's texts with contemporary case studies that engage, either thematically or technically, with his discourse - many times ad absurdum. In doing so, I hope to preserve as much as possible this flexibility of the critic's thought which, as his friend and colleague Roger Leenhardt phrased it, 'allows for the pleasure, I would almost say the emotion, of reading Bazin'.15

Considering the size of Bazin's oeuvre, finally, this study is by no means exhaustive. With his Écrits complets amounting to 2,681 texts, I have read approximately a quarter and ended up including less than 55 in this book. My research owes a great deal, if not everything, to the Bazin archives. ${ }^{16}$ Published

14 Joubert-Laurencin, 2014, p. 8.

15 Leenhardt, 1959, p. 15.

16 Prior to this integral publication in 2018, Bazin's work was held in two archives: one compiled by Hervé Joubert-Laurencin located at the Institut national d'histoire de l'art in Paris and another held by Dudley Andrew at Yale University in New Haven. The analyses described in this book are based on archival research at Yale University, where I accessed many untranslated, original French texts. To increase coherence in Anglophone Bazin studies, wherever English translations of a particular text were available, I reference those and, in some cases, modify them slightly. All other translations, including those of francophone scholarship on Bazin, are my own.

The location references for the texts from Bazin in the Écrits complets are indicated in the bibliography with EC, followed by the section number and the index number of the specific text (e.g. 'EC I, 1' for section 1, text number 1). Specific page numbers from the Ecrits complets 
originally in journals, newspapers, and monthly magazines rather than encyclopaedias or scholarly books, the two monolithic volumes published in 2018 restore an initial accessibility to Bazin's writing. At the same time, they emphasize a kind of 'archival' reading experience, which perhaps typifies Bazin's work today: with editorial montage kept to a minimum, the sheer amount of texts implies the reader's selection, ordering, interpretation and discovery. Already in 1958, collecting only the slightest fragment of his oeuvre, Bazin writes that:

It is true that we could have, and perhaps should have, fused these articles into a continuous essay. We have renounced doing so out of fear of falling into didactic artifice and preferred to trust the reader and leave it only to him or her to discover if this exists: namely, the intellectual justification for the reconciliation of these texts. ${ }^{17}$

'Editing prohibited!': Bazin's notorious aesthetic commandment applies to his texts as well, which turns reading Bazin today into an almost cinematic experience. In a preface to this new monumental publication, its editor Hervé Joubert-Laurencin takes on an attitude similar to that of Bazin. Rather than grouping these texts under pre-set thematic clusters, he stresses the necessity to:

leave it to the new reader, expert or novice, scholar or not, the chance to find his own reference points and to compose his own thoughts. Let's remind ourselves also that, for Bazin, 'all films are born free and with equal rights', and that we can therefore, without betraying it, apply this republican maxim onto his own texts. ${ }^{18}$

Bazin's reference here to Article 1 of the Universal Declaration of Human Rights is a methodological statement and already hints at his looming stance against an upcoming approach to film analysis: auteur theory. By praising the distinctive style of certain auteur-filmmakers, Truffaut and the other young critics at Cahiers risked ignoring the possible importance of lesser-known filmmakers or surprising newcomers: to them, some films were more equal than others. Concluding his famed response to them and affirming the necessity of 
close film analysis, Bazin wrote: 'author, yes, but of what?'19 And indeed, the same can be said of Bazin scholarship of the past decades: whether praising or disparaging Bazin, many scholars have indulged in lazy and deceptive repetitions of arguments claimed to be Bazin's', ${ }^{20}$ producing a distant, false memory of the texts, while others more recently have emphasized the necessity for closely analysing the 'bazinian text'. ${ }^{21}$ With this book, I want to push this motto even further and show that there is no Bazin theory: Bazin, today, is an empty concept that we should try to fill up by analysing his texts.

\section{Bibliography}

Andrew, Dudley (2013). 'Every Teacher Needs a Truant: Bazin and L'Enfant sauvage.' In: A Companion to François Truffaut. Eds. Andrew, Dudley \& Anne Gillain. West-Sussex: WileyBlackwell, pp. 219-241.

Bazin, André (1946/1958). 'Le Mythe du cinéma total.' Qu'est-ce que le cinéma? Paris: Éditions du Cerf (2008): pp. 19-24. EC OP I, 2.

--- (1947e). 'Païsa de Rossellini.' D.O.C. éducation populaire, No. 3-5 (November-December). EC IV, 344 .

--- (1952b). 'Pas de fossé entre un “cinéma de l'élite” et un "cinéma populaire”.' Radio cinéma télévision, No. 124 (1 June). EC X, 1051.

--- (1953b). 'Le cinéma est-il mortel?' France observateur, No. 170 (13 August). EC XIV,1404.

--- (1957b). 'De la politique des auteurs.' Cahiers du cinéma, No. 70 (April). EC XXI, 2275.

--- (1958a). 'Avant-propos.' Qu'est-ce que le cinéma? Tome 1: Ontologie et langage. Paris: Éditions du Cerf (1959): pp. 7-9. EC OP I.

Daney, Serge (1983a). 'André Bazin.' In: Ciné journal, Vol. II/1983-1986. Paris: Cahiers du cinéma (2006): pp. 41-46.

Gunning, Tom (2011). 'The World In Its Own Image: The Myth of Total Cinema.' In: Opening Bazin: Postwar Film Theory and Its Aftermath. Eds. Dudley Andrew and Hervé Joubert-Laurencin. New York: Oxford University Press, pp. 119-126.

Henderson, Brian (1972). 'The Structure of Bazin's Thought.' Film Quarterly, Vol. 25, No. 4 (Summer): pp. 18-27.

Joubert-Laurencin, Hervé (2018). 'Éloge de la dispersion. Petite introduction à la lecture d'André Bazin.' In : André Bazin: Écrits complets ı. Ed. Hervé Joubert-Laurencin. Paris: Éditions Macula, pp. 14-64.

--- (2014). Le Sommeil paradoxal: écrits sur André Bazin. Montreuil: Les Éditions de l'CEil .

Leenhardt, Roger (1959). 'Du côté de Socrate.' Cahiers du cinema, Vol. 16, No. 91 (January): pp. 15-17. Rohmer, Eric (1959). 'La “Somme” d'André Bazin.' Cahiers du cinema, Vol. 16, No. 91 (January): pp. 36-45.

Sadoul, Georges (1959). 'A Work In Progress.' Cahiers du cinema, Vol. 16, No. 91 (January): pp. 46-51. Ungaro, Jean (2000). André Bazin: généalogies d'une théorie. Paris: L'Harmattan (2000). 


\section{Other sources}

Truffaut, Francois. 'François Truffaut présente son film Les Quatre cents coups.' INA, Collection Reflets de Cannes (09-05-1959). [Accessed 30/10/2017] <http://fresques.ina.fr/festival-decannes-fr/fiche-media/Cannesooo55/francois-truffaut-presente-son-film-les-quatre-centscoups.html>.

\section{Filmography}

The 400 Blows [Les 400 coups] (François Truffaut, 1959)

\section{Used translations}

Bazin, André. What Is Cinema? Transl. Timothy Barnard. Montreal: Caboose (2009).

Bazin, André. André Bazin's New Media. Transl. Dudley Andrew. Berkeley: University of California Press (2014). 


\title{
1. Studying Film
}

\begin{abstract}
My intention in this first chapter is to situate Bazin's film criticism against and in dialogue with established academic methods (the Filmology movement and film historiography in particular). More critic than theorist, Bazin was firsthand witness to the technological changes at the time and the pitfalls of film theory, which shaped his particular approach to film history as well as his firm critique of institutionalized film studies.
\end{abstract}

Keywords: film theory, film criticism, film history, evolution techniques

The habits of academic training forbid the scholar from speaking about what he doesn't know. The academic rightly states that his cinema attendance is reasonably inferior to his practice of low Latin. He claims that he doesn't have the taste nor the age to indulge a bit in such vain pleasures. He learns Chinese faster than Chaplin's cinematography. André Bazin, 1951d

The times when Paul Souday responded to an interviewer of the Nouvelles littéraires that a serious critic couldn't take interest in cinema are over. We already have a history of the seventh art by a professor at the Sorbonne, we will one day have a $\mathrm{PhD}$ dissertation of 800 pages on comedy in American cinema from 1905 to 1917 , or something like that. And who would then dare to maintain that it's nothing serious? André Bazin, 1943a

Today, Media Studies is a discipline firmly embedded in academic programs worldwide. When it comes to film, university curricula can rely on almost a century of methodological inquiry, ranging from structuralist analyses to film philosophical explorations, to account for an art form that, despite considerable technological change, continues to uphold one constant

Joret, B., Studying Film with André Bazin, Amsterdam: Amsterdam University Press, 2019 DOI: $10.5117 / 9789462989528 / \mathrm{CHO1}$ 
feature: its indisputable popularity. The fairly short history of film studies, however, has been anything but constant, and the questions raised during the times of its academic inauguration period remain pertinent for media scholars today. From silent film to sound, black-and-white to color, from analogue to digital and 'flat' to 3 -D: time and time again, film theory has been destined, forced even, to re-define itself. Yet, while such methodological flexibility is more or less incorporated in today's New Media programs, film scholarship in its early days tended towards firmly delineating its object of study. 'This is cinema!', Georges Altman exclaimed in 1931: in an attempt to defend aesthetic theories of the moving image (nothing more: no sound, definitely no color), silent film theorists set out to denounce that which, they considered, was not cinema. As strange as it may sound today, 'that' was most often the medium's growing tendency towards realism: technological changes, such as sound, color or 3-D, were deemed to threaten cinema's newly acquired status as the seventh art. Fast forward to the structuralist theories from the seventies onwards: again, cinematic realism is under attack. However, this time it is its built-in essentialism that bothered film scholarship: its inability to account for the new developments cinema was facing following the digital turn. ${ }^{1}$ During the course of the twentieth century, the study of film was caught between a rock and a hard place: methodological consistency (worthy of an established academic discipline) or flexibility (appropriate for its object of study).

More critic than theorist, André Bazin was firsthand witness to the technological changes at the time and the pitfalls of film theory. With his career spanning from the forties continuing well into the Liberation, his particular approach to film history is shaped by the evolution of film and the gradual institutionalization of film studies, both of which were unfolding in front of his eyes. While pre-war silent film theory had typified distinct principles of a nascent film art, several of Bazin's texts sketch out a specific working method applicable to an art form in full growth: a myth of total cinema emerges from his critiques on academic film studies, his texts on film criticism and film history and, more specifically, his work on Charlie Chaplin which exemplifies Bazin's stance on these topics. This chapter provides an in-depth analysis of these works, and from thereon sketches a particularly bazinian film 'theory' based on realism. 


\subsection{Young Art, Old Critics}

'Can one take an interest in film?' Such is the title of Bazin's very first cinema essay, written in $1942 .{ }^{2}$ Coming from a cinephile and film critic, the answer seems obvious: yes! As rudimentary as it may sound, this question indeed carries the justification and relevance for his practice of film criticism. It was first asked during an interview with the literary critic Paul Souday in 1928 , to which he had answered: 'No, it is not the concern of a serious critic; cinema is less significant than the dung of a goat.' ${ }^{3}$ More than a decade after this interview, Bazin, aged twenty-four and at the outset of his career as a film critic, blames Souday's contempt for cinema on his old age and the reluctance to adapt his aesthetic preconceptions, in particular his implied maxim odi profanum vulgus (I hate the common masses). 'Cinema was about twenty or thirty years younger than Paul Souday; one shouldn't be too young to please the old critics. ${ }^{4}$ Such austerity that characterizes the old critics, Bazin continues, derives from 'their refusal to believe in anything which is not established with a bookish or academic tradition'. ${ }^{5}$ Naturally in complete disagreement with Souday, he then sets out to defend cinema's critical importance:

What social influence can this gigantic flow of images and myths have: circulating across all people of the world! One might say that, perhaps, the diffusion of cinema is the greatest recurring esthetico-social fact since the Middle Ages. ${ }^{6}$

Instead of condemning its popular and widespread character, Bazin not only considers this to be cinema's primary aesthetic value but relates it to the very origins of any 'bookish' tradition: the printing press. This comparison is significant and raises another, more pertinent question: to what extent can cinema, a young art form in a constant state of flux, fit an academic tradition?

The relevance of Bazin's defence of cinema resides in its anachronous yet ironically prescient vision. Indeed, why would he revisit such a cinephobe statement fourteen years after the fact? Bazin in fact sounds rather indifferent to the impertinence of Souday, and his essay is not invested in proving

2 Bazin and Chartier, 1942.

3 Paul Souday, 1928, cited in ibid., EC p. 72.

4 Ibid.

5 Ibid.

6 Ibid. 
him wrong. Cinema's increasing popularity would have solved that issue already. Instead, Bazin is struck by a similar ignorance of cinema among the filmgoers in his day, which he describes in an elaborated version of the first article, entitled 'Let's Rediscover Cinema' (1943):

Young people today, and perhaps especially intellectual young people, know absolutely nothing about cinema, ask themselves no questions about it, and express an opinion about it only to despise it. [...] They did not witness the birth of cinema, they did not know the intoxication of its future - [...] they did not live through its history.

No doubt they should have studied [film] history, just as they studied that of theater and poetry. Indeed, all culture implies the knowledge of a past, a past which we begin learning as soon as we enter school. It is here, however, that we touch on the very heart of the problem.

This art, which is only a few decades old, has left us no documentation. The previous generation, having lived through the history of film, did not suffer from this lack; its memory served as a cinématèque. Young people today, however, are the first of the generations who will know less and less about cinema even as they go to the movies more and more. ${ }^{7}$

Referring, again, to the notion of aging, Bazin now points to the growing importance of a critical investment in film history: since cinema had outlived its critics, the question of documenting its past would become increasingly vital and essential for its future development. Bazin's initial film essay thus formulates this inquiry into an indispensable history of cinema, and with this he was certainly not alone. ${ }^{8}$ But his proposal for what he termed a 'myth

7 Bazin, 1943a, EC pp. 73-74; Transl. Hochman, 1981, pp. 26-27.

8 In a chapter on the post-war 'renaissance of cinema', Laurent Le Forestier elaborates on the recurring use of the metaphor of ageing in French criticism: 'a French cinema is dead - the cinema of the Occupation, of the Anglo-Saxon absence, of subjects not directly related to reality, etc. - another French cinema is being born, with unclear outlines in 1945' (p. 35). Le Forestier then continues to argue that realism functioned much like an umbrella term to 'speak differently about the cinema of before, letting go of all evaluative dimensions, by articulating sources and descriptions' (p. 61); see La Transformation Bazin (Presses universitaires de Rennes, 2017). From thereon, Le Forestier maintains that Bazin's thinking, inherently realist, is not that distinct from other contemporary theories of film and that Bazin's thought in fact gradually becomes more 'scientific'. In this chapter, on the contrary, I emphasize Bazin's realism, in particular its function in the myth of total cinema, as a critique on existing and emerging film theories. From this perspective, to lose the singularity of Bazin's thinking, which is indeed Le Forestier's explicit intention in the chapter, is also to lose sight, at least partially, of the uniqueness and contemporary value of his critical method which, especially in his early texts, develops from a reaction against the academic tradition. 
of total cinema' stands out among the various emerging film histories, as it implies a particularly critical method that safeguards against the rigidity and cinephobia that Souday came to embody.

\subsubsection{Myth Versus History}

The discrepancy between a young art form in its tender age and the rigidity of old critics is a recurring theme in Bazin that directly informs his methodology. In his seminal essay 'The Myth of Total Cinema', written in 1946 (and edited for the publication of What Is Cinema? in 1958), Bazin develops his own critical approach to the evolution of film technologies in relation to pioneering efforts in film history. In this manner, I understand Bazin's myth of total cinema as carrying out a critical agenda appropriate to an art form in flux. ${ }^{9}$ Our understanding of the history of film cannot discard questions of technology, but precisely its continuous evolution prevents us from grounding any theoretical study of film on technology alone.

Originally written as a book review of the French film historian Georges Sadoul's The Invention of Cinema (1946), being the first volume of his extensive series General History of Cinema, Bazin's text on myth is outlined as an aside to his colleague's view on film history. Of all the aspiring historians in his day, Bazin admired Sadoul's work and appreciated the publication of his monumental book as enabling the birth of a true cinema history, an initiative that was not without reservations.

A remark in relation to the condition of the film historian is essential. This condition is very different from that of a historian tout court. [...] The importance of Sadoul, and that which lays down his homework in terms of its mission, is to contribute for a large part to the creation of a cinema history. By its scale and the critical system it supposes, his undertaking is the first that really deserves to be called history. ${ }^{10}$

9 Given the significance of the notion of 'myth' in several structuralist works, primarily Ernst Cassirer's Language and Myth (1925), Roland Barthes' Mythologies (1957), and Claude Levi-Strauss' 'The Structural Study of Myth' (1955), it is perhaps necessary to highlight Bazin's original usage of the term. As I hope to demonstrate, he understands myth as the point where art and reality ultimately meet, and it is therefore linked to his views on cinematographic realism. Though some overlaps between the structuralist views and Bazin's may be found, I maintain that it is historically more accurate and theoretically more fruitful to adhere closely to his own texts (e.g. specific words, examples or theories he adopts in his film analyses), and through that to seek resonances with his coterie or with lines of thought he actively engaged in.

10 Bazin, 1954d, EC pp. 1556-1557. 
And yet, while Bazin unambiguously defends Sadoul's comprehensive and exhaustive work as outstripping the partisan, incomplete or incorrect publications of others, their methods - the critic versus the historian - are different. As a Marxist, Bazin reasons, Sadoul sees technology as cinema's means of production, its infrastructure: technology determines the course of film history. ${ }^{11}$ From his side, Bazin explicitly reverses the standard historiographical method, leading to the essay's most-often quoted statement: 'every new improvement to cinema merely brings it paradoxically closer to its origins. Cinema has yet to be invented!' ${ }^{12}$ Inventions are not the only driving force of film history: 'total cinema', which Bazin defines as the integral representation of reality (in sound, color, movement and three dimensions), while it affirms the necessity of technological inventions, includes industrial as well as social and artistic factors in the equation. ${ }^{13}$

To today's filmgoers, this might come across as an outdated quarrel, yet a contemporary example, fully in line with the idea of total cinema, immediately explains the relevance of Bazin's reversal: three-dimensionality. While one could easily think that immersive 3-D spectacles are a result of technological progress, the technology itself in fact existed long before its enormous popularity we are witnessing today. Film historian Georges Potonniée, cited by Bazin in his essay, even claimed that stereoscopy (the process that enables three-dimensionality by copying binocular vision) predates the moving image. Why did 3-D take so long to hit the screen in the fifties, and why did it disappear so quickly only to reappear half a century later in full force? Technological determinism cannot answer this question, yet examples of this sort abound in film history. Bazin calls this the 'tenacious resistance of matter to the idea" ${ }^{\text {"14 }}$, which of course implies that in order to study the evolution of film one must refrain from applying prescriptive theories to the study of film.

As Sadoul had initiated, one could say, the 'bookish' tradition of cinema histories, which in its aftermath encouraged the emergence of an academic

11 As François Albera rightly argues in '1945: trois “intrigues" de Georges Sadoul', however, Sadoul's film historical work is in fact much more complex; Bazin thus appears to state a 'reversal' for the sake of his argument. For a full analysis of Sadoul's historiographic project, see Albera 2011.

12 Bazin, 1946/1958, p. 23/EC p. 2559; Transl. Barnard, 2009, p. 17.

13 Elsewhere, Bazin refers to these circumstances as 'an inverted pyramid' (Bazin, 1955b, EC p. 1652): the film itself is like the vertex of an inverted pyramid, with its social, industrial and technological conditions being its base. As this pyramid is inverted, the vertex touching the ground, a film cannot survive unless its base is fully in balance. For a brief elaboration of this concept in relation to the evolution of film language, see Joret, 2016.

14 Bazin 1946/1958, p. 19/EC p. 2558; Transl. Barnard, 2009, p. 13. 
study of film, cinema had become more or less established and possessed the attributes that should have pleased the older critics. But did this solve the problem? Not in the least, according to Bazin. While university professors turned their attention towards cinema, methodologies arose and books multiplied, the study of film was losing its most fundamental basis: its social character. Generally speaking, historians and filmologists - I will return to them later on in this chapter - tended towards what Bazin terms a 'scientific criticism' that reaffirms an outdated elitism in the face of cinema's development:

Thus, since four or five years, a situation arose partially comparable to that of literature: an elitist public for elitist criticism. Unfortunately, it is not as simple as that, because there is no such thing as an elitist cinema and, as 'scientific' or distinguished as they might be, the critics are very much obliged to speak of films unworthy of this attention. And this is the uncalled-for difficulty: how to apply to the whole of cinematographic production a critical reflection which is equally worthwhile? In other words, and in its most elevated manifestations, criticism suffers from a crisis of references. ${ }^{15}$

Bazin's particular interest in books on cinema, especially history books, reflects a broader critical investment in revisiting the relationship between the evolution of film technology and its impact on film theory. The myth of total cinema explicitly builds on a reversal of an image-oriented historical paradigm, and through that Bazin accuses early film theorists and the academic discipline of film studies of lacking the flexibility necessary to study film. But before turning to Bazin's rather fierce and polemical criticism, we must first take a closer look at the intersection of technology, myth and 'total cinema'. And where else to start than with the event that shook film theory: sound cinema.

\subsubsection{Case Study: Chaplin and the Talkies}

From the perspective of total cinema, the introduction of sound in film history was a logical step because it brought cinema closer to 'the complete and total representation of reality.'. ${ }^{16}$ Yet, for existing film theorists at the time, sound meant deep trouble: when silent film theorists had finally established film as an art form in its own right, a new technology came to 
knock it off its aesthetic pedestal. For Bazin, this tendency towards complete realism was not the beginning of cinema's decadence but rather its vocation. Furthermore, Bazin's defence of realism goes hand in hand with his defence of cinema's popularity: 'Film aesthetics will be social or film will do away with aesthetics. ${ }^{17}$ In this manner, Bazin's myth of total cinema follows a forethought that unties the study of film from prescriptive categories, especially those that had prevented earlier film critics from accepting the talking film as part of the development of film art.

To begin with, Bazin's notion of total cinema directly refers to the journalist and science-fiction writer René Barjavel's essay ‘Total Cinema: An Essay on the Future Forms of Cinema' (1944). Struck by a lack of serious attention given to sound cinema at the time, Barjavel writes:

When the infant art pronounced its first word, this unexpected sound provoked a real consternation in the world of the aesthetes and theoreticians of the screen. It took twenty years to create theories on the silent art. Were we [suddenly] supposed to change everything? We preferred to ignore the new invention. [...] If, just as your child is about to pronounce its first words, some sceptical philosopher came to tell you, with a smile: 'He will start talking nonsense. Cut off his tongue' - would you assent to it? ${ }^{18}$

According to Barjavel, sound cinema presented itself as a debacle to many film theorists at the time, which he describes as 'a very curious example of this resistance to reality, of this intellectual laziness', ${ }^{19}$ thereby pointing specifically to not only Jean Epstein but also Abel Gance, Marcel L'Herbier, René Clair and Germaine Dulac, among others. This defence of sound cinema is shared by Bazin, for instance when he writes: 'The primacy of the image is a historical and technological accident; the nostalgia some still feel for the silent screen does not go back far enough in the childhood of cinema. ${ }^{20}$ Elsewhere, Bazin, more radical than before, writes this nostalgia off as bare spitefulness:

Intellectuals don'tlike to be interrupted. When the screen started to talk, they kept quiet. This was not out of politeness. They enjoy making it heard that it is instead out of contempt or out of heartbreak. We think, from our

17 Bazin, 1943b, EC p. 76 . With this statement, Bazin references the more philosophical or scholarly approach of Émile Vuillermoz, founding father of French criticism, who stated: 'cinema will be bergsonian, or it won't be!' (Vuillermoz, cited in Plasseraud, 2011, p. 181).

18 Barjavel, 1944, p. 22.

19 Ibid.

20 Bazin, 1946/1958, EC p. 2559; Transl. Barnard, 2009, p. 17. 
side, that it is out of spite. Let's agree that such a boorishness was bound to offend our aestheticians. So much audacity of thought, so many turbulent articles and discussions, such generous advice and many oracles without appeal, only to arrive at this ungratefulness. By rejecting their rule, cinema indulged in a second-rate realism. This is it, this will end in tears. ${ }^{21}$

By adopting Barjavel's notion of 'total cinema', Bazin aims to counter a theoretical tendency to attribute the essence of cinema to the image alone. In 'The Evolution of Film Language', he repeats that the talking film diluted the image-versus-reality dichotomy, a dichotomy characteristic of the film theories from the silent film era, and thereby annihilates the film theoretical 'consternation' of those aesthetes Barjavel accused of intellectual laziness. Bazin writes:

When we stop seeing editing and the formal composition of the image as the very essence of film language, the arrival of sound no longer seems to be an aesthetic fault line dividing two radically different kinds of film. A certain kind of film believed itself to have died at the hands of the soundtrack, but it was in no way 'the cinema'. ${ }^{22}$

With his myth of total cinema, Bazin thus inverts the prescriptive paradigm. Both Bazin and Barjavel relate speech to rebellion: audacity, bad mouthing, speaking up against authority - against the intellectualist, elitist film theories. But not only the theorists struggled with accepting sound on film: cinema itself awaited major transformations, exemplified most clearly in the early sound films of the silent film icon, Charlie Chaplin.

Incidentally, this shift in cinema's visual paradigm also surfaces in Bazin's work on Chaplin, which develops from an almost nostalgic recollection of silent cinema via a 'mythification' of his famed silent film persona The Tramp, into an ambiguous defence of talking cinema. It is therefore indispensable to relate the myth of total cinema to Bazin's extensive work on Chaplin and its intrinsic relation to the introduction of sound in cinema history, ${ }^{23}$ As Rochelle Fack argues:

[Bazin's] defence of Chaplin's talking films rests upon a premise that can be unsettling. It consists of determining the links that tie the characters 
in Chaplin's talking films to the myth of Charlot. Charlot, the silent film character, acts as the seamark, the reference point that structures Bazin's criticism. [...] Bazin renders [Chaplin] as an evolving construction, an artistic phenomenon, and a myth that is converted into something else through a discursive use of speech. ${ }^{24}$

Bazin indeed articulates his particular understanding of myth most clearly throughout his work on Chaplin. As I will argue now, the coincidence of Chaplin's talking films with the film theoretical agenda directly connects 'total cinema' to its film historical counterpart: myth. From thereon, I derive a more detailed meaning of myth as a critical methodology for writing film history.

Chaplin's first sound film, Modern Times (1936), is a particular elegy for silent cinema: machine sounds or growling stomachs often turn into comic elements that complement his visual, slapstick comedy. A photograph of Chaplin is not nearly as funny as a moving clip; similarly, these particular sounds are necessary to understand the humour of Chaplin's very first sound film. But even in Modern Times, Charlie does not speak and at first sight the scenes in which he appears, give the impression of silent film: inter-titles articulate his lines and musical soundtrack accompanies his gestures. When Charlie finds a job as a singing waiter and rehearses his performance, he keeps forgetting the lyrics to his song. His girlfriend then writes down the lyrics on his cuff, the rehearsal apparently goes smoothly (even though, as spectators, we still do not hear his voice). Eventually, Charlie sings in his own voice for the first time ever, and his gibberish surely strengthens the comical effect of his characteristic gestures. Again, in The Great Dictator (1940), when the Jewish barber is mistaken for dictator Hinkel and urged onto the stage, his inability to speak - 'You must speak. / I can't!' - first appears as a straightforward reference to Chaplin's silent film icon; but then a newfound eloquence takes over that turns his famous speech into an embrace of sound cinema, immediately marking the end of The Tramp and the beginning of a

24 Bazin also develops his notion of myth in 'Soviet Cinema and the Myth of Stalin' (1950), where he criticizes the cinematic representation of Joseph Stalin for its lack of 'historical distance', which unfolds subtly into a critique of historical determinism: 'From then on, the identification between Stalin and History was accomplished once and for all, so that the contradiction of subjectivity does not crop up anymore in relation to him.' (Bazin, 1950a, EC pp. 670-671) This necessity for mythification in hindsight returns, for instance, in 'A Saint Becomes a Saint Only After the Fact' (1951): 'The problem that arises in cinema as well as theology is the retroactivity of eternal salvation. Now, in all evidence, a saint does not exist in the present, only a being that becomes it and, besides, up until his death risks to damn itself.' (Bazin, 1951b, EC p. 703). Similarly, the notion of myth, which Bazin applies to Chaplin's filmography as well as the evolution of cinema in general, stands as an alternative method to the 'eternal damnation' of prescriptive aesthetics of silent film theories. 
new type of cinema. From a comparable point of view, Antoine de Baecque writes, '[With The Great Dictator] Chaplin inaugurated a new era of historical film, in which history speaks in the present tense of cinema and holds forth on the present tense of the world in which it is screened. ${ }^{25}$ If Charlie in Modern Times is still unable to utter anything but mere gibberish in public, the Jewish barber's speech conveys an eloquence that speaks directly to film history. For Bazin, it is the face of the actor and the sound of his voice in this final scene that motivate his application of the myth to Charlie:

The discourse of the Dictator is precisely the only passage in the film that profoundly moved me, not for the script lines which I barely listened to, but for the sole and unique reason that we see Chaplin's face at length in close-up and that we hear his voice. I indeed say Chaplin and not Charlie, because for the first time we witness in this sequence of the Dictator the sketch of a metamorphosis. The proximity of the camera and maybe more even, the range of panchromatic grey reveal the clearly legible face of Chaplin, as if it were a superimposition under the mask of the little man with the moustache. [...] I owe to this shot, which is technically speaking banal, and to his completely superfluous discourse one of my most pure cinematographic emotions. This passage, which is unanimously condemned by the critics in favour of the dance with the globe or the barber being shaved to the waltz of Brahms - this scene is, on the contrary, from the perspectives of a critique in accordance with the myth, one of the most perfect scenes. The discourse envelops it in my memory with a transparent and transient smoke that leaves the image surrounded with the deafening aura of his voice. ${ }^{26}$

While the notion of myth in relation to sound and language is irrevocably related to youth and intellectual development (a child learning to speak), Bazin ultimately transforms it into a critical-historical category that reconciles itself with the idea of aging (Chaplin the actor shows his face). In 'If Charlie dies' (1953), for example, Bazin further develops his analysis alongside two reference points: the mask of Charlie, its smoothening plastic-like make-up, and the face of Chaplin, his wrinkles and old age - both combined in the famous peace speech in The Great Dictator. Once Bazin's myth is understood, via Barjavel's notion of 'total cinema', as directed against image-oriented silent film theories that ignored talking cinema, his work on Chaplin and 
the film historical arguments from 'The Myth of Total Cinema' run remarkably parallel. Charlie, whose most essential characteristics were based primarily on the absence of sound, has no choice but to reinvent himself and to accept sound as an integral element of film art. Thus, Bazin sees in Charlie the personification of a myth that is fundamentally concerned with the evolution of technology.

For Chaplin, talking cinema certainly posed itself as a challenge to the established Tramp persona. But even in his silent, typically visual comedy, Bazin sees a stubborn resistance to anticipation, which on a theoretical level resonates with the critic's rejection of prescriptive academic methods. In one of his most elaborate studies on Chaplin, Bazin writes:

\section{FROM CHARLIE TO THE MYTH:}

In less than fifteen years, the little man with a silly tail coat, a small trapezoid moustache, his cane and bowler hat occupied the consciousness of humanity. Never, ever, has a myth been so universally upheld. [...] We cannot understand anything of Charlie's character if we try to do so according to categories that are not his own. Charlie is a mythical character who dominates each adventure in which he gets involved. [...] For hundreds of millions of people on this planet, Charlie is a hero, as were Odysseus and Roland le Preux to other civilizations, except that today we know the ancient hero through completed literary works which have fixed their adventures and avatars. For the people of the twentieth century, on the contrary, Charlie can always play a new role in a new film. Chaplin, so to speak, is not the author of this or that film, his work does not align itself in a filmology, he is Charlie's creator and guarantor. ${ }^{27}$

Just as Bazin maintains that Chaplin cannot be understood using categories that are foreign to him, so too does he imply that established academic methods, such as filmology, are unfit to offer an appropriate study of cinema. In another essay, 'Introduction to a Symbolic of Charlie' (1948), Bazin elaborates on Chaplin's typical 'backwards kick' as a gestural expression of his capricious dismissal of the past:

The backwards kick, especially when it has no precise use (even if this use is mere revenge), perfectly expresses Charlie's constant concern not to be tied to the past, to drag nothing along behind him. ${ }^{28}$ 
His gestures and the situations he continuously encounters, and around which his comedy is based, all stem from a resistance to anticipation. Consequently, the objects themselves resist being used by Charlie in a conventional manner: 'The practical function of objects,' Bazin writes, 'is part of the human order which is itself practical and anticipates future events, ${ }^{29}$ but not for Chaplin:

[...] while makeshift solutions are always enough for him, he demonstrates an extraordinary ingenuity in the present moment. No situation ever leaves him at a loss. For him, there is a solution to every problem, even if the world, and perhaps the object world even more than the human world, was not made for him..$^{0}$

The backwards kick combined with the temporary solutions he invents to situations demonstrate Charlie's particular resistance to conformity. Charlie, furthermore, is mythical for Bazin in his creative adaptation of sound, and therefore incorporates his major critique of silent film aesthetes. From this point of view, Ivone Margulies writes that 'all of Bazin's work on Chaplin is about a body constructed and ravaged by cinema. Interweaving the man's ephemeral destiny with his filmic corpus, and frequently using foreboding qualifiers, Bazin associates cinema with existential time. ${ }^{31}$ To sum up, the emphasis on Chaplin's ironic relation to time and objects in Bazin's essays invokes an existential experience of time, which, as I maintain subsequently, directly ties in with his critical methodology. Rather than adhering to prescriptive categories or essentialist theories, Bazin implicitly relies on an existentialist mind-set, which maintains that cinema first exists before any theory can solidify an essence to film.

\subsection{In Search of a Method}

In 'For an Impure Cinema. In Defence of Adaptation' (1951) Bazin opposes Georges Altman's exclamation from 1931, 'this is cinema!', by which he glorified silent film as essentially different from other art forms. More broadly, he criticizes the idea that cinema is an art of the image and that it evolves completely independent from other arts, like literature and theater: 
according to Bazin, 'this [...] was a misunderstanding of the essential nature of film history'. $3^{2}$ The advent of sound cinema, or rather its rejection by certain film theorists, is Bazin's most referenced illustration of this misunderstanding of historical progress. Ultimately, through sound, it is the social function of cinema that he defends most vehemently:

\begin{abstract}
Cinema cannot exist without a minimum number (and this number is immense) of immediate viewers. Even when film directors challenge an audience's taste, their boldness is valid only to the extent to which we allow that viewers are mistaken about what they should like and what they will come to like one day. The only possible contemporary analogy is with architecture, because a house only has meaning when it is habitable. Film too is a functional art. Using another reference system, we would have to say that its existence precedes its essence. Critics must take this existence as their starting point, even in their most adventurous extrapolations. Like history and with many of the same reservations, taking note of a shift surpasses reality and is already a value judgment. This is something that those who damned talking cinema from the start did not want to admit, when it already had the incomparable advantage of silent cinema of having replaced it. [my emphasis] ${ }^{33}$
\end{abstract}

Bazin's conviction that writing history often comes with a value judgment takes caution rather than generalization as its methodological point of departure: 'Even if this critical pragmatism does not seem to readers to be very well founded, at least they will admit that it justifies humility and methodical prudence in the face of any sign of cinema's evolution. ${ }^{34}$ The direct reference to Jean-Paul Sartre's philosophy of existence, namely that existence precedes essence, shows, in the words of Dudley Andrew, 'a more historically tuned critic [who] watched, and celebrated, the sacrifice of the medium's pure self-conception'. 35 It proves, indeed, to be a methodological guide in Bazin's understanding of film history, as he consequently builds his methodical prudence on an existentialist approach to evolution. In his renowned lecture Existentialism Is a Humanism (1946), ${ }^{36}$ Sartre conceived of 'a being which exists before it can be defined by any conception of it':

Ibid.

36 While Sartre develops this maxim in a text in which he explicitly differentiates his views from the Christian existentialists, in particular Gabriel Marcel (1889-1973), I will argue in a later 
What do we mean by saying that existence precedes essence? We mean that man first of all exists, encounters himself, surges up in the world - and defines himself afterwards. If man as the existentialist sees him is not definable, it is because to begin with he is nothing. He will not be anything until later, and then he will be what he makes of himself. ${ }^{37}$

Bazin indirectly adopts the general premise of Sartre's maxim in his call for methodological prudence. His reaction to technological determinism as well as aesthetic essentialism can be traced back to this existentialist premise, which steps away from a prescriptive study of film by embracing instead, as Andrew described, evolution as its prime motive:

Bazin's existentialism kept him from trying to seek or formulate an essence which cinema ought to be or become. Instead, he hoped to do for cinema what Sartre had done for man: to make it aware of its freedom and possibilities, to unshackle it from old theories which tie it to particular self-conceptions or ideologies..$^{3}$

In fact, along with his existentialist undertone, Bazin's emphasis on the functional aspect of film - its social aesthetics, so to speak - leads to one final discussion on methodology. This time, he writes with an angry pen, not against the mistakes of earlier film critics (which, strange as it sounds, illustrates their love for cinema), but directly accusing the university professors - his contemporaries - of elitism and intellectual laziness.

\subsubsection{The Aseptic Study of Filmology}

Bazin's existentialism surfaces, albeit indirectly, in his scathing review of Gilbert Cohen Seat's General Introduction: Notions, Fundamentals and Vocabulary of Filmology (1946) and his very tough critique of the

chapter (see 3.1 Debates on Contemporary Art: Bazin, Marcel and Portmann) that Bazin's views on cinema history are in fact more closely aligned with Marcel's philosophy of existence. On Bazin's disagreements with Sartre, see also Jean Ungaro's chapter 'Sartre and Bazin: Antagonism as Outcome' in André Bazin: Genealogies of a Theory. About Bazin's 'The Technique of Citizen Kane' (1947), for example, Ungaro writes that 'Bazin appears to tell Sartre that he does not understand his discourse on cinema. The entire article is structured around the criticism of Sartre to forget, when he talks about cinema, that which he himself had said about American literature.' (Ungaro, 2000, p. 141).

37 Sartre, 1975, p. 349.

38 Andrew, 1976, pp. 172-173. 


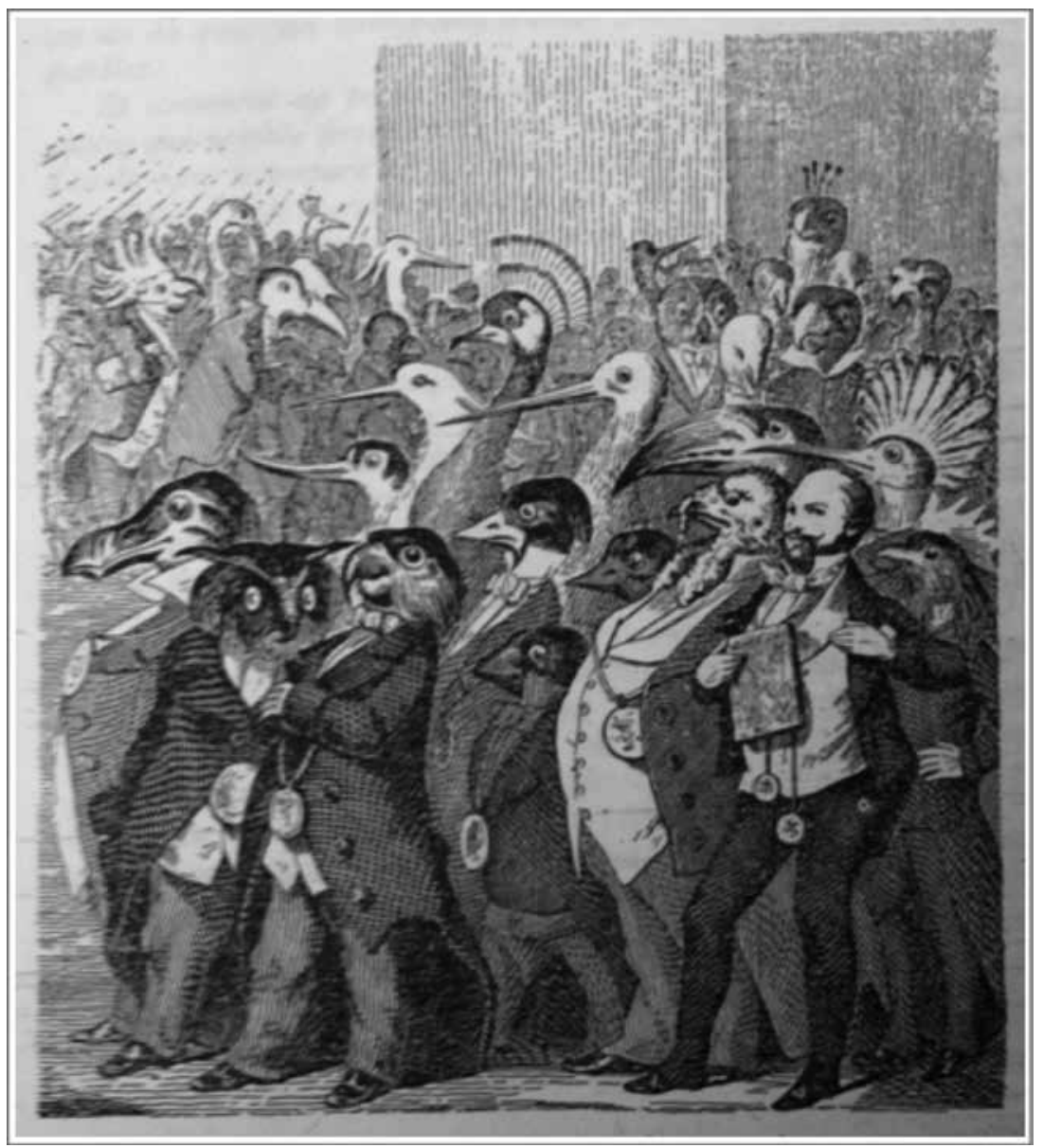

Fig. 1 Professors of film, according to Bazin

Filmology movement in general. This movement prided itself for being the first academic study of cinema, which followed a method characterized by a fundamental schism between a film itself and its greater sociological relevance: 'The filmic fact, which is individual, distinguishes itself from the cinematographic fact, which is much broader, more vague: in one word "social".39 Bazin, especially in his younger years, ${ }^{40}$ denounced the newfound

39 Botson, 1964, p. 632.

40 In La transformation Bazin (2017), Laurent Le Forestier argues that Bazin's thinking progressively grew more scientific and hence institutionalized. When it comes to Bazin's position towards the Filmology movement, Bazin did change his mind (see 1.3 Bazin's Mayonnaise Theory); however, his more favorable attitude towards the academics, in this case, appears to 
discipline as "ostentatious of "scientific" generalisation and of philosophical abstraction', ${ }^{41}$ and frequently called attention to 'an awareness of the cinematographic fact'. ${ }^{2}$ The satirical drawing included in the beginning of Bazin's essay with the ironic title 'Introduction to a Filmology of Filmology' (1951), perfectly illustrates his concerns: proud peacocks, wise owls in suits, and men with medals symbolize the institutionalization of a study of cinema that was itself anything but social (Fig. 1).

In this particular essay, which he for obvious reasons wrote under the pseudonym Florent Kirsch (Florent being the name of his son and Kirsch his wife's maiden name), Bazin attacks the filmologist methodology full-on as disinterested and unconcerned with films themselves:

It won't be necessary for a distinguished filmologist to have more familiarity with the classics of the screen than a matriculating student with palimpsests. Far from this ignorance being here a totally unacceptable obstacle, filmology glorifies it. Of course, filmologists are not forbidden to go to the film theater, but one should not recommend it to them either; instead, this redundancy risks obscuring the nascent science. Filmology is the study of cinema-in-itself. Nothing proves that Pavlov loved dogs. ${ }^{43}$

Taking account of cinema's social relevance or even watching a film would only distract the academics: as a general scientific rule, Bazin seems to imply, abstraction wins over the subtleties of film culture. A filmologist, Bazin also suggests, needs not be a devout cinephile, just as Pavlov was probably not an animal lover, given the torture-like setting of his experiments - incidentally, Bazin himself was both. ${ }^{44}$ In a presentation given at

have more to do with the Filmology movement's internal development rather than with Bazin's 'scientification'.

41 Bazin, 1951d, EC p. 770.

42 See: Bazin, 1943a; Bazin, 1944; Bazin, 1948b; and Bazin, 1948e.

43 Bazin, 1951d, EC p. 769.

44 Bazin's cinephilia is a given; his love for animals, too, is well-known and has in fact been associated with his film criticism. In his bibliography of Bazin, Dudley Andrew writes that 'Bazin kept animals around him all his life. [...] One early girlfriend recalls him picking her up for an excursion with a snake wrapped around his body and a smile on his face' (2013, p. 5). Bazin had dogs and cats but also turtles, lizards, snakes, insects, butterflies and even a crocodile (ibid., pp. 5-6). In 'On the Difficulty of Being Coco' (1954), Bazin gives an account of the great efforts he took to bring along a parrot on his way back to Paris from a film festival in Sao Paolo, which he considered to be a very refined animal: '[...] as my admiring neighbour tells me: "the only thing missing is his speech"' (1954b, EC p. 1501). For more on Bazin's film criticism in relation to animals, see for example: Jeong, 2011; Fay, 2008; Andrew and Jeong 2008; and Daney, 1972, which I discuss at length in a later chapter (see 2.I.I Editing Prohibited? CGI and the Dummy of Danger). 
the International Filmology Symposium, he eloquently relates this study of film, 'out of context, in relation to the film in itself', 45 to the ignorance of progress as an irrevocable consequence of such abstractions:

Here, I don't want to speak in favour of pessimism, but only plead an historical realism to which I, as a professional critic, am particularly sensitive. I want to say that the big movements of technological evolution of the cinema escape our initiative or our control; it is more fruitful and more interesting to consider these a priori as developments rather than to hold them for inventions on behalf of an a priori critique. It is this kind of critique which almost unanimously condemned the talking cinema at its birth. ${ }^{46}$

The foundation of being in existence, which Sartre succinctly expressed, thus proves to have been more to Bazin than a clever tongue-in-cheek reaction to, for instance, the abundant philosophical references in Cohen Seat's book. With only a few loose references, Bazin adheres to this existentialist framework in a remarkably casual fashion, which stands opposed to the detailed precision in his cinematographic analyses. In doing so, he promotes a study of cinema that takes the film itself as a point of departure rather than an abstracted, 'aseptic' study propounded by Filmology: 'the cinematographic purity of the scholars, whose patronage we desire, is a symbol of this new science: of the rigidity of its methods and the asepsis of its laboratories. ${ }^{27}$ Again ironically playful with philosophical references, Bazin writes in an ultimate reflection on his profession as a film critic:

45 Bazin, 1955b, EC p. 1651; Bazin's vocabulary in the critique to Filmology's methodology is reminiscent of Sartre's distinction between 'being in-itself' and 'being for-itself': 'One may be reminded here of that convenient fiction by which certain popularisers are accustomed to illustrate the principle of the conservation of energy. If, they say, a single one of the atoms which constitute the universe were annihilated, there would result a catastrophe which would extend to the entire universe, and this would be, in particular, the end of the Earth and of the solar system. This metaphor can be of use to us here. The For-itself is like a tiny nihilation which has its origin at the heart of Being; and this nihilation is sufficient to cause a total upheaval to happen to the In-itself' (Sartre, 1943, p. 786). This distinction, which affirms the potential influence of a single film on the evolution of film language, also reflects the difference between Bazin's more existentialist approach and semiotics, to which I return to briefly later on in this book (see 3.4 Recreation: The Language of Film), which upholds that linguistic systems cannot be disturbed by a single deviation.

46 Bazin, 1955b, EC p. 1652.

47 Bazin, 1951d, EC p. 769 . 
I don't remember which philosopher or psychologist maintained that consciousness was nothing but an epiphenomenon and that, with or without, Descartes would have just as well written the Discourse on the Method. Evidently, this theory is false, but I'll keep only its value as metaphor. With or without criticism, Chaplin, Griffith, Murnau, Stroheim, Dreyer would have existed in the same way: not a single shot in their films would have been changed. Regarding their work, the abundant criticism that it aroused is merely an epiphenomenal conscious fact, whose necessity does not tackle its usefulness. Nevertheless, I do think that this parasitical vegetation on an impressive tree maintains with it, a fortiori, symbiotic relations that are necessary not only, obviously, to its growth, but without a doubt to its happy aging. ${ }^{48}$

Instead of adhering to philosophical or pre-established historical categories, Bazin enthusiastically promoted the ciné-club movement, and considered film criticism to be 'useless but necessary': 'the principal satisfaction this profession gives me resides in its seeming uselessness: writing film criticism is almost like spitting into water from a bridge. ${ }^{49}$ As I will conclude now, Bazin advanced a form of critical writing that could be synergetic with the evolution of cinema, by always taking the film itself as a point of departure. The overall essayist style of his criticism, resulting in the fragmented, counter-prescriptive structure of his oeuvre, follows a similar principle that resists any form of solidification and stands in stark opposition to the aseptic tone of Filmology.

\subsubsection{A Social Study of Film}

Bazin's particular concern with the social relevance of film becomes most tangible in his categorical support of the ciné-club movement, in which he saw potentially one of the most important developments of post-war cinema. Certainly, the presentation and discussions of films in rural communities, factories, literary and student societies stand starkly opposed to the abstracted and distanced study of Filmology. Such pragmatism filters through Bazin's elaborate texts on the preparation and presentation of a film screening, ${ }^{50}$ as well as his extensive apology for film criticism. Most

48 Bazin, 1958b, EC p. 2517.

49 Ibid., EC p. 2516; Transl. Cardullo, 2014, p. 51.

$5^{0}$ See, for instance, Bazin 1948f; Bazin, 1947b, in which he writes: 'Let us not renew with cinema the mistakes of academic pedagogy in literature teaching, for example; mistakes against which 
historians and philosophers had witnessed the birth of this new art form and could recall its evolution from memory, having been a first-person witness to the earnest signs of change. The historical importance of the ciné-clubs, according to Bazin, was inherently linked with the gradually waning access to a memory of cinema:

Cinema starts to enter history. Twenty years ago, it was possible to have seen almost everything noteworthy in cinema; today many young people are ignorant about most of the outstanding works in film history. There could therefore be no more cinematographic culture which does not start with knowledge of the classics of the 'seventh art'. Besides, the evolution of cinema has been so the past twenty years, that the enlightened amateurs themselves will have the greatest benefit from revising their conceptions after a new viewing of the masterworks. ${ }^{51}$

As I have argued, the aversion to prescriptive film theories indeed serves as the foundation for Bazin's myth of total cinema, as it is the silent film aesthetes' refusal to hear of sound cinema that alerted him to the application of the existentialist maxim to the study of film. Stepping away from such a perspective, Bazin quite literally develops a methodology that follows the complexities of film culture itself rather than an a priori application of philosophical or art historical paradigms. In this sense, Bazin's myth of total cinema in fact suggests that, as with Chaplin, cinema does not align itself with a 'filmology'. Indeed, part of his dismissal of the Filmology movement, now specifically addressing its founder Gilbert Cohen Seat, is their scientifically abstract language and excessive references to frameworks that are foreign to cinema:

[Cohen Seat] has voluntarily obscured his work by transposing the most concrete facts to the vocabulary and the rhetoric of academic philosophy. With a calculated precocity he has, for instance, carefully eliminated all film titles, all references to specific cinematographic events, the slightest evocation of a name of a star, even one known to anyone; he refers to Plato, Bergson, Euripides, Shakespeare, Molière or Tabarin, but circumvents the names of Lumière, Méliès and René Clair with epiphrases and allusions.

the University itself is reacting today. To be more precise, when it comes, for instance, to the presentation, the commentary or the discussion of a film, the point will be to start from the normal sensitivity of the spectators [emphasis in original]' (EC p. 304).

51 Bazin, 1948b, EC p. 430. 
[...] Cinematographic language, the medium (provided that one goes to the theater) of the most childish melodramas, becomes for the filmologist (who avoids it) a 'logos in silver salt.'.52

Bazin thus rejects a direct application of categories coming from disciplines foreign to cinema, which becomes most evident in his proposal for a new critical historical paradigm that could apply to sound cinema. While he preferred the oral film criticism in the ciné-clubs as well as other more dynamic forms that he tentatively termed the 'affective presentation of a film', ${ }^{3}$ he understood the importance for the film critic to speak as much as possible in the present tense:

The function of criticism is not to bear on a silver platter a truth that may not exist, but, as much as possible, to further - in the minds and hearts of those who read it - the impact of the work of art which is true to itself.54

So, if film criticism cannot influence the artwork itself, as it often did during the silent film era when critics were also filmmakers, Bazin nevertheless considers his practice as necessary: criticism creates an echo of the film that reverberates and extends its significance into the minds of the audience. To return to the metaphor of filmology's aseptic methods and its laboratories smelling of ether: the scientist understands life, that of a testing animal for example, by killing in order to dissect it - a critic, sensitive to the social function of its subject, works to preserve its natural habitat.

\subsection{Bazin's Mayonnaise Theory}

One way in which Bazin's criticism differs from scholarly texts is his eclectic style and his use of metaphors. Even with the publication of a four-volume selection of his oeuvre, comprising several thousands of articles ranging from short periodicals to extensive essays, Bazin steers away from the encyclopaedic paradigm characteristic of bookish traditions. Well aware of the assorted selection of the publication, he indeed considered its gaps as productive rather than reductive. The 1958 introduction to What Is Cinema?,

52 Bazin, 1951d, EC p. 770.

53 In Bazin's formulation, this is 'some sort of creation of atmosphere in the theater, primarily by listening to records or reading texts' (Bazin, 1948f, EC p. 433).

54 Bazin, 1958b, EC p. 2519; Transl. Cardullo, 2014, p. 59. 
for instance, gives an interpretational directive regarding the compilation of articles:

It is true that we could have, and perhaps should have, fused these articles into a continuous essay. We have renounced doing so out of fear of falling into didactic artifice and preferred to trust the reader and leave it only to him or her to discover if this exists: namely, the intellectual justification for the reconciliation of these texts. 55

In that same introduction, Bazin defends the intentional blank spots that separate the essays as providing an interpretative freedom to the reader, which a conjunctive publication would have excluded. With several thousands of critical articles and many authorial studies, Bazin's work is characterized by an immense diversity that does not allow for any solidification into an intensive theory of film and indeed deliberately counters exhaustive histories as well as abstracted studies of film. Such fragmentation, then, reflects the underlying methodological premise by which Bazin intended to redirect cinephobic misunderstandings of film aesthetics, and subsequently of its history, towards an embrace of the film itself as a reference point for film criticism.

To conclude this first chapter, I would like to elaborate on a particular metaphor that might at first sight look like a random example but after careful consideration explains the counter-hegemonic structure of Bazin's film theory: mayonnaise. In fact, if there exists an all-encompassing 'theory' to which Bazin's body of critical writing tends, I want to propose this to be what François Truffaut (1932-1984) has termed 'Bazin's mayonnaise theory':

When I was twenty, I argued with André Bazin for comparing films with mayonnaise - they either emulsified or did not. "Don't you see," I protested, "that all [Howard] Hawks's films are good, and all [John] Huston's are bad?" I later modified this harsh formula when I had become a working critic: "The worst Hawks film is more interesting than Huston's best." This will be remembered as la politique des auteurs. [...] I feel we've all adopted Bazin's mayonnaise theory because actually making films has taught us a lot: it is as much trouble to make a bad film as a good one. Our most sincere film can seem phony. ${ }^{56}$ 
With the mayonnaise metaphor, Bazin opposed himself to the growing importance among critics of the auteur theory, which posited that 'there are no works, there are only authors 57 - a phrase by the playwright and novelist Jean Giraudoux (1882-1944) frequently cited by Truffaut but which Bazin judged 'a polemical sally which seems to me of limited significance. ${ }^{58}$ Instead, Bazin argues that, as with preparing mayonnaise, making a film involves combining different ingredients that either blend smoothly or not. A renowned filmmaker can definitely disappoint: "certain "greats" have suffered an eclipse or a loss of their powers', 59 and conversely 'there is no reason why there should not exist - and sometimes they do - flashes in the pan of otherwise mediocre filmmakers' ${ }^{60}$ From this point of view, he writes about Les Jeux sont faits (Jean Delannoy, 1947), of which he praises Sartre's scenario but critiques the whole: 'How come that this film completely failed, like mayonnaise that refused to "thicken"? Everything in it is good, yet all together it is inedible. ${ }^{61}$ And again: 'Agence matrimoniale [Jean-Paul Le Chanois, 1952] reminds me of curdled mayonnaise. In it, I perfectly distinguish the oil of realism from the egg yolk of good intentions. ${ }^{62}$ At several instances in his writing, Bazin uses the image of mayonnaise that did not thicken to describe a failed attempt at combining different elements, such as vinegar, oil, egg yolk, sometimes mustard, lemon juice and a pinch of salt.

Bazin's motivation for this particular metaphor builds on the fact that from a chemical point of view, mayonnaise is a prime example of so-called oxymoronic 'colloidal dispersions', i.e. mixtures of substances that do not blend: vinegar (a water-based substance) combined with oil, which is hydrophobic. ${ }^{6}$ Water, or $\mathrm{H}_{2} \mathrm{O}$, is a polar molecule that will attach to its own kind but strongly repel the oil, which is itself non-polar: the oil is pushed away from the water, as to minimize the contact surface between both liquids. In order to mix these two opposing ingredients, the egg yolk (together with the optional mustard) will act as an indispensable element for the mixture to thicken: it contains so-called 'emulsifying molecules' (lecithin, to be precise), which are partly hydrophobic and partly hydrophilic. On one side, the yolk will coat the neutral oil droplets, and on the other side

Truffaut, 1955, pp. 45-47.

58 Bazin, 1957b, EC p. 2151; Transl. Graham, 2005, p. 250.

59 Ibid., EC p. 2154; Transl. Graham, 2005, p. 255.

60 Ibid., EC p. 2153; Transl. Graham, 2005, p. $25^{2}$.

61 Bazin, 1947a, EC p. 294.

62 Bazin, 1952e, EC p. 946.

63 For an accessible explanation of the molecular structure of mayonnaise, see: This, 2007, pp. 39-43. 
attract the water molecules. The trick for mayonnaise to thicken, then, is to whisk vigorously and patiently to separate as many oil droplets as possible, slowly adding them to the yolk-vinegar mixture; the connection between the coated oil and the water will then be so strong that, even when left out at room temperature, the mayonnaise will not disperse.

Applied to cinema, the analogy suggests that all formal elements (such as the scenario, cinematography, performance, etc.) combined, the film will either 'look good' ${ }^{64}$ as a whole or feel stodgy. Furthermore, the emulsifying process of mayonnaise happens without changing the molecular composition of each ingredient: there is no need to boil or cook anything. All there is to mayonnaise is constant whisking to rearrange the ingredients into a new harmonious configuration, in which their individual structures remain nevertheless unaltered. From this, the mayonnaise metaphor in Bazin ranges from the argument on auteur theory to a more general institutional critique, as he writes in a later essay on Filmology, this time in favor of the discipline:

If Filmology 'thickened', this happened like with mayonnaise. All the ingredients existed, ignored, unconsciously and scattered for twenty years. All it took was to think, like a good housewife, of putting in some more egg yolk and to stir in a certain way. ${ }^{65}$

And in one of his more pragmatic texts on the organization of ciné-club debates, he again picks up the mayonnaise metaphor in affirmation of the methodological principles he drew regarding the abstracted and aseptic study of cinema:

One last remark: a debate is like mayonnaise. It can fail even when all the ingredients are there. But this shouldn't surprise us. It proves that this is not an arithmetic class, that there is more needed than competence: the complicity of chance, some unknown emanations, a certain grace that sometimes denies itself, and at other times sweeps down on you at the very moment of despair. I have seen debates gone astray for forty-five minutes saved by the last, and everyone pleased when they left.

It's that the film is not the only work of art, the critical reflection is one as well; it demands love, sincerity, inspiration. There is a muse of the ciné-clubs. ${ }^{66}$

64 In French, the expression la mayonnaise a 'pris' figuratively also means that 'things are looking good'.

65 Bazin, 1951d, EC p. 771.

66 Bazin, 1954c, EC p. 1083. 
From these examples, it is clear that the image of mayonnaise as an oxymoronic emulsion of elements is instrumental to grasp Bazin's counterprescriptive method as a 'whole', whose existence is nevertheless granted only by the individual workings of its disparate elements: the myth of total cinema as the acknowledgement, first and foremost, of the existence of film. The task of a film critic, then, is not to design prescriptive theories nor to derive strictly descriptive analyses but rather to engage in 'constructive criticism', to use Serge Daney's formulation: whisking the right ingredients together, based on a strong recipe, with ample skills along with good taste. ${ }^{67}$

While Bazin considered the debate following the auteur theory to be nothing more than a 'family struggle', and he in fact preferred this new critical approach of his younger colleagues to the 'naïve presuppositions' they were fighting, his objections are indeed illuminating. Against Truffaut, he writes: 'The drama does not reside in the growing old of men but in that of cinema: those who do not know how to grow old with it will be overtaken by its evolution. ${ }^{68}$ This is not the twenty-four-year old antagonistic critic speaking: by 1953, cinema culture was booming in Paris, with ciné-clubs and film journals, like his own Cahiers du cinéma, steadily building towards an established tradition of cinematographic critique. By this time, Bazin - though barely in his forties and already struggling against his imminent passing - is himself considered a critic of the older generation. Now, even more, he feels the necessity to warn fellow critics, like his protégé Truffaut, against not seeing the forest for the trees:

So? So perhaps in twenty years the 'young critics' of some new form of spectacle that we cannot even imagine, and which can't be guaranteed to be 'an art', will be reading our film criticism from 1953 with a condescending smirk. Our views today could seem to them more naïve than the aesthetic sectarianism we find in our predecessors from the 1930s, who were properly outraged at the death throes of an art of the pure image that had finally reached maturity. In the meantime, and while waiting, let's just play dodgeball; I mean, let's go to the cinema and treat it as an art. ${ }^{69}$

Another biographical reference illuminates the sequel of his quarrels with Truffaut: Bazin stuttered heavily, so much that it would have prevented him

67 On the role of taste in Bazin's views on criticism, see my discussion under 4.1.1 From Advertising to Poetry in Bazin.

68 Bazin, 1957b, EC p. 2154; Transl. Graham, 2005, p. 249.

69 Bazin, 1953b, EC p.1236-1237; Transl. Andrew, 2014, p. 316. 
from teaching at the university. ${ }^{70}$ Janine Chartier, colleague at Travail et Culture and later on his wife, recalls that Bazin's stutter during his screening sessions was both 'tragic and admirable', and according to Françoise Burgaud, the stammer also interfered with Bazin's capacity to read and write lengthy texts, all the while demonstrating a 'fabulous memory of images.' ${ }^{71}$ As in his essays on Chaplin, the notion of eloquence (when meaning is perfectly integrated into language) here supports Bazin's critique of auteur theory. However, this time he approaches the question from the perspective of an apparent regression, as he invokes a poet's tragic aphasia: 'When [Charles] Baudelaire was paralyzed and unable to utter anything other than his "cré nom", was he any less Baudelairian?'72 At the end of his life, Baudelaire suffered a series of strokes that left him partially paralyzed and affected his speech to such an extent that the poet, once so well-versed, was forced to use the only two words he could pronounce - Crénom - most commonly understood to be a concocted abbreviation of the blasphemous oath Sacré nom de Dieu, to cover an entire array of emotions from pure frustration to immense joy. From a neurological point of view, there is no evidence that Baudelaire's speech impediment was accompanied with cognitive regression, as Sebastian Dieguez and Julien Bogousslavsky write: 'What thought is without language is one of the oldest questions of philosophy, and it has received tremendous input through the study of aphasic patients. However as the specific case of Baudelaire is concerned, the question will forever remain unanswered. ${ }^{73}$ Bazin's remark suggests that he accepts the dissociation of speech and thought: the inability to speak does not make Baudelaire less Baudelairian. ${ }^{74}$ By placing the emphasis on the author as the sole creator

70 Andrew, 2013, p. 38.

71 Françoise Burgaud, in Pagliano, 1988 [Radio program].

72 Bazin, 1957b, EC p. 2154; Transl. Graham, 2005, p. 255.

73 Bogousslavsky and Dieguez, 2007, p. 136.

74 In doing so, Bazin subtly positions himself against the argument that Baudelaire's speech impediment was somehow the outcome he deserved or even wished for: 'In these circles Baudelaire's aphasia seems to almost make sense, in a way. This implies that Baudelaire's life can be examined retrospectively so that one can fully see the ironies of fate at work. [...] It is almost as if Baudelaire's ending as an aphasic was some sort of retribution for his dissolute lifestyle' (Bogousslavsky and Dieguez, 2007, p. 146). This view was supported by Sartre in his study on the poet from 1947, in which he discusses Baudelaire's misfortune as 'bad faith': 'Sartre is notorious in his analysis of Baudelaire's psyche for having rather exclusively focused on the poet's will (or rather the lack of it)' (Ibid., p. 125).

Sartre's essay was met with criticism, particularly from Auguste Angles in 'Sartre against Baudelaire' (1948), in which he criticizes Sartre's 'biographical criticism': 'The only reproach one can level at Sartre is that [...] he forgets most of the time that Baudelaire wrote Flowers of Evil and several other quite admirable books. His quarrels with Ancelle, the way Baudelaire 
of the artwork, Truffaut and his cohorts ignored the integral share of the subject matter, the existence of the film itself: the cinematic equation, so Bazin claims, then becomes 'auteur + subject (reduced to zero) = work', which he immediately nuances by stating that 'the equation I just used was artificial, just as much so, in fact, as the distinction one learned at school between form and content'. ${ }^{7}$ In the following chapters, I hope to illustrate that the same applies to studying Bazin: the content of Bazin's oeuvre is expressed through the style of his writing and vice versa, meaning that one cannot dismiss the text itself (the subject) when studying its author (Bazin).

Bazin's initial aversion to image-oriented aesthetics that deemed the sound film as 'low-grade realism' runs through his numerous historical and critical analyses and is firmly embedded in his general affirmation of cinema as the art of reality. As I will argue in the subsequent chapters of this book, Bazin applies these methodological principles in his original conception of 'integral realism', via which he attempts to overcome precisely this distinction between form and content - another canonical, art historical paradigm refuted by film.

\section{Bibliography}

Albera, François. '1945: Trois “intrigues” de Georges Sadoul.' Cinémas: revue d'études cinématographiques, Vol. 21, No. 2-3 (Spring 2011): pp. 49-85.

Andrew, Dudley (1976). The Major Film Theories: An Introduction. New York: Oxford University Press.

--- (2010). What Cinema Is! West-Sussex: Wiley-Blackwell.

--- (2013). André Bazin. New York: Oxford University Press.

--- and Seung-Hoon Jeong (2008). 'Grizzly Ghost: Herzog, Bazin and the Cinematic Animal.' Screen, Vol. 49, No. 1: pp. 1-12.

Angles, Auguste (1948). 'Sartre versus Baudelaire.' Transl. Charles Messner. Yale French Studies, No. 2: pp. 119-124.

did or did not make love, his changes of residency, his discouragements, occupy in the essay a much more prominent place than his poems, his articles, his translations. Here again, Sartre uses new language to dress up an old ghost: biographic criticism. The concierge has become a psychoanalyst (existentialist, to be sure), but she is still a concierge' (1948, p. 121). See also Georges Bataille's critique of Sartre's study in La Littérature et le mal (Paris: Gallimard, 1957). Interestingly, in his review of Lust for Life (1956) by Vincente Minnelli, one of the acclaimed auteurs he scrutinizes in his views against auteur theory, Bazin will take up this exact argument against biographic criticism (see 3.3.1 Mythic Reality Becomes Flesh). From this perspective, the anecdote of Baudelaire's speech impediment as well as Bazin's views on Van Gogh's aesthetics, which I discuss later on, can be seen as a rejection of gossipy, concierge-like criticism, and affirms the existence of the subject (e.g. film, poem, painting) as an integral part of the artistic equation. 75 Bazin, 1957b, EC p. 2154; Transl. Graham, 2005, p. 255. 
Barjavel, René (1944) . Cinéma total: essai sur les formes futurs du cinéma. Paris: Éditions Denoël. Barthes, Roland (1972). Mythologies. Transl. Annette Lavers. New York: Hill \& Wang. Bataille, Georges (1957). La Littérature et le mal. Paris: Gallimard.

Bazin, André (1943a). 'Redécouvrons le cinéma.' L'Information universitaire, No. 1145 (26 June). EC I, 2. --- (1943b). 'Pour une esthétique réaliste.' L'Information universitaire, No. 1168 (6 November). EC I, 5 .

--- (1944). 'Le Cinéma et l'art populaire.' L'Information universitaire, No. 1195 (25 June). EC I, 17.

--- (1946/1958). 'Le Mythe du cinéma total.' Qu'est-ce que le cinéma? Paris: Éditions du Cerf (2008): pp. 19-24. EC OP I, 2.

--- (1947a). 'Jean-Paul Sartre vedette du jour au festival de Cannes.' Parisien libéré, No. 934 (18 September). EC IV, 320.

--- (1947b). 'Travail et culture: ce public.' Écran français, No. 120 (14 October). EC IV, 336.

--- (1947d). 'Défense de Monsieur Verdoux.' Temps modernes, No. 27 (December). EC, V, 353.

--- (1948a). 'Les Sources: Landru-Verdoux-Charlot.' D.O.C. éducation populaire, No. 6 (January). EC V, 423,

--- (1948b). 'Le Mouvement des ciné-clubs en France depuis la Libération.' D.O.C. éducation populaire, No. 7 (January). EC V, 454.

--- (1948e). 'L'Avant-garde nouvelle.' Objectif 49 (July). EC VII, 640; republished in Cahiers du cinema, No. 10 (March 1952). EC X, 980.

--- (1948f). 'Conseils aux animateurs de ciné-clubs: comment on prépare les débats au ciné-club d'Annecy.' D.O.C. éducation populaire, No. 7 (Juin-August). EC V, 455.

--- (1949a). 'Misère, servitude et grandeur de la critique de films.' Revue internationale du cinéma, No. 2 (April). EC VII, 572.

--- (1950-1955). 'LÉvolution du langage cinématographique.' Qu'est-ce que le cinéma? Paris: Éditions du Cerf (2008): pp. 63-80. EC OP, 17.

--- (1950a). 'Le Cinéma soviétique et le mythe de Staline.' Esprit, No. 170 (August). EC VIII, 762.

--- (1951b). 'Un Saint ne l'est qu'après...' Cahiers du cinema, No. 2 (May). EC IX, 784.

--- (1951c). 'Théâtre et cinéma.' Qu'est-ce que le cinéma? Paris: Éditions du Cerf (2008): pp. 129-178. EC IX, 797 \& 817.

--- (1952e). 'Néo-réalisme et "reportage à thèse".' France observateur, No. 109 (12 June). EC X, 1058.

--- (1952f). 'Pour un cinéma impur. Défense de l'adaptation.' Qu'est-ce que le cinéma? Paris: Éditions du Cerf (2008): pp. 81-106. EC X, 923.

--- (1953b). 'Le cinéma est-il mortel?' France observateur, No. 170 (13 August). EC XIV,1404.

--- (1954b). 'De la difficulté d'être Coco. Histoire vécue par André Bazin.' Carrefour, No. 496 (17 March). EC XV, 1544.

--- (1954c). 'Comment présenter et discuter un film!' Ciné-club, No.4 (April). EC XV, 1548.

--- (1954d). 'Georges Sadoul, victime de sa passion.' France observateur, No. 223 (August). EC $\mathrm{XV}, 1585$.

--- (1955b). 'Techniques nouvelles.' Arts, No. 518 (1 June). EC XVII, 1790.

--- (1958a). 'Avant-propos.' Qu'est-ce que le cinéma? Tome 1: Ontologie et langage. Paris: Éditions du Cerf (1959): pp. 7-9. EC OP I.

--- (1958b). 'Réflexions sur la critique.' Cinéma: revue de la fédération des ciné clubs, No. $3^{2}$ (December). EC XXIV, 2681.

--- (signed Florent Kirsch) (1951d). 'Introduction à une filmologie de la filmologie.' Cahiers du cinéma, No. 5 (September). EC IX, 856.

--- and Jean-Pierre Chartier (1942). 'Peut-on s'intéresser au cinéma?' Maison des lettres (December). EC I, 1. 
Bogousslavsky, Julien and Sebastian Dieguez (2007). 'Baudelaire's Aphasia: From Poetry to Cursing.' In: Neurological Disorders in Famous Artists. Part 2. Eds. J. Bogousslavsky and M.G. Hennerici. Basel: Karger: pp. 121-149.

Botson, Claude (1964). 'Problèmes de cinéma et filmologie.' Revue philosophique de Louvain, Vol. 62, No. 76: pp. 631-637.

Carroll, Noell (1996). Theorizing the Moving Image. Cambridge: Cambridge University Press.

Cassirer, Ernst (1953). Language and Myth. New York: Dover Publications.

Daney, Serge (1972). 'The Screen of Fantasy (Bazin and Animals).' Transl. Mark A. Cohen. In: Rites of Realism: Essays on Corporeal Cinema. Ed. Ivone Margulies. Durham: Duke University Press (2002): pp. 32-41.

De Baecque, Antoine (2012). Camera Historica: The Century in Cinema. Transl. Ninon Vinsonneau and Jonathan Magidoff. New York: Columbia University Press.

Fack, Rochelle (2011). 'Bazin's Chaplin Myth and the Corrosive Lettrists.' In Opening Bazin: Postwar Film Theory and Its Aftermath. Eds. Dudley Andrew and Hervé Joubert-Laurencin. New York: Oxford University Press, pp. 246-253.

Fay, Jennifer (2008). 'Seeing/Loving Animals: André Bazin's Posthumanism.' Journal of Visual Culture, Vol. 7, No. 1 (April): pp. 41-46.

Jeong, Seung-Hoon (2011). 'Animals: An Adventure in Bazin's Ontology.' In: Opening Bazin: Postwar Film Theory and Its Aftermath. Eds. Dudley Andrew and Hervé Joubert-Laurencin. New York: Oxford University Press, pp. 177-185.

Joret, Blandine (2016). Review of André Bazin's New Media, by André Bazin (Transl. Dudley Andrew).Screen, Vol. 57, No. 4 (Winter): pp. 509-512.<https://doi.org/10.1093/screen/hjwo49>.

Le Forestier, Laurent (2017). La Transformation Bazin. Rennes: Presses universitaires de Rennes.

Levi-Strauss, Claude (1955). 'The Structural Study of Myth.' The Journal of American Folklore, Vol. 68, No. 270 (Fall): pp. 428-444.

Margulies, Ivone (2011). 'Bazin's Exquisite Corpses.' In: Opening Bazin: Postwar Film Theory and Its Aftermath. Eds. Dudley Andrew and Hervé Joubert-Laurencin. New York: Oxford University Press, pp. 186-199.

Plasseraud, Emmanuel (2011). L'Art des foules: théories de reception filmique comme phénomène. Villeneuve d'Ascq: Presses universitaires du Septention, p. 181.

Sartre, Jean-Paul (1943). Being and Nothingness: The Principal Text of Modern Existentialism. Transl. Hazel E. Barnes. New York: Washington Square Press (1984).

--- (1946). 'Existentialism Is a Humanism.' Transl. Philip Mairet. In: Existentialism from Dostoyevsky to Sartre. Ed. Walter Kaufman. New York: Penguin Group (1975): pp. 345-368.

Truffaut, François (1955). 'Ali Baba et la "politique des auteurs".' Cahiers du cinéma, No. 44 (February): pp. 45-47.

--- (1994). The Films In My Life. New York: Da Capo Press.

Ungaro, Jean (2000). André Bazin: généalogies d'une théorie. Paris: L’Harmattan.

\section{Other sources}

Pagliano, Jean-Pierre (1988). 'Profils perdus: André Bazin.' France culture (2o October). [Accessed 25/04/2019] <https://podcloud.fr/podcast/les-nuits-de-france-culture/episode/profils-perdusandre-bazin-2eme-partie-1ere-diffusion-27-slash-10-slash-1988 > [Radio program]. 


\section{Used translations}

Bazin, André. French Cinema of the Occupation and Resistance: The Birth of a Critical Esthetic. Transl. Stanley Hochman. New York: Frederick Ungar Publishing (1981).

---. 'On the Politique des auteurs.' Transl. Peter Graham. In: Cahiers du cinéma: The 195os Neo-Realism, Hollywood, New Wave. Vol. 1. Ed. Jim Hillier. Oxon: Routledge (2005): pp. 248-259.

---. What Is Cinema? Transl. Timothy Barnard. Montreal: Caboose (2009).

---.André Bazin's New Media. Transl. Dudley Andrew. Berkeley: University of California Press (2014).

---. Bazin On Global Cinema, 1948-1959. Transl. Bert Cardullo. Texas: University of Texas Press (2014).

\section{Filmography}

Modern Times (Charles Chaplin, 1936)

The Great Dictator (Charles Chaplin, 1940)

Monsieur Verdoux (Charles Chaplin, 1947)

Les jeux sont faits (Jean Delannoy, 1947)

\section{Illustrations}

Figure 1. Caricature included in 'Introduction to a Filmology of Filmology' (A. Bazin, 1951), probably from J.J. Grandville (1803-1847). 


\title{
2. The Art of Reality
}

\begin{abstract}
This chapter is a contemporary examination of cinema as the art of reality: I explain the ways in which Bazin understands the complex, often paradoxical relation between reality and its image, which places him in direct dialogue with existing classical film theories as well as foundational scientific and philosophical concepts. Consequently, I extend his line of thought to include more recent examples involving digital image technologies that illustrate the relevance of integral realism today. I conclude the chapter with an exploration of existentialist influences in Bazin's notion of integral realism.
\end{abstract}

Keywords: realism, editing, scientific metaphors, existentialism

Reality is not art, but a realist art is one which can create an integral aesthetic of reality.

André Bazin, 1948d

It's the paradox of film that an abstract idea can only be expressed by means of the most concrete form of representation, namely reality. This is its strength, but also its risk.

André Bazin, 1953e

Regardless of Bazin's fierce rejection of prescriptive aesthetics, several of his major essays could easily be - and often have been - qualified as an attempt at formulating fundamental laws or basic principles of cinema: a theory of film. In 'The Myth of Total Cinema' (1946), for instance, he approaches film

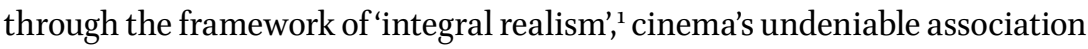

1 In his 2009 translation, Timothy Barnard translates réalisme intégral as 'complete realism'; this, however, does not do justice to the term originally chosen by Bazin, as it empties it of its mathematical reference, which I explain in the following chapter (see, 2.2 Integral Realism: Reality and Cinema 'Ultimately Equal').

Joret, B., Studying Film with André Bazin, Amsterdam: Amsterdam University Press, 2019 DOI: 10.5117/9789462989528/CHO2 
with reality, which he grounds in the ontology of film, explained in another seminal essay, 'The Ontology of the Photographic Image' (1945). Perhaps uncomfortable with the philosophical weight of the term, he reformulates 'ontology' in lay terminology for his introduction to What Is Cinema? (1958): 'in less philosophical terms: cinema as the art of reality.' Realism, Bazin's cornerstone concept, supposedly led to aesthetic prescriptions, such as his assumed prohibition of editing or his preference for long takes and depth of field. While these texts are now considered foundational for the discipline, it is nevertheless because of his focus on realism that Bazin's work is often considered outdated, unable to account for the many technological changes cinema has encountered since the digital turn, which radically overthrew the ontology of film. And yet, Bazin's film analyses build on philosophical questions and scientific references and metaphors that upon closer examination reveal a useful interpretative framework - solid yet flexible enough to stand the test of time.

This chapter is a contemporary examination of cinema as the art of reality: I explain the ways in which Bazin understands the complex, often paradoxical relation between reality and its image, which places him in direct dialogue with existing classical film theories as well as foundational scientific and philosophical concepts. Consequently, I extend his line of thought to include more recent examples involving digital image technologies that illustrate the relevance of integral realism today. I conclude the chapter with an exploration of existentialist influences in Bazin's notion of integral realism.

\subsection{Paradox: The Existence of Film}

By way of introduction, I propose to take a closer look at one particularly outstanding critique relating to documentary authenticity, namely Bazin's discussion of Thor Heyerdahl's documentary film Kon-Tiki (1950). Heyerdahl's renowned exploratory expedition was set out as a counter-proof to established theories of migration: according to him, the people of Polynesia had travelled westwards on a raft from the coast of Peru around 500 BC. The hypothesis was rejected by Heyerdahl's professors, and no serious publisher was interested in disseminating his research. As ultimate proof of this theory, Heyerdahl accompanied his thesis with a real-life expedition, documented by film. He built a raft, in original style and with the materials 
the Peruvian Indians would have used, and embarked on the expedition with five fellow explorer-scientists. Their documentary film, in Bazin's words, 'does not exist':

Kon-Tiki is the most beautiful of all films, but it does not exist! [Kon-Tiki est le plus beau des films mais il n'existe pas!'] Like those moss-covered stones that, surviving, allow us to reconstruct buildings and statues that no longer exist, the pictures that are here presented are the remains of an unfinished creation about which one hardly dares to dream. ${ }^{3}$

Because of the crew's inexperience in filmmaking and the spatial restriction of the raft, the film lacked intriguing shots, and the material itself was of extremely poor quality. But rather than weakening the film, Kon-Tiki's uninviting shooting conditions enhanced the documentary authenticity so dear to Bazin:

These few images in the midst of a flood of film rolls with close to no objective interest, are like invaluable and very moving flotsam on the monotonous swell of the ocean. It's that their poor state is not experienced as a lack; the huge gaps in these films are in reality a fullness, the fullness of human adventure to which [these images] so fully testify only through their emptiness. ${ }^{4}$

In fact, Bazin's preference for an authentic image over aesthetic perfection extends beyond the particular case of Kon-Tiki into his wide-ranging understanding of cinematic realism, more precisely, in what he termed 'ontogenetic realism': in short, for an image to be authentic, it usually means it doesn't look perfect.

Whereas he would name this procedure only in 1958, the idea of an ontogenetic realism 5 is already clearly formulated in 'The Ontology of the

3 Bazin, 1953-1954, EC p. 2562; Transl. Gray, 2005, p. 160.

4 Bazin, 1955a, EC p. 1703.

5 For more on Bazin's usage of the term 'ontogeny', I refer to Hervé Joubert-Laurencin's analysis in Le Sommeil paradoxal: 'This term appears in an addition from 1958 [...], which suggest, given its rarity, that it was included out of a desire for belated accuracy, able to qualify as scientistic; it indeed appears more serious, and is practically never used in any of its two meanings in French' (2014, p. 20). Stepping away from the common explication of Bazin's ontogeny thesis in biological and philosophical terms, in particular Dominique Chateau's in Cinéma et philosophie (2003), Joubert-Laurencin writes: 'the phrase in Bazin means that the functioning of cameras for both photography and cinema (the "genesis" extends from the mechanical operation of image creation) is known just well enough by the average viewer to credit in his eyes the resulting 
Photographic Image': 'The image may be out of focus, distorted, devoid of colour and without documentary value; nevertheless, it has been created out of the ontology of the model. ${ }^{6}$ Similarly, in defence of Kon-Tiki's poor cinematography, Bazin ultimately argues for decay and dissemblance as a sign and proof of authenticity:

[...] this film is not made up only of what we see - its faults are equally witness to its authenticity. The missing documents are the negative imprints of the expedition - its inscription chiselled deep. ${ }^{7}$

It is precisely because we do not see the image clearly that we can rely on its authenticity: if I were to film a murder in the streets with my cell phone, the shakiness and blurred quality of the footage would in fact be much more convincing than the same scene captured in a smooth 360 degree shot. This negative imprint of adventure, which implies authenticity without direct visibility, is put at work most clearly in Bazin's description of a shark attack scene: 'it is not so much the photograph of the shark that interests us as the photograph of danger.'8 Ever since, simply filming a shark attack, regardless of the aggravating circumstances of Heyerdahl and his crew, has proven to be anything but easy. Even Steven Spielberg, hoping to achieve a higher degree of realism, decided to shoot Jaws (1975) on location rather than in the usual massive bassins of Hollywood studios, it was his mechanical shark which disappointed him most, since it failed drastically in conveying the imminent danger of a real shark attack; in such cases, Spielberg nicknamed the shark 'the great white turd'. ${ }^{9}$ Moreover, in the context of this discussion it is intriguing to note that the shooting conditions on location particularly aggravated and accentuated the shark's artefactual qualities: it sank immediately when put to water at Martha's Vineyard, and the salty ocean water repeatedly damaged the material of the mechanical shark. For these reasons, Spielberg ended up filming with subjective point of view shots assuming the position of the shark so that most scenes were recorded without explicitly showing it. This dramatic technique, then, brings us back full circle to Bazin's argument concerning

image as a faithful trace of recorded reality, regardless of its "objective" qualities of resemblance' (Joubert-Laurencin, 2014, p. 21).

6 Bazin, 1945, EC p. 2557; Transl. Barnard, 2009, p. 8.

7 Bazin, 1953-1954, EC p. 2562; Transl. Gray, 2005, p. 162.

8 Ibid.; Transl. Gray, p. 161. [Slightly modified: Gray turns Bazin's requin into a whale and adds an emphasis on 'danger' that is absent in the original text.]

9 'Jaws: Trivia.' The Internet Movie Database. IMDB.com. Web. 28/05/2014<http://www.imdb. com/title/ttoo73195/trivia?ref_=tt_trv_trv> 
the shark attack in Kon-Tiki. The paradox of documentary authenticity crystallizes in the burden of shark attacks in the cinema. In a similar way, in a review of The Silent World (Jacques-Yves Cousteau \& Louis Malle, 1956), Bazin derives a fundamental principle of authenticity from the indispensable bond between the cinematographic image and reality:

What the film records is the repetition of events that should or could have, in all likelihood, happened the same way in the absence of any camera. This principle of course precludes fantasies like 'death struggle with a shark'. Not because ultimately the event is inconceivable but because its repetition would be the denial of the danger that imbues the event with pathos. Either the shark is harmless and it is an ignoble comedy, or it is dangerous and the cameraman who continues to film is found guilty of failing to assist a person in danger. ${ }^{10}$

So Bazin's argument of cinema as an art of reality manifests itself in the analysis of sharks throughout the history of cinema, and it formulates the fundamental question pertaining to documentary authenticity, namely: did the camera influence the event? Concerning sharks in cinema, the question then is not one of probability but of authenticity.

Of course, this discussion on documentary authenticity presumes analogue film, the 'photographic image' on which Bazin's ontological realism is built. Yet, from the perspective of myth, the same logic may apply just as well to contemporary, digital filmmaking: if bad quality testifies to a film's authenticity, crisp aesthetics might attest to its inauthenticity. Interestingly, a recent feature film remake of Kon-Tiki by Joachim Rønning and Espen Sandberg (2012) includes a similar shark attack scene, in which precisely those limitations that, for Bazin, proved the documentary authenticity of the original have been spectacularly disregarded. The film makes abundant use of helicopter shots and underwater filming, and the shark attack scene in particular is a remarkable display of over five hundred instances of computer-generated imagery and effect shots. The contemporary Kon-Tiki expedition therefore stands in stark opposition to the description by Bazin of the original Kon-Tiki documentary:

Naturally enough, there could be no traveling shots, no dolly shots, and scarcely a chance to get a full shot of the 'vessel' from the little boat bouncing on the waves astern. Finally, and most important of all, whenever 
something of significance occurred, the onset of a storm for example, the crew were too busy to bother about running a camera. The result was that our amateur filmmakers simply wasted endless reels filming their pet parrot and the rations provided by the American armed force. But when an explicit moment arrives, say a whale hurling itself at the raft, the footage is so short that you have to process it ten times over in the optical printer before you can even spot what is happening. ${ }^{11}$

In the context of Bazin's $195^{2}$ critique, and more generally in light of his views on ontogenetic realism, the remake of the Kon-Tiki expedition, and the shark attack scene in particular, can now be seen as a surprising take on the status of the image in today's contemporary visual culture. Rønning and Sandberg's film enters into a direct dialogue with cinematic realism, of which the re-enactment of the shark attack scene is indeed an intriguing case, given the implications of Bazin's critique outlined above. In an interview with The Hollywood Reporter, commenting on the difficulty involved in shooting Kon-Tiki, Sandberg and Rønning state:

Rønning: To make a whale shark and other sharks, CGI needed to be at a certain level. Personally, we had never seen sharks in movies that we felt were one hundred percent life-like.

Sandberg: The reason it worked so well in Jaws is because you basically never see the shark. We had to have it on deck and everything. So, I think that was part of the reason it hadn't been made before because it would have been too expensive. ${ }^{12}$

Under no circumstance would Heyerdahl and his crew have been able, or indeed willing, to shoot the shark attack scene from below the water surface, for instance. And for that matter, neither did Spielberg or anyone else. Thus, while Kon-Tiki from 2012 in many aspects radically overturns Bazin's notion of ontogenetic realism, it is most definitely an impressive exposé of the possibilities of CGI that produce the very visibility that Bazin considered inconceivable, provided that the shark is inoffensive or, in this case, virtual: at most a dummy. ${ }^{13}$

11 Bazin, 1953-1954, EC p. 2562.

12 Trier and Weinstein. "Kon-Tiki” Directors Discuss the Making of Their Offshore Epic (Q\&A).' The Hollywood Reporter. Web. 28/05/2014 <http://www.hollywoodreporter.com/news/ kon-tiki-directors-discuss-making-447386>.

13 For a short clip on the shooting conditions 'in open water' of the 2012 remake, see: 'Kon-Tiki: The Incredible True Story: Shooting in Open Water.' National Geographic. [Accessed 28/05/2014] 
Although there are many examples from which to draw illustrating subjects that pose a serious threat to documentary authenticity, the filmic image of the shark stands out in this regard, and it is this subject that Bazin uses to explain documentary authenticity. Those who have seen Monster Shark (Lamberto Brava, 1989), Cruel Jaws (Bruno Mattei, 1995) or Deep Blood (Raffaele Donato \& Joe D'Amato, 1990) are aware that shark films often build on explicit B-movie aesthetics whenever a shark is clearly visible. Throughout film history, sharks in cinema have been 'jumping the shark', so to speak, and the act of filming an attack (even disregarding the difficult circumstances for Heyerdahl and his crew) has proven to be a cumbersome endeavour. ${ }^{14}$ Where Spielberg liberally employed the artifice of a rubbery looking mechanical shark in his attempt to depict danger, CGI effects were put to use excessively during the shark attack scene in Kon-Tiki's recent remake from 2012. In the case of Kon-Tiki 2012, CGI radically overturns the logic of Bazin's ontogeny thesis: the visibility of the shark becomes proof of the inauthenticity of the image - proof, at least, that the shark was never filmed (and that the cameraman therefore did not fail in his duty to rescue). Evidently, the image of the shark in Kon-Tiki 2012 is nothing like the photograph of danger of which Bazin spoke. And yet, to this day the very heart of the problem - a shark on film - remains the same. CGI thus appears to have brought the contemporary cinematographic image to the reverse side of the ontogeny argument, where the result predominates over the authenticity derived from the photographic genesis of the image: the dummy comes as the culmination of a history of mechanical sharks in cinema.

\subsubsection{Editing Prohibited? CGI and the Dummy of Danger}

The abundant use of CGI in the Kon-Tiki remake inevitably brings us to the question of editing: in his famed essay 'Editing Prohibited' from 19531957 , Bazin generally rules out montage or editing when it would mean

$<$ http://channel.nationalgeographic.com/channel/videos/shooting-in-open-water/>. For an extensive CGI breakdown reel, see: 'Kon-Tiki: Complete VFX-Breakdown.' YouTube. [Accessed 28/05/2014] <http://www.youtube.com/watch?v=gFpL2XzAn44>.

14 One example in particular illustrates the danger involved when filming attacks 'too realistically': Shark! (1969) by Samuel Fuller is dedicated to 'fearless stuntmen who repeatedly risked their lives against attacks in shark-infested waters during the filming of this picture...' (IMDb, 'Shark! Trivia'). One stuntman, Jose Marco, was in fact killed on camera while fighting a supposedly sedated white shark: Fuller quit the production when the company used the incident to promote the film. 
the annihilation of danger. Together with ontological realism, this topic is generally considered Bazin's most prescriptive and therefore medium essentialist film theory. From this perspective, his views on documentary authenticity and cinematic specificity directly relate to his condemnation of editing. However, rather than entirely dismissing editing as anti-cinematic, Bazin is in fact much subtler when he writes that 'there are cases where, far from constituting the essence of cinema, editing is its negation'. ${ }^{15}$ It appears that Bazin's title is in fact a rhetorical play on persisting theories of editing, which were in Bazin's days among the most essentialist. In this manner, 'Editing Prohibited' is not a categorical dismissal of the cinematic possibilities montage; rather, his ban on editing is an ironic attempt to trespass the borders of prescriptive film theories.

In his deepening of what appears to be Bazin's one and only aesthetic commandment, French film critic Serge Daney (1944-1992) indeed describes editing as a correlation of risk. In an essay from 1972 entitled 'The Screen of Fantasy (Bazin and Animals)', he writes:

We can see that what justifies the prohibition of editing is [...] the nature of what is being filmed, the status of the protagonists (in this case men and animals) who are forced to share the screen, sometimes at the risk of their lives. The ban on editing is a function of this risk. ${ }^{16}$

Daney further develops the paradox of irreversibility on screen in qualitative terms, as it risks being effaced by quantitative repetition. The same principle, we have seen, guides the authenticity argument of an invisible shark on screen, thereby running the risk that the film itself ceases to exist: 'Kon-Tiki is the most beautiful of all films, but it does not exist! [...] [these images are] the remains of an unfinished creation about which one hardly dares to dream.17 And just as the photograph of the shark could be the negation of danger, so too can editing (not always, but in specific cases) be the negation of cinema. But if the question of documentary authenticity involves minimizing the camera's influence on the event, the inevitable consequence of this would be the effacement of cinema itself. Conversely, Bazin proposes Man of Aran (Robert J. Flaherty, 1934) as an example, a fictional documentary of everyday struggles on the western coast of the Aran Islands, where at one point we clearly see a shark for an extended period of time, soothing right beneath 
the water surface. In this case, 'splendid cinematography' rids the shark of its essential features. In the context of sharks, Bazin then introduces what he terms an 'insoluble dilemma" ${ }^{18}$ between reality and its abstraction on screen: what can the camera capture from the event without destroying its essence? But also: if cinema cannot be more than an extraction from reality, then why bother making films at all?

Where Heyerdahl used a real-life expedition to prove his theory, Bazin saw the film's poor aesthetic quality as proof of its authenticity: both men obviously value objectivity and proof, in science and on film. Using the exact same materials for the raft as the Peruvian natives would have in their time, the 1947 expedition happened under the exact same conditions of $500 \mathrm{BC}$ (reminiscent of the scientific principle of replicability). Similarly, the camera they brought along did not influence the events on board (nothing, not even the shark attack, was staged). Just as Heyerdahl's motivation was a scientific one, the following section shows that Bazin, too, implicitly engages with scientific principles, such as observation and probability theory, which shape his understanding of authenticity and ultimately formulate his critique of existing film theories.

\subsubsection{Authenticity: Bazin's Shark and Schrödinger's Cat}

The implications of Bazin's analysis of sharks perfectly illustrate the way in which realism on screen always necessitates that 'some aspect of reality will always have to be sacrificed to reality'. ${ }^{19}$ In both Heyerdahl's lived documentary as well as Spielberg's feature film, the very properties of the image are sacrificed to enhance the authenticity of the attack. In this manner, the screen becomes a double-edged sword, as each gain in reality involves a loss in the image, and vice versa.

From this perspective, the analysis of the shark in Kon-Tiki appears to lean towards a similar observational theory as initiated by Erwin Schrödinger (1887-1961), who set out to challenge the Copenhagen interpretation of quantum indeterminacy, in particular their concept of the wave- or psifunction which calculates the probability of objective reality. ${ }^{20}$ After Werner Heisenberg's description in 1927 of the so-called uncertainty principle,

18 Ibid., EC ibid.

19 Bazin, 1948c, EC p. 355; Transl. Barnard, 2009, p. 232.

20 Quantum indeterminacy, also called the uncertainty principle, is the fundamental assertion in quantum physics that the state of a certain physical system cannot fully determine the actual observed values. Diverging from classical mechanics, the study of phenomena on a quantum level cannot predict or determine the behavior of individual particles. Beyond being an apology 
natural science acknowledged a radical shift in perspective, as it turned its back to physical determinism. Where classical mechanics is based on the assumption of scientific reproducibility, which assumes that if all conditions are meticulously recreated, repeated scientific experiments should produce the same results, quantum physics, on the contrary, is founded upon the unpredictable behavior of particles on a quantum level, so that 'chance must be elevated to the status of an essential feature of physical behaviour'. ${ }^{21}$ Heisenberg's uncertainty principle soon developed into the Copenhagen interpretation, which extends the principle from the infinitesimal level of quantum physics onto 'the macroscopic objects of sense experience', ${ }^{22}$ based largely on probability in its understanding of physical reality. In order to demonstrate the absurdity of their particular calculated, almost statistical approach to indeterminacy, Schrödinger imagined the by now famed thought experiment of the cat paradox, of which I cite here his full description:

At all events, it [the psi-function] is an imagined entity that images the blurring of all variables at every moment just as clearly and faithfully as does the classical model its sharp numerical values. [...] But serious misgivings arise if one notices that the uncertainty affects macroscopically tangible and visible things, for which the term 'blurring' seems simply wrong. [...] One can even set up ridiculous cases. A cat is penned up in a steel chamber, along with the following device (which must be secured against direct interference by the cat): in a Geiger counter, there is a tiny bit of radioactive substance, so small, that perhaps in the course of the hour one of the two atoms decays, but also, with equal probability, perhaps none; if it happens, the counter tube discharges and through a relay releases a hammer which shatters a small flask of hydrocyanic acid. If one has left this entire system to itself for an hour, one would say that the cat still lives if meanwhile no atom has decayed. The psi-function of the entire system would express this by having in it the living and dead cat (pardon the expression) mixed or smeared out in equal parts.

It is typical of these cases that an indeterminacy originally restricted to the atomic domain becomes transformed into macroscopic indeterminacy, which can then be resolved by direct observation. That prevents us from

for inaccurate measurement or miscalculations, quantum indeterminacy is an essential and necessary uncertainty in our understanding of reality.

21 Peres, 1995, p. 7.

Stapp, 1972, p. 1098. 
so naively accepting as valid a 'blurred model' for representing reality. In itself it would not embody anything unclear or contradictory. There is a difference between a shaky and out-of-focus photograph and a snapshot of clouds and fog banks. ${ }^{23}$

In the cat-paradox experiment, Schrödinger transfers quantitative probability, which he calls the 'blurred model' of superimposing all possible variables (i.e. the cat has an equal chance of being dead or alive, hence it is both), onto the macroscopic and qualitative level of an actual cat in a box, where merely opening the box reveals the cat to be either dead or alive. Though at first sight Schrödinger's condemnation of the out-of-focus photograph appears to contradict Bazin's views on ontogenetic realism, which favors the blurred photograph over the faithful drawing, their argumentations in fact run parallel. In the face of the uniqueness of an irreversible event, unreproducible either as a scientific experiment or in the artificial environment of a studio, both Bazin and Schrödinger condemn the inauthenticity involved in quantitative probability: death, Bazin argues, is 'the qualitative instant in its purest form', ${ }^{24}$ and '"reality" should obviously not be understood quantitatively'. ${ }^{25}$

Such an approach that engages with a statistical mind-set fits within a more general 'epistemological break with traditional notions of determinism $^{26}$ in the earlier days of cinema, which Mary Ann Doane analyzes at length in a chapter called 'Temporal Irreversibility and the Logic of Statistics' in The Emergence of Cinematic Time (2002): 'classical cinema', she writes, 'aligns itself with the logic of statistics as a way of measuring and hence mapping chance events, contingency'. ${ }^{27}$ Like Schrödinger, Bazin appears to reject this probabilistic logic that informs classical cinema as 'the exemplar of temporal irreversibility, as the most effective means of clarifying the idea of an "arrow of time"'. ${ }^{28}$ As Doane points out, the connection between quantitative accumulation and modern technology can be found, for

\footnotetext{
23 Schrödinger, 1983, p. 157.

24 Bazin, 1949c, EC p. 796; Transl. Cohen, 2002, p. 30.

25 Bazin, 1948c, EC p. 354; Transl. Barnard, 2009, p. 228.

26 Doane, 2003, p. 112.

27 Ibid., p. 139.

28 Ibid., p. 117. Bazin's view of authenticity in film provides a particular take on the concept of irreversibility, as it ties in with the idea of an arrow of time through his notion of 'integral realism'. More specifically, it offers us an innovative answer to Zeno's infamous paradoxes, which Doane in another chapter considers constitutive of the emergence of cinematic time, to which I will turn subsequently (see 2.2 Integral Realism: Reality and Cinema 'Ultimately Equal').
} 
instance, in Walter Benjamin's seminal essay 'The Work of Art in the Age of Mechanical Reproduction' (1936), when he writes that:

To pry an object from its shell, to destroy its aura, is the mark of a perception whose 'sense of the universal equality of things' has increased to such a degree that it extracts it even from a unique object by means of reproduction. Thus is manifested in the field of perception what in the theoretical sphere is noticeable in the increasing importance of statistics. $^{29}$

From this perspective, then, mechanical reproduction, Doane argues, 'robs the object of its uniqueness and permanence [as] technical reproduction reduces all things to a common denominator,.$^{30}$ In a comparable manner, ${ }^{31}$ Bazin argues that repeating the event would efface its essence, especially if it involves imminent danger such as a death threat. But the paradox of authenticity does not stop there, since it is only on screen that this qualitative moment (death) can be repeated eternally, amounting to Bazin's ironic adaptation of the medium essentialist notion of 'cinematic specificity'.

\subsubsection{This Is Cinema!}

The fact that many early film theories were concerned with the true nature or the essence of cinema should come as no surprise: film theorists and critics were eager to defend film as a worthy art form by stressing its difference with the other more established arts. As argued in the preceding sections, Bazin, too, was concerned with specifically cinematic traits, such as authenticity, to pinpoint the aesthetics of a filmic image. Yet he does this in the form of a paradox, affirming first and foremost the existence rather than the essence of film: existence precedes essence, the most beautiful film does not exist, and in some cases editing is cinema's negation. From this perspective, death as the final and unrepeatable event

29 Walter Benjamin, 1936; cited in ibid., p. 130.

30 Ibid.

31 On resonances of Benjamin in Bazin, see for instance Dall'Asta's 'Beyond the Image in Benjamin and Bazin: The Aura of the Event' (2011), in which she suggests Bazin's prohibition of montage to formulate an answer to Benjamin's 'Work of Art' essay. Especially relevant in the context of the 'ontological equality' of events on screen is her discussion of Jean Epstein's notion of photogénie in relation to both Bazin and Benjamin's views on montage in film (pp. 5961), to which I will turn later on [see 2.2.1 No Moment Suprême: Bazin Opposes Ellipsis (and Photogénie)]. 
proves, for Bazin as well as for Schrödinger, the authenticity of the event. Such specificity of the event results in Bazin's oxymoronic statement of 'cinematic specificity':

Death is surely one of those rare events that justifies the term, so beloved by Claude Mauriac, cinematic specificity. Art of time, cinema has the exorbitant privilege of repeating it [...] Cinema only attains and constructs its aesthetic time based on lived time, Bergsonian 'durée', which is in essence irreversible and qualitative. [...] I cannot repeat a single moment of my life, but cinema can repeat any one of these moments indefinitely before my eyes. [...] For every creature, death is the unique moment par excellence. The qualitative time of life is retroactively defined in relation to it. It marks the frontier between the duration of consciousness and the objective time of things. Death is nothing but one moment after another, but it is the last..$^{22}$

In Bazin's days, medium specificity was a commonly accepted way of thinking about the objective nature of cinema. However, this framework is fundamentally alien to his understanding of film history: even in his essay on photographic ontology, arguably associated with the notion of medium specificity, Bazin refrains from adopting such a prescriptive framework. His explicit reference to Mauriac in this particular case therefore suggests that he uses this framework to his own advantage: rather than concerning himself primarily with the specificity of photography, a theory that would lead to a priori accepting the authenticity of any filmed event, he instead clearly valorizes the specificity of reality. In so doing, he implicitly supports his argument of cinema as the art of reality rather than that of the image or technology. Thus, by alluding to Mauriac's essentialist view, Bazin here cleverly morphs an argument concerned with medium essentialism into his own valorization of the specificity of the event and cinema's fundamental capacity to repeat irreversibility: 'Dead without requiem, the eternal deadagain of the cinema!'33 From this filmic specificity, which draws cinema to the point of its own annihilation, Daney develops the idea of a 'trip switch' of cinema: 'Bazin indicates the exact spot where the cinema he would not dare dream of becomes a reality and then annuls itself, becomes itself the impossible. This is a limit that is not so distant, whose simple possibility valorises the most banal image: the risk of death for the cameraman, of 
impossibility for the film: "occupational hazards"'. ${ }^{4}$ Daney continues, citing Bazin:

\begin{abstract}
Although the filmmaker sometimes risks death, it can also happen that he may film it without risk or even provoke it by means of his simple presence. The exorbitant power of the camera. You can die just to save face. This is what happened with Valentin, the bird-man (in Paris 19oo): 'This is how it is in this prodigious bird man scene where the poor fool is obviously getting frightened and has finally realized that the bet was idiotic. But the camera is there to capture him for eternity, and he dare not disappoint its soulless eye. If there had been human witnesses, a wise cowardice would certainly have won out (Bazin, 1947).35
\end{abstract}

The death drive of cinema thus functions in two directions that either way involve a certain loss or gain in reality: either the cameraman risks his or her life, or the camera is itself responsible for causing a coward to jump to his death. ${ }^{36}$ Death then becomes the ultimate moment, fundamentally irreversible and irreproducible, when cinema shows its morbid specificity by means of a sacrificial death.

\title{
2.2. Integral Realism: Reality and Cinema 'Ultimately Equal'
}

If the prohibition of editing is first and foremost aimed at countering essentialist theories of film, and bearing in mind Bazin's application of the existentialist maxim 'existence precedes essence' discussed in the previous chapter, then his assertion that the film 'does not exist' is rather problematic, to say the least. In 'Editing Prohibited', however, Bazin offers a way out of this impossibility of film by introducing a 'threshold of trickery' where the myth, which is cinema, both integrates and substitutes for reality:

$[\ldots]$ if what we see on the screen were real and carried out in front of the camera the film would cease to exist, because it would cease thereby to be a myth. It is on the fringes of trick effects, on the margins of the

34 Daney, 1972, p. 37 .

35 Ibid., p. 39 .

$3^{6}$ For the original footage of Frans Reichelt's fatal jump off the Eiffel tower on 4 February 1912 in his attempt to test his so-called 'flying tailor', see: 'Death Jump - Eiffel Tower 1912.' British Pathé. Web. 28.05.2014 <http://www.britishpathe.com/video/death-jump-eiffel-tower/query/ reichelt $>$. 
subterfuge necessary to the logic of the story, that the imaginary is able both to join reality and to replace it [à la fois d'intégrer la réalité et de s'y substituer]. ${ }^{37}$

This simultaneous integration of and substitution for reality should be taken quite seriously, as it provides a reformulation of traditional film theoretical issues via the notion of 'integral realism', which is a guiding principle in Bazin's work. In what follows, I hope to demonstrate the ways in which Bazin overrides this insoluble dilemma between image and reality by seeing both in a Newtonian sense as 'ultimately equal'. By analyzing in Bazin's writing, as well as Daney's interpretation of Bazin, a series of mathematical and philosophical references, such as the ellipsis/ellipse, the asymptote and quantitative measurements versus qualitative leaps, I argue that Bazin's proposition for 'integral realism' is to be understood not in the sense of a complete substitution or total illusion of reality but rather in mathematical terms as an integral calculus: an approximation and measure of reality. With this, Bazin held an entirely different and original view on the relation between art and reality: he situates himself explicitly against the essentialist approach to film art from the silent film theorist Jean Epstein (1897-1953), and more implicitly reformulates basic principles of the documentary in the work of Roger Leenhardt (1903-1985).

\subsubsection{No Moment Suprême: Bazin Opposes Ellipsis (and Photogénie)}

Bazin's solution for the dilemma between image and reality lies in his firm acknowledgement of the ontological equality of instants, in reality as well as on screen. This view, both canonical and highly original, comes to the foreground in his praise of Italian neo-realism, which he considered 'the great event of post-war cinema' ${ }^{3}{ }^{8}$ For him, neo-realism provided a victorious new solution to post-war aesthetic conflicts by creating a new kind of image, which he calls the image-fait:

[...] a fragment of raw reality, inherently multifacious and ambiguous, whose 'meaning' becomes apparent after the fact, through other 'events', connected up in our minds. Rossellini undoubtedly chose these events [faits] wisely but while respecting their integrity as events [faits]. [...] The nature of an 'image-event' [image-fait], however, is not simply to connect 
with other 'image-events' [images-faits] in ways invented by our minds. This in a sense is the centrifugal nature or the image, which makes it possible to create a narrative. Because each image, seen on its own, is only a fragment of reality and exists prior to its meaning, the entire surface of the screen must have the same concrete density. ${ }^{39}$

The premise of ontological equality prevents him from adopting theories of film that claim cinema to be either more or less than reality. As I will argue, within the context of medium specificity, Bazin's notion of image-fait opposes the former view as crystallized in Epstein's concept of the photogénie, while the latter solidifies in Roger Leenhardt's assertion of cinema as the art of ellipsis. In both cases, Bazin's notion of integral realism supports the existentialist rather than an essentialist view on film.

Bazin's implicit criticism of unequal treatments of moments in the context of medium essentialism becomes most apparent in a passage in Daney's reading of the prohibition of editing, in which he concerns himself with a 'way out' of this trip switch of an impossible cinema:

In 'classic' cinema, transformation as the result of a quantitative accumulation without a qualitative leap, as a new state always given but never produced, is resolved or rather it does not get resolved.

- Either there is no transformation

- Or it occurs as a teleological coup.

[...] Representation is no longer the condition for a good exfoliation of the story but a sort of travesty that can say nothing about the nature of things, about their heterogeneity or the laws of their mutations. ${ }^{40}$

Daney conceives classical representation in cinema as a travesty, a distorted reproduction that effaces the true nature of the event, and stresses in a remarkably Kierkegaardian fashion ${ }^{41}$ the importance of a 'qualitative leap'

39 Ibid., EC p. 358; Transl. Barnard, 2009, pp. 241-242, slightly modified. [Barnard drops Bazin's '...'; also, Bazin's own image-fait is more accurate than 'event', cf. his stance against the notion of dramatic events.]

40 Daney, 1972, pp. 39-40.

41 In his Concluding Unscientific Postscript (1846), Danish philosopher and theologian Søren Kierkegaard maintains that transformation from one state to another happens only by means of a qualitative leap, and that those two states cannot exist simultaneously. The qualitative leap of faith relates to Kierkegaard's view on the accidental nature of historical events, where possibility turns into actuality: 'The whole point of the historical, for Kierkegaard, is that it constitutes the realm of "becoming" that makes intelligible the movement from possibility to actuality, a movement that remains impossible within the realm of necessity' (see: Michalson, 
over 'quantitative accumulation': that which makes something happen is the leap from possibility into actuality. Beyond the implicit references to statistics, as seen previously with Benjamin, and accordingly the outspoken preference of the qualitative instant over quantitative probability, which supports Bazin's authenticity argument, Daney here extracts a twofold criticism that is contained in Bazin's ironic affirmation of cinematic specificity. Essentially, both options relate to a different understanding of cinematic specificity, either viewing film as an abstract (option 1) or a surplus (option 2) of reality. In order to set the ground for a novel understanding of 'integral realism', I will discuss both these points that the image-fait opposes, as crystallized respectively in terms of the ellipsis and photogénie.

Daney's first point of criticism in classical narration, namely that nothing ever happens, resonates with the age-old philosophical paradox of motion stipulated by Zeno of Elea (490-430 BC), who derived from an infinitesimal division of distance that motion itself is impossible: Achilles will never surpass the tortoise and the arrow is in fact motionless. In The Emergence of Cinematic Time, Doane argues that 'Zeno's fallacy finds its technological embodiment in the cinema - in its spatialization of time, its investment in the reality of instants. ${ }^{42}$ Doane posits two main interpretations of the paradox in relation to film theory: Bergson, from his side, upheld that 'movement slips through the interval ${ }^{43}$ and that therefore cinema can only give an illusion of movement, while Epstein, who dispersedly references Zeno's paradox in his writing, argues altogether that cinema ultimately shows Zeno's false reasoning to be accurate: a succession of still images creates movement through flickering light. ${ }^{44}$ In this manner, Epstein solves what

1979, p. 330). Bazin, from his side, indeed implicitly takes on this dynamic in his discussion of cinematic montage: '[...] on pourra remarquer à fort juste titre que si Ballon Rouge ne doit rien essentiellement au montage, il y recourt accidentellement [emphasis in original]' (Bazin, 1953-1957, EC p. 2566): '[...] if The Red Balloon owes essentially nothing to editing, it resorts to it fortuitously.' (Transl. Barnard, 2009, p. 79) [Barnard drops the emphasis on 'essentiellement' and 'accidentellement' and loses the implied opposition between essence and accident.]

42 Doane, 2003, p. 174.

43 Ibid.

44 On numerous occasions, Epstein references Zeno's paradox, for instance in 'Intelligence of a Machine' (1946): 'One breaks a window, counts the pieces and declares: this window was composed of four triangular, two quadrangular, six pentagonal pieces and so on. This is the model of the false reasoning of all atomic theory, which is, besides, very similar to Zeno's reasoning' (Epstein, 1946, p. 264). And again: 'the cinematograph appears as a mechanism mysteriously destined to the expertise of the false accuracy of the famous reasoning of Zeno about the arrow, to the analysis of this subtle metamorphosis of rest in mobility, of the emptiness in fullness, of continuity in discontinuity - a transformation that staggers as much as the generation of life out of the inanimate' (Ibid., p. 26o). 
he calls the 'insoluble problem', the 'irreconcilable contradiction', which Bergson upholds, by asserting that continuity and discontinuity, movement and interruption are not incompatible but rather 'two modes of unreality that are easily interchangeable. ${ }^{45}$

In his quest for the essence of cinema, which he saw crystallized in the close-up as 'the soul of cinema', ${ }^{46}$ Epstein radically sought a surplus of reality on screen, which he conceptualized in his notion of photogénie:

I would describe as photogenic any aspect of things, beings, or souls whose moral character is enhanced by filmic reproduction. And any aspect not enhanced by filmic reproduction is not photogenic, plays no part in the art of cinema. ${ }^{47}$

Epstein's photogénie could not be further removed from Bazin's image-fait; in fact, it appears to me as though Bazin developed his argument with Epstein's film theory in the back of his mind. In an analysis of Paisà (Roberto Rossellini, 1946), Bazin indeed opposes the image-fait to the shot and the close-up, in which Epstein had found the essence of film:

The unit of Paisà's narrative is not the shot, with its abstract perspective on the reality being analysed, but the event $[$ fait $]$. [...] In Paisà (and by this I mean, to varying degrees, most Italian films), close-ups of doorknobs are replaced by the image-event [l'image-fait] of a door, all of whose concrete qualities are equally visible. ${ }^{48}$

Bazin's dissatisfaction with the close-up as a tool in cinematographic narrative as well as Epstein's essentialist notion of photogénie reflects Daney's second point of criticism, the 'teleological coup': an unequal organization of events that cannot convey the concrete density of reality on screen.

But the teleological critique in Daney's phrasing suggests yet another, intrinsically related approach to film that Bazin appears to oppose, namely that in the process of abstraction, cinema itself 'slips through the interval'. Following French filmmaker and editor Roger Leenhardt who shared many ideas 
on realism with Bazin, ${ }^{49}$ this interplay, which borders on the in-existence of cinema itself, is often referred to as the 'elliptical' nature of film:

When Leenhardt claims that the primary figure of cinema is the ellipsis not the metaphor, he is insisting that cinema is not a symbol system substituting one set of signs for another (as classic film aesthetics believed), but an always partial view of something significant that tries to appear through it. ${ }^{\circ}$

In his views on documentary authenticity epitomized by the shark attack, Bazin comes close to affirming Leenhardt's claims, and indeed Andrew argues that '[ellipsis] stands as the key technique necessary for the very operation of the documentaire, that genre of film he [Leenhardt] was proud to practice'. ${ }^{1}$ But while Andrew stresses the similarities between their assertion of 'primordial realism', $5^{2}$ he nuances this connection when it comes to the notion of the ellipsis and argues that Bazin understands it differently.

[I] $\mathrm{t}$ is time that Bazin, following Bergson, treats as pre-existent, time that extends before and after the spatial designs that humans construct. His feel for the integrity of time explains Bazin's hesitancy about ellipsis [...]. Ellipsis does violence to the continuity of nature that the camera respects in its 'take'. [...] On the one hand, ellipsis derives from the condition that keeps us from knowing everything; on the other, ellipsis organizes experience to suit our needs and projects; writers and filmmakers deploy it systematically for their 'plots' as they pare away what they deem inessential. Ellipsis is the temporal equivalent of framing. And framing, Bazin asserts, can only be provisional in the cinema, a medium sensitive like

49 Bazin and Leenhardt both uphold a counter-determinist view on film history following the advent of the talking film, which would become so prevalent both in Bazin's proclamation of realism and his prohibition of montage. As Andrew writes in 'A Film Aesthetic to Discover', 'For both men, the existence of sound changed the essence of cinema [emphasis in original]' (Andrew, 2007, p. 57).

50 Andrew, 2013, p. 25.

$5^{1} \quad$ Andrew, 2007, p. 58.

52 Ibid., p. 59. On Leenhardt's notion of 'primordial realism', see also Joubert-Laurencin, 2014, pp. 30-32. While he maintains that '[...] Bazin will entirely transfer that which is, in Leenhardt, still a stylistic description based on a literary trope, onto the theoretical definition of a cinematographic mechanization' (p. 31), I hope to demonstrate that Bazin distances himself from Leenhardt's literary trope and instead seeks in natural sciences, in particular the work of Isaac Newton, a proper framework for his argument of cinema as the art of reality. 
no other to what lies beyond the edges of the screen in the infinite and unknowable volume (and continuity) of space-time. ${ }^{53}$

Here, the narrative abstraction in ellipsis is dismissed as a dramatization of the proportional analysis of reality, i.e. the close-up; again, this comes down to Bazin's notion of image-fait which he describes as including 'the centrifugal nature of the image, which makes it possible to create a narrative'. ${ }^{54} \mathrm{By}$ evoking cinema's 'centrifugal properties', a recurring reference to Newtonian physics in Bazin which I will discuss at length later on (see Section 3.2. Cinema and Painting), Bazin again implicitly rejects Epstein's essentialist mind-set, as it denies not only the universal equality of moments (photogénie) but also the fundamental laws of nature that cinema, according to Epstein, destroys:

The non-contradiction ceases to be a valid criterion of truth. Zeno's arrow, which is immobile in flight, does not surprise us anymore. Any being combines movement and stillness, solidity and fluidity, languor and precipitation, tininess and immensity according to space-time conventions, where the lens arbitrarily places that being. Had the neurotic Pascal seen a few films, he would have had to find a new support to this anguish other than the size differences between mite and man - a difference that cinema can cancel or reverse at will, like the most banal optical illusion..$^{55}$

Unlike Epstein's approach, which stresses the difference between cinema and reality, Bazin's entire ontological project, his view of cinema as the art of reality, is firmly embedded in an acknowledgement of cinema's offscreen origins, in reality. Unlike Epstein, Bazin reaffirms rather than rejects the pascalian 'double infinity', which views the universe as 'an infinite sphere, the centre of which is everywhere, the circumference nowhere'. ${ }^{6}$ In this manner, his rejection of both photogénie and ellipsis gives way to a centrifugal understanding of l'image-fait. Accordingly, Bazin's notion of 'integral realism' adheres to the laws of nature. The most striking example of this sort in Bazin's writing, is his occasional reference to the calculus, as it was stipulated by Isaac Newton in Lemma II of his Philosophiae Naturalis Principia Mathematica (1687). ${ }^{57}$

Andrew, 2012, p. 128.

4 Bazin, 1948c, EC p. 358; Transl. Barnard, 2009, p. 242.

55 Epstein, 1947, p. 32; Transl. Nguyen, 2012, p. 332.

56 Pascal, 1670 , p. 16-17.

57 Though Newton had already started developing calculus in Methods of Fluxions (1671), it remains historically unclear whether Newton ultimately was its sole and independent inventor, 


\subsubsection{Bazin on Umberto D: Reformulating the Pregnant Instant}

In order to fully grasp Daney's criticism in the context of the discussion on editing and cinematic specificity, it is important to recognize in it the subtle references to parts of Bazin's essay on Umberto $D$, in which the ellipse is understood as 'the moving conclusion to a dramatic series of events [emphasis in original]': $5^{8}$ the 'teleological coup' in Daney's formulation. Bazin puts this in plain words in an essay on Umberto $D$ (Vittorio De Sica, 1952), when he praises Cesare Zavattini's scenario for following precisely the opposite of ellipsis:

The cinema here is conceived as the exact opposite of that 'art of ellipsis' to which we are much too ready to believe it devoted. Ellipsis is a narrative process; it is logical in nature and so it is abstract as well; it presupposes analysis and choice; it organizes the facts in accord with the general dramatic direction to which it forces them to submit. 59

Bazin here rejects Leenhardt's elliptical approach to narrative form, as this would imply a considerate selection of events in which seemingly irrelevant or meaningless moments are eliminated to emphasize others that weigh more on the course of events. ${ }^{60}$ Instead, by acknowledging the double meaning of l'ellipse in French, both referring to the stylistic figure as well as the geometrical concept of the conic section, I argue that Bazin's system enables a subtle but consequential change of paradigm from linguistics to analytical mathematics. As Andrew already suggested, in its temporal abstraction, the stylistic figure of an ellipsis, the cut, in some way relates to that 'infinite and unknowable volume' of the three-dimensional volume, by which Bergson conceives his famed spatialization of lived time in Matter and Memory (1896). Ultimately, the discussion of editing, then, brings us to the heart of the insoluble dilemma

or whether the final and complete publication of his methods in 1704 had been circumstantially influenced by Gottfried Leibniz, who had started working on a similar method in 1674 which he then published before Newton's completed work on calculus. Essentially, this quarrel is irrelevant for the current debate on integral realism, but since Bazin also points to Newtonian physics when he declares the screen as centrifugal and fundamentally opposed to the centripetal frame of painting, it is fair to assume that here, too, Bazin finds in Newton a fitting framework to develop his views on film.

58 Bazin, 1952a, EC p. 1024; Transl. Gray, 2005, p. 80.

59 Ibid., EC ibid.; Transl. Gray, 2005, p. 81.

60 As Jean-François Chevrier points out in 'The Reality of Hallucination in André Bazin', Bazin makes a mistake and conflates two kitchen scenes into one, which he would in 1953 support, quite ironically, as being anti-elliptical (Chevrier, 2011, p. 48). 
between continuous reality and its abstraction - a dilemma that Bergson maintains (cinema is less) and Epstein dissolves (cinema is more).

From his side, Bazin answers to the dilemma without having to reject either reality nor the image, by means of a method that, to use Bazin's formulation, allows 'both to join reality and to replace it ${ }^{6}{ }^{1}$ The bridge he builds, I argue, between image and reality is essentially similar to the one Isaac Newton lays between the continuous curve and its infinite approximation in discrete units, which he establishes in the fundamental theorem of calculus. Newton originally developed calculus as a method to enable calculating a curvilinear volume by dividing it into discrete, measurable units (Fig. 5), and in so doing he provided an ingenious countermand to the age-old paradox of Achilles and the tortoise. Lemma II of his Principia explains the basic reasoning supporting the first theorem of integral calculus:

If any figure AacE, comprehended by the straight lines Aa and $\mathrm{AE}$ and the curve acE, any number of parallelograms [...] are inscribed upon equal bases [...]: if then the width of these parallelograms is diminished, and their number increased indefinitely, I can say that the ultimate ratios which the inscribed figure AKbLcMdD, the circumscribed figure AalbmcndoE, the curvilinear figure AabcdE have to one another are ratios of equality. [...]

$[T]$ he inscribed figure and circumscribed figure and, all the more, the intermediate curvilinear figure become ultimately equal to each other. ${ }^{62}$

By dividing the curvilinear space into a number of parallelograms, and the more this number reaches infinity, the sum of these discrete units will ultimately equal the space enclosed by a continuous curve. Similarly, I argue, Bazin's notion of 'integral realism' postulates that cinema can be ultimately equal to reality; the ever-increasing frame rates in contemporary film, even the perfecting resolutions of digital cinema transferred into a thickening pixelation, can be said to proceed from this Newtonian logic, which Bazin is the first to apply to film in his praise of Italian neo-realism.

In the essay on Umberto $D$ specifically, Bazin takes up the Newtonian framework $^{63}$ as he sees the narrative development alongside reality as a succession of 'concrete instances' that are all 'ontologically equal':

61 Bazin, 1953-1957, EC p. 2566; Transl. Barnard, 2009, p. 80.

62 Newton, 1999, p. 433.

63 See also Dalle Vacche, 2016, who takes a different, bergsonian approach to the mathematical references in Bazin's work on Italian neo-realism. 


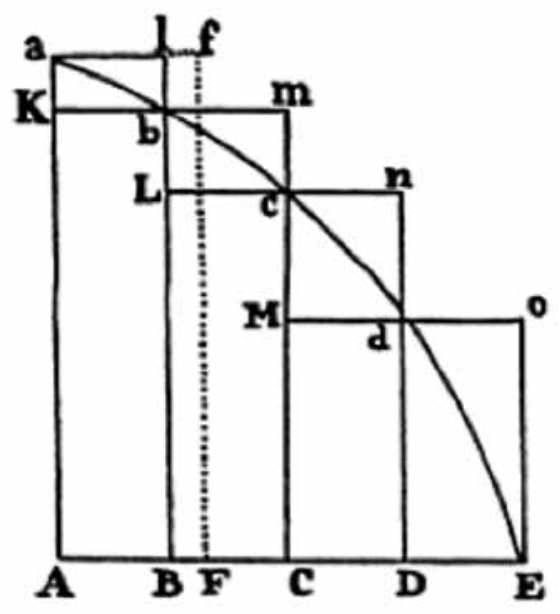

Fig. 2 Newton's calculus, 'ultimately equal'

If one assumes some distance from the story and can still see in it a dramatic pattern, a single general trend in its component events, this is only after the fact. The narrative unit is not the episode, the event, the sudden turn of events, or the character of its protagonists; it is the succession of concrete instants of life, no one of which can be said to be more important than another, for their ontological equality destroys drama at its very basis. [my emphasis] ${ }^{64}$

He further develops the implicit interest in calculus most clearly in his remarkable analysis of the wake-up scene in Umberto $D$ :

De Sica and Zavattini attempt to divide the event up in still smaller events and these jump to events smaller still, to the extreme limits of our capacity to perceive them in time. Thus, the unit of event in a classical film would be 'the maid's getting out of bed'; two or three brief shots would suffice to show this. De Sica replaces this narrative unit with a series of 'smaller' events: she wakes up; she crosses the hall; she drowns the ants; and so on. But let us examine just one of these. We see how the grinding of coffee is divided in turn into a series of independent moments; for example, when she shuts the door with the tip of her outstretched foot. As it goes in on her the camera follows the movement of her leg 
so that the image finally concentrates on her toes feeling the surface of the door. ${ }^{65}$

If one were to follow either the elliptical or photogenic logic, perhaps a close-up of Maria's hand on her belly might have sufficed to reveal her pregnancy to us, but instead the scene develops through a series of both temporally and spatially infinitesimal units: from the bedroom, through the hallway, into the kitchen, the matches, the ants and the water, the chair, the door, her foot, her toe (Fig. 3-8).

By now we know of Maria's pregnancy, and yet everything appears to follow her everyday routine. This idea is reinforced when she first tells Umberto D. of her secret:

Maria: Have you seen all the ants? Mr. Umberto, can you see anything? Umberto D.: No, nothing.

M.: You can, a little. Did you know I'm pregnant?

U.D.: My god! And you just say it like that?

M.: How do you want me to say it?

The revelation of Maria's pregnancy becomes no more than the ants on the wall, which are, by the same token, of no lesser importance than the heavy memory of wartime. In his analysis of this sequence, Jean-François Chevrier points out that during WWII, Zavattini had compared the overwhelming sight of war spreading with an ant-infested kitchen: 'War seems more formidable when you aren't in the middle of one. Ants have overrun a wall in the kitchen; they march along in a way that reveals their certainty that I won't discover their nest. ${ }^{66}$ While Chevrier sees the close-up of the ants in the sink as relating to Epstein's photogénie, I believe that, given the explicit references to limits and infinities in Bazin's analysis, De Sica's usage of close-ups is better served by the notion of image-fait, which opposes Epstein's unequal treatment of moments as well as his rejection of pascalian double infinity.

In the same way that death on screen, which is 'nothing but one moment after another', best illustrates Bazin's notion of cinematic specificity because 'it is the last', ${ }^{6} 7$ its opposite, pregnancy, follows the rule of ontological equal-

65 Ibid.

66 Cesare Zavattini, cited in Chevrier, 2011, p. 51.

67 Bazin, 1949c, EC p. 796; Transl. Cohen, 2002, p. 30; Bazin does not discuss pregnancy as such, but he compares the uniqueness of death to love, sex specifically: 'Yet two moments in life radically escape this concession to consciousness: sex and death. Both are in their own way 

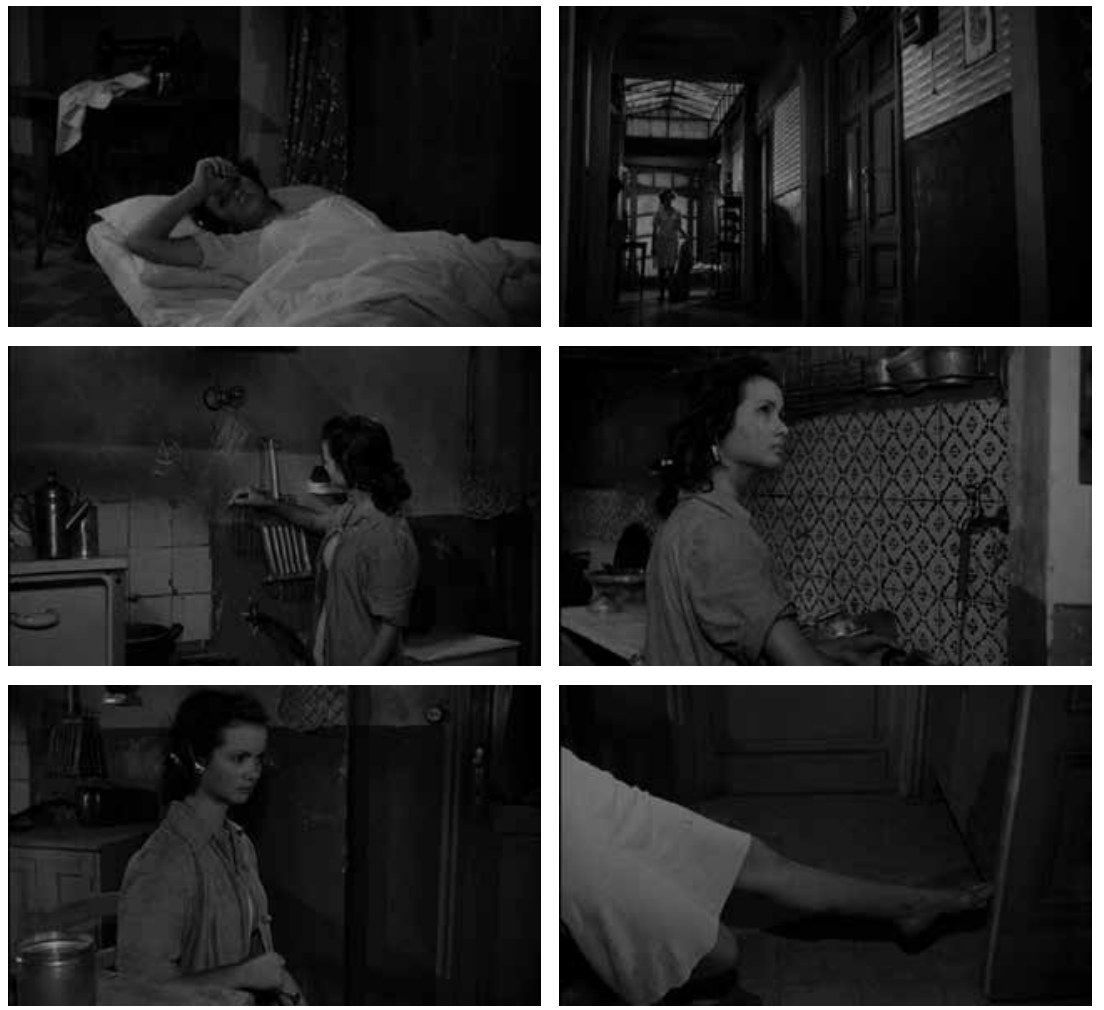

Fig. 3-8 Morning routine, a division of instants

ity. In this manner, the essay on Umberto $D$ offers itself as an original take on what Jacques Aumont, following German philosopher and art critic Gotthold Lessing, discusses in terms of a 'pregnant instant':

A painter, whose means are spread out in space, does not need to worry about time, but about choosing an instant, or the skilful deduction of the best instant, the most significant, the most typical and the most 'relevant' [le plus pregnant]. ${ }^{68}$

The 'pregnant instant' in art history stands precisely for the prevalence of one moment over any other; we can see clearly that the photogenic

the absolute negation of objective time: the qualitative instant in its pure state. Like death, love is lived and cannot be imagined [ne se représente pas] [...]' (ibid.).

68 Aumont, 1989, pp. 75-76. [Pregnant in French also means 'meaningful', which Aumont links to grossesse, pregnancy in English.] 
moment would appear too centripetal and painterly for Bazin. Moreover, Aumont remarks that this instant 'does not exist in reality', ${ }^{69}$ when he describes it, following a rather familiar train of thought, as an oxymoron: 'One can only harmonize instantaneity and relevance [la prégnance], the authenticity of the event with its significant charge, at the expense of a trick. ${ }^{70}$ Similarly, Bazin takes precisely the scene from Umberto $D$ that reveals the pregnancy as a challenge to the conventional 'unité-événement' of classical narration.

This is, I would argue, an important point in Bazin's view on cinema and its relation to reality. Since pregnancy, like death, is itself a life-changing event, but mostly because, unlike the finality of death, it announces a beginning, the analysis of Umberto $D$ ultimately makes a strong case for the existence of film in accordance with 'the laws of mutations' that frame Daney's reading of Bazin. In this manner, Bazin understood Italian postwar cinema to be a new realism, in which 'the need for narrative is more biological than dramatic in nature. It buds and grows with the verisimilitude of life itself' ${ }^{11}$

\subsubsection{The Asymptote of Reality: Reality $\simeq$ Cinema}

At the end of his essay on Umberto $D$, Bazin himself solidifies the implied mathematical mind-set as he introduces almost conjecturally his oft-cited suggestion of cinema as the asymptote of reality:

De Sica and Zavattini are concerned to make cinema the asymptote of reality - but in order that it should ultimately be life itself that becomes spectacle, in order that life might in this perfect mirror be visible poetry, be the self into which film finally changes it [Telle qu'en elle-même enfin, le cinéma la change $].^{72}$

In analytic geometry, an asymptote is a straight line to which a curve tends at infinity, but which it never crosses. From this point of view, an elliptical figure in fact has no asymptote, so when Bazin then proposes to consider cinema as the asymptote of reality, the distance he takes from Leenhardt's literary trope is rather radical. Bazin is clear in assigning to cinema the role of

71 Bazin, 1948c, EC p. 356; Transl. Barnard, 2009, p. 234.

72 Bazin, 1952a, EC p. 1024; Transl. Gray, 2005 p. 82. 
the asymptote, the straight line, which implies, following the mathematical logic, that it is reality that ultimately tends to cinema and that therefore, such as into itself, finally, cinema changes reality.

The enigmatic closing line to this article is one of many bazinian reformulations, this one taken from Stéphane Mallarmé's The Tomb of Edgar Allan Poe (1877), which he repeats about eleven times throughout his writing: 'Tel qu'en lui-même enfin l'éternité le change.73 In this specific instance, Bazin reuses the phrase to conclude a discussion on narrative progression without teleological coup, in which cinema shows reality as poetic. In an essay entitled 'William Wyler, or the Jansenist of the Mise-en-scene', Bazin repeats the poetic potential of integral realism:

There is a kind of 'cinema' that is like poetry. It is madness to see cinema as something isolated that can be set down on a piece of celluloid and projected on a screen through an enlarging lens. [...] Cinema is not some sort of independent matter whose crystals must be isolated at all costs. It is, rather, matter in an aesthetic state, a form of narrative entertainment. ${ }^{74}$

It is not coincidental, then, that in the essay on Wyler, Bazin praises what he calls a 'realist ethics' as a style without style ${ }^{75}$ against the mannerist style of others (Capra, Ford, Lang). ${ }^{76}$ Bazin here again finds a fitting comparison with mathematics, as he concludes that 'a film's purity, or better yet, to my mind, its cinematic coefficient should be calculated by the effectiveness of the way its scenes are conceived'.77 From this poetic potential, Hervé Joubert-Laurencin reads Bazin's reformulation as recalling his ontological foundation of film in the 'mummy complex':

If one recalls that for Bazin, in his first essay, 'cinema is the mummification of change', it becomes evident that this formula substitutes for theory:

See Joubert-Laurencin's analysis of this precise phrase: Joubert-Laurencin, 2014, pp. 153-158.

75 Ibid., EC p. 373; Transl. Barnard, 2009, p. 46: 'The only way to imitate Wyler would be to adopt the ethic of his mise en scène [...] There can be no imitators of Wyler, only disciples.'

76 By supporting a certain anti-mannerist aesthetics, Bazin here indirectly aligns himself with the Jansenists of Port-Royal (and he does this obviously in the title of his essay), a Christian theological movement that upheld original sin and divine grace and with which Pascal associated himself. On Pascal and mannerism, see Gheeraert, 2006, pp. 285-305.

77 Bazin, 1948d, EC p. 389; Transl. Barnard, 2009, p. 67. [Barnard translates 'coefficient' into 'quotient', which is a different mathematical concept.] 
to change nothing (to the adjacent world) to change everything (making a film = changing the world) is the maxim of ontological realism at its purest reformulation of classical mimesis. $^{78}$

Moreover, upon closer examination the line borrowed from Mallarmé summarizes the mathematical metaphors by which Bazin conceives the reality versus image dilemma: cinema takes the place of eternity or infinity - the asymptote - which continuous reality (Bergsonian durée), taking the place of the poet, approaches.

As a tentative answer to the insoluble dilemma between image and reality, embedded in Bazin's reformulation of cinematic specificity, James Tweedie understands the asymptote-analogy to mean that cinema 'brackets off' the flux of reality and links it to 'the foundational premise of [Alain] Badiou's system of thought [based on] modernity's "laicization" of the infinite'.79 He writes:

Film can enclose that infinite expanse momentarily in a frame whose closest physical analogies he saw as the window and the mirror - Bazin cycles through these familiar comparisons, seemingly unsatisfied with all of them - but whose closest conceptual analogue may be the provisional brackets of a mathematical set formed under specific conditions. ${ }^{80}$

Yet, Tweedie appears to turn the analogy around, seems to view reality as the asymptote and consequently rids cinema of its transformative power. Instead, as I have established, with concepts like the asymptote, integration and substitution, Bazin pushes the mathematical analogy beyond the contingency of set theory, against the backdrop of infinity and eternity: $\int$ not $[\ldots, . .$.$] . Rather than initiating a laicization of infinity, then, Bazin's integral$ realism, like Newton's calculus, does not solve the dilemma between image and reality. As I have argued, it maintains this difference as insoluble: a paradox.

Reality is not art and art is not reality, but in the cinema they are ultimately equal. It is not a coincidence, then, that in any serious attempt at explaining Bazin's realism, one needs to invoke inherent contradictions, such as Zeno's paradox of the tortoise or Schrödinger's cat paradox, because the very existence of film, at least for a realist like Bazin, ultimately involves 
its own impossibility (ultimate reality, no more film). In the final part of this chapter, I will approach the realist paradox from a more philosophical perspective as a wager: as with flipping a coin, cinematic realism involves risk, loss and gain.

\subsection{Bazin's Wager}

On numerous occasions, Bazin adheres to a paradigm of choice, as his views on cinematic realism appear to derive from the conviction that one cannot have both, for instance, authenticity and figuration. Schrödinger's cat cannot be both dead and alive - we cannot depict a shark attack as well as real danger. Instead, his discussion of sharks on screen is built around a certain pragmatism, where a gain in reality implies the loss of its qualities of resemblance. As such, the hesitating between the real shark and a substitute dummy in the film history of sharks perfectly lends itself to the 'I know, but all the same' paradigm, around which Daney reads Bazin's prohibition of editing:

Bazin [...] always oscillated between 'I know it' and 'but all the same'. At times, he clearly sees the realization of cinema's essence - aided by technique - in its move toward greater and greater realism: this is his famous 'gain in reality'. At other times, when he is reader to acknowledge his own fantasy, he points out that for every gain in reality there is a corresponding loss of reality' in which abstraction insidiously returns. ${ }^{81}$

Daney extracts on the one hand a 'risk function', i.e. the probable cost associated with greater realism, and on the other hand an expected value, a hoped-for gain that is worth the cost associated with it. It is no coincidence that Daney constructs the realist argument in terms of a wager. In fact, this paradigm of loss and gain pervades Bazin's thought process to such an extent that one could conceive his work on documentary authenticity, cinematic specificity and editing altogether as a realist wager.

\subsubsection{Calculated Risk}

This chapter brought forth two tentative equations:

1. $\quad$ editing $=$ probability, and

2. event $=$ authenticity. 
But it would be all too easy to rank Bazin under the latter only: both are indeed diverging approaches to reality (quantitative versus qualitative), yet they are two sides of the same coin. Bazin's prohibition of editing, too, is only one side of the realist coin: in 'Death Every Afternoon', a critical review of Bullfight (Myriam Borsoutsky \& Pierre Braunberger, 1951), he praises Myriam Borsoutsky's editing technique precisely because, in some cases, 'it is an essential element in the film's creation'. ${ }^{82}$ The essay's title is an obvious reference to Ernest Hemingway's Death in the Afternoon (1932), and for good reasons. The article as well as the book deal, of course, with bullfights: Hemingway wanted to convey 'the feeling of life and death's3 based on personal experience, Bazin admits 'never [having] been to a bullfight [...] but [the film] gives me its essential quality, its metaphysical kernel: death, ${ }^{84}$ Both authors also implicitly or explicitly deal with editing. Compare these two citations:

the art of bullfighting, which is only kept from being one of the major arts because it is impermanent, in the arrogant slowness of his veronicas becomes, for the seeming minutes that they endure, permanent. ${ }^{85}$

Hemingway sees slow motion in the torero's tense movement, described here as a 'veronica' - a term referring to the basic starting position of a bullfighter but also a metaphor Bazin uses throughout his texts to describe the cinema screen. ${ }^{86}$ Now Bazin:

This is why the representation on screen of a bull being put to death (which presupposes that the man has risked death) is in principle as moving as the spectacle of the real instant that it reproduces. In a certain sense, it is even more moving because it magnifies the quality of the original moment through the contrast of its repetition. It confers on it

82 Bazin, 1949c, EC p. 795 .

83 Hemingway, 1932, p. 3.

84 Bazin, 1948d, EC p. 795 .

85 Hemingway, 1932, p. 12.

86 See, Bazin, 1945; Bazin, 1953-1945; Bazin, 1951a. Interestingly, Sergei Eisenstein is the first to interpret the official term metaphorically in his drawings of bullfighting in Mexico, dating from 1931 to 1932: at least two of these drawings show the bull's head in true iconic fashion imprinted on the torero's veil. See also François Albera's “'The Heritage We Renounce": Eisenstein in Historiography.' In: Sergei M. Eisenstein: Notes for a General History of Cinema. Eds. Kleiman, Naum \& Antonio Somaini. Amsterdam: Amsterdam University Press (2016): p. 275 . 
an additional solemnity. The cinema has given the death of Manolete [a famous matador who died during the fight] a material eternity.

On the screen, the toreador dies every afternoon. ${ }^{87}$

Or again, specifically relating to editing, Hemingway suggests that a first visitor should choose:

[...] a seat not too near the ring so that he will see the entire spectacle rather than, if he is too close, have it constantly broken up into bull and horse, man and bull, bull and man - and a hot sunny day. ${ }^{88}$

In other words, having to turn your head from the bull back to the torero in a real-life experience lines up with what in cinema would be an editing sequence such as a shot reverse shot or a close-up inserted in a long shot (which, in turn, would be the distant seating of Hemingway's spectator). Needless to say, Borsoutsky's Bullfight is full of editing techniques and montage sequences, but instead of rejecting them as cutting up the action, Bazin praises the freeze frames and especially its matches on action: "Without us noticing the switch, a "veronica" beginning with one matador and bull ends with a different man and a different animal. ${ }^{89}$ His discussion of neo-montage, as he calls it, goes well beyond the traditional Kuleshov effect: ${ }^{90}$ here, ' $\mathrm{t}$ ] he linkage of two bulls in a single movement does not symbolize the bulls' strength; it surreptitiously replaces the photo of the non-existent bull we believe we are seeing'. ${ }^{91}$ Like the torero fighting off the bull with his cape, the editor's job is risky business, directing the action through cuts and pastes while having to preserve its 'metaphysical kernel'. One might think an editor in the editing room is safer than the torero in the ring. Yet the analogy is fair, as bullfighting rarely involves the death of a torero: following the strict rules of the game, the bull will certainly die..$^{2}$

87 Bazin, 1948d, EC p. 796.

88 Hemingway, 1932, p. 13.

89 Ibid., p. 28.

9o The Kuleshov effect illustrates that the meaning of an image in a montage sequence is derived from the images that precede and proceed it: the expressionless face of a man on screen will look hungry when it follows the image of a bowl or soup, or sad when it follows that of a child's corpse. Bazin's notion of 'neo-montage' moves in a different direction: rather than suggesting (or symbolizing) meaning via the combination of two shots, Myriam's cut substitutes for the shots we cannot see.

91 Bazin, 1948d, EC p. 795 .

92 Once a bull enters the ring, it will certainly die. If it were to get the upper hand at the torero, other toreros would immediately take over, or a picador on horseback will put the animal down. And if the bull does win, it is killed afterwards anyway: a winning bull, Hemingway writes, 
There is a risk, of course, but it is calculated: the skills of the torero should bring the fight to the very limit, enraging the bull to the extent that it will continue its attack, yet without really reaching equal risk for man/animal (that would simply be foolish). Similarly, an editor should choose his or her cuts and 'movements' carefully, pushing the ongoing trickery to its extreme. From this perspective, the bullfight and the editing process both occur on a probability scale.

A scene from Intacto (Juan Carlos Fresnadillo, 2001) illustrates this dynamic perfectly. In voice-over accompanying a slow-motion sequence of a bull winning from the bullfighter, a retired torero, Alejandro, expresses the thrill of the profession and then explains why he quit:

A great fight can only come out of fear. Not fear of failure, not with a real bullfighter. But fear of pain... yours, those around you, your gang. That fear that makes you look for what's real through bullfighting. [...] And I lost my fear of the bull, without that you can't fight.

A real bullfighter won't lose the game - at least not his life, if he is skilful and all goes according to the rules - but for a worthy fight, fear must be present: it simply would not work otherwise. Alejandro then found another place to look for what's real': gambling on life and death with a select group of four, all extremely gifted: lucky people. One of them is Tomas, a novice in the game and the main protagonist of the film. As the sole survivor of a plane crash, he catches the attention of the gambling organization:

- You're a lucky man, Tomas... the chances of a plane crash are 1/1.000.000. The chances of a crash with you as the sole survivor - out of how many? 237 passengers? - are 237.000.000/1. Why were you the only survivor of that crash? Why? There were many good people on board. What saved you, a common thief: God?

- Chance.

- For you, there's no such thing. Your gift lets you take other people's luck. All you need is luck.

The story unfolds as a knockout, including running through a forest and crossing busy highways blindfolded, guessing games and fraudulent practices 
with a life-insurance company. Out of the four players only one will survive to play the end game, which is a Russian roulette with Samuel (performance by Max von Sydow), mastermind of the game. His luck was proven at a young age, when he was the only child in his pavilion to survive the Holocaust. Before Tomas gets to play the final game (and wins), Samuel tells him his childhood story:

I don't usually talk to the people I'm going to play. But this time I will make an exception. Every morning, the door of the barrack would open, and they took a few out. First the oldest, then our parents, then their brothers and sisters. In a couple of weeks, there were only about fifty of us left, all children. Suddenly, they just stopped coming. Then one day a man appeared, he was not a guard, he was wearing a sand-coloured suit. Spotless, it was. And he held a black handkerchief to his nose (we didn't smell too good, you see), and one by one he took us by the arm and jotted our numbers down in his notebook. We would be 'called and reunited with our parents', and then he left and never came back. But the guards returned, they lined us up and shouted a number - and I looked at my arm, it wasn't me, it was one of the others. And as he walked to the door he turned and looked at us all, thrilled to bits that he won, and disappeared. And so on, every day another number... or two, or none. [...] In the end, only Daniel and I were left, for four days alone. [...] Daniel knew that it wasn't our parents waiting for us on the other side. And the day the door opened again, I took my friend's hand and closed my eyes, willing it not to be my number. When Daniel let go, I couldn't open my eyes, I didn't want to look at his face. The next time the doors opened, the uniforms had changed.

Ultimately, the film conflates gambling and betting with larger-than-life tragedies like the Holocaust, thus making explicit an implied philosophy of existence. Does luck play a role in real-life events? (Could Samuel have been the next to last child?) Are some privileged in this regard, or is everything left to chance? (Why was Tomas, a petty thief, the sole survivor?) In the concluding section, I will argue that the idea of a wager bears explicitly existentialist questions and as such also pervades Bazin's realist paradigm.

\subsubsection{Les jeux sont faits: rien ne va plus?}

Samuel offers three options for Tomas' survival of the plane crash: God, chance, or luck. However, all these options give the characters little agency. 
Surviving a blindfolded run through a forest, for example, has little to do with skill or tactics. Similarly, no single strategy is proven to be effective in winning at American, French, or even Russian roulette: as much as they rely on chance events (themselves unpredictable), once the dice are thrown nothing can change the outcome. As the traditional phrase puts it, les jeux sont faits, rien ne va plus! From this perspective, then, gambling in and of itself effaces the authenticity of the outcome: the ball could have fallen on any number, the winner in fact is as gifted as all the losers together. Without agency, these narratives do not 'make [the characters] aware of [their] freedom and possibilities', ${ }^{93}$ as existentialists would have it. Thus, the existentialist's maxim 'existence precedes essence' questions a predetermined outcome based on chance, and instead affirms the necessity of agency and participation in fate. In Ingmar Bergman's The Seventh Seal (1957) - an obligatory title in this discussion - a knight, Antonius Blok (again, performance by Max von Sydow), encounters the Grim Reaper on his way back from a crusade (the film is set in the Middle Ages against the backdrop of the Black Plague). The Grim Reaper has been following him for quite some time now and decides to introduce himself. Rather than accepting his fate, Antonius negotiates extra time, which he will use 'for one meaningful deed', since his life so far has been 'a futile pursuit'. He seals a deal:

You play chess, don't you? [...] I've seen it in paintings and heard it in songs. [...] The condition is that you let me live for as long as I can stand against you. If I win, you let me go.

The game of chess frames the film and regularly appears as a prop on set whilst Antonius embarks on a quest for 'knowledge, not faith, not suppositions, but knowledge'. The fact that Death plays chess is important from an existentialist point of view: if the all-famous phrase 'God does not throw dice' may counter an aleatory approach to events in life, a chess-playing Grim Reaper suggests that there are rules and tactics involved, at least to some extent. Death will always win, of course, but when that time comes and Antonius is checkmated, Death asks him: 'What have you gained by this reprieve?', to which Antonius answers: 'a great deal!' Instead of being one moment after the other, or rather: one probability like any other, death for Antonius appears to be qualified. 
Both Tomas in Intacto and Antonius in The Seventh Seal look for an essential principle in life (luck, chance, maybe God for Tomas or knowledge for Antonius), and in doing so they test the limits of a certain death. In short, in order to find 'what's real' (the most authentic), they must challenge a determined course of events (the most probable) by means of a wager. The notion of a wager, in particular a calculated and reasoned wager, in relation to existentialist thought goes a long way. In his Pensées, the French philosopher, physician, inventor and mathematician Blaise Pascal (1623-1662) draws out his renowned wager over the existence of God, which would in combination with his mathematical work be seen to touch upon the foundations of calculus and prefigure mathematical probability theory. Pascal first stresses the necessity of the wager, and then considers reason alone as unfit to solve the dilemma of the existence of God:

'God is, or He is not.' But to which side shall we incline? Reason can decide nothing here. There is an infinite chaos which separated us. A game is being played at the extremity of this infinite distance where heads or tails will turn up. What will you wager? According to reason, you can do neither the one thing nor the other; according to reason, you can defend neither of the propositions. [...] but you must wager. It is not optional. You are embarked.

You have two things to lose, the true and the good; and two things to stake, your reason and your will, your knowledge and your happiness; and your nature has two things to shun, error and misery. Your reason is no more shocked in choosing one rather than the other, since you must of necessity choose. This is one point settled. But your happiness? Let us weigh the gain and the loss in wagering that God is. Let us estimate these two chances. If you gain, you gain all; if you lose, you lose nothing. Wager, then, without hesitation that He is. [...] [T]here is here an infinity of an infinitely happy life to gain, a chance of gain against a finite number of chances of loss, and what you stake is finite. It is all divided; wherever the infinite is and there is not an infinity of chances of loss against that of gain, there is no time to hesitate, you must give all. And thus, when one is forced to play, he must renounce reason to preserve his life, rather than risk it for infinite gain, as likely to happen as the loss of nothingness. ${ }^{94}$

Possibly the most well-known and pronounced account of Pascal's wager on screen is Eric Rohmer's My Night at Maud's (1969), which draws clear 
parallels between Pascal's wager and its mathematical implications as related to probability theory. Jean-Louis (Jean-Louis Trintignant), an engineer and practicing Catholic with a passion for maths and probability theory, walks into a bookshop and, after skimming through a new publication on probability, stumbles upon the Pensées. Later on, he reconnects with his old college friend Vidal, an atheist Marxist and philosophy professor at the local university, and their conversation sets the ground for the further development of the narrative:

- Jean-Louis: Are you interested in mathematics?

- Vidal: It's increasingly important for a philosopher. In linguistics, for example. But even basic things. Pascal's arithmetical triangle is connected to his wager. That's what makes Pascal so amazingly modern. Mathematician and philosopher are one.

- J.-L.: Good old Pascal.

- V.: Are you surprised?

- J.-L.: Funny you mention him, I'm just rereading him at the moment. [...] I'm very disappointed. [...] I feel I know him almost by heart, and yet he tells me nothing. I find it all so empty. I'm a Catholic, or at least I try to be, but he doesn't fit in my notion of Catholicism. It's exactly because I'm a Christian that his austerity offends me. If that's what Christianity is about, then I'm atheist. Are you still Marxist?

- V:: Absolutely. For a communist, Pascal's wager is very relevant today. Personally, I very much doubt that history has any meaning. Yet I wager that it has, so I'm in a Pascalian situation. Hypothesis A: Society and politics are meaningless. Hypothesis B: History has meaning. I'm not at all sure B is more likely to be true than A. More likely the reverse. Let's even suppose $B$ has a 10 percent chance of being true, and $A$ has 8 o percent. Nevertheless... I have no choice but to opt for B, because only the hypothesis that history has meaning allows me to go on living. Suppose I bet on A, and B was true, despite the lesser odds. I'd have thrown away my life. So, I must choose B to justify my life and actions. There's an 80 percent chance I'm wrong, but that doesn't matter.

- J.-L.: Mathematical hope. Potential gain divided by probability. With your hypothesis B, though the probability is slight, the possible gain is infinite. in your case, a meaning to life. In Pascal's, eternal salvation.

- V.: It was Gorky, Lenin or maybe Mayakovsky who said about the Russian revolution that the situation forced them to choose the one chance in a thousand. Because hope became infinitely greater if you took that chance than if you didn't take it. 
Vidal, a reasonable man, translates Pascal's God into meaningfulness as opposed to nothingness: he opts for B to 'justify his life and actions', regardless of the possibility that he chooses wrongly. As such, Pascal's wager implies a particular inadequacy of rational arguments. Terrence Penelhum writes about this that:

The most oft-quoted passage of Pascal is the one that says the heart has its reasons which the reason does not know. This is not, I would suggest, a simple appeal to wallow in emotionalism, but partly a way of saying that the canons of rationality of belief and unbelief are different. If the Wager argument is right, the bridge between the two can be crossed by a process which will be differently described by both sides, but which will have its rational element whichever way it is viewed. ${ }^{95}$

Just as Pascal emphasizes the necessity of wagering the existence of God, Bazin rules out the possibility of escaping the bet: in the presence of the camera, a choice - Daney calls it a qualitative leap - has to be made. Similarly, the 'I know, but all the same' paradigm put forth by Daney suggests that reason is not the deciding factor in these types of bets. This paradigm of infinite gain over finite loss, then, accurately reflects what proves to be a pragmatic paradigm of choice guiding the insoluble dilemma between image and reality: we have no choice but to choose. Choice is, in this manner, an existential agency that defies a predetermined course of events (like death).

In this chapter, I presented Bazin's original take on integral realism as a rejection of medium essentialism (in particular Claude Mauriac but also Jean Epstein and even Roger Leenhardt). From a similar perspective, Angela Dalle Vacche suggests that Bazin instead was more affiliated with Gabriel Marcel's notion of 'ontological exigency' rather than engaging in the intended essentialist mind-set of Mauriac's 'cinematic specificity'. She argues that '[i]t is in the margins of the unknown that photography and the cinema explore and expose in ways no other medium, craft, digital imaging, or art form can even begin to match. ${ }^{96}$ Whereas my analyses have shown that Bazin's realism, when it is understood as a wager, in fact equally applies to digital image techniques, there is indeed a strong connection with Marcel's

95 Penelhum, 1964, pp. 206-207.

96 Dalle Vacche, 2011, p. 150. For a detailed analysis of Bazin's affinity with Marcel on the cross-influence between cinema and other arts, see 3.1 Debates on Contemporary Art: Bazin, Marcel and Portmann. 
philosophy of existence, in which ontological exigency plays a crucial role. He explains this process as follows:

Being is - or should be - necessary. It is impossible that everything should be reduced to a play of successive appearances which are inconsistent with each other... or, in the words of Shakespeare, to 'a tale told by an idiot'. I aspire to participate in this being, in this reality - and perhaps this aspiration is already a degree of participation, however rudimentary. ${ }^{97}$

Here, Marcel's ontological exigency indeed resonates with the realist wager discussed in this chapter, as well as with Bazin's rejection of medium essentialism. Marcel acknowledges that it is participation in reality, which is like choice necessary: an exigency that defines being or essence. Rather than a tale told by an idiot, life is meaningful and participation can change the course of history. In the following chapter, I will solidify the connection between Bazin and Marcel in their shared views on the social function of art, cinema in particular, in post-war society. This will bring me to the consequence of Bazin's anti-essentialist stance, as it involves his rigorous work on the undeniable relation between the medium of film and other art forms, of which I will single out his discussions on cinema in relation to painting and poetry

\section{Bibliography}

Albera, François (2016). “The Heritage We Renounce:” Eisenstein in Historiography.' In: Sergei M. Eisenstein: Notes for a General History of Cinema. Eds. Kleiman, Naum \& Antonio Somaini. Amsterdam: Amsterdam University Press.

Andrew, Dudley (1976). The Major Film Theories: An Introduction. New York: Oxford University Press.

--- (2007). 'A Film Aesthetic to Discover.' Cinémas:Journal of Film Studies, Vol. 17, No. 2-3: pp. 47-71.

--- (2012). 'Malraux, Benjamin, Bazin.' In: Film, Art, New Media: Museum without Walls? Ed. Angela Dalle Vacche. New York: Palgrave Macmillan, pp. 115-140.

--- (2013). André Bazin. New York: Oxford University Press.

Aumont, Jacques (1989). L'CEil interminable: Cinéma et peinture. Paris: Librairie Siguier.

Bazin, André (1945). 'Ontologie de l'image photographique.' Qu'est-ce que le cinéma? Paris: Éditions du Cerf (2008): pp. 9-18. EC OP, 1.

--- (1948c). 'Le Réalisme cinématographique et l'école italienne de la Libération.' Esprit, No. 141 (January). EC V, 362.

--- (1948d). 'William Wyler ou le janséniste de la mise en scène.' Qu'est-ce que le cinema? Vol. 1: Ontologie et langage. Paris: Éditions du Cerf (1958). EC V, 382. 
--- (1949c). 'Mort tous les après-midi.' Qu'est-ce que le cinema? Tome 1: Ontologie et langage. Paris: Éditions du Cerf (1958): pp. 65-7o. EC IX, 899.

--- (1951a). 'Le Journal d'un cure de campagne et la stylistique de Robert Bresson.' Qu'est-ce que le cinema? Paris: Éditions du Cerf (2008): pp. 107-128. EC IX, 798.

--- (1952a). 'Une grande œuvre: Umberto D.' Qu'est-ce que le cinéma? Paris: Éditions du Cerf (2008): pp. 131-337. EC XI, 1141.

--- (1953-1954). 'Le Cinéma et l'exploration.' Qu'est-ce que le cinéma? Paris: Éditions du Cerf (2008): pp. 25-34. EC OP I, 7.

--- (1953-1957). 'Montage interdit.' Qu'est-ce que le cinéma? Paris: Éditions du Cerf (2008): pp. 50-61. EC OP I, 16.

---(1955a). 'L'Évolution du film d'exploration.' Le Monde nouveau (May). EC XVII, 1754. EC OP, 17.

--- (1956b). 'Le Monde du silence: Icare sous-marin.' Radio cinéma télévision, No. 319 (26 February). EC XIX, 1993.

--- (1958a). 'Avant-propos.' Qu'est-ce que le cinéma? Tome 1: Ontologie et langage. Paris: Éditions du Cerf (1959): pp. 7-9. EC OP I.

Chevrier, Jean-François (2011). 'The Reality of Hallucination in André Bazin.' In: Opening Bazin: Postwar Film Theory and Its Aftermath. Eds. Dudley Andrew and Hervé Joubert-Laurencin. New York: Oxford University Press, pp. 42-55.

Dall'Asta, Monica (2011). 'Beyond the Image in Benjamin and Bazin: The Aura of the Event.' In: Opening Bazin: Postwar Film Theory and Its Aftermath. Eds. Dudley Andrew and Hervé Joubert-Laurencin. New York: Oxford University Press, pp. 57-65.

Dalle Vacche, Angela (2011). 'The Difference of Cinema in the System of the Arts.' In: Opening Bazin: Postwar Film Theory and Its Aftermath. Eds. Dudley Andrew and Hervé Joubert-Laurencin. New York: Oxford University Press, pp. 142-152.

--- (2016). 'Miraculous Mathematics: André Bazin's Film Theory.' Discourse, Vol.38, No.2 (Spring): pp. 117-141.

Daney, Serge (1972). 'The Screen of Fantasy (Bazin and Animals).' Transl. Mark A. Cohen. In: Rites of Realism: Essays on Corporeal Cinema. Ed. Ivone Margulies. Durham: Duke University Press (2002): pp. 32-41.

Doane, Mary Ann (2003). The Emergence of Cinematic Time: Modernity, Contingency, the Archive. Cambridge: Harvard University Press.

Epstein, Jean (1921). ‘Bonjour cinéma.' In: Écrits sur le cinéma 1921-1953. Vol ı. Ed. Pierre Lherminier. Paris: Éditions Saghers (1974): pp. 71-104.

--- (1926). 'Le Cinématographe vu de l'Etna.' In: Écrits sur le cinéma 1921-1953. Vol 1. Ed. Pierre Lherminier. Paris: Éditions Saghers (1974): pp. 131-168.

--- (1946). 'Intelligence d'une machine.' In: Écrits sur le cinéma 1921-1953. Vol 1. Ed. Pierre Lherminier. Paris: Éditions Saghers (1974): pp. 255-354.

---(1947). 'La Logique des images.' In: Écrits sur le cinéma 1921-1953. Vol 2. Ed. Pierre Lherminier. Paris: Éditions Saghers (1975): pp. 30-33.

Gheeraert, Tony. 'Pascal et les reines de village: baroque et maniérisme à Port-Royal.' Études epistèmè, No. 9 (2006): pp. 285-305.

Hemingway, Ernest (1932). Death in the Afternoon. London: Vintage Books, 2000.

Joubert-Laurencin, Hervé. Le Sommeil paradoxal: écrits sur André Bazin. Montreuil: Les Éditions de l'CEil (2014).

Marcel, Gabriel (1933). 'On the Ontological Mystery.' In: The Philosophy of Existentialism. Transl. Manya Harari. New York: The Citadel Press (1970): pp. 9-46.

Michalson, G.E. (1979). 'Lessing, Kierkegaard, and the "Ugly Ditch": A Reexamination.' The Journal of Religion, Vol. 59, No. 3 (July): pp. 324-334. 
Newton, Isaac (1684). The Principia: Mathematical Principles of Natural Philosophy. Transl. Bernard

Cohen, Anne Whitman and Julia Budenz. Berkeley: University of California Press, 1999.

Pascal, Blaise (1670). Pascal's Pensées. Transl. W.F. Trotter. New York: E.P. Dutton \& Co., $195^{8}$.

Penelhum, Terence. 'Pascal's Wager.' Journal of Religion, Vol. 44, No. 3 (1964): pp. 201-209.

Peres, Asher (1995). Quantum Theory: Concepts and Methods. Dordrecht: Kluwer Academic Publishers.

Schrödinger, Erwin (1935). 'The Present Situation in Quantum Mechanics: A Translation of Schrödinger's “Cat Paradox Paper." Transl. John D. Trimmer. In: Quantum Theory and Measurement. Eds. J.A. Wheeler and W.H. Zurek. New Jersey: Princeton University Press (1983): pp. 152-167.

Stapp, Henry Pierce (1972). 'The Copenhagen Interpretation.' American Journal of Physics, Vol. 40, No. 1098: pp. 1098-1116.

Tweedie, James (2011). 'André Bazin's Bad Taste.' In: Opening Bazin: Postwar Film Theory and Its Aftermath. Eds. Dudley Andrew and Hervé Joubert-Laurencin. New York: Oxford University Press: pp. 275-287.

\section{Other sources}

'Kon-Tiki: The Incredible True Story: Shooting in Open Water.' National Geographic. [Accessed 28/05/2014] <http://channel.nationalgeographic.com/channel/videos/ shooting-in-open-water/>.

'Death Jump - Eiffel Tower 1912.' British Pathé. [Accessed 28/05/2014] <http://www.britishpathe. com/video/death-jump-eiffel-tower/query/reichelt>.

'Jaws: Trivia.' The Internet Movie Database. [Accessed 28/05/2014] < http://www.imdb.com/title/ ttoo73195/trivia?ref_=tt_trv_trv>.

'Kon-Tiki: Complete VFX-Breakdown.' YouTube. [Accessed 28/05/2014] <http://www.youtube. com/watch?v=gFpL2XzAn44>.

'Shark! Trivia.' The Internet Movie Database. [Accessed 26/04/2019] <https://www.imdb.com/ title/ttoo66365/trivia?ref_=tt_trv_trv>.

Trier, Joachim \& Harvey Weinstein. “Kon-Tiki” Directors Discuss the Making of Their Offshore Epic (Q\&A).' The Hollywood Reporter (26/04/2014) [Accessed 28/05/2014] <http://www.hollywoodreporter.com/news/kon-tiki-directors-discuss-making-447386>.

\section{Used translations}

Daney, Serge (1972). 'The Screen of Fantasy (Bazin and Animals).' Transl. Mark A. Cohen. In: Rites of Realism: Essays on Corporeal Cinema. Ed. Ivone Margulies. Durham: Duke University Press (2002): pp. 32-41.

Bazin, André. What Is Cinema? Vol. 1 \& 2. Transl. Hugh Gray. Berkeley: University of California Press (2005).

---. What Is Cinema? Transl. Timothy Barnard. Montreal: Caboose (2009). 
Epstein, Jean. 'The Cinema Seen from Etna.' Transl. Stuart Liebmann. In:Jean Epstein: Critical essays and New Translations. Eds. Sarah Keller and Jason N. Paul. Amsterdam: Amsterdam University Press (2012): pp. 287-310.

---. 'The Logic of Images.' Transl. Thao Nguyen. In:Jean Epstein: Critical essays and New Translations. Eds. Sarah Keller and Jason N. Paul. Amsterdam: Amsterdam University Press, (2012): pp. 330-333.

\section{Filmography}

Man of Aran (Robert J. Flaherty, 1934)

Diary of a Chambermaid [Journal d'une femme de chambre] (Jean Renoir, 1946)

Paisà (Roberto Rossellini, 1946)

Paris 19oo (Nicole Védrès, 1947)

Kon-Tiki (Thor Heyerdahl, 1950)

Bullfight (Myriam Borsoutsky \& Pierre Braunberger, 1951)

Umberto D. (Vittorio De Sica, 1952)

The Seventh Seal (Ingmar Bergman, 1957)

My Night at Maud's [Ma nuit chez Maud] (Eric Rohmer, 1969)

Jaws (Steven Spielberg, 1975)

Intacto (Juan Carlos Fresnadillo, 2001)

Kon-Tiki (Joachim Rønning \& Espen Sandberg, 2012)

\section{Illustrations}

Figure 2. Diagram of Isaac Newton's Calculus, Principia Lemma II

Figure 3-8. Film stills from Umberto D. (Vittorio De Sica, 1952) 



\title{
3. Film and the Other Arts
}

\begin{abstract}
In this chapter, I situate Bazin's studies on film and painting within a postwar endeavor to renew artistic forms and to revive their social implication, which crystallizes in an encounter with the French existentialist philosopher Gabriel Marcel (1889-1973) and Swiss biologist Adolphe Portmann (1897-1982). From there on, I pinpoint certain specifically cinematographic aspects, both on film and in painting, to support Bazin's notion of a 'myth of total cinema'.
\end{abstract}

Keywords: film and painting, myth, Vincent van Gogh, Pieter Bruegel

Er ligt een lijk onder het struikgewas. Vier eeuwen na zijn dood zag men het pas, als in Blow Up, maar op z'n Boeren-Breughels

[A corpse lies under the shrubs.

It took four centuries for people to find, as in Blow-Up, but in Peasant Bruegel-style].

Jan Kal, 1974

The first time you stood in front of this painting, your eye was immediately drawn to the ploughman's red shirt. Later on, discovering Icarus on the right, you smiled. Immediately, then, a strange litany started to reverberate in your head. It continued all afternoon: a man works his field; a shepherd looks at the sky; a boat slowly navigates towards a port; the sea is calm; a man is drowning. Claudio Pazienza, 1997

The prominence of painting in Bazin's oeuvre is exemplified by the contextual framework it sketches from the first version of 'The Ontology

Joret, B., Studying Film with André Bazin, Amsterdam: Amsterdam University Press, 2019 DOI: $10.5117 / 97894629895^{28 / \mathrm{CHO}}$ 
of the Photographic Image', published in a collected volume Problems of Painting (1945): in it, painting functions as a counter-reference to cinema. Photography and by extension cinema have changed painting because they freed '[the visual arts] from the obsession of resemblance.' The initial interest in painting thus accompanies Bazin's film criticism from the very beginning and culminates in his later essays, where he further develops this thesis in support of an 'impure cinema' into a series on cinema and painting (1949) and its relation to theater ('Theater and Cinema', 1951) and literature ('For an Impure Cinema', 1952). For Bazin, film defines itself in a constant dialogue with other art forms to address contemporary societal issues, post-war apathy specifically. We know from his correspondence with his close friend Guy Léger in 1940 that Bazin's depression caused by the Nazi invasion of France had everything to do with his 'guilt at being so far from the front, but he realized that his urge toward self-sacrifice was hardly patriotic. It stemmed, he said, from a massive sense of personal worthlessness'. ${ }^{2}$ Later that year, Bazin actively engaged with others in 'sorting out the political, philosophic, and moral disaster that had fallen on their country and was being accepted with disgusting effortlessness'. ${ }^{3}$ Bazin's firm belief in a fundamentally social aesthetic of film can thus be viewed in light of a cultural movement that sought in the arts the moral re-armament against social apathy. From this perspective, his particular concern with cinema and other arts is informed by both his rejection of medium essentialism as well as with his views on cinema's social dimension.

In this chapter, I situate Bazin's studies on film and painting within a postwar endeavour to renew artistic forms and to revive their social implication, which crystallizes in an encounter with the French existentialist philosopher Gabriel Marcel (1889-1973) and Swiss biologist Adolphe Portmann (1897-1982). From there on, I pinpoint certain specifically cinematographic aspects, both on film and in painting, to support Bazin's notion of a 'myth of total cinema' with a specific emphasis on the myth of Icarus in Bazin's oeuvre, in painting as well as in poetry. From Bazin's writings on Vincent van Gogh, as well as those of Antonin Artaud and Georges Bataille, I argue for a particularly realist film language.

1 Bazin, 1945, EC p. 2556; Transl. Barnard, 2009, p. 7; On the role of painting in Bazin's ontology essay, see for example, Joubert-Laurencin, 2014, pp. 63-67.

2 Andrew, 2013, p. 33.

3 Ibid., p. 34 . 


\subsection{Debates on Contemporary Art: Bazin, Marcel and Portmann}

In 'For an Impure Cinema', Bazin firmly embeds his anti-essentialist mind-set in the existentialist lemma, 'existence precedes essence', ${ }^{4}$ a common denominator under which Jean-Paul Sartre places himself alongside Gabriel Marcel, despite the latter's outspoken Christian perspective. ${ }^{5}$ While it is in these Sartrian terms that Bazin's general views on film history can be explained, his association with Marcel, as a literary critic, playwright and a philosopher, remains to this day unconfirmed. As mentioned in the previous chapter, Bazin's affinity with Marcel is indirectly implied by the latter's notion of 'ontological exigency', which Angela Dalle Vacche opposes to Claude Mauriac's views on 'medium specificity', ${ }^{6}$ and Dudley Andrew provides in his biography of Bazin the setting for this plausible influence:

Only recently did I [Andrew] learn that Marcel and Bazin conducted a dialogue on cinematographic art, which was broadcast on the radio in 1948. This doesn't surprise me, as Marcel, a philosopher-playwright, like Sartre, who eagerly engaged the cinema, was also close to Bazin's friend Amédée Ayfre. ${ }^{7}$

Chaired by the poet Emmanuel Clancier, the roundtable discussion was in fact recorded at the International Encounters in Geneva around the necessity of renewal in the history of art. ${ }^{8}$ The theme of the talk was fully in line with

4 Bazin, 1952f, EC p. 830; Transl. Barnard, 2009, p. 133.

5 Sartre, 1946, p. 349.

6 Dalle Vacche, 2011, p. 150; Dalle Vacche references Jean Leirens' Le Cinéma et le temps (p. 96, 110). In a passage on Bergsonian durée in Diary of a Chambermaid (Robert Bresson, 1951), Leirens writes in a remarkably Bazinian fashion: 'This is without a doubt the only film to this day entirely dedicated to one of his paintings "from inside". Cinema here comes closer to painting, but in the domain where painting itself touches upon philosophy. I'm only talking about these comparisons, by the way, for the sake of convenience, since it would be vain to try to assign boundaries to the arts.' (Leirens, 1954, pp. 96-97).

7 Andrew, 2013, p. xxx. The exact broadcast Andrew references is from 20 September 1948 on Tribune de Paris, which featured a debate between Bazin, Marcel and Swiss zoologist Adolphe Portman. The debate was held in the context of the third Rencontres Internationales de Genève on contemporary art, to which both Marcel as a keynote speaker and Bazin contributed.

8 For a transcription of speeches and interviews, see Débats sur l'art contemporain. Tome 3. Neuchâtel: Les Éditions de la Baconnière (1948) < http://www.rencontres-int-geneve.ch/ volumes_pdf/rigo3.pdf $>$. 
a general demand for change after the Second World War, as Clancier points out in his introduction:

For years, people have suffered to such an extent that they all aspire change. It appears to me that each of us, unsatisfied with the miserable world around us, awaits and wishes, more or less, that this world would change. It seems to me that this desire, this wish for change, works equally well in relation to the artistic domain, as it does in the material or moral world. ${ }^{9}$

The conference in Geneva was organized to provide an interdisciplinary platform that fosters discussion on the role of contemporary art in post-war society. From a film perspective, it is cinema's particular form of the postwar art documentary that throws light on other, perhaps less popular art forms and thereby extend their social relevance. As Dalle Vacche writes: 'By associating the art documentary with an avant-garde orientation, Bazin theorized the relation between cinema and painting with the hope that art and cinema together could generate a sensibility more open to the value of spirituality in daily life. ${ }^{10}$ Precisely because of its popular character, film can bring about not only a renewal of artistic forms but also a revived popular interest in other arts. In 'The Art Documentary in the Postwar Period', Dalle Vacche continues:

\begin{abstract}
After 1945, in order to avoid paralyzing pessimism and endless revenge, the hope and need for human outreach called for a communal effort towards good will, despite the echoes, the mistakes, and the loose ends from the past. [...] Well aware of social struggles, religious divisions, and cultural boundaries, [Bazin] underlined cinema's universal and egalitarian address. After 1945, there was a feeling of urgency about peace on earth. [...] His hope was that well-made art documentaries could inspire audiences with new humanist, anti-anthropocentric values that would bring about a more tolerant, less greedy, and more self-critical mass culture. ${ }^{11}$
\end{abstract}

In fact, a closer examination of this particular debate, which I provide subsequently, clearly shows that Marcel, Portmann and Bazin share distinctive ideas on the fundamentally social character of cinema as well as the 
cross-influence between different art forms (literature, theater, painting, photography and cinema).

The topics discussed in this encounter resurface prominently in Bazin's later work, comprising a large amount of essays on cinema and other arts, most of them published after this debate. ${ }^{12}$ In fact, Bazin's general film historical orientation ('Cinema has yet to be invented!'3) aligns with the research interests of Portmann, the third member of this roundtable discussion and at the time zoology professor at the University of Basel, which was invested in the physiological prematurity of man (man is 'an animal born too early'). From this biological perspective, Portmann fully embraces the suggestion to renew the arts: 'I am absolutely certain that art has to transform itself, because art, from an aesthetic point of view, is a human function which is profoundly rooted in our being. ${ }^{14} \mathrm{~A}$ similar biological undercurrent is clearly present in Bazin's description of the interaction between cinema and painting, when he writes on Alain Resnais' Van Gogh (1948):

Like a lichen born from the symbiosis between the seaweed and the mushroom, the combination of cinema with painting here gives birth to a new aesthetic being; its ontology will perhaps enlighten us on some fundamental laws pertaining to the existence of painting and of cinema. ${ }^{15}$

As Dalle Vacche notes, underlining Bazin's adherence to a biological framework: 'The critic's scientific vocabulary, here, is crucial: the lichen is the paramount example of organic or intermedial symbiosis. ${ }^{16}$ From this frame of reference, Bazin's views on painting and cinema, more precisely the new aesthetics born from their combined ontology, coincide with an art critical discourse on the necessity or possibility for artistic forms to renew themselves. ${ }^{17}$ Marcel, for his part, initially looks at the avant-garde for fulfilling this desire for change rather than the general taste of the public, but later on, in his keynote lecture at that same conference, explicitly aligns himself with Bazin:

17 From this point of view, the biological resonances in the term 'ontogeny', Portman's primary research area, need not oppose the mechanism described by Joubert-Laurencin (Joubert-Laurencin, 2014, p. 21; see note ${ }_{5}$ Chapter II). 
It is extremely interesting to notice, as André Bazin very rightly said, that upholding the communication between art and the people is here an absolutely vital condition; it is a condition without which, given its financial conditions, cinema cannot even exist. It is for this reason that we can not only conceive of, but know, and point out works that are considered beautiful by the artists, in cinema, and works which can perfectly affect a popular audience. ${ }^{18}$

Bazin, who is always straightforward and univocal when it comes to this topic, states: 'cinema makes novels being read and popularizes theater plays. I position myself on this ground in a very worldly manner: cinema gives passport to the theater and the novel. ${ }^{\prime 19}$ Cinema, then, is able to bring out the socio-aesthetics of any art, in particular of painting which is, compared to literature and especially the theater, traditionally more removed from a broader audience. From this perspective, Andrew writes about Bazin's first defence of such a hybrid film, Rubens (Paul Haesaerts \& Henri Storck, 1948), that:

[...] the film operates both on the painting and on the spectator by forcing an aesthetic conjunction that tells us something about painting, about cinema, and about spectatorship. 'Who can complain of this?' [Bazin] innocently asks, pre-empting the scoffs he knew would come from art scholars. $^{20}$

One of those art scholars Bazin may have had in mind, according to Andrew, was the novelist and art theorist André Malraux, who occupies an ambivalent place in Bazin's views on the relation between cinema and painting. ${ }^{21}$ From an art historical point of view, Malraux adhered to what is often referred to as the 'Basic Story': a 'chronicle of technological progress'. ${ }^{22}$ This historical approach to the evolution of art forms entails that a painting made before the invention of the camera could not - stylistically speaking - be cinematographic: cinema might have influenced the history of painting, but this influence depends entirely on the actual invention of the camera. Initially, Bazin appears to adopt the idea that photography introduced an

18 Marcel, 1948, p. 202.

19 Bazin, 1948 [Radio broadcast].

20 Andrew, 2011, p. 155.

21 Bazin, 1945, EC p. 2555; Transl. Barnard, 2009, p. 7; on Bazin versus Malraux in relation to The Mystery of Picasso, see Andrew, 2011.

22 Bordwell, 1999, p. 27. 
abstraction in the development of modern painting (e.g. cubism, impressionism), stressing again its social function: 'Freed from the complex of resemblance, modern painters surrendered it to the people, who henceforth identified it with photography on the one hand and with the only kind of painting that applies itself to it on the other.'23 However, during the Geneva debate in 1948, as well as in his essays on painting and cinema specifically, his mention of myth, which I explain subsequently, proposes a more nuanced orientation that unties film aesthetics from technology.

\subsubsection{The Invention of Cinema Is a Myth}

While Marcel and Portmann appear to follow the Malrauxian argument, namely that the invention of photography has changed painting, ${ }^{24}$ Bazin takes a slightly different orientation. He elaborates on the particular influence of cinema on painting, as he sees the impressionist painter Edgar Degas (1834-1917), whose paintings from a historical perspective precede the invention of cinema, nevertheless mythically influenced by cinematographic realism:

It seems to me that if we go into the veritable influence or inter-influence of these arts more closely, we would be incited to take on a more flexible and more sceptical position, which would perhaps be this: namely that the influence, if really there is an influence of cinema on other arts and I indeed believe that it is blatant, among others in the novel and for photography on painting, if really there has been an influence, then this is not one from cause to effect. This would not be an influence through which painters at one point, seeing photographs, would have said to themselves: 'It is absurd to make portraits, I am going to do something else than portraits; I am going to make things that don't need to resemble

23 Bazin, 1945, EC p. 2556; Transl. Barnard, 2009, p. 7.

24 Portmann states: 'any art, the art of every day if you will, which was for a long time concerned with painting the portrait of citizens, that particular art has largely been transformed and replaced by photography. I'm thinking of illustrations in numerous books, scientific and biological ones, where photography has also largely rendered the activity of the artist almost useless, superfluous' (Portmann, 1948, n. pag.). In the Ontology article, Bazin appears to follow a similar line of thought in a footnote on book- and journal illustrations but reverses the order of causality: 'It would be interesting, from this perspective, to examine the rivalry in the illustrated press in the period 1890-1910 between photographic reportage, which was still in its infancy, and drawings. The latter in particular satisfied the Baroque need for the dramatic (consider Le Petit journal illustré). The sense of the photograph as a document emerged only gradually' (Bazin, 1945, EC p. 2555; Transl. Barnard, p. 11). 
nature anymore', that's not the case. Besides, historically speaking one finds that the history of photography is on the contrary a history of influences from painting on photography. Indeed, the first photographers tried hard to attempt to resemble painters. It is rather [...] an influence of the sensibility of the time period, of a profound need of that time period. In this manner, Degas for instance composes his paintings exactly like the end of a sequence on screen. Yet, cinema needed fifty years to recall the style of Degas on screen, and to construct its cinematographic framing totally naturally throughout the evolution of its language, like Degas made a painting. But this is because Degas was prophetic in his time and felt throughout this scientific and mechanistic nineteenth century the need to represent reality seized in some sort of simultaneously realist and dramatic synthesis, which cinema would find much later. So, if it is really there, we can speak of an influence of cinema on Degas, but not historical, since Degas precedes the cinema, but somehow of a myth of cinema, which was still subconscious at the time and which has influenced painting through an artist as sensible as Degas. ${ }^{25}$

According to Bazin, Degas' work is influenced by cinematographic realism, despite the historical anachronism: technically speaking, Degas could not have made cinema, yet his impressionist style might allude to more dynamic, cinematographic techniques like slow motions or fade-outs. Picking up the same theme, while rewriting his seminal essay 'The Myth of Total Cinema' in 1958, Bazin includes another reference to a particular myth, the myth of Icarus, to explain this ahistorical invention of film:

Of course, other examples of the convergence of research could be found in the history of technology and inventions, but we must distinguish those which are, precisely, the product of scientific advances and industrial (or military) needs from those which clearly precede these advances. The ancient myth of Icarus had to wait the internal combustion engine before descending from Plato's higher world, but this myth has been present in every human being since we began to observe birds. ${ }^{26}$

Bazin's mention of the myth of Icarus in this passage is anything but anecdotal: portrayed here as preceding the antiheroes of a technological invention, driven either by financial profit (the Lumière brothers and Thomas Edison) 
or scientific achievement (Etienne-Jules Marey and others), Bazin places Icarus among those 'fanatics, the maniacs, the disinterested pioneers' who had first imagined cinema. ${ }^{27}$ Cinema, of course, is an inherently mechanical art, but Bazin subordinates the technological inventions to the power of imagination: 'Cinema', he famously wrote, 'has yet to be invented!'28 With the myth of Icarus, Bazin not only solidifies the connection between the invention of film as imaginative rather than technological, but also nuances film histories that draw parallels between cinema and industrial (or military) needs. ${ }^{29}$ Bazin's parentheses bring us back to the historical context of the Geneva debate: the necessity for renewal in artistic forms implicitly requires a renewal of art theories and critical methodologies in which different media (cinema, painting, theater and literature, or poetry) mutually inform each other.

Again, a contemporary example illustrates this point. In his critically acclaimed animation film The Wind Rises (2013), Hayao Miyazaki blends artistic forms (more precisely animation film, literature and poetry) with human history on a mythical subject - human flight. The film tells the story of Jiro, a Japanese boy who dreams of flying airplanes, but his poor eyesight might keep him from realizing this dream. In the opening scene, he flies a small airplane over the city and countryside when, suddenly, his view is disturbed by a colossal, war-like flying machine. The goggles do not fit over his thick glasses and, cross-eyed, Jiro falls like Icarus back to earth. After an imaginary conversation with his mentor, the Italian aircraft designer Count Caproni, he realizes he can be an engineer instead of a pilot, as 'engineers turn dreams into reality'. Partly fictionalized from a novel by Hori Tatsuo, The Wind Has Risen (1936-1937), from which Miyazaki borrows the title (which, in turn, is a line from Paul Valéry's The Seaside

27 Ibid.

28 Ibid.; Transl. Barnard, 2009, p. 17.

29 See primarily Paul Virilio's War and Cinema: Logistics of Perception, in particular his chapter entitled 'Cinema Isn't I See, It's I Fly' in which he argues that 'Since the battlefield has always been a field of perception, the war machine appears to the military commander as an instrument of representation, comparable to the painter's palette and brush. [...] For men at war, the function of the weapon is the function of the eye. It is therefore quite understandable that, after 1914, the air arm's violent cinematic disruption of the space continuum, together with the lighting advances of military technology, should have literally exploded the old homogeneity of vision and replaced it with the heterogeneity of perceptual fields [emphasis in original]' (1989, p. 20). While industry usually shows itself particularly interested in warfare, the myth of Icarus in Bazin's writing posits a different view on the origins of cinema as combining a technological invention with an age-old dream of human flight. 
Cemetery $\left.3^{30}\right)$, the two protagonists of the film are based on historical figures: Italian aircraft designer Giovanni Battista Caproni (1886-1957), whose company built bombers for the Italian air force, and Jiro Horikoshi (1903-1982), known for designing the Mitsubishi A6M Zero fighter that was used in the Pearl Harbor attacks in 1940. Yet Caproni declares that 'Airplanes are not tools for war. They are not for making money. Airplanes are beautiful dreams. Cursed dreams... waiting for the sky to swallow them up.' Against the background of the Second World War, Miyazaki views the human desire for flight from an openly pacifist mind-set: where bombs only add weight to already bulky aircrafts, Jiro wants to design airplanes light as air. From this perspective of 'airplanes that don't return', Miyazaki questions the perversions of wartime all the while affirming the pacifist force of imagination, as Bazin does with his reference to Icarus. The film gradually merges Jiro's dreams with the harsh reality of a devastating war and personal loss, as his wife Naoko dies from tuberculosis. In the final sequence, Jiro meets Caproni again in his dream world, which is now a land covered with plane wrecks under a sky clouded by burning cities: 'it's the land of the dead.' Valéry's poem clearly guides the film from beginning to end: 'entre les tombes', despite such disasters, out of the clear blue sky 'le vent se lève' and Jiro must try to live!

By means of such intertextuality, then, specific artworks can adapt traditional themes or forms according to the 'sensibility of the time' and thereby answer to 'a profound need of that period'. Bazin's critical work is full of implicit intertextuality in which existing forms (myths, paintings, poetry) are given new meaning through their contemporary societal relevance. Rather than tipping into a dominantly formalist practice, ${ }^{31}$ however, this intertextuality in Bazin resonates with his distinctive cinephilia, which Serge Daney describes as follows: 'Loving cinema is loving this idea that we always make do with bodies that have already served, that have existed

30 As I will argue extensively later on, it is around this particular poem that Bazin constructs his critique of Le Monde du silence, ultimately making the formalist statement that accompanies his Myth argument (see Chapter IV - A MATTER OF FORM).

$3^{1}$ Intertextuality is a major sub-field in semiotic analysis which, following Julia Kristeva's initial account of the topic in 'Word, Dialogue and Novel' (1966), inspired Roland Barthes' (post-) structuralist statement that 'the text is a tissue of quotations' (Barthes, Roland. S/Z: An Essay. London: Cape (1974): p. 146). Barthes' publication is known to have put an end to the realist tradition in French criticism, which sought meaning in the mediating link between text and reality. Bazin's notion of 'recreation', however, could be seen as a realist alternative to, or even precursor of formalist intertextuality: film art is always an adaptation of reality, as much as writing criticism is always an adaptation of the original work of art. 
for others. ${ }^{32}$ From a realist point of view, cinema will always borrow forms: from other artworks but also, being itself a recreation of the world, from reality. In what follows, I want to analyze the apparent opposition between cinema and painting in accordance with his conviction that form and content in art can and should mutually inform each other: a particular painter's aesthetics had already been cinematic, and a painting's influence on film brings about a 'new aesthetic cosmology' to the screen.

\subsubsection{Bruegel Cinematographer}

By way of introduction to the extensive topic of cinema and painting in Bazin's body of work, I want to elaborate further on the myth of Icarus interpreted from a post-war perspective by examining a short, intertextual exercise offered by Bazin as an original entry into major ontological themes emerging from his discussion of cinema and painting. Let us then focus first on one painterly reference in his critique of the underwater exploratory documentary, The Silent World (Jacques-Yves Cousteau \& Louis Malle, 1956): not the impressionist style of Degas, but an implicit allusion to Pieter Bruegel the Elder's original interpretation of the Icarus myth in his Landscape with the Fall of Icarus from 1556 (Fig. 9). Bazin mentions it seemingly in passing but then uses the reference to construct his entire analysis of Cousteau's underwater universe. He writes:

In Bruegel's admirable painting, Icarus falling to the water in rustic indifference prefigures Cousteau and his companions diving into the green sea off some Mediterranean cliff, ignored by the farmer who works his field and takes them for swimmers. ${ }^{33}$

Here, again, Bazin sees a particular painting as prophetic of a film to come, exactly 300 years later. His description of the painting specifically pinpoints Bruegel's framing of the myth as fundamentally cinematographic: reduced to a detail, the tragedy of Icarus loses its prominence in the painting (his feet and some feathers are its only reminders). Moreover, Bruegel's masterpiece itself also offers a significantly original take on the classical myth, which 'loses its importance in face of this new conception of the cosmos' ${ }^{34}$ In fact,

34 De Tolnay, 1935, p. 28; Much has been written on Bruegel's interpretation of the Icarus myth; see, for example: Baldwin, 1986, pp. 101-114; Harries, 2002, pp. 93-103; De Vries, 2003, pp. 4-18. 
Bazin's description centers precisely on those elements of the painting that are originally and uniquely Bruegel's. The art historian Charles De Tolnay describes these as follows:

[T] here is no doubt that Bruegel would have resorted directly to the text [by Ovid], because he is the first to have represented the farmer at work, the shepherd on his staff, the fisherman with his line by hand. But he does this by reversing this exact text: rather than contemplating Icarus and Daedalus with astonishment, flying through the sky like gods, the carefree farmer continues his work, the shepherd turns his back to Icarus, stares fixedly at the emptiness ahead of him and the fisherman continues to be absorbed by his fishing; even the partridge, whose wings Ovid makes flap to eternally mock Daedalus, sits here immobile on its branch; even better, the ship next to which the catastrophe unfolds, clears off with its sails inflated towards the sun. ${ }^{35}$

Admittedly, Bazin's ekphrasis in the critique of The Silent World is rather brief and at first sight perhaps isolated from the painting/cinema question, but the fact that he reiterates the indifference of the peasant as well as the ignorance of Icarus' tragedy unfolding in the background strongly suggests that he picked up on a more general contemporary interest in the old master's work, which reinterprets the painting and the myth of Icarus from a modern perspective. ${ }^{36}$

Before and after Bazin, the myth of Icarus has been interpreted and reinterpreted through various art forms and from different historical perspectives. The resonances between the painting, Bazin's citation and its recent reiterations in fact allow us to find in Bruegel's work a particularly cinematographic ontology. In what follows, I will contextualize the brief citation as instrumental in what Bazin describes in his essays on painting and cinema in terms of a 'new cosmology of film', just like Bruegel's painting that, as his critics generally agree, offers a 'new conception of the cosmos' ${ }^{37}$ More specifically, I elaborate

Ibid., p. 29 .

36 Incidentally, as was the case with Miyazaki's The Wind Rises, Bazin's interpretation of this underwater documentary also relies explicitly on Paul Valéry's The Seaside Cemetery, to which I will return the final chapter (see 4.1.1 From Advertising to Poetry in Bazin). Though his analysis of The Silent World is brief, his film criticism can in this instance be read as an exercise in intertextuality or recreation, as I will call it later on: it illustrates his critical methodology in practice.

37 On Bruegel's 'cosmology', see for example: Alpers, 1983, in particular her analysis of the 'mapping impulse' in his paintings (pp. 133-136), which she relates back to the Alexandrian astronomer Claudius Ptolemy's ideas from Geography (145 AD). From a cinematic perspective, 


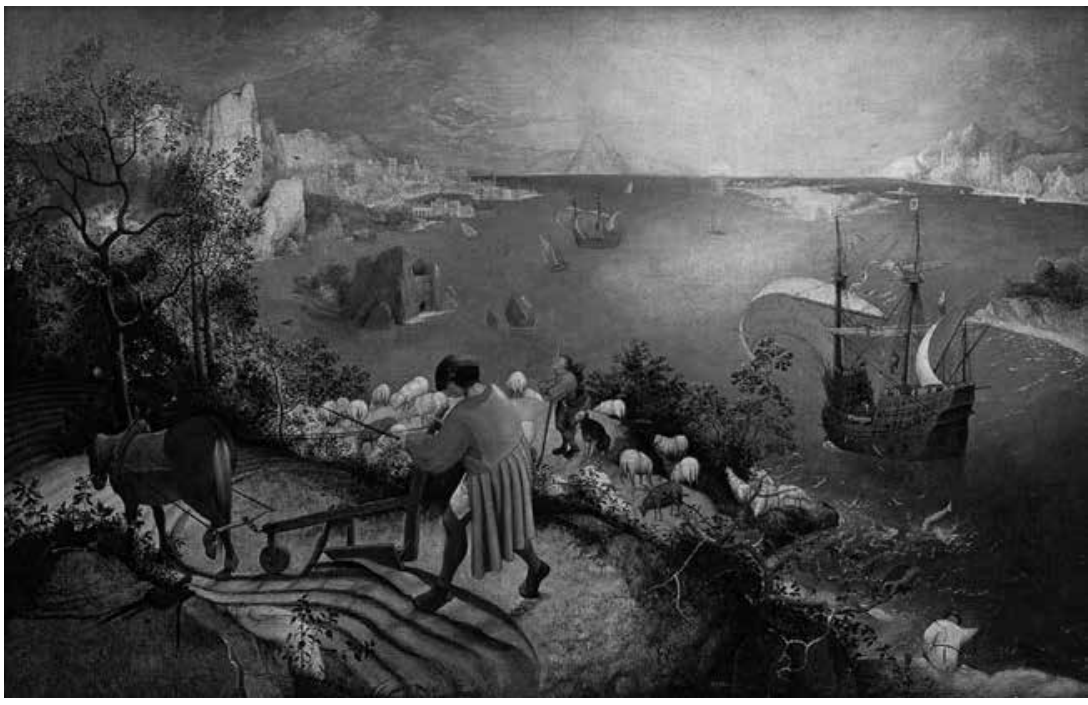

Fig. 9 Landscape with the Fall of Icarus, Pieter Bruegel the Elder (1556)

on Bazin's notion of the 'centrifugal screen' via a selection of references to both painting and poetry in his writing. First, however, I will follow up on the Icarian analogy in the 'Myth' essay, by situating Bazin's reference to Bruegel alongside W.H. Auden within a tradition of twentieth-century anti-war poetry. In this manner, I maintain that such an anachronistic influence between painting and cinema - suggesting that Bruegel would have painted according to a particularly cinematographic aesthetic - is not exceptional in Bazin's views on art history and indeed supports his notion of myth.

Tom Conley in Cartographic Cinema first looks at Bazin's Icarus anecdote to construct his general argument: 'to each film its map' (Conley, 2007, p. 5), and in a later chapter also refers to the work of Ptolemy in a specific discussion of maps as they appear in The Gladiator (Ridley Scott, 2002). Ptolemy's work is indeed intriguing when it comes to the 'new cosmology' or worldview in cinema. In his astronomical study the Almagest (150AD), Ptolemy describes the apparent motion of the stars and planets based on observations and lays the foundations for a cosmology that holds earth at the center of the universe. His calculations fit within ancient Greek physics that intended to 'save the appearances [sozein ta phainomena]', as the French mathematician Pierre Duhem (1861-1916) famously wrote (Sōzein ta phainomena: essai sur la notion de théorie physique de Platon a Galilée, 1905). With the Copernican revolution in the sixteenth century, the Ptolemaic cosmological model was replaced by a heliocentric worldview. It seems to me that Bazin might be dipping into these issues when he writes at the outset of his Ontology essay that it is a photographic image's primordial function to 'save being by appearance [sauver l'être par l'apparence]' (1945, EC p. 2555); in any case, the notion of 'cosmology' clearly guides his analysis of Vincent van Gogh's aesthetics transformed on screen, discussed later on in this chapter. 


\subsection{3. 'How Everything Turns Away': Icarus as Anti-War Statement}

During the course of the twentieth century, Bruegel's version of the Icarus myth gained remarkable attention, following the initiative of the AngloAmerican poet W.H. Auden's Musée des Beaux-Arts, written in December 1938 during a visit to the Royal Museum of Fine Arts in Brussels and published the following year. Auden begins his poem with the more general approach of the Old Masters to the theme of human suffering in an always apathetic setting, and then picks up the Bruegelian indifference in the Icarus painting:

About suffering they were never wrong,

The Old Masters; how well, they understood

Its human position; how it takes place

While someone else is eating or opening a window or just walking dully along;

How, when the aged are reverently, passionately waiting

For the miraculous birth, there always must be

Children who did not specially want it to happen, skating

On a pond at the edge of the wood:

They never forgot

That even the dreadful martyrdom must run its course

Anyhow in a corner, some untidy spot

Where the dogs go on with their doggy life and the torturer's horse

Scratches its innocent behind on a tree.

In Breughel's Icarus, for instance: how everything turns away

Quite leisurely from the disaster; the ploughman may

Have heard the splash, the forsaken cry,

But for him it was not an important failure; the sun shone

As it had to on the white legs disappearing into the green

Water; and the expensive delicate ship that must have seen

Something amazing, a boy falling out of the sky,

Had somewhere to get to and sailed calmly on. ${ }^{38}$

Auden reinterprets the painting within the zeitgeist of the period, shaded by social apathy and anxiety following the Great War, as a wakeup call. As Judith Bernstock argues: 'twentieth century artists generally revive ancient myths as part of their search for a common ground accessible to all.'39 More specifically, Alexander Nemerov argues that '[the painting] 
is Bruegel's aesthetic lesson to other artists of the 1930 and 1940 os about the incorporation of social content', ${ }^{40}$ and so the Icarian theme provides a platform for universal anti-war statements. Following Auden, several poets and painters have repeated the reference to Bruegel's Icarus, giving it an enduring significance in relation to the contemporary concerns of a century marked by wartime: 'in both the original work and modern versions, life continues - the fall of Icarus fails to disturb the harmony between man and nature. ${ }^{41}$ The shared interpretation of Bruegel's Icarus as an address to social apathy in wartime implicitly builds on a lesser-known etching by the painter, which portrays the fall of Icarus in a much more dramatic setting. In Man of War Sailing to the Right; Above, the Fall of Icarus (1561-1562), Daedalus is there, witnessing his son's tragedy as it happens, and instead of 'calmly sailing on', the ship is caught in a stormy ocean (Fig. 10). The title of this etching deliberately frames the mythic tragedy from the point of view of war: in Bruegel's time, the man-of-war was a vehicle of war, armed with canons and driven by sails rather than oars, which were the usual propellers of combat ships like galleys, for example. The ship is in fact identical to the one in Landscape with the Fall of Icarus: by the look of the wind in its sails, we know now that this ship is going to war. Where in Bruegel's etching, then, Icarus' tragedy is dramatically aligned with the implied sufferings of wartime, his subsequent painting depicts war, in Auden's words, from a 'human position; how it takes place while someone else is eating or opening a window or just walking dully along'. These recent reiterations of Bruegel's interpretation of Icarus indeed raise pertinent questions regarding the social impact of documenting epic tragedies (like war, or a little boy falling from the sky), while elsewhere life goes on. As the old proverb, often associated with Bruegel's painting, has it: 'no plough stands still just because a man dies. ${ }^{.22}$

Tackling the same issues at stake, the surrealist writer André Breton (18961966) includes in First Papers of Surrealism (1942) a cut-out that reinterprets, again, Bruegel's Icarus in the context of the Second World War; this time, with a

40 Nemerov, 2005, p. 804; Nemerov reads Musée des Beaux-Arts against the backdrop of Journey to a War (published in 1939), in which Auden and Christopher Isherwood recount their travels to China during the Sino-Japanese war (1937-1945) as they witnessed an air raid on the city of Hankow: 'Aerial machines, squinting upwards, innocent victims - these experiences so fresh in Auden's mind must have given the fate of Bruegel's falling boy a contemporary resonance' (Ibid., p. 785). 41 Bernstock, 1993, p. 179; For instance, incorporating the myth of Icarus on war in painting, there are Felice Casorati (Icarus, 1936), Henri Matisse (Icare, 1943), Pablo Picasso (La Chute d'Icare, 1958), Anselm Kiefer (Icarus, March Sand, 1981); from the side of the poets, William Carlos Williams (Landscape with the Fall of Icarus, 1960), Anne Sexton (To a Friend Whose Work Has Come to Triumph, 1962).

42 Glück, 1936, p. 24. 
particular reference to a news report on excessive bombings on Düsseldorf(Fig. 11). This print is featured in the section 'On the Survival of Certain Myths and on Some Other Myths in Growth or Formation',43 and clearly positions Bruegel's Icarus in a new light. Breton radically changes the original composition: he eliminates the sky, the sun, the ocean and the field, and in doing so urges the viewer to combine all the characters involved into one diagonal strip, with the city at the top. Anna Blume describes Breton's composition as follows:

Breton cuts out this detail in the shape of the ploughman's foot. By doing this Breton leads us to wonder what the relationship might be between bombs at Dusseldorf, the single step of the ploughman, and the falling Icarus. ${ }^{44}$

'Detail: Bruegel', the print's subheading reads. By aligning one detail (Icarus falling) with another (the ploughman's foot), Breton pushes the analogy of the image-fait as fait divers: a devastating war takes the form of an unimportant, almost banal instant, the footstep, and vice versa. Considering the other textual element in the composition, Breton furthermore explicitly frames the tragedy of Icarus in an address to the role of news reporting media: 'Düsseldorf has been bombed yesterday for the fiftieth time. (The Newspapers).' In Bruegel's etching, his painting, as well as Breton's interpretation of it, meaning is derived from the formal organization of the tableaus: a tragedy of mythical proportions, Icarus' death or bombings on Düsseldorf, is presented as a detail, taking up no more, no less space (hence: importance) than the fisherman, the ploughman, the setting sun, or even - another detail, barely visible - Auden's untidy spot, the corpse in the bushes on the left. 45

The interplay between front-page news and faits divers brings me to another, more contemporary interpretation of Icarus. In his documentary film Tableau avec chutes (1997), Claudio Pazienza captures the implications of Bruegel's message well: dressed in a red shirt, like the dutiful ploughman,

43 Breton and Duchamp, 1942, n. pag.

44 See Anna Blume's full discussion of this cut-out in 'In the Wake of Production: A Study of Bruegel's Landscape with the Fall of Icarus' (1995, pp. 240-241).

45 Following W.H. Auden, many poets of the twentieth century have interpreted Bruegel's painting. In relation to the corpse, see specifically Jan Kal's 'The Fall of Icarus [De valvan Icarus]' (1974), which I cited at the outset of this chapter. It was the art historian De Tolnay, also cited earlier in this chapter, who in the 1930s discovered the corpse hidden on the left of the frame. Kal's reference to Michelangelo Antonioni's Blow Up (1966) makes sense and points again to the masterpiece's inherent cinematographic aesthetics: as in the film, an unclear detail blown out of proportion makes for an entirely new interpretation of an apparently undisturbed scene. 


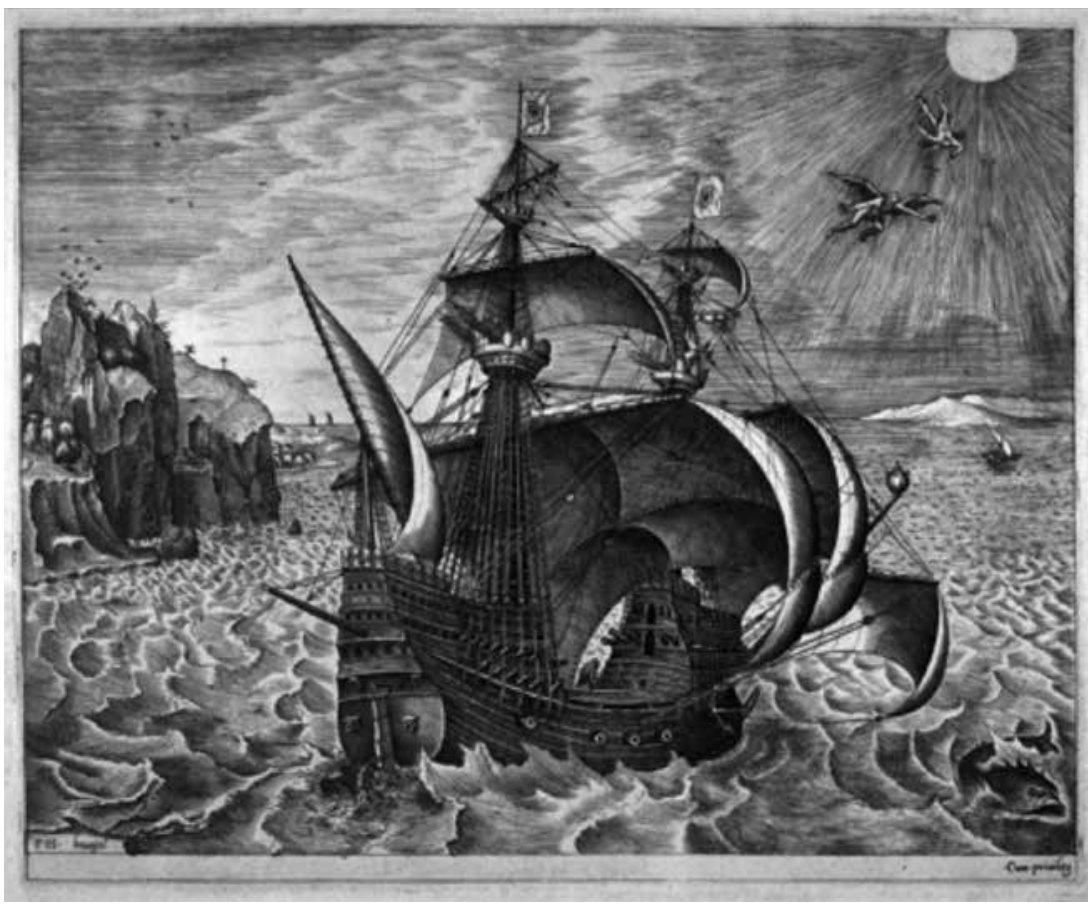

Fig. 10 Man of War Sailing to the Right; Above, the Fall of Icarus, Pieter Bruegel the Elder (1561-1562)

and with a print of Landscape with the Fall of Icarus and a camera in hand, Pazienza sets out to ask the Belgians (his parents, the dentist, professors, the prime minister, his neighbors, those on social welfare) what they see in this painting: 'Icarus swims, from both sides of the linguistic border.' Most people do not notice Icarus, others take him for a bather or, perhaps, someone who is drowning. 'But this happens here as well', a Flemish woman remarks: 'Sometimes people are just looking, and something happens and they don't do anything either.' By setting the documentary against the background of several nationwide revolts in the nineties, ${ }^{46}$ Pazienza explores the social and political involvement of a people in specific historical events: Bruegel's painting of Icarus poses the question concerning 'the distance between the one who is looking and that which is being looked at'. Why do certain events

46 For instance, large-scale strikes against educational reform; the child abuse cases of Julie and Melissa, An and Eefje, and Sabine and Letitia; the nationwide 'white march' following the dismissal of their investigating magistrate Jean-Marc Connerotte: these current affairs put the finger on injustice and flaws in the judicial system that mobilized the Belgians to speak out against the government. 


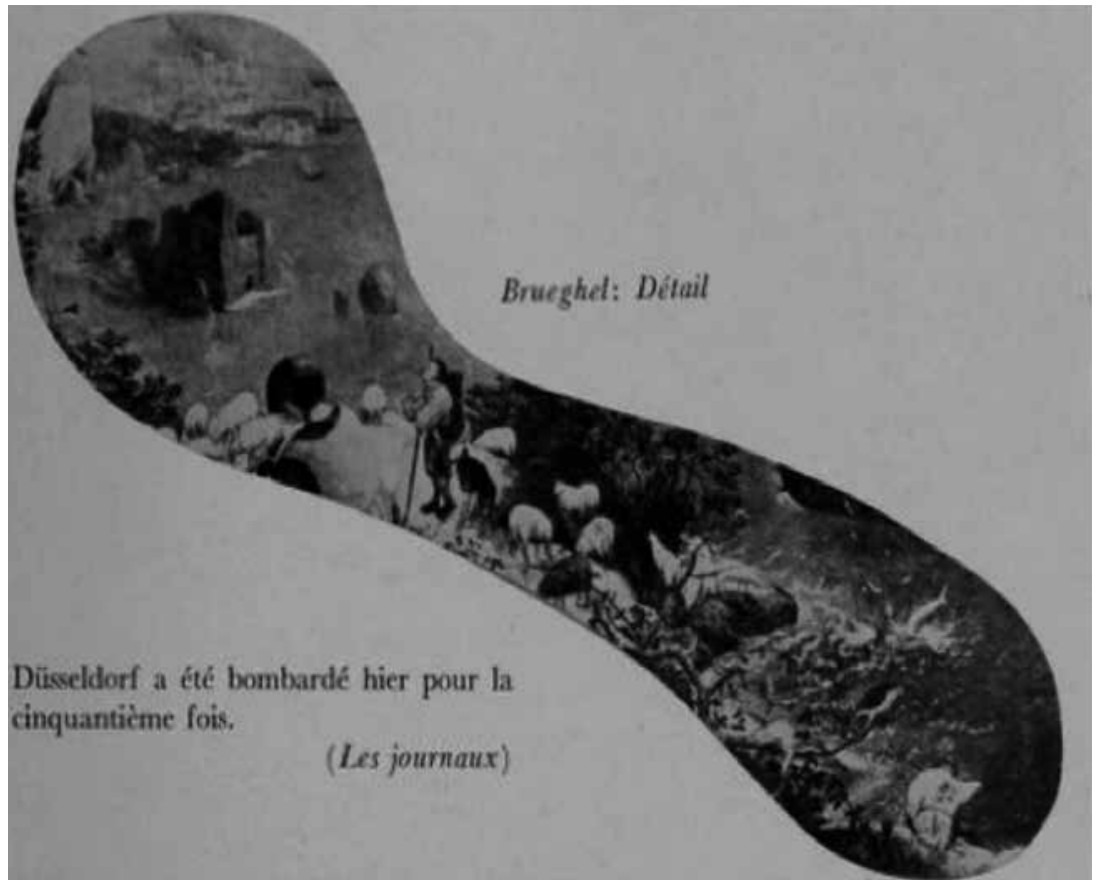

Fig. 11 Cutout by André Breton (1942)

make us instantly drop whatever we are doing, while others leave us cold; and what role do images play in our closeness to tragedies that, to take on a French phrase, ne nous regardent pas? Against social apathy, Pazienza's interpretation of Icarus follows the centrifugal principle of human reality: the documentary as 'a hymn to man with his feet anchored on earth'. In Bazin's words: rather than a succession of front-page events, cinema is 'a printing press of reality'. ${ }^{4}$

To sum up, there are two theoretical implications proceeding from Bazin's short reference to Landscape with the Fall of Icarus that both concern the relation between cinema and painting in Bazin's oeuvre. First, it acknowledges that the spatial qualities of a particular sixteenth-century painting prefigure the cosmology of the cinema screen, which supports his thesis of film invention being a myth. Secondly, it is important to note that the fall of Icarus is the only mythical theme painted by Bruegel, whose usual subjects were either biblical or everyday sceneries, and that he interprets the myth in such a way that it decreases the mythical proportions of its traditional treatment: in short, and using Bazin's terminology, he interprets 
a fundamentally painterly and centripetal subject in a centrifugal manner. In fact, the phrase in Auden that most pertinently describes this indifference - he writes: 'how everything turns away' - already carries the kernels of Bazin's invention of the image-fait in post-war neo-realist cinema. Bazin's references are in that sense fully in line with the twentieth-century revived interest in the Icarus myth, as the prevalence of painting in his oeuvre finds itself especially concerned with cinematographic realism. We clearly see that, unlike the so-called 'pregnant instant' of painting, its realism derives from the ontological equality of events, which is inherently cinematographic. In Bruegel's Icarus, everything turns away from the center of the drama: all the characters and even the sheep in the foreground have their backs turned to Icarus. In his extensive studies on cinema and painting, Bazin further develops this view in terms of a 'centrifugal screen' of cinema, which I will discuss in more detail below.

\subsection{Cinema and Painting}

Bazin's affirmation of cinema as the art of reality, discussed extensively in the previous chapter, lays the foundations for what he calls the 'centrifugal' force of cinema. As argued, integral realism entails that on film, as in reality, not a single moment prevails over another, because there is no prescribed ontological preference of one moment over the other: cinema and reality are ultimately equal. In his essays on cinema and painting, Bazin further develops the Newtonian references as he opposes the screen of cinema to the 'centripetal frame' of painting. Where he employed a biological metaphor to indicate the symbiosis between painting and cinema in films on art, his writing on Vincent van Gogh presents a comparable interaction in the metaphor he borrows from Newtonian mechanics, more precisely in his description of the cinema screen as centrifugal:

Each painting is defined in relation to a frame, at least virtual, which carves in some way the hole of the painter into the world, reserves in the natural macrocosm the microcosm of the artist. This comes back to noticing that the frame of the painting is oriented from the exterior towards the interior, that it defines a heterogeneous centripetal space in the background which it surrounds. [...] In this manner, whereas the frame orients the closed off space of the painting towards the interior, 
the screen on the contrary diffuses the space of the cinematographic image into infinity: it is centrifugal. ${ }^{48}$

In his juxtaposition of cinema and painting, Bazin here alludes to Dutch physicist and mathematician Christiaan Huygens (1629-1695), who first proposed the idea of a vis centrifuga: 'Heaviness is a tendency to fall. [...] Thus, when a heavy body is suspended from a string, then the string is pulled, since the heavy body tends to fall away along the lines of the string with an accelerated motion of this sort. ${ }^{49}$ However, this centrifugal force, Isaac Newton reminds us later, does not exist on its own; it is instead a reactionary force. In Definition 5 , he replies to Huygens and develops his theory of centripetal force:

Centripetal force is the force by which bodies are drawn from all sides, are impelled, or in any way tend, toward some point as to a centre.

One force of this kind is gravity, by which bodies tend toward the centre of the earth [...]

A stone whirled in a sling endeavours to leave the hand that is whirling it, and by its endeavour it stretches the string, doing so the more strongly the more swiftly it revolves; and as soon as it is released, it flies away. The force opposed to that endeavour, that is, the force by which the sling continually draws the stone back toward the hand and keeps it in orbit, I call centripetal, since it is directed toward the hand as toward the centre of an orbit. [emphasis in original $]^{5^{\circ}}$

Thus, the most characteristic of centripetal forces is gravity, precisely this force that cinema in its analogy with human flight desires to escape: freed from the burden of subjectivity bound by a representational frame, cinema abides by an opposing force, that of an off-screen, out of frame. From this perspective, Bazin clearly starts off affirming that both art forms are anything but equal:

[...] despite an apparent similarity with the frame of a painting, the screen maintains essentially different relationships with the image. The cinema screen is not a frame, but a mask, it does not serve to show, but to reserve, to isolate, to choose..$^{1}$ 
In his extensive enquiry into the relation between painting and cinema, Bazin pinpoints their fundamentally different ontologies as respectively centripetal and centrifugal. In principle, the world of a painter for Bazin is not that of the filmmaker: 'The infinity of a landscape by Jean-BaptisteCamille Corot is an infinity that is internal to the existence of the painting; it cannot merge with the infinity of nature without (and this would be absurd) acting as its substitute. $5^{2}$ Where the existence of a painting depends first on the canvas and the frame, the existence of film relies primarily on a pre-existing reality: the image is a fact [fait], 'a fragment of raw reality's3 that exists somewhere in reality, even if it is absent from the screen. Hence, according to Bazin, the screen is a mask rather than a frame: with a close-up of a pair of shoes on screen, for example, we know that these shoes exist in a larger setting off-screen, whereas nothing proves, strictly speaking, that the same is true for Vincent van Gogh's famous Pair of Shoes (1888). ${ }^{54}$

To explain this principle in more detail, Bazin introduces a definition of cinema that references a sequence from Jean Cocteau's The Blood of a Poet (1930). In the second episode of the film, the poet and a statue are stuck in a room, from which there is only one exit: the mirror. Against common sense, the statue tells him: 'Indeed, but you have written that one does enter mirrors, and still you don't believe it! Try it!' After diving into the mirror, he floats (or flies) through a boundless space. He then arrives in the hallway of the Hotel of Dramatic Lunacies with a series of closed doors that, despite his firm efforts, remain closed. So he looks through the keyhole, and sees and hears a variety of things: a slow-motion execution of a Mexican in rewind,

52 Ibid.

53 Bazin, 1948c, EC p. 358; Transl. Barnard, 2009, p. 241.

54 That is to say, nothing proves that these shoes as painted objects have an off-screen setting. When it comes to the artwork's ontological grounding in the world, see Martin Heidegger's analysis of this specific painting in 'The Origin of the Work of Art' (1935-1936): 'There is nothing surrounding this pair of peasant shoes in or to which they might belong, only an undefined space. [...] A pair of peasant shoes and nothing more. And yet.' (p. 14) This 'and yet' is then followed by a series of associations through which Heidegger senses in these shoes 'the silent call of the earth' (ibid.). Tempering Heidegger's interpretation of the shoes, Meyer Schapiro's famous answer states: 'Alas for him, the philosopher has indeed deceived himself. [...] He has indeed "imagined everything and projected it into the painting". He has experienced both too little and too much in his contact with the work. [...]. Heidegger would still have missed an important aspect of the painting: the artist's presence in the work' ('A Note on Heidegger and Van Gogh.' In: Theory and Philosophy of Art: Style, Artist and Society. New York: George Braziller (1998): pp. 138-139). With key topics like the artist's subjectivity, the frame and the painting's extension into the world, the contribution that Bazin's analysis of painting versus film could bring to this discussion is significant, but it exceeds the scope of this footnote. 
a Chinese shadow play, a little girl's flying classes, a hermaphrodite, etc. From this sequence, Bazin concludes that:

One will at least admit that everything we see in cinema is perceived as real, i.e. as participating in a uniformly stretched out space, in other words: in a universe. One of the most correct definitions of cinema is the one from Jean Cocteau: 'reality seen through a keyhole'. What the keyhole hides from us does not seize to exist itself outside our visual field. ${ }^{55}$

The episode of The Blood of a Poet condenses two aspects that Bazin considers fundamentally cinematographic, or centrifugal: the screen as a mirror and as a mask [un cache]. That which is not visible on screen (or in the mirror and through the keyhole) still exists in reality. To think otherwise would be like assuming that nothing exists behind a door because it is closed. From a similar perspective, the doorknob, in a text on Italian neo-realism, becomes the opposite of cinema's centrifugal image:

Once again, this is the opposite of 'doorknob' mise-en-scene, in which the colour of paint, the grime at hand height, the shininess of the metal and the wear on the latch are perfectly useless facts, concrete parasites of the abstraction which are best disposed of. ${ }^{5}$

Being the opposite of the shot [plan], which I have previously discussed as fundamentally alien to Bazin's views on integral realism, the centrifugal image gives way to and assumes what lies beyond the screen, whereas the painterly image thanks its existence to the surface of a centripetal canvas. Cocteau's poet embodies this paradigm shift: where a mirror implies the superficial gaze of Narcissus, the surface here gives way to a threedimensional world. Bazin's studies on cinema and painting develop alongside a comparable shift in perspective, in which the surface of a painting is transformed into a universe that takes on the spatial properties of lived, three-dimensional perception. Thus, whereas Bazin initially opposes cinema and painting, this dichotomy in his work is always overruled by an interest in their shared aesthetics. To explain these shared aesthetics, I will now turn to his essays on art documentaries with filmed paintings, first Picasso and then Van Gogh, in which Bazin labels the formal transformation of painting on film as a 'geographic temporality'. 


\subsubsection{Two Revolutions on Film: Geographic Temporality}

When a painting is filmed, what we see on screen is no longer a painted image but a spatial as well as a temporal metamorphosis of the original composition. Traditionally, when it comes to depicting space, a painting is tied to its canvas; and with expressing time, it is stuck with one single frame. From an explicitly Bergsonian perspective, Bazin reinterprets this relation between form and content in his analysis of Henri-Georges Clouzot's The Mystery of Picasso (1956), which shows Picasso at work, in terms of 'pictorial duration': 'What The Mystery of Picasso reveals is not what we already know, the duration of creation, but this duration that might be an integral part of the work itself, a supplementary dimension, stupidly ignored at the finishing stage. ${ }^{57}$ From this point of view, Bazin differentiates between 'the picture [le tableau]' and 'painting [la peinture]': 'We see clearly that already the notion of the picture [le tableau] is subordinated here to the more integral notion of painting [la peinture] of which the picture is but a moment. ${ }^{5}{ }^{8}$ Clouzot films Picasso at work by placing the camera alternately either behind his back or behind the canvas, capturing the strokes as they appear through the cloth. Against the time constraints of depleting film stock, the process of painting unfolds its dramatic suspense in real time:

Because, in the end, every trait, every stain of colour appears - appearing is the right word - rigorously unforeseeably. This unpredictability supposes, inversely, that the whole of the composition cannot be explained by its parts. This is so much true that the entire principle of the film as spectacle itself, more precisely its 'suspense', lies in this waiting and this continuous surprise. Each trait of Picasso is a creation that entails another, not in the way that a cause implies an effect but as life generates life. 59

Each trait, each moment is ontologically equal to the previous stroke and therefore the images that appear on screen arise from mutations of previous forms (Fig. 12-13): 'The spectacle as such is then a fascination by the appearance of forms, free and in nascent state. ${ }^{\prime 60}$ Content is literally induced by form: 'the fish becomes a bird and the bird becomes wildlife. ${ }^{61}$ When 

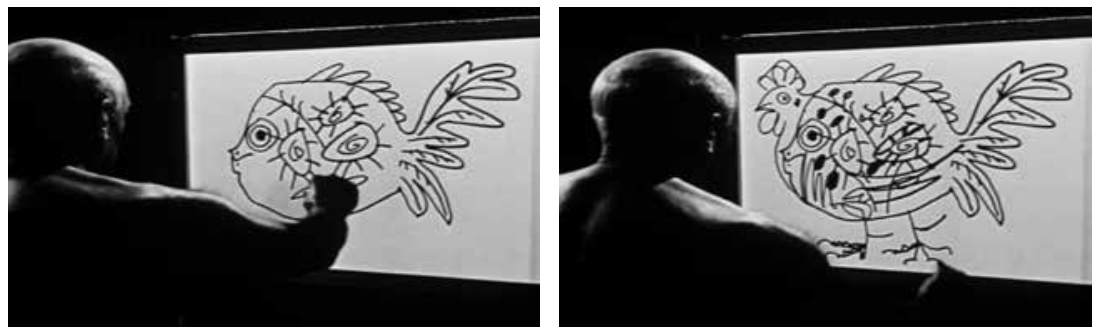

Fig. 12-13 A fish becomes a bird in The Picasso Mystery

filmed, Picasso's image is transformed into a temporal, essentially cinematic sequence: there is no pregnant moment, no single frame, but painting in action twenty-four frames/second.

While The Mystery of Picasso comprises an essentially temporal revolution in the hybrid form of painting and cinema, this was, according to Bazin, preceded by an initially spatial revolution in Alain Resnais' Van Gogh (1948), in which 'everything settles as if painting would truly become soluble in the duration only after having undergone a mutation of its spatial structures under the action of cinema, ${ }^{62}$ As argued, Clouzot challenges the painterly moment suprême by transforming each moment in painting into a cinematic image-fait; Resnais, as I will demonstrate now, turns the centripetal frame centrifugal. Resnais' short documentary on Van Gogh is entirely composed of shots inside paintings: the camera's gaze wanders from painting to painting as if the painted world of Van Gogh became real. In Bazin's words:

Thanks to the cinema, the 'world' of a painter is not merely a metaphor anymore, 'entering in his universe', the privilege of a sensible and cultivated spectator, the pictorial imaginary has become the reality of our perception. ${ }^{63}$

Resnais attains this assimilation of the imaginary and real perception by ignoring the frames surrounding the paintings. The house in Nuenen, the city of Paris, the yellow house in Arles, the bedroom and the café, the courtyard in the asylum, and a field with crows: the camera combines all these places into one geographical space rather than separating them off in different paintings.

62 Bazin, 1949b, EC p. 525 .

63 Ibid. 
[...] the sequence of a film gives it a unity in time that is horizontal and, so to speak, geographical, whereas time in a painting, so far as the notion applies, develops geologically and in depth. ${ }^{64}$

This sort of directional inversion, from a geological temporality to a geographical temporality, occurs each time the camera 'enters' painting: under the influence of the camera, Van Gogh's universe is now turned centrifugal.

In his text on The Mystery of Picasso, an art documentary by a director mostly known for his suspenseful films, Bazin already emphasized the dramatic potential of painting in film, and indeed the cinematic interest in painting often exceeds a purely documentary purpose. Examples of films about paintings abound in film history, yet when it comes to dramatizing a still picture, Dario Argento's rather graphic, violent thriller The Stendhal Syndrome (1996) offers a particularly intriguing case of 'entering the world' of a painter, in this case Rembrandt. The opening sequence, incidentally the first time an Italian film production had used CGI, clearly addresses the dramatic interaction between painting and cinema. For reasons she does not yet remember, a police inspector on a rape and murder case, Anna, visits the Uffizi gallery in Florence on what looks like an ordinary busy day. Once inside, a montage sequence accompanies close-ups of paintings with sounds as they appear to come to life: impalements and crossbows in the Battle of San Romano by Paolo Uccello (1436-1440), suddenly interrupted by a tourist taking its picture. In the Sala del Botticelli, there are Venus (1486) carried by the Zephyr wind and La Primavera (1481-1482). Anna longs to touch the flowers surrounding the feet of the three graces, but she is stopped by the alarm as if an invisible screen reminds her that it is a painting, that there is a surface. She then enters the Gallery of Maps, where maps and globes surround the space. Caravaggio's Medusa (1595-1598) makes her dizzy: the paintings are everywhere, on the walls and ceiling. Anna is about to lose her sense of orientation at the very moment when the sequence culminates in Bruegel's Icarus. Noticing his legs still peeking above the surface of the water, she falls and busts her lip, dives underwater into the painting, floats back to the surface and regains consciousness on the floor in the museum. She is then left with a noticeable bloodstain on her white shirt, which features in the subsequent scenes as a temporal disruption proper to painting, and in doing so, offers a novel take on what Bazin calls geographic temporality. 
Anna has the Stendhal syndrome, a psychosomatic condition that causes certain people to become dizzy, hallucinate or faint under the overwhelming effect of art and great beauty. ${ }^{65}$ After the fall in Florence, she cannot remember who she is, and why she happens to be in that city; with a bloodstained shirt, she hurries back to the hotel room that matches the key in her purse. Her name is written on a prescription for sleeping pills: she is Anna Manni, a police inspector from Rome. After taking her pills, while resting on her bed, it happens again: this time, she is caught up in a reproduction of Rembrandt van Rijn's Nightwatch (1642). ${ }^{66}$ The camera cuts from drums to feet, faces to arms and accompanied with the soundtrack of a crime scene, the paint fades as Anna enters into a murder scene in the streets of Rome (Fig. 14-19). There, a rapist and serial killer left the police with yet another case for Anna and her colleagues to solve; it now becomes clear that she will have to travel to Florence to catch the murderer. Even though the crime scene develops as if Anna's Stendhal syndrome was nothing but a bad dream, at best a flash-forward offering a glimpse of her future manhunt in Florence, the bloodstain on her shirt is still there in Rome; or, the stain was already there. As is the case often in painting, when a single figure is presented multiple times in the picture plane to portray a chronological succession of events within a single frame, Anna's bloodstain here functions as a refracted temporal element when she walks inside the painting and literally invades the frame. Once she enters the universe of the painter, the narrative takes a fascinating turn: whereas, logically, one could think that either the opening scene in Florence was a prophetic dream, or the sequence inside the Nightwatch had been a flashback, the bloodstain on Anna's shirt prevents us from adopting one or the other interpretation. Much like in Resnais' Van Gogh, Argento's close-ups transform the space of painting into the real streets of Rome, but the geological temporality of painting somehow affects the horizontal temporal unity of cinema.

65 The Stendhal syndrome is named after the French writer Stendhal who had first reported it after his visit to the Basilica of Santa Croce in 1817. In his diary, Stendhal describes the experience as follows: 'Absorbed in contemplation of sublime beauty, I saw it up close, I touched it so to speak. I had arrived to that point of emotion where celestial sensations offered by the fine arts meet passionate sentiments. Leaving the Santa Croce, my heart was pounding, phrenic nerves as it is called in Berlin. I was emptied of life, I was walking with the fear of falling.' (Stendhal, 1862. Rome, Naples et Florence. Paris: Gallimard, 1987: p. 272).

66 The interplay between cinema and painting that Argento incites here has been claimed more recently by Peter Greenaway in his series of animated paintings: using light projections combined with sound installations, Greenaway's first revision was Rembrandt's Nightwatch at the Rijksmuseum in Amsterdam, the result of which is very close to Argento's. 

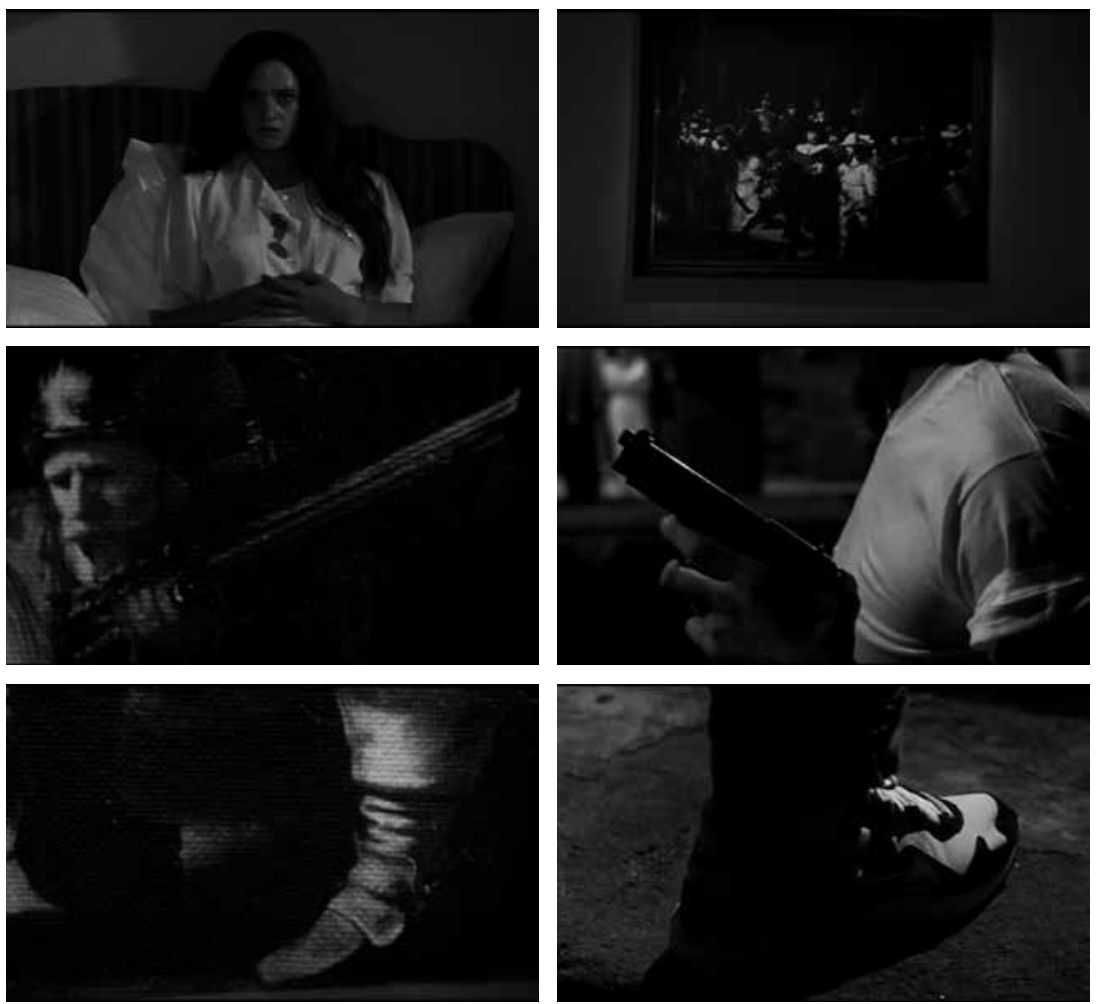

Fig. 14-19 Nightwatch and geographic temporality

In fact, the discourse of Anna's stain in The Stendhal Syndrome is reminiscent of a remark made by Bazin in his critique of Van Gogh, which further explains this interaction between geological and geographical temporality in terms of space. When filming the Starry Night (1989), he writes, Resnais refused to simultaneously show the threefold repetition of the sun but chose instead to reorganize the space on screen following a 'new aesthetic cosmology':

Van Gogh's landscape spreads nature to substitute for three suns at the same time, if it pleases the master to assemble them in a sequence of images that turned irrefutably in this new aesthetic cosmology. ${ }^{67}$

Bazin's description of a 'new cosmology', an idea that, as I have established previously, had also been used by critics to describe Bruegel's Icarus, draws 

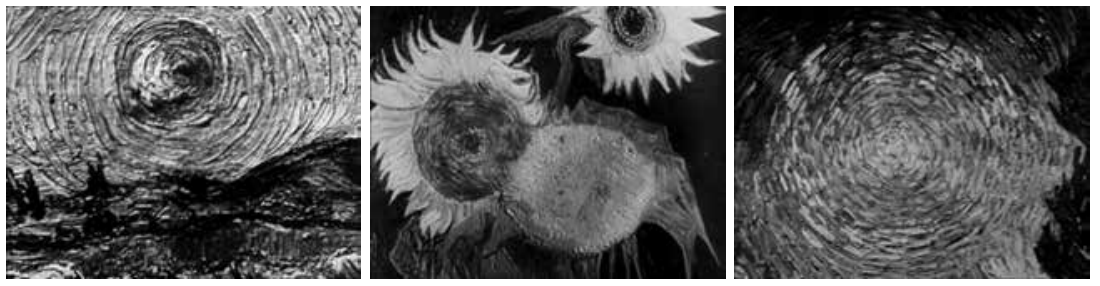

Fig. 20-22 Stars and sunflowers in Van Gogh

parallels between Van Gogh's suns and his sunflowers. Anna's bloodstain in The Stendhal Syndrome can thus be understood as a new aesthetic cosmology, in which the spatial-temporal qualities of the screen and the frame are altered under the combined influence of painting on film, and vice versa. The three suns to which Bazin refers are in fact stars, but behind this seemingly careless mistake there lies an array of literary references, which also inform Resnais' particular sequence in the film (Fig. 20-22). These references align Van Gogh's approach to nature (in other words, his aesthetics) with his sunflowers, as well as his questioned insanity. Bazin's commentary on Van Gogh, which I discuss below, indeed proves that he had carefully examined two seminal studies on the painter: Georges Bataille's 'Sacrificial Mutilation and the Severed Ear of Vincent van Gogh' (1930) and Antonin Artaud's 'Van Gogh: The Man Suicided by Society' (1947). From these perspectives, I want to analyze the centrifugal ontology of film by close-reading a particular reference in Bazin to Van Gogh's cut-off ear.

\subsection{Case Study: Van Gogh's Ear}

If Bazin's writing on painting and film start off by distinguishing both art forms, it is ultimately their combined aesthetics that interests him the most: a painted detail in Bruegel that turns a painting filmic, or a filmed painting that renders the pictorial frame centrifugal. In other words, it is cinema's recreation of painting that interests him, just as it is cinema's recreation of reality on which his concept of realism is built. One final reference to Van Gogh in Bazin specifically concerns this connection between art and reality: the particular image of Vincent van Gogh's dismembered ear. Bazin briefly mentions it in his discussion of Resnais' art documentary: 'Van Gogh's cut off ear exists somewhere in this world, which inevitably beseeches us. ${ }^{\prime 68}$ 
Though this reference appears trivial, it lends itself as a particularly fruitful case for studying the effect of film on painting, as it deals explicitly with the transparency of the screen versus the opacity of the canvas. Tracing this recreation in Bazin, furthermore, positions his examination of painting and film into an intricate patchwork of contemporary critiques, from Georges Bataille (1879-1962) to Antonin Artaud (1896-1948) and Fernand Deligny (1913-1996), on the effect of art on reality.

We all know the story of the artist's ear: on the advent of Christmas 1888, Van Gogh cut off his left ear lobe with a razor, supposedly following an argument with his colleague painter Paul Gaugin (1848-1903) with whom he maintained a tumultuous friendship. Van Gogh had been waiting for him in Arles, hoping to start an artist community in the yellow house. But when Gaugin announced his premature departure, Van Gogh supposedly lost his mind. Gaugin's version of the story was that Van Gogh had threatened him with the razor, after which he cut off his own ear in a flare of madness and brought it to a prostitute named Rachel later that evening, with a request to 'keep this object carefully' ${ }^{69}$ Gaugin's portrayal of his friend as a madman who turned against his person, however, is contested: '[Gaugin's] behaviour during their final days together and in the later attempts to vindicate himself through condemning Vincent were hardly those of a friend. ${ }^{70}$ In what follows, I close-read the critiques of Alain Resnais' Van Gogh (1948) as well as Vincente Minnelli's Lust for Life (1956), in which Bazin develops his notion of a new cosmology of film and thereby aligns himself with Antonin Artaud's conception of 'mythic reality' and Georges Bataille's studies on the painter's supposed madness. Both Bataille and Artaud reject the idea that Van Gogh was mad: the fight with Gaugin was also an aesthetic struggle and, hence, the cutting incident must relate to the painter's artistic vision. Bazin adopts their ideas in his discussion of these two films: again, he sees in the symbiosis of painting with cinema their shared aesthetics, which he qualifies as myth.

\subsubsection{Mythic Reality Becomes Flesh}

The lineage to Artaud's study of Van Gogh is previously established by Dudley Andrew, who points out that these ideas must have reached Bazin via French educator Fernand Deligny, known for his involvement in special

69 Lubin, 1972, p. 156.

70 Ibid., p. 179. 
needs education..$^{11}$ Andrew writes that Bazin and Deligny shared an office at Travail et culture and that:

Deligny was moved to assemble an imaginary dialogue between Van Gogh's letters and Antonin Artaud's book on Van Gogh's suicide when Artaud died in 1948. This occurred just as [Chris] Marker's friend Resnais was bringing to a close his film on the artist. There must have been innumerable discussions among these men since Bazin had found Deligny an apartment in the same building..$^{2}$

Artaud's main argument in 'Van Gogh: The Man Suicided by Society' (1947) is that Van Gogh's self-mutilation (e.g. burning his hand to catch the attention of his cousin and love interest Kee, or slicing off his ear lobe) evade the standard label of madness: 'As for the cooked hand, that is heroism pure and simple; as for the severed ear, that is straightforward logic. ${ }^{73}$ Ultimately, Artaud recognizes the suicide almost as a socially organized crime: as the title of the article reads, Van Gogh was 'suicided', murdered by society:

Van Gogh could have found enough of the infinite to last his whole life if the brutish consciousness of the masses had not wanted to appropriate it to nourish their own orgies, which have never had anything to do with painting or poetry. ${ }^{74}$

Thus, Artaud understands the ear mutilation as a logical consequence of a painter whose relation with the world has been continually denied as impaired by a people in their attempt to safeguard a collective 'sick consciousness'.

What interests me most in the connection between Bazin and Artaud on Van Gogh is the fact that Artaud frames the disagreement between Van Gogh and Gaugin, generally understood to be the cause of the ear incident, in terms of a conflicting conception of myth and reality. On the occasion of

71 Andrew, 2011, p. 162; Thus, it is from a pedagogical context that Bazin may have been drawn to discussing Van Gogh in relation to cinema. Pedagogy was one of Bazin's major points of interest before cinema, see for example 'L'Enseignement primaire supérieur, suivi de Péguy et les instituteurs.' Rencontres, No. 3 (20/07/1941), which he wrote under the pseudonym André Basselin. I return to the pedagogical undertone of Bazin's critical work in the concluding section of this chapter.

72 Andrew, 2011, p. 162.

73 Artaud, 1947, p. 486.

74 Ibid., pp. 510-511. 
a Van Gogh exhibition at the Musée de l'Orangerie in Paris, Artaud writes that the relationship between both painters was troubled by:

[...] a profound human division between the two natures of Van Gogh and Gaugin.

I believe that Gaugin thought that the artist must look for symbol, for myth, must enlarge the things of life to the magnitude of myth, whereas Van Gogh thought that one must know how to deduce myth from the most ordinary things of life.

In which I think he was bloody well right.

For reality is frighteningly superior to all fiction, all fable, all divinity, all surreality.

All you need is the genius to know how to interpret it,

Which no painter before poor Van Gogh had done, which no painter will ever do again, for I believe that this time,

Today, in fact,

Right now,

In this month of February 1947,

Reality itself,

The myth of reality, mythic reality itself, is in the process of becoming flesh. ${ }^{75}$

Thus, the supposed madness at the root of the ear incident and ultimately Van Gogh's suicide fundamentally relate to what Artaud calls 'mythic reality'. Where Gaugin painted from 'imagination', Van Gogh 'neither ignored nature, nor slavishly followed it'. ${ }^{6}$ Instead, he found that in reality, fiction and myth 'become flesh', a view Bazin must have considered was related to his notion of integral realism. Furthermore, as was the case with the reference to Bruegel's treatment of the Icarus myth, Artaud emphasizes the contemporary value of myth in combination with a turn to the everyday, 'the ordinary things of life'.

The connection between Bazin and Artaud on the topic of Van Gogh finds solid support almost a decade later in the critique of Vincente Minelli's Lust for Life (1956). Firstly, Bazin criticizes the overly biographic attempt to provide reasons for Van Gogh's supposed madness (a fight with Gaugin? missing his brother?):

The point is not to explain to us why Van Gogh was 'mad' and what the necessary connection was between this madness and his predilection 
for yellow, for example, but to bring us closer to this point of spiritual incandescence where the transmutation will be made sensible to us through its radiance..$^{77}$

Like Artaud, Bazin deemphasizes the relation between madness and the preference for a certain aesthetic, but rather accepts it as a justification for Van Gogh's painterly soundness. Secondly, Artaud asserts that Van Gogh's paintings permanently alter reality:

these flowers of bronze gold are painted; they are painted as sunflowers and nothing more, but in order to understand a sunflower in nature, one must go back to Van Gogh, just as to understand a storm in nature, a stormy sky, a field in nature, it is henceforth impossible not to go back to Van Gogh. ${ }^{7}$

Artaud's argument here comes close to the transformative potential of art, which Bazin conceptualizes as the asymptote of reality, discussed in the previous chapter. ${ }^{79}$ Bazin indeed repeats this line of thought in a critique of Minelli's all too painterly characters:

This is to make nature resemble art, as [Oscar] Wilde said, which is true only a posteriori. Van Gogh has transformed our vision of sunflowers but before he had painted them, sunflowers were not yet 'Van Goghs. ${ }^{80}$

Here, again, Bazin's reading of Lust for Life takes on remarkable similarities with Artaud's argument that 'even external nature, with her climates, her tides, and her equinoctial storms cannot, after Van Gogh's stay upon earth,

77 Bazin, 1957a, EC p. 2107.

78 Artaud, 1947, pp. 503-503.

79 See also Joubert-Laurencin, who elaborates on the anti-mimetic formula by Oscar Wilde, namely that 'nature imitates art', and Alain Roger's notion of 'artialisation', i.e. the intervention of art in nature via both 'modelling [modélisation]' and 'anticipation': 'Furthermore, if ontological realism, following the advice of Rohmer (great meteorological filmmaker, of four seasons), dictates that "art is in the model", in the sense that it is in the landscape, and the anticipation [artialisation] of Alain Roger says that art offers its models to landscape, then cinema is the double trigger: on the one hand, as a machine of automatic reproduction, it captures the schemes offered by the other arts, on the other hand, as art, it offers them to nature.' Joubert-Laurencin, 2014, pp. 78-79.

80 Bazin, 1957a, EC p. 2107. 
maintain the same gravitation, ${ }^{81}$ Both Bazin and Artaud suggest that Van Gogh's paintings are not the symptoms of a man's madness but rather that their 'cosmology' altogether changes the commonplace conception of reality.

It is not coincidental, then, that Bazin finds in Resnais' documentary on Van Gogh, which would have initiated Artaud and Bazin's shared interest in the painter, the kernel for his notion of a new cosmology of film. Based on the sequence of the triple suns, and in combination with a posteriori sunflower transformation, Bazin's reading follows the film's commentary, which states: 'It's not for nothing that sunflowers are called suns [Ce n'est pas pour rien que les tournesols s'appellent des soleils].' This line from the film is an almost literal adaptation from a passage from 'Sacrificial Mutilation and the Severed Ear of Vincent van Gogh', written in 1930 by Georges Bataille:

in order to show the importance and the development of Van Gogh's obsession, it is necessary to link suns with sunflowers [...]. This flower is also simply known (in French) by the name 'the sun'; in the history of painting it is linked with the name of Van Gogh. ${ }^{82}$

The commentary here relates the sunflowers to a new worldview, a connection Bazin readily incorporates in his critique. Incidentally, the link between the sun and sunflowers, in addition to a posteriori influence of art on reality that guides both Artaud and Bazin's texts, equally leans on an argument put forth by Bataille in a later essay entitled 'Van Gogh as Prometheus' (1937):

Given the forgoing, it must be said that after the night of December '88, when, in the house to which it came, his ear met a faith which remains

81 Artaud, 1947, p. 484.

The recurring allusion to cosmology in Bazin and Artaud's treatment of Van Gogh's aesthetics, furthermore, brings to mind a series of more recent astronomical studies of The Starry Night in particular. See, for example, Whitney, 1988, pp. 351-362; and Boime, 1984, pp. 86-103. Based on meteorological records, Whitney writes that 'all the elements of the sky in Starry Night were on view through van Gogh's window at one point or another that spring. They were not all in view at the same time, but we need to give up the notion that he painted the scene as a snapshot. I think he assembled his own sky from impressions gathered over an interval of a month or so' (p. 358). From his side, Boime connects the swirly stars in the painting to popular drawings of spiral nebulae dating from 1845, which illustrated the popular publications of the French writer and astronomer Camille Flammarion (1842-1925, p. 89). These two studies suggest that the Starry Night was not, as is often assumed, painted from memory (and therefore believed to be a concession to Gaugin's aesthetics) but rather that it is in fact painted from nature and thus an inherently realist work.

82 Bataille, 1930, p. 260. 
unknown (one can only dimly imagine the laughter and discomfort which preceded some unknown decision), Van Gogh began to give to the sun a meaning which it had not yet had. ${ }^{83}$

Bataille furthermore relates Van Gogh's cosmology to the sunflowers, the suicide and the ear: 'How can we ignore the chain of knots which so surely links ear, asylum, sun, the feast and death?' ${ }^{84}$ And so, rather than affirming the supposed madness of Van Gogh, Bataille and after him Artaud and Bazin all relate the self-mutilation, via the sunflowers, to his cosmological intelligence. Just as Artaud views the ear injury as 'straightforward logic', so too does Bazin ground the new cosmology of film as a logical consequence of the ontological difference between painting and film, and he does this, as I suggest throughout the following pages, via the ear reference.

\subsubsection{Self-Portraits with Bandaged Ear: Mirror and Mask}

Just as Artaud and Bataille frame their studies on Van Gogh against his assumed insanity, Bazin also indirectly presents the centrifugal foundations of cinema as straightforward logic. When he writes, 'Van Gogh's cut-off ear exists somewhere in this world, which inevitably beseeches us', ${ }^{85}$ Bazin is making a strong statement about the ontology of film as well as the influence of art on reality. I will now juxtapose the ear covered with a bandage in the series of self-portraits painted by Van Gogh after the incident to the eerie phenomenon of the missing ear in two films: the particular scene from Minelli's Lust for Life that moved Bazin to write about the ear, and a sequence from David Lynch's Blue Velvet (1986), possibly the most referenced and original cinematic treatment of Van Gogh's severed ear.

In January 1889, Van Gogh completed a series of self-portraits in which he painted himself with a bandaged ear: having severed his left ear, both portraits 'being mirror images, [...] show the bandage on the right side'. ${ }^{86}$ In his depiction of the incident, Minelli places Van Gogh literally in front of a mirror (Fig. 23): after a short pause, he then moves out of frame and cuts off his lobe (Fig. 24), we hear him screaming, after which he returns to the mirror with one ear too few. Minelli copies the spatial organization of Van

83 Bataille, 1937, p. 498; Transl. Michelson, 1986, p. 59.

84 Ibid., p. 499; Transl. Michelson, 1986, pp. 59-6o.

85 Bazin, 1949b, EC p. 525 .

86 Lubin, 1972, p. 156. 
Gogh's mirrored portraits, showing the right ear damaged (rather than, in Van Gogh's reality, the left). In doing so, this particular scene combines the mirror ${ }^{87}$ and the mask - two images that, as shown previously in the reference to Cocteau's The Blood of a Poet, summarize the spatial principles of the centrifugal screen. In Bazin's words: 'The cinema screen is not a frame, but a mask; it does not serve to show, but to reserve, to isolate, to choose. ${ }^{.88} \mathrm{In}$ the cinema, we know that when Van Gogh moves out of the frame, especially when he screams off-screen, that he is still in the same room; upon his return, we know for sure that his cut-off ear did not mysteriously vanish, despite its absence on screen. This very principle can be used for dramatic purposes. In Blue Velvet, Van Gogh's ear is the catalyst for a detective adventure into a dark and sickening world of sexual violence and abuse. On his way home from a visit to his father at the hospital, Jeffrey discovers an ear, which he wraps in a brown paper bag and brings to the police (Fig. 25): 'That's a human ear, alright!' says the police inspector. And because an ear does not exist without a corresponding body, there is no doubt that somewhere in Lumberton a man must be missing his ear. Even though Jeffrey was explicitly asked not to inquire after the ongoing investigation, he starts his own with the help of the detective's daughter Sandy. They find out that the ear belongs to Don, the husband of a nightclub singer Dorothy, mother of little Donny. A dangerous man named Frank keeps Dorothy's husband and their young child hostage, while forcing her to partake in all sorts of abusive practices: 'Stay alive, baby. Do it for Van Gogh', she is told. So, where Van Gogh cut off his own ear for assumed reasons, either 'to sacrifice himself, to kill a

87 In 'Theater and cinema' (1951c), Bazin most explicitly develops the metaphor of the screen as a mirror: 'The nineteenth century, with its objective visual and sound reproduction technologies, introduced a new category of images. Their relationship with the reality at their source needs to be rigorously defined. [...] Cinema's efficacy can also be found in its ontology. It is false to state that the movie screen is completely powerless to place us in the presence of an actor. It does so like a mirror (which, we can all agree, conveys the presence of the person it reflects) - a mirror whose reflection is at a variance with the person whose image is imprinted on its silvering' (EC p. 734; Transl. Barnard, 2009, p. 185). In a subsequent part of this research I will return briefly to the relation between cinema and theater to address the notion of presence in relation to three-dimensionality (see 4.2.1 From a Realist Perspective: 'The Imaginary Image). When Bazin writes that 'just as footlights and scenery in the theater serve to mark the contrast between it and the real world so, by its surrounding frame, a painting is separated off [...] from reality as such [...]' (Bazin, 1952d, EC p. 2569; Transl. Gray, 2005, p. 165), he compares the difference between painting and cinema alongside its opposition with the theater stage. However, just as his interest ultimately lies in the combined aesthetics in filmed painting, so too is his embrace of 3-D largely based on a symbiotic relation between cinema and theater.

88 Bazin, 1949b, EC p. 525 . 
part of his own body, and turn his friend Gaugin into a murderer, ${ }^{89}$ the husband's ear is used as leverage. The final scene in Dorothy's apartment actually shows Don, tied to a chair with the left ear cut off (Fig. 26), unlike Minelli's version. Despite the real possibility that these are merely continuity errors, the comparison with the series of self-portraits as mirror images is noteworthy: Minelli's camera appears to have entered Van Gogh's universe, whereas Lynch seems to depict Van Gogh's lived reality.

To assume, as Bazin does, that Van Gogh's cut-off ear 'exists somewhere in this world', even if one might not see or find it, is indeed not far-fetched an idea: there is no need to bring in neurological evidence for the experience of phantom limbs to understand the beseeching relation between a particular ear and the person to which it belongs, regardless of its visible presence. In Lust for Life, we do not see the actual deed, but we hear his scream off-screen; similarly, in Van Gogh's self-portrait, the ear is covered with a bandage. In fact, the ear in these particular portraits is missing, obviously, in two senses: first from a logical point of view, they were painted after the mutilation, and secondly from an ontological perspective, there is no evidence that a painter would in fact have included a layer depicting an ear underneath the bandage. In this manner, the comprehension of the screen as a mask conceptualizes the major ontological difference between painting and cinema. With painting, there is no reason to assume that that which is invisible on the surface (e.g. out of frame, covered either by clothing, hair or, in this case, a bandage) is actually there or has been painted somewhere: logically speaking, there is nothing to mask, because the canvas shows all there is in paint. On film, on the contrary, it would be completely irrational, madness even, to see the image on screen as separate from the reality to which it refers: cinema and reality, Bazin affirms, are thick as thieves in the same way that we know sensibly that an ear covered by a hat or a bandage exists somewhere, regardless of the fact that it remains hidden to us.

The existence of Van Gogh's ear off-screen, somewhere in the world, perfectly aligns itself with the centrifugal principles of cinema, which comprise a temporal and spatial ontological equality between cinema and reality. Where the painterly canvas is traditionally pure surface, the cinema screen is a surface much like the skin: as Paul Valéry wrote, 'the skin is that which is the most profound in us. $9^{90}$ From this point of view, Bazin's

89 Lubin, 1972, p. 176.

90 Paul Valéry, cited in Timothée Gerardin's short but insightful essay, entitled 'A la surface' (Le Rotor*, No. 10 [Accessed: 20/02/2015]), in which he takes Valéry's citation as a starting point 


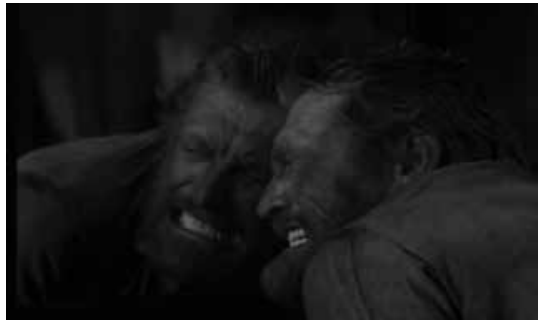

Fig. 23 Van Gogh's mirrored portrait

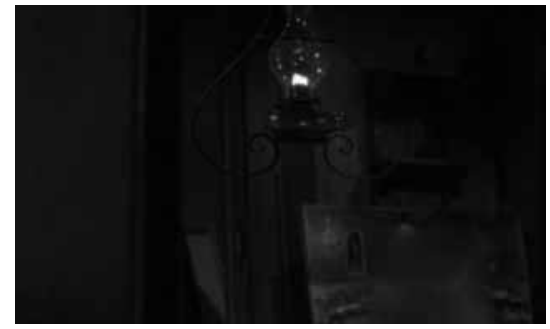

Fig. 24 Off-screen mask

fascination with surgical images and X-rays on screen further explains this necessary link between the centrifugal image on screen and the universe beneath the skin: 'To view the X-ray of a beating heart in the cinema is already a marvel', ${ }^{91}$ he writes, reaffirming his praise of science films in which 'cinema reveals that which no other procedure of investigation, not even the eye, can perceive'. ${ }^{2}$ Van Gogh's ear, then, materializes the centrifugal ontology of cinema: mythic reality becomes flesh.

\subsection{Recreation: The Language of Film}

The arguments and analyses presented in this chapter are built almost exclusively on intertextual references, or recreations: from Bruegel's Icarus, W.H. Auden and Cousteau, to including more contemporary interpretations of the same image - from Van Gogh, to Artaud and Bataille, Resnais, Minelli and Lynch. ${ }^{93}$ This method, in itself heuristic and perhaps too serendipitous for certain academic discourses, nevertheless works towards our understanding of fundamental concepts in Bazin's thinking. In fact, recreation can be seen as instrumental in Bazin's practice as a film critic: in one of his essays on painting and cinema, he writes, 'there is also a certain type of literary

to discuss Bazin's ontology argument, more precisely the mummy complex as well as the shroud of Turin, from the perspective of a 'profondeur à fleur de peau'. As I will argue later on in this book, Valéry's views on depth and surface, in particular his poem The Seaside Cemetery, will prove instrumental, if not indispensable, to understanding integral realism as a reformulation of the conventional notions of form and content (see Chapter IV - A MATTER OF FORM).

91 Bazin, 1956a, EC p. 1874; Transl. Andrew, 2014, p. 120.

92 Bazin, 1947c, EC p. 309; Transl. Herman, 2000, p. 145.

93 Parts of this conclusion are also published in the conference proceedings of Encontro Fernand Deligny, Rio de Janeiro (August 2016), as 'Can you 'Ear me? Lautoportrait de Vincent Van Gogh vu par Bazin et Deligny', Cadernos Deligny, Vol.1, No.1 (2018): pp. 225-238. 

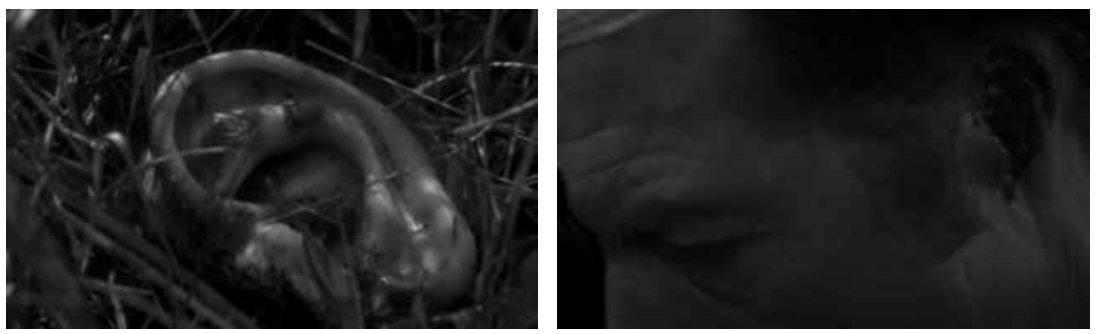

Fig. 25-26 Van Gogh's ear in Blue Velvet

criticism which is likewise a re-creation - Baudelaire on Delacroix, Valéry on Baudelaire, Malraux on Greco'. ${ }^{94}$ Just as cinema in these case studies recreates and therefore transforms painting into a new aesthetic cosmology, so too does art criticism engage in a process of semantic intertextuality. Bazin's usage of the word 're-creation', furthermore, can be linked to his more general expression of cinema as a 'recreation of the world in its own image':95 the intertextuality between cinema and painting equally applies to the semantics of cinema as the art of reality - in other words, the language of film.

To explain this, let me return in conclusion to the professional context for Bazin's interest in Van Gogh, referenced earlier in this chapter: his time at Travail et culture in the late forties, where he worked in popular education shoulder to shoulder with the experimental pedagogue Fernand Deligny (1913-1996). ${ }^{96}$ During this time, Deligny was undertaking a documentary project with socially excluded, delinquent teenagers under the provisional title Children Without Future? To facilitate their reintegration into society, Deligny resorted to cameras, because 'language', he writes, 'intoxicates them and fails them whenever they need to make themselves heard'. ${ }^{97}$ Though their collaboration at the time was brief, decades later Deligny still expresses a deep affinity for Bazin's work:

94 Bazin, 1952d, EC p. 2570; Transl. Gray, 2005, p. 169.

95 Bazin, 1946/1958, EC p. 2559; Transl. Barnard, 2009, p. 17.

96 Andrew, 2013, p. 140. Bazin and Deligny met in 1946 on the occasion of a film screening, organized by Deligny who was then regional director at Travail et culture for the region NordPas-de-Calais. Starting in 1948, Bazin and Deligny met on a regular basis, as Deligny had been transferred to Paris where he now worked with Bazin for the same organization. For several years, they shared an office, lived in the same building, and found themselves personally involved with the reintegration of the then young delinquent François Truffaut.

97 Deligny, 1955, p. 414. 
It's a happy coincidence that you brought along the Cahiers du cinéma with Bazin, Bazin's articles. In it, I happen to stumble on a citation from Malraux: 'the possibility of linking man and the world through other means than language'. That's it, this is what cinema is for him. For Malraux, cinema is the possibility of linking man to the world by other means than language. And here again, this really reassured me! With my stories about images I'm not that donnish after all, I'm not alone... There is, the way I see it, a tradition which was interrupted by psychoanalysis and other ways of thinking for which language is... everything. ${ }^{98}$

Deligny's aversion to language-based ways of thinking grows when, in the seventies, he develops successful therapies for mute autistic children: unable to communicate through language and therefore left untreated in existing psychiatric programs, these children used cameras to connect meaningfully with the world around them. In this manner, he describes Bazin's interrupted tradition as 'ethical': for Deligny, the Cahiers du cinéma presented 'a momentum that pushed us to run our heads against the limits of language'. ${ }^{99}$ Bazin's realist semantics, I will explain subsequently, occurs through what he called a 'language of objects' rather than a system of signs: a radically concrete and direct process of signification, through recreation.

Bazin's realist approach to film language becomes most tangible in an anecdote that deals implicitly with the photographic recreation of a painting. During the time at Travail et culture, a photograph was taken probably by Chris Marker, who was then Bazin's secretary, or Janine Chartier, his girlfriend at that time and future wife (Fig. 28). ${ }^{100}$ In it, we see Bazin hard at work in his office, making a phone call. From his biography, we know that the years working in that office were among Bazin's happiest years; ${ }^{101}$ and despite his rather tormented expression in the picture, the photograph in fact appears to be a practical joke, a tongue-in-cheek reference to Vincent van Gogh's self-portrait with bandaged ear (Fig. 29). Juxtaposed, the photograph indeed reveals striking similarities with Van Gogh's self-portrait: both men wear a heavy coat, where one would expect a shirt in the office. In the background, a poster announcing the program for the month of April corresponds with the Japanese print in the portrait, while the cupboard in Bazin's office aligns with the window frame of Van Gogh. The pitchforked 
hook of the telephone is reminiscent of the painter's easel. Bazin's bandage does not cover his ear but takes the place of Van Gogh's fur hat - the telephone, in turn, replaces both in form and composition the bandage of the painter. The replacement of the bandage with a telephone solidifies the discussion of Van Gogh's ear off-screen, discussed at length earlier in this chapter: provided that Bazin's phone is connected, his ear - invisible on screen - extends to a reality outside of the picture frame. ${ }^{102}$

This playful instance of recreation resonates with an article from 1953, titled 'Language of our time', which Bazin wrote for People et culture, the mother organization of Travail et culture. Emphasizing his interest in popular education as well as his views on film language, he dismisses the disappearance of illiteracy for having been unable to elevate the intellectual and cultural sensibility of the masses and instead praises the emancipatory potential of film: 'during the time of the development of primary schools, new techniques for the diffusion of thought appeared. ${ }^{103}$ Among these modern technologies Bazin counts the telephone:

The car, the telephone, the typewriter are a kind of concrete language spoken by hundreds of thousands of people. Undoubtedly, this universalization of expression of lifestyles needs a corresponding medium of expression, more immediate and with a vocabulary which is itself also concrete and universal: a language of objects. ${ }^{104}$

These technologies, we could call them Bazin's new media, are all means of communication - ways to connect with the world around us. This is indeed what Deligny points out when he laments Bazin's lost tradition in light of semiotics: 'the possibility of linking man to the world by other means than language'. Like the bandage in Van Gogh's portrait, the telephone in Bazin's photograph immediately refers to off-screen reality; for Bazin, it would be senseless to ignore this indispensable link between film and reality. From this perspective, the kind of semiotics for which 'language is everything' is indeed much more precarious: a word - for example 'telephone' - could

102 In 'The Elevator and the Telephone', Michel Chion considers the telephone in relation to film language as follows: 'In fact it turns out that the elevator and the telephone are perhaps at the origin of the language of cinema. Indeed, the telephone, and its predecessor the telegraph, in making possible an immediate interaction from a distance, inspired parallel montage, without which cinema never would have gone very far.' (Chion, 2013, p. 453).

103 Bazin, 1953e, EC p. 1078.

104 Ibid., EC p. 1079. 

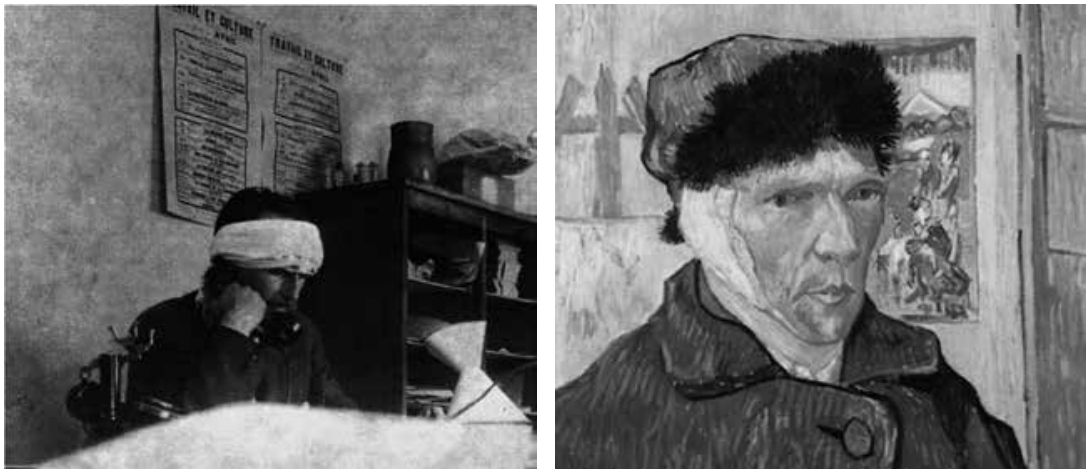

Fig. 27-28 Bazin copies Self-portrait with Bandaged Ear, Vincent van Gogh (1889)

also refer to the salt at the table. ${ }^{105}$ Cinema, on the contrary, signifies by reference to concrete objects in reality: it is the world (signified) in its own image (signifier). In realist semantics, then, the traditional distinction between signifier (any object, or stylistic means) and signified (meaning), which in semiotics constitutes the sign, is abolished: instead, form and content are inseparable.

Historically speaking, Bazin's generation is indeed characterized by the realist approach to film, which in fact almost exclusively carries his signature. Throughout the previous chapters, I have shown that the myth of total cinema represents Bazin's opposition to the prescriptive silent film theories. After Bazin, this realism was in turn heavily criticized by semiotic film studies from the sixties onwards. 'The Humanities', Joubert-Laurencin explains, 'in their academic dimension, when they started being interested in cinema, have moved beyond Bazin back to preceding theories on expressive film language, with its technically coded structure'. ${ }^{106}$ In the following and final chapter of this study, I want to test the validity of this realist momentum, specifically focussing on his myth of total cinema, within a contemporary media landscape. A close examination of Bazin's reformulation of form and content in art criticism will first bring us right to the heart of a fierce discussion among Bazin and his colleagues on film style and meaning, pushing Bazin from his acquired realist position almost into the camp of

105 On this topic, see also my brief analysis of the film Dogtooth (Yorgos Lanthimos, 2010), presented at the Encontro Fernand Deligny, Rio de Janeiro (August 2016) and published in its conference proceedings as 'Can you 'ear me? L'autoportrait de Vincent Van Gogh vu par Bazin et Deligny.' Cadernos Deligny, Vol.1, No.1 (2018): pp. 225-238.

106 Joubert Laurencin, 2001, p. 115 . 
the formalists. Against Bazin, Georges Sadoul for example argued that 'if cinema is a language, it is so primarily because it tells stories. Therefore, the content of the scenarios is essential, because it must dictate the style. ${ }^{107}$ As I hope to demonstrate below, Bazin radically counters this position: to him, form and content (in film and in film criticism) are synthetic. Ultimately, then, this discussion on content and form will lead to an examination of his prescient views at the time on three-dimensional cinema, and enable a concluding discussion on Virtual Reality from a realist perspective.

\section{Bibliography}

Alpers, Svetlana (1983). The Art of Describing. Dutch Art in the Seventeenth Century. Chicago: Chicago University Press.

Andrew, Dudley (2010). What Cinema Is! West-Sussex: Wiley-Blackwell.

--- (2011). 'Malraux, Bazin, and the Gesture of Picasso.' In: Opening Bazin: Postwar Film Theory and Its Aftermath. Eds. Dudley Andrew and Hervé Joubert-Laurencin. New York: Oxford University Press, pp. 153-166.

--- (2013). André Bazin. New York: Oxford University Press.

Artaud, Antonin (1947). 'Van Gogh, the Man Suicided by Society.' Transl. Helen Weaver. In: Antonin Artaud: Selected Writings. Ed. Susan Sontag. Berkeley: University of California Press (1988): pp. 483-512.

Auden, W.H. (1939). 'Musée des Beaux-Arts.' In: Collected Poems: Auden. Ed. Edward Mendelson. New York: Vintage Books (1991): p. 179.

Baldwin, Robert (1986). 'Peasant Imagery and Bruegel's Fall of Icarus.' Kunsthistorisk Tidskrift/ Journal of Art History, Vol. 55, No. 3: pp. 101-104.

Barthes, Roland (1973). S/Z: An Essay. London: Cape, 1974.

Bataille, Georges (1930). 'Sacrificial Mutilation and the Severed Ear of Vincent Van Gogh.' Transl. Allen Stoekl. In: Visions of Excess: Selected Writings, 1927-1939. Ed. Allen Stoekl. Minneapolis: University of Minnesota Press (1985): pp. 61-72.

--- (1937). 'Van Gogh as Prometheus.' Transl. Annette Michelson. October, Vol. 36 (Spring 1986): pp. 58-6o.

Bazin, André (1945). 'Ontologie de l'image photographique.' Qu'est-ce que le cinéma? Paris: Éditions du Cerf (2008): pp. 9-18. EC PO, 1.

--- (1946/1958). 'Le Mythe du cinéma total.' Qu'est-ce que le cinéma? Paris: Éditions du Cerf (2008): pp. 19-24. EC OP I, 2.

--- (1947c). 'Le film scientifique: Beauté du hasard.' Écran français, No. 121 (21 October). EC IV, 339.

--- (1948c). 'Le Réalisme cinématographique et l'école italienne de la Libération.' Esprit, No. 141 (January). EC V, 362.

--- (1948d). 'William Wyler ou le janséniste de la mise en scène.' Qu'est-ce que le cinema? Vol. 1 : Ontologie et langage. Paris: Éditions du Cerf (1958): pp. 149-173. EC V, 382.

--- (1949b). 'A Propos de Van Gogh. L'Espace dans la peinture et le cinéma.' Arts, No. 210 (15 April). EC VII, 581.

107 Sadoul, 1948, p. 71. 
--- (1952d). 'Peinture et cinéma.' Qu'est-ce que le cinéma? Paris: Éditions du Cerf (2008): pp. 187192. EC OP II, 6.

--- (1952f). 'Pour un cinéma impur. Défense de l'adaptation.' Qu'est-ce que le cinéma? Paris: Éditions du Cerf (2008): pp. 81-106. EC X, 923.

--- (1953e). 'Le langage de notre temps.' In: Regards neufs sur le cinéma. Eds. Jacques Chevallier and Max Egly. Paris: Éditions du Seuil (1963): pp. 5-17. EC XII, 1202.

--- (1956a). 'Grâce à la T.V. on peut maintenant "Descendre en soi-même”.' Radio cinéma télévision, No. 312 (8 January). EC XVIII, 1952.

--- (1956c). 'Le Monde du silence.' France observateur, No. 303 (1 March). EC XIX, 1997.

--- (1956f). 'Un film bergsonien: Le Mystère Picasso.' Qu'est-ce que le cinéma? Paris: Éditions du Cerf (2008): pp. 193-202. EC XIX, 2059.

--- (1957a). 'La Vie passionnée de Vincent Van Gogh.' Éducation nationale, No. 6 (7 February). EC XX, 2229.

Bernstock, Judith E. (1993). 'Classical Mythology in Twentieth-Century Art: An Overview of a Humanistic Approach.' Artibus et Historiae, Vol. 14, No. 27: pp. 153-183.

Blume, Anna (1995). 'In the Wake of Production: A Study of Bruegel's Landscape with the Fall of Icarus.' In: The Delegated Intellect: Emersonian Essays on Literature, Science, and Art in Honor of Don Gifford. Ed. Donald E. Morse. New York: Peter Lang, pp. 237-264.

Boime, Albert (1984). 'Van Gogh's Starry Night: A History of Matter and a Matter of History.' Arts Magazine, Vol. 59, No. 4 (December): pp. 86-103.

Breton, André and Marcel Duchamp (1942). First Papers in Surrealism. New York: Coordinating Council of French Relief Societies.

Chion, Michel (2013). 'The Elevator and the Telephone.' A Companion to François Truffaut. Eds. Dudley Andrew and Anne Gillian. West-Sussex: Wiley-Blackwell, pp. 448-453.

Conley, Tom (2007). Cartographic Cinema. Minneapolis: University of Minnesota Press.

Dalle Vacche, Angela (2014). 'The Art Documentary in the Postwar Period.' Aniki: Portuguese Journal of the Moving Image, Vol. 1, No. 1: pp. 292-313.

--- (2011). 'The Difference of Cinema in the System of the Arts.' In: Opening Bazin: Postwar Film Theory and Its Aftermath. Eds. Dudley Andrew and Hervé Joubert-Laurencin. New York: Oxford University Press, pp. 142-152.

Daney, Serge (1991). 'The Demise of Critical Thinking.' Transl. Stoffel Debuysere. Diagonal Thoughts. [Accessed 30/10/2017] <http://www.diagonalthoughts.com/?p=1521>.

De Tolnay, Charles (1935). Pierre Bruegel l'ancien. Brussels: Nouvelle société d'éditions.

De Vries, Lyckle (2003). 'Bruegel's Fall of Icarus: Ovid or Solomon?' Simiolus: Netherlands Quarterly for the History of Art, Vol. 30, No; 1-2: pp. 4-18.

Deligny, Fernand (1955). 'La caméra, outil pédagogique.' Vers l'éducation nouvelle: pp. 414-417.

---(1989). 'A propos d'un film a faire.' In: CEuvres. Ed. Sandra Alvarez de Toledo. Paris: L'Arachnéen (2007): pp. 1751-1752.

--- (1990). 'Ce qui ne se voit pas.' In: CEuvres. Ed. Sandra Alvarez de Toledo. Paris: L'Arachnéen (2007): pp. 1774-1775.

Duhem, Pierre (1905). Sōzein ta phainomena: essai sur la notion de théorie physique de Platon à Galilée. Paris: Librairie scientifique A. Hermann et fils.

Gerardin, Timothée. 'À la surface.' Le Rotor*, No. 10 [Accessed: 20/02/2015] <http://lerotor.free. fr/article.php3?id_article $=91>$.

Glück, Gustav (1936). Pieter Bruegel the Elder. Transl. E.B. Shaw. London: Commodore.

Harries, Karsten (2002). Infinity and Perspective. Cambridge: The MIT Press.

Heidegger, Martin (1935-6). 'The Origins of the Work of Art.' In: Off the Beaten Track. Transl. Julian Young and Kenneth Haynes. Cambridge: Cambridge University Press (2002): pp. 1-56. 
Huygens, Christiaan (1659). 'On Centrifugal Force.' Transl. M.S. Mahoney. [Accessed 20/02/2015] <https://www.princeton.edu/ hos/mike/texts/huygens/centriforce/huyforce.htm>.

Joret, Blandine (2018). 'Can you 'ear me? L'autoportrait de Vincent Van Gogh vu par Bazin et Deligny.' Cadernos Deligny, Vol.1, No.1: pp. 225-238.

Joubert-Laurencin, Hervé (2001). 'SA.B./S.D. ou les frères passeurs.' Serge Daney: après, avec. Trafic, No. 37 (Spring): pp. 107-116.

--- (2014). Le Sommeil paradoxal: écrits sur André Bazin. Montreuil: Les Éditions de l'CEil

Kal, Jan (1974). 'De val van Icarus,' n. pag. [Accessed 26/04/2019] <https://beeldgedicht.info/ poezie/algemeen/kal-breughel>.

Leirens, Jean (1954). Le Cinéma et le temps. Paris: Éditions du Cerf.

Lubin, Albert J. (1972). Stranger on the Earth: A Psychological Biography of Vincent van Gogh. New York: Henry Holt and Company.

Marcel, Gabriel (1948). 'Les Conditions d'une rénovation de l'art.' In: Débats sur l'art contemporain. Tome 3. Neuchâtel: Les Éditions de la Baconnière, pp. 169-204.

Naifeh, Steven and Gregory White Smith (2011). Van Gogh: The Life. New York: Random House.

Nemerov, Alexander (2005). 'The Flight of Form: Auden, Bruegel, and the Turn to Abstraction in the 1940s.' Critical Inquiry, Vol. 31, No. 4: pp. 780-810.

Newton, Isaac (1684). The Principia: Mathematical Principles of Natural Philosophy. Transl. Bernard Cohen, Anne Whitman and Julia Budenz. Berkeley: University of California Press (1999).

Sadoul, Georges (1948). 'La Métaphysique de la profondeur de champ.' 1895: Revue d'histoire du cinéma, No. 67 (Summer 2012): pp. 132-137.

Sartre, Jean-Paul (1946). 'Existentialism Is a Humanism.' Transl. Philip Mairet. In: Existentialism from Dostoyevsky to Sartre. Ed. Walter Kaufman. New York: Penguin Group (1975): pp. 345-368.

Schapiro, Meyer (1968). 'A Note on Heidegger and Van Gogh.' In: Theory and Philosophy of Art: Style, Artist and Society. New York: George Braziller (1998): pp. 135-142.

Stendhal (1862). Rome, Naples et Florence. Paris: Gallimard (1987).

Virilio, Paul (1989). War and Cinema: Logistics of Perception. Transl. Patrick Camiller. London: Verso. Whitney, Charles A. (1988). 'The Skies of Van Gogh.' Art History, Vol. 9, No. 3: pp. 351-362.

\section{Other sources}

Bazin, André, Georges Emmanuel Clancier, Gabriel Marcel and Adolphe Portmann (1948). 'L'Art contemporain: faut-il renouveler l'art?' Tribune de Paris (2o September) [Accessed: 20/02/2015] <http://boutique.ina.fr/art-et-culture/arts-du-spectacle/audio/PHD85011662/lart-contemporain-faut-il-renouveler-l-art.fr.html>.

\section{Used translations}

Bataille, Georges (1937). 'Van Gogh as Prometheus.' Transl. Annette Michelson. October, Vol. 36 (Spring 1986): pp. 58-6o.

Bazin, André. 'Science Film: Accidental Beauty.' Transl. Jeanine Herman. In: Science Is Fiction: The Films ofJean Painlevé. Eds. Andy Masaki Bellour, Marina McDougall and Birgitte Berg, Cambridge: The MIT Press (2000): pp. 114-147. 
---. What Is Cinema? Vol. 1 \& 2. Transl. Hugh Gray. Berkeley: University of California Press (2005).

---. What Is Cinema? Transl. Timothy Barnard. Montreal: Caboose (2009).

---.André Bazin's New Media. Transl. Dudley Andrew. Berkeley: University of California Press (2014).

\section{Filmography}

The Blood of a Poet [Le Sang d'un poète] (Jean Cocteau, 1930)

Rubens (Paul Haesaerts \& Henri Storck, 1948)

Van Gogh (Alain Resnais, 1948)

Journal d'un curé de campagne (Robert Bresson, 1954)

Lust for Life (Vincente Minelli, 1956)

The Mystery of Picasso [Le Mystère Picasso] (Henri-Georges Clouzot, 1956)

The Silent World [Le Monde du silence] (Jacques-Yves Cousteau \& Louis Malle, 1956)

Blue Velvet (David Lynch, 1986)

Tableau avec chute (Claudio Pazienza, 1996)

The Stendhal Syndrome (Dario Argento, 1996)

The Gladiator (Ridley Scott, 2002)

Dogtooth (Yorgos Lanthimos, 2010)

\section{Illustrations}

Figure 9. $\quad$ Pieter Bruegel the Elder, Landscape with the Fall of Icarus (ca. 1558), oil on canvas, the Royal Museums of Fine Arts of Belgium

Figure 10. Etching by Pieter Bruegel the Elder, A Man-of-War near the Coast, with the Fall of Icarus (ca. 1562), courtesy of Fine Arts Museums of San Francisco, California USA

Figure $11 \quad$ Cut-out by André Breton, included in First Papers of Surrealism (1941)

Figure 12-13. Film stills from The Mystery of Picasso (Henri-Georges Clouzot, 1956)

Figure 14-19. Film stills with Rembrandt's Nightwatch from The Stendhal Syndrome (Dario Argento, 1996)

Figure 20-22. Film stills from Van Gogh (Alain Resnais, 1948)

Figure 23-24. Film stills from Lust for Life (Vincente Minelli, 1956)

Figure 25-26. Film stills from Blue Velvet (David Lynch, 1986)

Figure 27. André Bazin in his office at Travail et culture, 1948, taken either by Janine Bazin or Chris Marker

Figure 28. Vincent van Gogh's Self-portrait with Bandaged Ear (1889), oil on canvas, The Courtauld Institute of Art 



\title{
4. A Matter of Form
}

\begin{abstract}
The previous chapters show that Bazin was never keen on all-inclusive formulas for studying film; this chapter illustrates that he even found himself occasionally either defending his opponents or reconsidering his own arguments. I elaborate on the relationship between form and content, with a specific emphasis on advertisement and poetry, which is crucial to understanding Bazin's methodology. This discourse in fact exceeds Bazin's context: it surfaces decades later in the work of Serge Daney and returns today in discussions on 3-D (and even to a certain extent, Virtual Reality). The analyses in this chapter follow Bazin's lineage and should show that his critical work stands the test of time and the tide of evolution of film.
\end{abstract}

Keywords: form and content, film analysis, 3-D, Virtual Reality

To refuse the evolution of techniques is to condemn civilization to a static life; it is to refuse to be modern; that is, to refuse to be at all.

André Bazin, 1953d

To this day, Bazin's film criticism has been associated almost exclusively with realism. Yet there were times that he had to defend the exact opposite position. In 1948, when he wrote some of his best pieces on depth of field in William Wyler, ${ }^{1}$ for example, he was accused quite strongly of being a 'formalist', and from the debate that followed we can see a much more nuanced but nevertheless fierce Bazin. The most direct accusation was made by Georges Sadoul, who argued that Bazin and his colleagues at Écran français 'attach more importance to form than to content'. ${ }^{2}$ The nuances

1 A concise but clear overview of the debates following 'William Wyler, or the Jansenist of the Mise en scene' (1948) between Bazin and Sadoul has been published under the title 'Convergences et divergences sur la profondeur de champ et le sujet' (1895: Revue d'histoire du cinéma, No. 67, Summer 2012: pp. 126-143), comprising excerpts of six texts that clarify the discussion from both sides.

2 Sadoul, 1948, p. 135 .

Joret, B., Studying Film with André Bazin, Amsterdam: Amsterdam University Press, 2019 DOI: $10.5117 / 97894629895^{28 / \mathrm{CHO}} 4$ 
Bazin provides in his responses are indicative of the ways in which Sadoul's claims caused him to rethink the realist and the formalist discourse. Here, for example, he writes:

Since two or three years, a quarrel divides cinematographic critique. It is true that it might seem as nothing but the shadow of a great dispute between realism and formalism in art [...]. Nevertheless, I think that the problem of formalism arises very differently in cinema and in most of the arts. ${ }^{3}$

Even though these comments were raised in a specific historical context, this assertion in fact summarizes Bazin's view on the evolution of cinematographic language, which inevitably leads to current matters in film theory. Bazin's criticism generally oscillates from a 'realist' defence of sound cinema, discussed in the first chapter of this book, to a 'formalist' treatment of depth of field, which I will analyze from the perspective of contemporary criticism of three-dimensional cinema.

In the following pages, I focus on Bazin's particular defence of 'realist formalism', which is how I understand his notion of 'integral realism': the achievement of increased realism inherent in the evolution of forms. In a similar vein, Jon Wagner reads in Bazin's myth of total cinema 'a realism formalist in its formation'. ${ }^{4}$ He puts it very convincingly:

Integral realism; a recreation of the world unburdened by the irreversibility of time; myth: when Bazin describes the genesis of cinema in terms of his realist ideal, and when this ideal entails illusory representation and temporal recreation, I think he comes close to defining his own formalism. ${ }^{5}$

The previous chapters have shown that Bazin was never keen on all-inclusive formulas for studying film; this chapter illustrates that he even found himself occasionally either defending his opponents or reconsidering his own arguments. In fact, as I will argue, the quarrel between form and content exceeds Bazin's context: it surfaces decades later in Serge Daney's famed critique of the popular feature film The Big Blue (Luc Besson, 1988) in terms of 'amnesic, aphasic images' without content, and returns today in discussions on $3-\mathrm{D}$ (and even to a certain extent Virtual Reality). The analyses in this chapter 
follow Bazin's lineage and should show that his critical work stands the test of time and the tide of evolution of film.

\subsection{Form + Content}

The first chapter of this book on Bazin's critical methodology ended with a section on his mayonnaise theory: a quarrel with Truffaut on auteur theory. In it, I have already raised the importance for Bazin of form and content: as much as he rejects the artificial distinction between the author and his work, he also rejects 'the distinction one learned at school between form and content'. ${ }^{6}$ By now, it's clear that Bazin's teaching, through debates at the ciné-clubs and in his writing, was different from traditional school or university systems. In a preface to Bazin's biography, a eulogy titled 'We Miss André Bazin' (1977), Truffaut reformulates the auteur theory formula in favour of Bazin into a 'politique des auteurs-critiques': 'one negative review by Bazin described the film better than an eloquent article by any of us. ${ }^{7}$ For Bazin, being a film critic was 'more than a job [...] it was a pleasure that he felt, a pleasure and a necessity linked to his educational calling. ${ }^{8}$ Truffaut's text is centered on one particular image related to Bazin's flexibility of thought and characteristic of his educational calling: aquarium light.

In 1948, Bazin wrote an article on Jean Renoir's The Diary of a Chambermaid, a film Renoir made during his Hollywood years in the late forties. Bazin then wrote, dismissively, in Écran français, that the sunshine on the roses of Burgess Meredith made 'this entire film bathe in that aquarium light, characteristic of the Hollywood studios'. ${ }^{9}$ Several years later, he changed his mind and described this experience as follows:

I in fact had a painful impression during the first minutes of the projection, the time to finally understand my mistake and how absurd it was to persist in wanting to see a lack of realism in the most dreamlike film and the most deliberately imaginary film in Renoir's oeuvre. [...] About this aquarium light that shocked me so much before, of course again I found it, but it appeared to me as the light coming from the earth. ${ }^{10}$

6 Bazin, 1957b, EC p. 2154; Transl. Graham, 2005, p. 255.

7 Truffaut, 1983 , p. 57 .

8 Ibid., p. 55 .

9 Bazin, 1956c, EC p. 2004.

10 Ibid., EC p. 2005. 
This is in 1956, about a decade later, and Bazin admits he had had back then a prejudice which, as the title of the essay reads, 'cost him dearly'. According to Truffaut, "this "aquarium light" is an important find, it puts the emphasis on the most startling contrast of post-war cinema: the forms of Hollywood and neo-realism'." Aquarium light technically refers to a specific lighting technique typical of Hollywood studios but also adopted by the New Wave film directors. It involved projecting light towards the ceiling of an interior, which created a uniformly lit space without shadows. In Nestor Almendros' words: 'Unlike before, looking like it was carved out, the light invades everything almost evenly, as an aquarium light. ${ }^{\prime 2}$ Itself a poetic image, this aquarium light shows a two-sided Bazin: realism in 1948, and formalism almost a decade later. When we read his work today, then, we find two seemingly opposing strands combined. Highlighting the same binary in Bazin's work, Dudley Andrew writes:

Bazin affirmed that in the cinema 'poetry' and 'realism' were congenitally conjugated, that there was no way of speaking of realism without poetry and conversely that no film or technique could approach the poetic without a degree of realism. ${ }^{13}$

By acknowledging two sides of the coin, Bazin's body of work displays a flexibility unlike any comprehensive study of film. Truffaut indeed does not describe Bazin's second thoughts about Renoir as an apology or a guilty confession; instead, aquarium light is 'an enthusiast and stimulating deepening' of his criticism, which he qualifies as 'in-depth criticism'. ${ }^{14}$ Beyond a simple expression of regret, Bazin acknowledged that prejudice illuminates a particular semantic process in his work centered on the poetic use of forms.

\subsubsection{From Advertising to Poetry in Bazin}

The title of the particular essay in which Bazin points to his own misconception, 'A Prejudice that Cost Me Dearly' [Un préjugé qui me coûtait cher],

11 Truffaut, 1983, p. 57.

12 Almendros, 1990, p. 14; The Spanish cinematographer Nestor Almendros (1930-1992), working with Eric Rohmer as well as with Truffaut among many others, used this lighting technique abundantly. With aquarium light, the set is illuminated from below (with the lights themselves carefully placed out of frame, of course), towards the ceiling; this created indirect, diffuse light. It eliminated shadows, uniformly lighting up the space much like an aquarium. This technique was used in Italian neo-realism, Nouvelle Vague films as well as in the Hollywood studios.

13 Andrew, 1995, p. ix.

14 Truffaut, 1983, p. 57; Truffaut here recalls Bazin's own aspirations from 1942. 
refers to a French advertisement slogan for a margarine brand Astra, widely disseminated during the fifties (Fig. 30). Competing with real butter, Astra needed to tilt the French towards buying cheaper margarine - a difficult endeavour in post-war France: why go for the cheaper alternative now the war was over? As a rhetorical tactic, the brand developed a campaign entirely based on refuting prejudice by staging everyday culinary habits, much like the script of a theater or film scene. During the same time, and with the exact same advertisement in mind, the semiotician Roland Barthes (1915-1980) describes this strategy as an 'immunization' of the people: Astra used 'a narrative pattern which clearly shows the working of this new vaccine'. ${ }^{15}$ Published in 1957, his Mythologies would become foundational for visual semiotics and discourse analysis: from a structuralist point of view, Barthes argued that messages coded within a certain discourse, such as advertising, contain certain signs (an image, a dialogue) that signify or connote something beyond their apparent denotation. This sentence, 'a prejudice that cost me dearly', does not signify that some French housewife changes her mind about margarine, but is instead designed to sell a product. Taking the infamous line in a different direction, Bazin's title turns it into a methodological inquiry: in criticism, what could be the role of prejudice, second thoughts or, to stick with food preferences: personal taste? In his own text on auteur theory, Bazin indeed affirms the necessity of taste in criticism:

I feel there are two symmetrical heresies, which are (a) objectively applying to a film a critical all-purpose yardstick, and (b) considering it sufficient simply to state one's pleasure or disgust. The first denies the role of taste, the second presupposes the superiority of the critic's taste over that of the author. Coldness ... or presumption! ${ }^{16}$

Personal taste, in itself a kind of prejudice, has its place in film criticism; yet, so Bazin argues, it should never overrule the taste or style of the filmmaker. The fact that Bazin concerns himself with advertising in the title is important and offers a slightly different signifying process by using the most powerful yet least meaningful form as a methodological inquiry.

From a semantic point of view, Bazin's reference to the Astra advertisement should be seen as poetic: ${ }^{17}$ as the poets do with language, he takes

15 Barthes, 1957, p. 42.

16 Bazin, 1957b, EC p. 2154; Transl. Graham, 2005, p. 256.

17 This line in particular has indeed been used by the writer Georges Perec (1936-1982), who includes it in his memories from 1946-1961 in Les choses communes: Je me souviens (1978): 'Je 


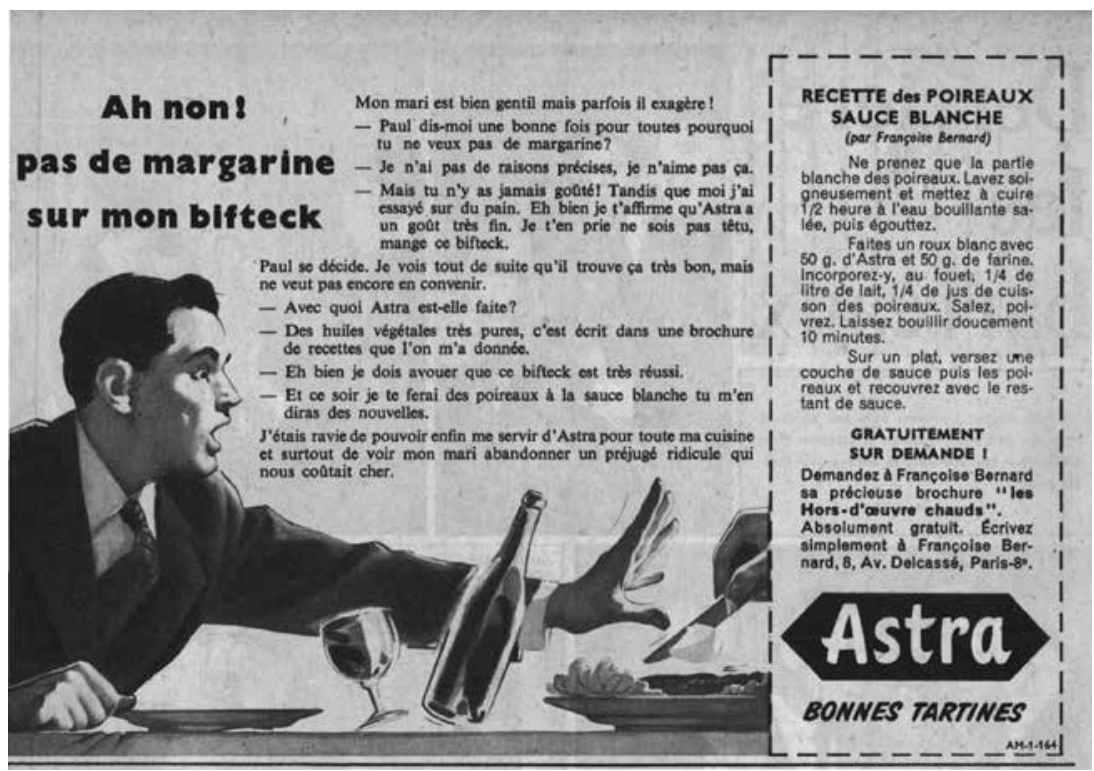

Fig. 29 Form: A prejudice that cost me dearly

an existing sentence with its own form, sound or rhythm and then fills it up with new content. Before turning to the notion of advertising images linked with the form and content debate, crucial in order to fully grasp the formalist traits in Bazin's methods as well as his relevance in more contemporary media contexts, let me first explain this poetic use of language in his work. On numerous occasions, poetry is used to frame and explain central concepts in Bazin's work: for example, Stéphane Mallarmé's famed final phrase illuminates in Bazin 'the maxim of ontological realism at its purest reformulation of classical mimesis. ${ }^{18}$ A lesser-known case of poetry in Bazin's texts is the essay mentioned previously on the underwater documentary film, The Silent World (Jacques-Yves Cousteau and Louis Malle, 1956). In it, Bazin writes:

La mer scintillante de lumière n'était au poète méditerranéen qu'un toit tranquille où marchent les colombes, celui des focs et non des phoques.

me souviens... Astra, un préjugé qui vous coûtait cher' (Perec, 1978, p. 39). With his frequent wordplays, crosswords, or univocalisms, among other experiments in language, Perec is known for his innovative use of form.

18 Joubert-Laurencin, 2014, p. 49; pp. 153-158. 
[The sea shimmering with light was to the Mediterranean poet but a tranquil roof where the doves walked by, the roof of the jibs and not the seals. $]^{19}$

The Mediterranean poet Bazin refers to is Paul Valéry (1871-1945). A symbolist poet like Mallarmé, he seeks meaning beyond appearances in nature: put bluntly, a tranquil sea symbolizes death, or a breeze symbolizes hope. Bazin's choice of words in his critique of The Silent World indeed betrays a recurring preoccupation with this particular poem, titled The Seaside Cemetery (1920). Consider its very first and last sentence: ${ }^{20}$

$\begin{array}{ll}\begin{array}{l}\text { Ce toit tranquille, où marchent des } \\ \text { colombes, }\end{array} & \begin{array}{l}\text { This quiet roof, where dove-sails } \\ \text { saunter by, }\end{array} \\ {\left[\begin{array}{l}{[. .]} \\ \text { Ce toit tranquille où picoraient }\end{array}\right.} & {[\ldots]} \\ \text { des focs! } & \text { This quiet roof where sails like doves } \\ \text { were pecking. }\end{array}$

From beginning to end, Bazin incorporates Valéry's symmetries pertaining to water and air: wings (les colombes) and feet (marchent), sails (des focs) and fins (et non des phoques). Following the rhythmic organization of this poem, the essays on The Silent World ultimately bring about a reformulation of the critical categories of form and content. Through homonym, Bazin suggest that the sea can symbolize either a superficial, shiny surface (le toit des focs) or a three-dimensional body (celui des phoques): 'the space below, which is the space of life. ${ }^{21}$ On several occasions, Bazin in fact mentions this particular poem, always in defence of a certain degree of formalism:

If nature proceeds from the inside to the outside, from cause to effect, it is the privilege of art, as of science, to induce matter or to deduce form. Paul Valéry built The Seaside Cemetery upon the cadence of a single line of verse. ${ }^{22}$

And so Bazin's article on Cousteau is in turn built on a poem that was written from 'an obsession with a certain rhythmic frame, initially empty, which Valéry then fills little by little with content that he thought was freely 
chosen'. ${ }^{23}$ More specifically, in his interpretation of Cousteau's underwater exploration, Bazin reformulates Valéry's vision of the surface of the ocean as the roof of an unexplored part of the universe, and thereby moves beyond symbolism: there is depth underneath the surface. By converting Valéry's The Seaside Cemetery, Bazin thus ultimately claims his invested interest in recreation as an affirmation of trans-forming the world in its image, or a text in a text, or indeed film into criticism.

Where Bazin's oft-cited reference to Mallarmé relates to the process of recreation in realism, the reference to Valéry applies recreation to methodology and film criticism. With this discourse in mind, Truffaut's description of criticism being 'in-depth' is equally important. From a physiological perspective, depth perception depends on binocular vision; likewise, aquarium light in Bazin defies one-sighted, superficial criticism. In Bazin's words, from 1943: 'One would say that this particular art has no past, no thickness, like those ephemeral shadows on a screen. It's high time to invent three-dimensional film criticism. ${ }^{24}$ Taking into consideration that shadow plays are pre-cinematic practices, Bazin's call for three-dimensional criticism is, ultimately, a call for criticism sensitive to the evolution of forms which, I argue throughout the following pages, logically culminates in his essays on 3-D cinema.

\subsubsection{Depth, Water and the Evolution of Forms}

Rather than favoring content over form, it is as a realist that Bazin rejects the distinction traditionally made in art criticism. Building on the Newtonian framework discussed previously to explain Bazin's radical approach to realism as no more and no less than reality, I now add a corollary to this: form and content are in his view ultimately equal. Already in the ontology essay, he writes that, ultimately, 'every image should be experienced as an object and every object as an image.' ${ }^{25}$ It is, furthermore, in semiotic terms that he envisions this equilibrium from a film critical point of view:

[...] every technique is completely responsible for what it expresses, or every form is a sign, and where nothing is really said without its being couched in the necessary form. Criticism could then be practiced, at least on the best films, as it has been practiced now for a century on the best literature, beyond [au-delà] the otherwise artificial categories of 
form and content. Nevertheless, I would like to point out that 'content' and 'form' in cinema are not always what a biased or superficial analysis might assume. This is the reason why criticism cannot remain indifferent. It must discern from vain technical acrobatics the artistic imagination, which enables cinema to go deeper and further. ${ }^{26}$

Bazin's desire for tradition, to move from the ephemeral shadows towards 3 -D, is clearly tangible in this passage. In 'The Myth of Total Cinema', he initially defends the talking film as an imperative stage in the development toward integral realism: techniques such as sound, color and ultimately relief all contribute to an increased realism, 'the recreation of the world in its own image'27 - the ultimate, aspired equality between object and image. Yet recreation, I have just argued, also functions in his film critical work: to use Truffaut's formulation, when Bazin discusses aquarium light he is at his best, 'like a fish in the water'. ${ }^{28}$

To grasp the full meaning of this in-depth methodology, another scientific reference in Bazin needs elaboration: Archimedes' principle of buoyancy, which states that 'any solid lighter than a fluid will, if placed in the fluid, be so far immersed that the weight of the solid will be equal to the weight of the fluid displaced.. ${ }^{29}$ Alongside his Newtonian framework, Bazin writes about Cousteau's underwater film:

The only thing needed was, first, to be freed from this reversed gravity which is Archimedes' principle; then, to be given ambient pressure by the pressure modifier to not end up in the fleeting and dangerous situation of a diver, but in that of Neptune, master and inhabitant of water. Finally, man flies with his arms! ${ }^{30}$

Bazin makes it very clear that the water in The Silent World is threedimensional: 'It is not anymore about a symbolism attached to superficial, mobile, streaming, lustral water, but rather about the Ocean: a three-dimensional milieu, more stable, moreover, than air and in which submergence frees us from gravity. ${ }^{31}$ In water, several things can happen: you can swim, drift, dive, or drown - but Bazin now seems more interested

28 Truffaut, 1983 p. 59 .

29 Archimedes, 1897, p. 257.

30 Bazin, 1956c, EC p. 1915.

$3^{1}$ Ibid. 
in the experience of weight, or volume, rather than weightlessness. Under water, mass does not prevent flight but instead, thanks to the buoyancy principle, enables it. Eureka! Finally, man flies with his arms: 'the fish becomes bird. ${ }^{32}$

Water, especially in relation to its reservoir, indeed articulates Bazin's particular views on the evolution of film language - and, in effect, perhaps because of its fluid, formless state, it permeates the larger debate on film form after Bazin. Arguing against Bazin's supposed formalist turn, Sadoul wrote: 'To lose sight of the subjects ends up in classifying films according to their technology $[. .$.$] which is like thinking that the vintage of a wine is determined$ by the form of the bottle, of a Champagne, Bordeaux or Bourgogne. ${ }^{33}$ All the while pursuing the analogy with fluids, Bazin replies to this that: 'The relationship between form and matter is not that of container and contents, of bottle to liquid, but more that of shell to clam. ${ }^{34} \mathrm{He}$ further develops the maritime reference to a symbiotic existence into his famed metaphor of the 'equilibrium profile of a river flow', by which he explains the evolution of film language:

Once it has reached its equilibrium profile, a river flows effortlessly from its source to its mouth without further eroding its bed. But should any geological movement occur to raise the peneplain and modify the height of its source, the river's water sets to work again, penetrating the ground underneath it, eating away at, boring and breaking through it. Sometimes it encounters limestone and hollows out a new and almost invisible course across the tableland, a course whose flow of water is twisted and complex. ${ }^{35}$

The course of a river is determined by processes of erosion, transportation and deposition, which make it impossible to dissociate the water flow from its bed. Similarly, without its container, water has no form: technological inventions, social situations as well as political contexts, for example, shape the evolution of film language - and without water the container loses its purpose: the image becomes no more than an empty signifier.

32 Bazin, 1956f, EC p. 1968.

33 Sadoul, 1948, p. 135; As a side-note, it is perhaps worth pointing out that Sadoul's example is ill-founded: all these wines, in fact, develop their particular qualities in relation to the shape of their bottles.

34 Bazin, 1951e, EC p. 686; Transl. Cardullo, 2014, p. 17.

35 Bazin, 1950-1955, EC p. 978; Transl. Barnard, 2009, p. 96. 
Bazin's entire discourse on recreation is built around change and evolution in film form, theory and criticism. As such, it initiates a strong lineage in French film criticism specifically relating to water, depth and surface in terms of meaning and form. Continuing this tradition, Bazin's most prominent successor Serge Daney (1944-1992) introduces a generational revolution in French film criticism: a radical 'return to cinema' in the eighties, following the structuralist and semiotic orientation in the sixties, ${ }^{36}$ echoes Bazin's call for the existence of film as the critic's point of reference. Facing the 'defeat of (film) critical thinking', Daney emphasizes the need for a cinephile tradition:

[...] cinema has a completely original connection to filiation and when this connection ceases to exist, like today, cinema risks to cease as well, finding itself replaced overnight by images of another country, by a genetically produced visual.

Loving cinema is loving this idea that we always make do with bodies that have already served, that have existed for others. ${ }^{37}$

The bodies Daney refers to are both realist (cinema borrows existing forms from reality, which it transforms) as well as formalist (cinephilia necessitates knowledge or usage of existing artistic forms). Surprisingly (or not), it is to water that Daney takes in his melancholic essay on post-modern film culture, titled 'Cinema and the Memory of Water' (1989). In what follows, I focus on his critique of Luc Besson's popular feature film The Big Blue (1988), which stirred the critical discourse with highly aestheticized imagery. In many ways, Daney's work on Besson puts recreation to work as a critical method: as Joubert-Laurencin writes on the topic of Besson's underwater documentary Atlantis (1991), 'through Daney, Luc Besson has seen Bazin'. ${ }^{8}$ More specifically, I maintain that Daney's film criticism implicitly builds on Bazin's discourse, which speaks of shadows and bodies as well as tradition through recreation, and extends its validity into an entirely different media context.

\subsubsection{On Floating Bodies: Serge Daney and the Case of Le Grand Bleu}

Roughly thirty years after Bazin, Daney's film culture is at first sight far removed from neo-realist and nouvelle vague stylistics. The cinema of 
Besson, characteristic of the so-called cinéma du $l o o k^{39}$ of the eighties, displays an advertising, glossy magazine aesthetic: stereotypical, cliché-like imagery with vibrant colors, soothing soundtracks and an impeccable mise-en-scène dominate a more authentic depiction of reality. The question that drives Daney's discourse is still, however, an ontological one:

The filmed cinema, that of Besson, inherits 'forms' but no 'bodies' (Platonic, not Aristotelian). These forms, which are rather derisory, are nevertheless the only existing memory (genetic memory of cinema) and the only truth. [...] What is needed are bodies that correspond to the publicity advertising world that surrounds us. [emphasis in original ${ }^{40}$

These forms without body, Daney continues, are 'amnesiac images', images with memory loss: 'when I see The Big Blue, I don't see the sea, I see an advertising concept of the sea that has once and for all replaced the sea. ${ }^{41}$ In short, Daney sees Besson's blue movie as emblematic of a collective aphasia: "The famous "crisis of scenarios", which bores our ears, it is there: in the privatization of experience and the aphasia it produces, especially among the youth. ${ }^{42}$ When form takes over content, nothing is left to say, nothing is being exchanged: collective apathy reflected in a lack of dialogue.

Indeed, in The Big Blue everything is set for a romance that never unfolds: a once-in-a-lifetime chance meeting somewhere in the Peruvian middle of nowhere, the subsequent man-hunt that leads a woman, Joanna, from New York all the way to the Mediterranean coast, where finally she reunites with her love at first sight. But this man, Jacques Mayol, is only interested in diving, even when Johanna turns out to be pregnant; even when his best friend Enzo has died, running after the same obsession with depth. 'To hold your breath, to stop breathing', ${ }^{43}$ as Daney puts it, is characteristic of free-diving as well as Besson's film aesthetics. In fact, the only time when Jacques explains his apathy towards life on dry land, he reinforces again his aphasia: 'you have to find a good reason to come back up, and I have a hard time finding one.' Ultimately, the highly aestheticized, smooth forms of The Big Blue tell the story of suicide. Jacques chooses to be with the mermaids:

39 The term cinéma du look was first coined by the critic Raphaël Bassan in 1989, applicable to Besson's films as well as those from Leos Carax and Jean-Jacques Beineix. On this topic, see Austin, 1996, pp. 119-134.

40 Daney, 1993, p. 238.

41 Ibid., p. 293.

42 Ibid.

43 Daney, 1989, p. 164. 
Do you know how it is; do you know what you're supposed to do to meet a mermaid? You go down to the bottom of the sea, where the water isn't even blue anymore, where the sky is only a memory. And you float there, in silence, and you stay there and you decide that you'll die for them. Only then do they start coming out. They come, and they greet you and they judge the love you have for them. If it's sincere, if it's pure, they'll be with you and take you away forever.

Beyond aesthetics, then, Daney's critique is indeed political: the film's immense popularity at the time pushed an entire generation of copycats, nicknamed les allumés du Grand Bleu, to engage in deep-sea diving (often to death). ${ }^{44}$ It is not a shark this time but dolphins and mermaids where authenticity is sought after. Thus, in The Big Blue, Besson provides another discourse on the connection between authenticity and death, and he does so via a certain 'pure' formalism traditionally emptied of authenticity: from the point of view of Narcissistic superficiality rather than Icarian audacity.

Platonic forms as opposed to Aristotelian bodies: in Daney's work as well as in Bazin's, these references are in fact crucial to understand the interrelation between content and form. For example, in his 'Myth' essay Bazin speaks of an ideal cinema descending from its platonic heaven, just as airplanes have realized the Icarus myth (human flight). He then picks up the Icarus myth again in his review of Cousteau's documentary, to argue for an Aristotelian cinema: thanks to buoyancy, Icarus swims/flies with his arms. In this manner, the discourse surrounding Besson's highly aestheticized imagery inevitably brings us back to Bazin, more specifically to the notion of water discussed earlier in this chapter. In The Big Blue, shiny surfaces, the sunlit ocean and wet, dolphin-like bodysuits are the dreamy clichés that altogether constitute this 'symbolism attached to superficial, mobile, streaming, lustral water', 45 to which Bazin opposes The World of Silence as a return to origins:

[the images] are the accomplishment of an entire mythology of water, of which the material fulfilment by these subaquatic supermen encounters within ourselves secret, profound and age-old connivances. ${ }^{46}$

44 Claude Chapuis, cited in 'Tout le mal que "Le Grand Bleu” a fait à l'apnée.' 20 minutes, 02/06/2016 [Accessed 30/10/2017] <http://www.2ominutes.fr/marseille/1857651-201606o2-toutmal-grand-bleu-fait-apnee>. After receiving an account of irresponsible free-diving in Lake Titicaca, copying an enigmatic scene from the film, Chapuis - himself world champion in 1990 - founded the AIDA (or the International Foundation for the Development of Free-diving).

45 Bazin, 1956c, EC p. 1914.

46 Ibid. 
It is precisely the lack of the latter, the three-dimensional ocean, that portrays The Big Blue as nostalgia for reality: a bit of a blue movie about having the blues. ${ }^{47}$

Similarly, many films set in or around swimming pools find themselves at the crux of imagination, memory loss, superficiality, and nostalgia. Exemplary of luxury and wealth, swimming pools are the ultimate advertisement settings where image takes the upper hand over reality. In The Graduate (Mike Nichols, 1967), the swimming pool offers Ben, a recent graduate anxious about his yet undefined future, the perfect escape from the expectations of his parents, their friends and his much older lover Mrs. Robinson: 'It's very comfortable to just drift here.' The pool feels like a movie, as does his affair (the drinks, the hotel, the pool parties), and fits perfectly in the narrative of an impasse. Both as an escape and amnesiac, Neddy in The Swimmer (Frank Perry, 1968) hops from pool to pool, remembering clichéd forbidden desires (the babysitter), a love affair gone wrong and actual financial debt, as he swims 'home', all the while realizing that there is no more home. Swimming Pool (François Ozon, 2003) associates the pool with imagination, mystery and murder, which is also the morbid conclusion of Deep End (Jerzy Skolimowski, 1970), when Mike's adolescent, obsessive desire for his co-worker Susan is finally answered as they drift lifelessly in the pool. Nanni Moretti's Red Wood Pigeon (1988) seems to be the exception that proves the rule, as the swimming pool becomes a political playground. Juxtaposing it with Besson's superficiality, Daney defends Moretti's 'refusal of depth':

Water. Filmed as never before. [...] A refusal of depth - which makes of this film the answer of cinema to the audio-visual (Le Grand Bleu). Water is a special surface that one needs to cover incessantly, ploughing it with one's body (boustrophedon). ${ }^{48}$

47 From this point of view, it is perhaps not coincidental that in French ' $n$ 'y voir que du bleu' comes to mean precisely the inability to see. Closely entangled with the expression ' $n$ 'y voir que du feu', worth the mention since we are talking about Icarus after all, this phrase etymologically goes back to La Bibliothèque bleue, which encompasses a series of French early-modern publications from the seventeenth to the nineteenth century. Typically distributed in small format, with a blue cover and on low quality paper, these booklets covered a wide range of popular subjects and came to stand for the origins of popular and mass media in France (Chartier, 2003, pp. 294-295). From this historical perspective, 'blue' gradually came to stand for 'dreamy' as in un conte bleu, a fairy tale.

48 Daney, 1993, p. 168; 'Boustrophédon', from Ancient Greek literally meaning 'ox-turning' as in farming, here refers to a bi-directional text, in which each line is written in the opposite direction as the preceding one. Rather than reading from left to right (as in English, for example), or from right to left (as in Hebrew), these manuscripts need to be read alternately from left-to-right-to-left. 
The water surface becomes workable: the swimmer, Michele, becomes its ploughman. However, here again, the protagonist suffers from memory loss, and his continued repeated shouting 'I remember, I remember!' shows a narrative that struggles with amnesia. In any case, and to use Daney's formulation, 'the new [post-modern] individual [...], in principle, should know how to swim. ${ }^{49}$

Amnesia, forgotten bodies, and forms without content: in The Big Blue as well as a series of swimming pool films, something is always lacking, and this lack goes hand in hand with highly aestheticized imagery. If I have argued before that imperfect images tend to aid authenticity, here this same logic seems reversed: gain in image equals loss of reality. And indeed, Besson's Mediterranean Sea is nothing like the ocean crossed by Thor Heyerdahl on his raft: in the former, dolphins are our friends (Jacques even calls them his family), in the latter, the sharks are a real danger that makes for an authentic but nevertheless non-existent film. The lack of 'body' in Besson, the nostalgia for content and meaning, surfaces in the water-logged, always shiny imagery of pool films as a longing for content: the image exists in all its glory, but it has lost touch with reality. Yet, Daney writes, 'the (moral) parenthesis of modern cinema being finished, cinema (or what remains of it) rediscovers the question of depth [le fond]: where do the dream bodies come from? ${ }^{\prime 50}$ In the following section, I argue that this ontological question is also a question of filiation: from the Platonic shadow plays to Aristotelian 3-D, Bazin's realist-formalist discourse can effectively be used to understand contemporary film language.

\subsection{Perspectives on 3-D}

The decisive event was undoubtedly the invention of the first scientific and, in a sense, already mechanical system: perspective (with Leonardo da Vinci's camera obscura prefiguring Niepce's darkroom).

André Bazin, 1945

As Daney writes, in Red Wood Pigeon Michele 'ploughs' the surface of the pool with his body, swimming back and forth, just like an ox works the field or a bidirectional text is read.

49 Daney, 1989, p. 161; the necessity for learning how to swim is loaded today with an immense political message, as several tens of thousands of refugees cross the Mediterranean Sea on their way to Europe. Contemporary cinema responds to this: Welcome (Philippe Lioret, 2009), for example, tells the story of Simon, a former champion turned local swimming teacher, and Bilal, an Iraqi refugee stranded in Calais. 'You want to learn to swim?', Simon asks him - 'Yes, crawl', the boy answers, and the two continue to develop an intense emotional bond through swimming classes that should help Bilal cross the English Channel.

50 Ibid., p. 146. 
The dialectic between form and content leads me, now, to briefly consider the special place Bazin reserves for the notion of perspective in 'The Ontology of the Photographic Image', in particular its role in painting as enabling the illusion of content: 'Perspective made it possible for artists to create the illusion of three-dimensional space in which objects could be placed the way they would if we perceived them directly. ${ }^{51}$ While he sees the introduction of linear perspective in fifteenth-century Western painting as a first attempt to mechanically combine 'the expression of spiritual realities in which the model was transcended by the symbolism of form - while the other was simply a psychological desire to replace the outside world with its double [my emphasis], ${ }^{52}$ he clearly denounces its usage in facilitating, for instance, 'the pseudo-realism of trompe l'œil (or trompe-l'ésprit), which is content with the illusion of form'.53 Whereas formerly the size, color and shape of objects on a canvas had been informed by their spiritual meaning, 54 linear perspective reorganizes them according to their relative distance from the spectator. From this viewpoint, Bazin denounces the painterly illusion of depth, when he writes:

[...] the art of the Middle Ages, for example, appears immune to this conflict: both violently realist and highly spiritual, it did not know the upheaval that technical possibilities have since introduced. Perspective was the original sin of Western painting.

$* * *$

Niépce and Lumière were its redeemers. ${ }^{55}$

51 Ibid.

52 Ibid.

53 Ibid., p. 11; Transl. Barnard, 2009, p. 6.

54 See, for instance, Karsten Harries' notion of 'spiritual perspective', which he juxtaposes with Alberti's perspectiva artificialis: 'The spiritual perspective of medieval art would have us look through painting in a very different sense: through the material to its spiritual significance. The mundane is transformed in a divine sign. Alberti's art is incompatible with this spiritual perspective. A God-centred art gives way to a human-centred art' (Harries, 2002, p. 85). Harries sees this conflict of perspectives reflected, for instance, in the clash between a growing interest in three-dimensionality in late Medieval painting and the use of gold. Linear perspective thus becomes entangled with the idea of a fall of man, of a profanity introduced in the history of painting with the invention of linear perspective.

In a similar manner, Dudley Andrew, in the biography of Bazin, elaborates on the notion of perspective in painting in 'Ontology' as 'the golden calf of painters' (2013, p. 65), thus invoking the theme of vanity and idolatry, which indeed runs through the essay via the double reference to Blaise Pascal's Pensées.

55 Bazin, 1945, EC p. 2556; Transl. Barnard, 2009, p. 6. 
As he does explicitly in his argument for a centrifugal screen, Bazin again places cinema in opposition to painting, here with a particular focus on perspective and three-dimensionality. Already in the summer of 1943, Bazin had started to develop his views on perspective through the analogy between cinema and Medieval painting. As Françoise Burgaud recalls that Bazin explained: 'I want to make you understand that medieval painting and cinema are the same thing! [...] These painters had tried to introduce in their works the meaning of the world, because they did not know perspective. ${ }^{5} 6$ These ideas in fact crystallize his view on linear perspective as having changed the history of Western painting, which would from then onwards be satisfied with the illusion of forms up until its redemption by the cinematograph: the conflict between form and content, impression and expression, ultimately resolved. In this manner, after the cinematograph, Bazin is able to conclude in an addition the ontology essay: 'And when, with Cézanne, form took back the canvas, it was no longer in the service of perspective's illusionist geometry.'57 With this phrase on Cézanne, Bazin readily aligns his views on perspective with those held by French philosopher Maurice Merleau-Ponty (1908-1961) in 'Cézanne's Doubt' (1945): $:^{8}$

[Cézanne] was pursuing reality without giving up the sensuous surface, with no other guide than the immediate impression of nature, without following the contours, with no line to enclose the colour, with no perspectival or pictorial arrangement. 59

Merleau-Ponty emphasizes the painter's ability to combine expression with form by leaving the illusionist geometry of perspective behind: similar to the medieval painters, Cézanne found expression outside the realm of perspective. The real problem with linear perspective, the veritable 'sin of Western painting', then, is that it inclines to emptied formalism: images cease to express meaning.

In fact, as I will establish throughout the following pages, Bazin's dismissal of the illusion of three-dimensionality created by linear perspective ties in

56 Bazin, cited by Françoise Burgaud, in Pagliano, Jean-Pierre. 'Profils perdus: André Bazin.' France culture (20/10/1988) [Radio program]; Burgaud's anecdote indeed makes one wonder whether it was perhaps the very first sketch of the Ontology essay that Bazin had started to develop that summer of 1943 .

57 Bazin, 1945, EC p. 2557; Transl. Barnard, 2009, p. 10.

$5^{8}$ As Andrew writes, Bazin was in fact in contact with the philosopher during the time Merleau-Ponty wrote the essay on Cézanne (Andrew, 2011, p. 159).

59 Merleau-Ponty, 1945, p. 12. 
with his subsequent embrace of 'relief', or three-dimensionality. Though he deals with it explicitly in his later essays, Bazin's concern with $3-\mathrm{D}$, in which he finds, again in concert with Merleau-Ponty, a more realist perspective, is already present as a constitutive element of integral realism in 'The Myth of Total Cinema':

In their imagination, they conceived of cinema as the complete and total representation of reality. From the outset, they foresaw the creation of a perfect illusion of the outside world through sound, colour and three-dimensionality.

With respect to the latter, the film historian Georges Potonniée has even gone so far as to suggest that 'it was not the discovery of photography but rather that of stereoscopy [...] which opened the thinkers' eyes'. ${ }^{60}$

Where linear perspective manipulates color, size and shape to facilitate the illusion of depth, Niepce and Lumière mechanized it. In the following pages, I suggest that Bazin completes this train of thought in his $195^{2}$ essay entitled 'Math Equations for $3 \mathrm{D}$ ', when he elaborates on stereoscopy as a decisive step towards a 'perfect illusion' of reality: synthetic relief integrates form and content rather than setting them off against each other.

\subsubsection{From a Realist Perspective: 'The Imaginary Image'}

Bazin's so-called realist-formalism effectively culminates in his embrace of stereoscopy, which he describes as an 'imaginary image' that gives body to a synthesis of both the realist and the formalist tendencies: because a three-dimensional image is formed by mentally combining two slightly diverging perspectives, stereoscopy literally imitates our direct perception and creates a 'more realist' image that paradoxically exists only in imagination. In 'Math Equations for 3D' (1952), he embarks on a rather technical explanation of three-dimensional cinema in which, beyond prophesying a future ideal cinema, ${ }^{61}$ he revives the foundations of the myth of total cinema, i.e. integral realism:

60 Bazin, 1946/1958, EC p. 2558; Transl. Barnard, 2009, p. 16.

61 Bazin was well aware of the technologies offering stereoscopic vision, as his mention of Georges Potoniée's Les Origines du cinématographe (1928) in the Myth essay indicates. Writing in 1953, then, he knew of Louis Lumière's efforts in stereoscopy and in fact subtly criticizes his disinterested, purely technical approach. The fact that the technology had existed long before it was put to use at the Festival of Britain, where Bazin encountered the poetic use of $3-\mathrm{D}$, illustrates 
If one day $3 \mathrm{D}$ cinema evolves beyond a trivial scientific curiosity, as it will likely do, directing the garden hose to spray the audience will not be enough to astonish us. The distant future of ${ }_{3} \mathrm{D}$ cinema will see a leap as great as the one from L'Arrivée d'un train en gare de La Ciotat to the train engine sequence in La Bête humaine. The labour of Mr. Spottiswoode and its still-experimental application in the films at the Festival of Britain already prove that $3 \mathrm{D}$ affords the same interpretations, with a function as orchestrated and utterly artistic as 'flat' cinema. Let us nimbly take this new and decisive step toward total cinema. ${ }^{62}$

While 'flat cinema' mechanized and thus 'redeemed' Western painting from emptied formalism, it nevertheless relies on a fixed, one-point perspective (Fig. 31): while in reality both eyes (D and G) perceive from slightly diverging points of view, they see on screen one and the same image, captured with the exact same camera lens. In today's terminology, this is referred to as a zero parallax, meaning that the discrepancy between the two projected images on screen equals zero. ${ }^{6}$ Stereoscopy, then, moves away from this abstract, cyclonic set-up towards a binocular model: the second diagram illustrates a positive parallax, where two slightly diverging images are projected simultaneously, maintaining the median distance between the right and left eye (Fig. 32). This procedure is more or less comparable to our actual perception of depth at a great distance, since the axes of each projection run parallel (the discrepancy on screen equals the distance between the eyes). This type of stereoscopy, however, has the disadvantage that objects at close distance will appear blurred or cause discomfort: 'When I look at the end of my nose, I go cross-eyed and work hard to see clearly. But at the cinema, I dissociate these two physiological actions. ${ }^{64}$ Even though the camera is equipped with two lenses, it is nevertheless forced to remain static, since a rapid succession of planes involving different depth cues would

his argument against the mere industrial demand or scientific invention of film and in favor of myth, which includes the imagination and artistic use of those technologies.

For a comprehensive historiography of stereoscopic cinema, see for example Zone, 2007 and 2012. See also the recently published Ross, Miriam. ${ }_{3}$ D Cinema: Optical Illusion and Tactile Experiences (2015), especially her chapter on 'New Realisms' (pp. 72-94).

62 Bazin, 1952c, EC p. 966; Transl. Andrew, 2014, p. 241.

63 The parallax is the degree of perspectival difference between two diverging points of view, which lies at the basis of our perception of depth. Because of the distance between our left and our right eye; on different parallax classifications used to create stereoscopic vision, see: Stereographics Developers' Handbook. Stereographics Corporation (1997): pp. 9-10 <http://www. cs.unc.edu/Research/stc/FAQs/Stereo/stereo-handbook.pdf>.

64 Bazin, 1952c, EC p. 965; Transl. Andrew, 2014, p. 240. 
tire our brain (which is where the images are put into focus) and enhance such cross-eyed outcome. The true 'revolution in three-dimensionality' that reminds Bazin of the integral realism he had envisioned in 'The Myth of Total Cinema' is the creation of depth in front of the screen: by inverting the axes of projection on screen, a negative parallax creates the point of convergence in between the screen and the spectator (Fig. 33). Owing to specific calculations of British film theorist Raymond Spottiswoode (19131970), this convergence in the projection could be calculated depending on the actual distance between the camera and the filmed objects. Bazin encountered the results of this invention at the Festival of Britain in 1952, where Spottiswoode had commissioned Canadian filmmaker Norman McLaren (1914-1987) to produce 3-D animations based on these principles. ${ }^{65}$ The resulting films, Around Is Around (1952) and Now Is the Time (1952), were, according to Bazin, 'revolutionizing the field of animation with his brilliance and poetic sensibility. [...] abstract painting in motion and in 3-D' [emphasis in original]. ${ }^{6}$

When Bazin envisions a future cinema in three dimensions by comparing Lumière's train to the sequence in The Human Beast (Jean Renoir, 1938), he is not merely imagining this train in 3-D for the sake of making a clever film-historical reference. The train arriving at La Ciotat could have easily been recorded using a positive parallax, because the camera remains static throughout the entire period of shooting. In fact, by 1903 Lumière had already successfully recreated the sequence in stereoscopy; he had patented his ideas on this technology at the turn of the century, and published an essay under the title 'Stereoscopy On the Screen' in 1936, which I will discuss later on in this chapter. ${ }^{67}$ Renoir's famed train sequence, quite the opposite with its rapid succession of shots captured by a camera moving at train speed, would only be possible in three dimensions by means of 'synthetic $3 \mathrm{D}$ ' because of its relative axis of convergence, 'corresponding to the normal angle of vision in the real world'. ${ }^{68}$ Bazin's train examples are telling: of course, he attributes the curiosity element to Lumière and the 'great artistic use' to Renoir's famed train sequence, which in Bazin's days had not yet been filmed in 3-D. One could indeed think that Bazin juxtaposes the static camera of Lumière to Renoir's train, which penetrates space, because the

65 Zone, 2012, p. 401.

66 Bazin, 1952c, EC p. 966; Transl. Andrew, 2014, p. 241.

67 See: Zone, 2007, pp. 141-143; Lumière's essay can be found in Journal of the Society of Motion Picture Engineers, Vol. 27, No. 3 (September 1936): pp. 315-320.

68 Bazin, 1952c, EC p. 964; Transl. Andrew, 2014, p. 236. 

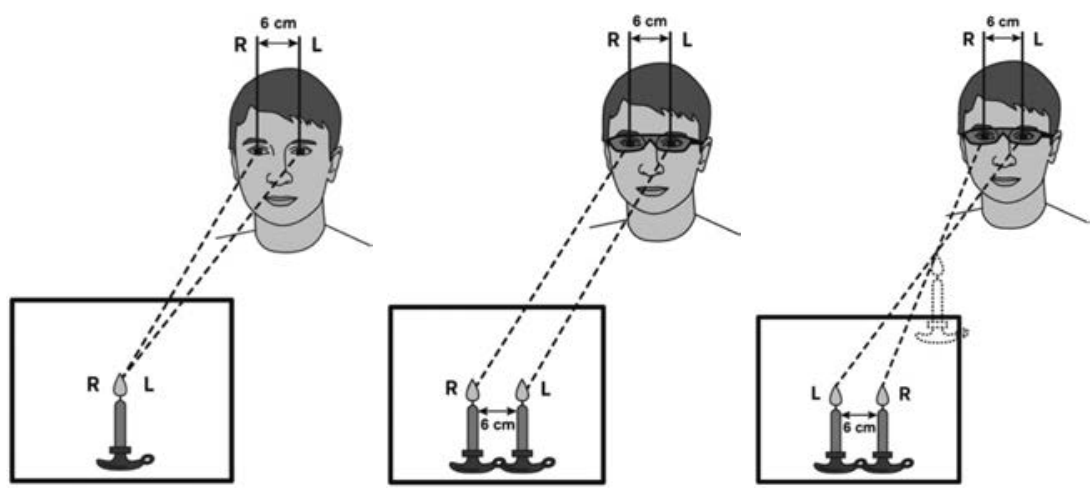

Fig. 30-32 Diagrams on parallax view

moving train could not be shot with a positive parallax. Yet Bazin's claim is bigger here, as these train sequences are the exact examples he uses in his text 'Language of Our Time':

The spectators of the Grand Café understood that a train was rushing towards them, but nothing is more hypothetical than the extrapolation that would consist of thinking that they would have understood the accelerated montage of the locomotive on the loose used 25 years later by Abel Gance in The Wheel [...]. It's precisely that between L'Entrée du train en gare de La Ciotat and the silent cinema of the 1920s, there is already a great depth of language, which is montage. The first was content with showing an advancing train [...] The point of Gance is exactly not anymore to show a locomotive going faster and faster but, by means of the temporal and spatial relations implied by montage, to signify speed. ${ }^{69}$

Of course, he does not evoke Abel Gance's train from 1923 in an argument on 3 -D, but more generally to make the point of a fundamental evolution in film language: Lumière showed an accelerating train, Gance signified it. 'This difference is important', he continues, '[i]t is quite simply at the basis of thought as language: the decisive passage from concrete to abstract. The birth of a semantic and of a syntax'.$^{\circ}$ Will 3 -D ever reach this stage of signification, or is it doomed to remain a special effect? I will come back to this in the concluding section of this chapter, but for now it is important to highlight Bazin's particular semantics, also discussed in the previous 
chapter: beyond semiotics, which typically dissociates signifier (form) and signified (content), cinema can signify in a concrete way.

The juxtaposition of these iconic trains in film history anticipates a series of references that articulate three-dimensionality as the integration of image with reality or form with content. In the introduction to "The "Return" of 3-D' (2013), appropriately subtitled 'Trains of Thought', Thomas Elsaesser engages in the current discourse on three-dimensionality, which he considers not merely as a special effect but rather as 'a different kind of mental image ${ }^{71}$ involving a veritable paradigm change. Like Bazin, he references Lumière and Renoir's trains, both condensed in a sequence from Martin Scorsese's 3-D Hugo (2011), in which the little boy has a nightmare involving the derailment of a train at the Montparnasse station:

[...] for the cinephile, there is an in-joke within the in-joke within the in-joke. The train seen roaring twice into the station is not just any old train from the 1920 . It is the digitally enhanced proleptic train from Jean Renoir's 1938 La Bête humaine, complete with Jean Gabin's begoggled sooty face leaning out of the locomotive; Scorsese's mise en abyme of film history in reverse is giving us this train wreck as an in-joke in 3-D, considered as a temporal anamorph rather than an optical effect. ${ }^{72}$

To add to these ongoing cross-references (again: recreations, or cinephile filiation), the visual effects of the train landing in a heap were in fact entirely inspired by the historical photograph of an actual derailment at the Montparnasse railway station that had occurred about a week before the Lumière brothers' first screening. ${ }^{73}$ From this point of view, Scorsese revisits in this dream sequence the so-oft cited and debunked 'origin myth' of cinema: Lumière's terrified spectator would have been unable to dissociate the moving image of an approaching train from reality. On this topic, Tom Gunning, for example, writes: 'Far from fulfilling a dream of total replication of reality - the apophantis of the myth of total cinema - the experience of the first projections exposes the hollow centre of the cinematic illusion. ${ }^{74}$ However, in an attempt to nuance the story's by now fabled status, Ray Zone

71 Elsaesser, 2013, p. 218.

72 Ibid., p. 217.

73 Legato, Rob. 'Hugo and the Joy of Filmmaking.' CreativeCOW.net [Accessed 21/02/2015] <https://library.creativecow.net/legato_rob/magazine_30_HUGO/1>.

74 Gunning, 2004, p. 91; also see Loiperdinger, 2004, pp. 89-118. 
adds to its mythical origins that it seems highly likely that this train disaster may have been on the minds of Parisian patrons viewing L'Arrivée d'un train at the Grand Café and affected their response to the motion picture image of an approaching locomotive'.$^{75}$ Imagine a box-office release involving collapsing towers in the aftermath of September 11, or a train crashing into Spanish theaters following the Santiago de Compostella derailment in July 2013: such disastrous events show reality to be stranger than fiction, and shocked reactions to their depictions are perhaps less related to a naive mistaking of fiction for reality but may instead arise as a result of collective trauma. The implied convergence between history and fiction in Scorcese's sequence of trains, then, projects new light on the mythical status of Lumière's train. Hence, another 'in-joke' completes this chain of trains in 3-D: Louis Lumière, Jean Renoir, Martin Scorsese and somewhere in between André Bazin, whose notion of stereoscopy as an 'imaginary image' now appears more than ever as 'a really existing hallucination' ${ }^{7}$

Beyond affirming, once again, the importance of recreation in criticism, this short excursion on cinematic trains brings me back to the core of Bazin's views on perspective, condensed in the reference to Cézanne and synthesized in his embrace of synthetic relief. While Lumière's original (2-D) train sequence is arguably already an exercise in 'stereoscopic aesthetics',77 the static camera position reveals its reliance on analytic geometry to create depth. Bazin's elaborate technical explanations suggest, on the contrary, that the more realist perspective of stereoscopy, i.e. the mental convergence of two distinct images into one three-dimensional image, is neither linear nor is it indeed photographic. In a similar vein, Merleau-Ponty, who may have had Lumière's train in mind, puts it this way in his essay on Cézanne:

[...] the lived experience, that which we actually perceive, is not a geometric or photographic one. The objects we see close at hand appear smaller, those far away seem larger than they do in a photograph. (This can be seen in a movie, where a train approaches and gets bigger much faster than a real train would under the same circumstances. $)^{78}$

75 Zone, 2005, p. 147; Zone's anecdote in fact calls to mind Bazin's notion of film as a social documentary, which highlights the hallucinatory nature of reality and vice versa (see 3.1.3 'How Everything Turns Away': Icarus as Anti-War Statement).

76 Bazin, 1945, EC p. 2557; Barnard, 2009, p. 10.

77 For a detailed analysis of depth in L'Arrivée du train, see Loiperdinger, 2004, pp. 102-107.

78 Merleau-Ponty, 1945, p. 14. 
From this viewpoint, objects on the flat cinema screen appear closer than they really are. ${ }^{79}$ Here, again, Bazin seems to follow Merleau-Ponty's description of 'lived perspective' when he praises stereoscopy's perspectival apparatus as 'an eye for an eye'. Moreover, the shift from analytic to synthetic relief proposed by Spottiswoode literally does away with the flat surface of the image, which is now mentally 'imagined' in between the screen and the spectator: '[...] a perfect illusion of the outside world through sound, colour and three-dimensionality. ${ }^{80}$ Surprisingly, the more realist the perspective, the more the image becomes imaginary; the synthetic image is, as Bazin writes, 'an imaginary image' that is mentally put into focus in between the screen and the spectator. In short, the image ceases to exist as such and instead gives way to an enhanced realism. The imagination of cinema had never felt so real!

The reference to the trains in Bazin's citation, then, is a subtle repetition of the objections he had made against the inventors and in favor of an imagination of cinema. Lumière's train, even re-shot in 3-D, does not exceed the level of 'scientific curiosity', whereas Bazin envisions the signification of a train in full speed and in three dimensions: 'a function as orchestrated and utterly artistic, as "flat" cinema, ${ }^{81}$ Bazin's careful dismissal of Lumière's writings on stereoscopy, or indeed his 3-D version of the arrival of the train, runs along the lines of his myth as the imagination rather than the inventions of cinema. In fact, the contextual reference with which Bazin opens 'Math

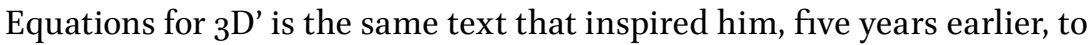
write 'The Myth of Total Cinema': Georges Sadoul's first volume of the General History of Cinema on the invention of cinema. As I will establish, this is not a coincidence: where the first essay is a strong justification of the talking film, the latter aspires to recall this agenda in support of cinema in 3-D - a vital component, alongside sound and color, of integral realism.

\subsection{2. 'Will This Be the Triumph of the Fat?'}

In many ways, the dry and scientific tone of Louis Lumière's essay on stereoscopy illustrates his more general disinterest in the future

79 On the effects of such distortions during the Lumière projection, see Loiperdinger, 2004, pp. 103-104: 'Every object is reduced in size by the square of its actual distance from the camera's lens. Objects filmed close up appear larger; those filmed from afar seem smaller than we are used to from human spatial perception. [...] This cinematic effect makes the approaching and seemingly rapidly growing locomotive on the screen appear to be accelerating while, in reality, the locomotive arriving at the station is slowing down.'

8 o Bazin, 1946/1958, EC p. 2558; Transl. Barnard, 2009, p. 15.

81 Bazin, 1952c, EC p. 966; Transl. Andrew, 2014, p. 241. 
artistic possibilities of the technologies he invented. ${ }^{82}$ His apathy in fact becomes all the more striking when juxtaposed with the ideas on the same topic of a visionary such as Sergei Eisenstein (1898-1948), who in 'On Stereocinema' (1947) goes as far as to applaud three-dimensionality as a new artistic form that enables the elevation of post-war consciousness. He writes:

What of consciousness, struggling tirelessly in these post-war years to forge a concrete model of a genuinely democratic international ideal? Are they not clamouring for artistic expression of wholly new, never-before-seen forms and dimensions, far beyond the limits of the palliatives proffered by traditional theater, traditional sculpture, and traditional ... cinema? To be sure, the new, dynamic stereosculpture will toss traditional, static sculpture - with its yardstick, still wielded by the likes of Chavance - beyond the limits of dimensions and unique qualities.

We must not fear the advent of a new era in art. ${ }^{83}$

A brief digression into this former discourse via Eisenstein's essay shows that he takes on a similar critical agenda as Bazin did back in 1946. Both critics are offended by an elitist dismissal of a novel technology brought to the screen; and Eisenstein, traditionally more of a formalist than a realist, holds views on 3-D that are remarkably similar to Bazin's. He begins his elaborate study of stereoscopic cinema with an apology that derides the opposition:

These days you run into a whole lot of people asking: 'Do you believe in stereocinema?' To my mind this question sounds about as absurd as if they were to say: do you believe that it will be night-time at midnight, that one day the snow in the streets of Moscow will melt away, that there will be green trees in the summer and apples in the fall? That today will give way - to tomorrow! To doubt that tomorrow belongs to stereocinema is just as naïve as it is to doubt the very coming of tomorrow! [...] How is it, indeed, that we are able to make such bold predictions? The answer is that no species of art is truly capable of survival unless it bears in its essential character some aspect of our deepest yearnings and aspirations. ${ }^{84}$

82 In an interview with Georges Sadoul in 1948, Lumière would have stated clearly that his interest in stereoscopy was purely scientific (Zone, 2007, p. 143).

83 Eisenstein, 1947, p. 56.

84 Ibid., p. 20. 
One of those people in disbelief about 3-D was Louis Chavance (1907-1979), French screenwriter and critic at Revue du cinéma, who Eisenstein accuses of 'wilful obscurantism' ${ }^{85}$ when he dismissively wrote: 'is this technological discovery able in some way to heighten the dramatic tension of a scene? Does an actor, represented in three dimensions, find there some additional expressive means? A physical plumpness? ... Will this be the triumph of the fat? ${ }^{86}$ In reaction to such opinions, Eisenstein interestingly resorts to 'deep-seated human needs, ${ }^{87}$ with three-dimensionality being 'the most thorough and immediate expressions of such aspirations. ${ }^{88}$ Again much like Bazin, Eisenstein argues that this third dimension meets such inherent human needs by integrating image and reality (Eisenstein calls this binary set 'Fiction and Reality'), when he writes:

Here these two 'partners' are understood as the embodiment of two fundamentally distinct realms, divided by the rampe; the realms of Fiction and Reality. ${ }^{89}$

And:

Not only had cinema - that ultimate stage in the developmental history of the theatrical art - realized successfully the tendency to reunite spectator and performer, it was also able to merge the realm of Fiction with that of Reality, transformed by an artistic will..$^{9}$

The parallels between Eisenstein's praise of 3-D and Bazin's notion of integral realism appear to bring out the formalist side of Bazin's realism; conversely, Eisenstein's 'social interpretation of reality' ${ }^{\text {'91 }}$ shows the realist element in his ardent formalism, i.e. fiction as it relates to reality. Three-dimensionality adds volume, quite literally more image on screen, and at the same time brings about an increase in realism: it lessens the gap between film and reality. Whereas

85 Ibid., p. 55 .

86 Louis Chavance (1946), cited in ibid., p. 55 .

87 Ibid., p. 26.

88 Ibid., p. 21.

89 Ibid., p. 47; Eisenstein's mention of the rampe, which are the footlights that illuminate the actors on stage and thus separate them from the audience, draws parallels between stereoscopy and the theater. Having been actively involved with the theater before his career as a film director, it should come as no surprise that a major part of the essay on 3-D seeks the precursors of this novel technology in the theater.

90 Ibid., p. 49.

91 Ibid., p. 26. 
three-dimensionality was dismissed by some critics as mere 'physical plumpness' with no expressive means, both Eisenstein and Bazin thus considered it a potentially revolutionizing technique. In short, from a realist-formalist perspective, 3-D in and of itself, either as an imaginary image or as Fiction and Reality combined, embodies the synthesis of form and content.

\subsection{Bazin Put to the Test: Godard and Wenders}

To refuse or not to refuse depth: in today's film criticism, this still appears to be a concern. For example, a contemporary critic of 3-D writes, confidently: 'I cannot imagine a serious drama, such as Up In the Air or The Hurt Locker, in 3-D.92 But is rashly rejecting this technique based on its previous abundant use in spectacular cinema not precisely like discarding continuous soundtracks, color or indeed movement on screen? From a more realist perspective, the imaginary image of 3 -D does precisely that: integrating image and reality, turning every image into an object and every object into an image. Yet, there exists a convinced and ardent opposition to 3-D in today's critical discourse, which Thomas Elsaesser groups under the unheard voices of the 'Cassandras of 3-D':

[...] despite such high-calibre interest and endorsement, another prestigious and reputable consensus holds that the wave has already peaked, that the revival is sputtering, and that the operation has never been a success, either economically or aesthetically. 93

Admittedly, from an economic point of view, the film industry is today again facing a real threat, not from television, as it did in the 1950 s when 3 -D first peaked, but from the internet: 3 -D is 'reaching out of the screen [...] and robbing your wallet'. ${ }^{4}$ From the perspective of myth, however, such reasoning shows itself to be a speculative fallacy that is fundamentally distinct from aesthetics and risks gagging cinema for a third time in history: first the talking film, then Besson's aphasic images as the highpoint of a crisis of scenarios, today the financial suicide attempt of an art form. Contemporary

92 Ebert, Roger. 'Why I Hate 3D.' Newsweek (05/10/2010) < http://www.newsweek.com/ roger-ebert-why-i-hate-3d-movies-70247>.

93 Elsaesser, 2013, p. 218.

94 Kirsten Thompson, cited in Elsaesser, 2013, p. 219; see pp. 219-220 for a concise overview of recurring arguments against $3-D$. 
critiques of 3-D cinema - whether they emphasize its lack of content, portray it as unfit for regular storytelling or consider it as an industrial gimmick - can in fact be understood as a repetition of this former discourse. Yet, with recent films like Jean-Luc Godard's Adieu au langage (2014) and Wim Wenders' Every Thing Will Be Fine (2015), Bazin's twofold wish for an artistic and consorted use of three-dimensionality becomes more tangible. Concluding this chapter on 3-D, I argue that each of these filmmakers, adding to an already extensive and established oeuvre, affirms either through drama or as a film essay that 3 -D now belongs to the language of film.

\subsubsection{Goodbye to Language}

Si la perspective fût le péché originel de la peinture occidentale, la technique était son fossoyeur. La conquête de l'espace fit perdre la mémoire à tous. [Ifperspective was the original sin of Western painting, technology was its gravedigger. The conquest of space made us all lose memory.]

[emphasis in original] Jean-Luc Godard, Les Trois Désastres, 2013

In his first 3-D film-essay Les Trois Désastres (2013), Godard recites the phrase on perspective from Bazin's 'Ontology' essay - 'La perspective fût le péché originel de la peinture' 95 - with yellow streetlights superimposed over an image of the Madonna against a dark-blue background. Godard is known for quoting Bazin,${ }^{96}$ and this specific sequence offers itself as a condensed moment in a succinct scheme for a new cosmology of cinema, in three dimensions. From a contemporary point of view, Godard revisits Bazin's critique of illusionist perspective, applied to 3-D cinema: 'You see, Sergei, you have felt that there is no space in the Kremlin and not in San Francisco either, isn't that true Orson Welles?' The fear of emptied formalism, of meaninglessness and memory loss, clearly runs through Godard's inaugural manifesto for $3-\mathrm{D}$; or is it its requiem? His rather cynical allusion to Titanic 3- $D$ (James Cameron, 1997) - 'and then, depth; depth! Declares the professor of the Titanic' - appears to suggest an overall sarcastic tone

95 Bazin, 1945, EC p. 2556.

96 'I think that one should cite Bazin in every article on cinema' (Jean-Luc Godard, cited in Joubert-Laurencin, 2014, p. 14); See also the citation in the opening scene of Le Mépris (1963), in which Godard claims Bazin would have said that 'cinema substitutes for our gaze a world according to our desires'. While it definitely has some bazinian undertones, this statement was in fact uttered in 1959 by Michel Mourlet, film critic at Cahiers du cinéma (see: Joubert-Laurencin, 2014, pp. 37-39). 
vis-à-vis 3-D technology, which is confirmed by a superficial reading of the film's title: the three disasters, the 3 D's. Taken literally, les trois désastres indeed appears to be a foreboding for his subsequent 3-D film, Adieu au langage (2014): from three disasters follows an excess of imagery that disables communication and meaning. In Adieu au langage, Godard criticizes the empty, meaningless images that flood our contemporary screens under the 'dictatorship of the digital'. The nostalgia to which he still holds on in Les Trois Désastres is replaced by rather grim Instagram aesthetics: iPhones and Google, so he suggests, have replaced our books and our knowledge. Again, superficially, the title gives a negative impression when it comes to the expressive means of $3-\mathrm{D}$, a goodbye to language for lovers stuck in miscommunication: 'Make sure that you can hear me', she repeatedly says, to which he answers: 'make sure that I can speak'.

Read differently, Adieu au langage [Goodbye to Language] transforms via intertitles into 'Ah Dieu, oh langage [Ah God, oh language]'. And indeed, more than a farewell, the film is an affirmation of the possibilities to reinvent the language of cinema: as the cinematographer Fabrice Aragno puts it, 'we weren't interested in using 3 -D as an effect. The film had to be about using 3-D to express new things. ${ }^{97}$ Godard includes, among many innovations, nudes descending a staircase in $3-\mathrm{D}$, and he constantly plays with layering, double exposures and superimposition. Changing the parallax degrees, for example, causes the two layers that combined produce the 3-D effect to suddenly split, forcing each eye to follow a different image cross-eyed. Godard's most recent investment in 3-D, then, not only 'breaks the rules of $3-\mathrm{D}^{\prime 98}$ but creates new ones altogether. Aragno explains that in order to achieve this, he:

built a rig to separate the images, which happens at several points in Goodbye to Language, and I first did a test with two friends. I had them stand together in a shot, and then I asked the boy to walk away, over to the kitchen. I followed him with the right camera, while the left camera stayed on the girl. You suddenly have two images, with the girl on the left, and the boy on the right, and your brain begins to mix the two. Then I had the boy walk back to the girl, and the 3-D image returns. It hurts a bit when you watch it. ${ }^{99}$

97 Fabrice Aragno in Dallas, Paul. '1+1=3.' Film Comment (November/December 2014) <http:// www.filmcomment.com/article/fabrice-aragno-interview $>$.

98 See: Frazer, Bryant. 'Five Ways Jean-Luc Godard Breaks the ${ }_{3} \mathrm{D}$ Rules in Farewell to Language.' StudioDaily (03/10/2014) < http://www.studiodaily.com/2014/10/ five-ways-jean-luc-godard-breaks-the-3d-rules-in-farewell-to-language/>.

99 Aragno, cited in Dallas, 2014, n. pag. 
The result of this experiment was called shot of the year by the critics when the film was released, as it pushes the limits of cinematographic language: 'It's montage taken to its logical extreme: in-eye editing. This isn't simply a great shot - it's a new kind of shot altogether.' ${ }^{100}$ David Bordwell, admitting he was wrong when he had previously dismissed the potential of $3-\mathrm{D}$, sees in it the 'temptation to close one eye, then the other, in creating your own shot/reverse-shot editing'. ${ }^{101}$

Already in his first 3-D essay, Godard returns to language, more precisely to poetry, when he has an excerpt from Charles Baudelaire's The Voyage (1861) whispered over a superimposition of a ferry on the shimmering surface of the ocean and a piano play, altogether creating some sort of double 3-D:

\section{Nous avons vu des astres}

Et des flots, nous avons vu des sables aussi;

Et, malgré bien des chocs et d'imprévus désastres,

Nous nous sommes souvent ennuyés, comme ici.

La gloire du soleil sur la mer violette,

La gloire des cités dans le soleil couchant,

Allumaient dans nos cours une ardeur inquiète

De plonger dans un ciel au reflet alléchant.

[We've seen the stars

And waves, and we have seen the sandy shores;

Despite disasters, all our jolts and jars,

On sea, on land we find that we are bored.

The glorious sun across the violet sea,

Great sunlit cities dreaming as they lie,

Made our heart yearn with fierce intensity

To plunge towards those reflections in the sky. $]^{102}$

The title now becomes 'the three stars', like those in Van Gogh's Starry Night, which Bazin in a liberal poetic turn described as 'three suns', alluding to the sunflowers as motifs of a new cosmology of film discussed extensively in the previous chapter. Not much later, a woman will fall from the sky, impaled

100 Marsh, Calum. 'The Shot of the Year.' The Dissolve (19/12/2014)<https://thedissolve.com/ features/2014-in-review/866-the-shot-of-the-year/s.

101 Bordwell, David. 'Adieu au langage: 2+2x3 D.' Observations on Film Art (07/09/2014)<http:// www.davidbordwell.net/blog/2014/og/o7/adieu-au-langage-2-2-x-3d/>.

102 Baudelaire, 1861, pp. 308-309; Transl. McGowan, 1993, p. 513. 
by the mast of a sailboat; or is it, as the subsequent shot suggests, the crane of a camera? The fall of Icarus has gone terribly wrong: boredom, despite unforeseen disasters. 'Those who lack imagination', the voice-over in Adieu au language narrates, 'seek refuge in reality'. Nevertheless, to dive into the sky, to fly with your arms, affirms imagination as the transformative force of poetry. Baudelaire writes, 'Nous voulons voyager sans vapeur et sans voile! [We want to travel without wind or sails!],' to which Valéry adds: 'Le vent se lève! [The wind rises!]'

\subsection{2. $\quad 3-D$ as Realist Grammar}

Still, my deepest desire, or biggest hope, is that this future 3 -D cinema will in fact ignite a new interest in the act of seeing. In the physiology and psychology Of what our eyes and our brains do together, in unison, In the most amazing perfection, To create space, depth, volume and presence. [emphasis in original] Wim Wenders, 2013a

With his recent return to fiction in Every Thing Will Be Fine (2015), followed by The Beautiful Days of Aranjuez (2016) and Submergence (2017), Wim Wenders confirms that his initial interest in 3-D for Pina (2011), a dance documentary about the German choreographer Pina Bausch, and for his subsequent documentary on architecture, Cathedrals of Culture (2014), was not short-lived. In fact, after years of experimenting with this new technology, Wenders is now one of the most outspoken defenders of 3-D, which he sees, against the big Hollywood studios, as capable of a 'realist grammar':

Human reality. Our planet. Our existence. Our concerns. But: I am convinced that this is what 3-D was invented for and what it can do. [...] It should/it will/it must become the very language of future-reality based movies, documentaries as well as fictional films. It is absurd that the contemporary notion of a 'fictional film' means, for more and more people today, that it is not related to any reality. That is a cultural disaster; a tsunami wiping out our imagination. Stories are rooted in myth, and myth is distilled from human experience, from life. [...] 3-D belongs in the hands of documentary filmmakers, of independent writers, directors, authors, of people willing and able to forget limits, rules, formulas, recipes, 
and enter a whole new age of cinema, where there is more... connexion.

Existential connection. $3^{-D}$ has that connecting power... ${ }^{103}$

Wenders makes a clear statement about putting 3-D technology back into the hands of filmmakers who can reclaim this technology as part of the language of film: to make films speak again. His choice to use 3-D for Pina relied, in the fashion of Eisenstein, on concepts that are typically associated with the theater: an emphasis on a newfound presence and interpersonal closeness. It enables what Wenders calls a connexion, all the while without resorting to what Bazin calls the 'hyperbole' of overacting, a direct consequence of the gap between audience and stage: 'The stage thus incites [the actors], even obliges them, to indulge in hyperbole. Only in film could Charlie achieve his perfect mathematics of situation and gesture, to convey the greatest degree of clarity in the least amount of time. ${ }^{104}$ It is therefore no coincidence that, for Wenders, 'the most exciting experience was the simplest one: close-ups'. ${ }^{105}$ The intimate close-ups of Bausch's dancers are not only the most simple, least spectacular cinema experience but also the least theatrical and therefore perhaps the most specific to 3 -D. In this manner, they somehow already stand in opposition to the common assumption that 3-D only cares for spectacle, which dance to a certain extent still is. In 2013, then, Wenders writes that 'the 3 -D I am dreaming of will be pleasant to the eyes, it will not hit you over the head, it will never feel like a roller-coaster ride. It must feel natural and unpretentious. Sincere! The opposite to gimmicky'. ${ }^{106}$

With Every Thing Will Be Fine, Wenders takes on these principles of 3-D as a realist grammar as he returns to fiction after a series of documentary films. The opening scene shows Tomas in his writer's shed, sharing artistic struggles with the local fishermen on a frozen lake in Québec: he writes two pages a day, which is actually not bad at all. When he has his girlfriend on the phone, it becomes clear they have conflicting expectations and that their relationship is tilting: she wants a child, he simply wants to be able to write. 'You're a good writer, Tomas', she assures him, but her kind words are quickly dismissed as empty and meaningless. In the car on his way home, he returns her call with an apology: 'everything will be different from now on'. And it will be: the road is icy and when two children on a sled cross his path, fate hits inevitably as Tomas accidentally kills Christopher's little

103 Ibid., pp. 172-173.

104 Bazin, 1951c, EC p. 710; Transl. Barnard, 2009, p. 164.

105 Wenders, 2013a, p. 169.

106 Wenders, 2013b, p. 223. 
brother Nicolas. From this very moment, nothing will ever be the same, for Tomas, Christopher or his mother Kate. Tomas' guilt is at first unbearable, but it soon becomes clear that the traumatic event is making him a better writer - perhaps even a better person? When Christopher, who appears to have developed an obsession with the writer, recognizes a scene in his latest best-selling novel as based on their first encounter the evening of the accident, one cannot but wonder: how far can a writer, or a filmmaker, go in fictionalizing someone's lived suffering? 'An author writes partly based on reality and imagination', Tomas reassures him; and indeed, his somewhat naive smile directed to the audience in the final shot of the film, unconventional in its simplicity, conveys consolation and confidence that the two can go together.

Throughout the film, Wenders shuns spectacle. ${ }^{107}$ The sequence when Tomas realizes there were in fact two children on the sled (and that therefore, he must have hit the second) expresses the terror of the moment in a way that no crash or obvious blood could have done. Kate's grief when she sits at the kitchen table feels very real, and the frequent overlays, either superimposing two images or working with mirroring surfaces, convey a most concrete closeness between characters on screen and with the audience. Shooting and editing 3 -D, Wenders explains, entirely changes the filmmaking experience as well as the effect of the images on the audience:

3-D has a built-in capacity to involve you in a different way than 'flat cinema' does. It even involves different areas of your brain! So, one can certainly tell a story differently. In 3-D, I come up with different shots, I edit differently, I look at my actors differently. We are involved differently, myself as well as my audience, so don't you think an intimate drama could also come out differently?108

In fact, the most remarkable effect of 3-D in Every Thing Will Be Fine is, precisely, that it immediately feels normal and goes almost unnoticed:

107 Ironically, though, it is precisely for this reason that several critics have labelled Wenders' latest film as 'tone-deaf and structurally haphazard' (Lodge, Guy. 'Every Thing Will Be Fine.' Variety $(10 / 02 / 2015)<$ http://variety.com/2015/film/reviews/berlin-film-review-every-thing-will-befine-1201429546/>), or ironically labelled 'a fine film!' (Pattinson, Michael. 'Wim Wenders' Every Thing Will Be Fine is a Major Disappointment.' Indiewire (10/02/2015) <http://www.indiewire.com/article/ berlin-review-wim-wenders-every-thing-will-be-fine-is-a-major-disappointment-20150210 $>$ ). 108 Wim Wenders, cited in Roxborough, Scott. 'Wim Wenders on How 3 D Is Drowning "In a Lack of Imagination" (Q\&A).' The Hollywood Reporter (02/05/2014) <http://www.hollywoodreporter. com/news/berlin-wim-wenders-how-3d-677303>. 
natural, yet profoundly moving and intimate. Wenders' choice for 3 -D was a straightforward and deliberate one: to find pictures in reality, and to find reality in pictures. For example, one scene in particular is based on the American painter Andrew Wyeth's Wind from the Sea (1947), in which a laced curtain with embroidered little birds flows lightly into an attic window:

I found some of Wyeth's pictures, so to speak, in Kate's house, and it was wonderful that the curtains in the film were moved by real wind, and not by a ventilator, with the yellow soy field in the background and this beautiful tree right in the middle. With that small intimate scene in the kitchen, you could feel that 3 -D was dead right for the film and see how it literally 'places' you in the emotional space of these people. ${ }^{109}$

Wenders often frames his shots through windows, and their resistance to complete transparency best conveys the real splendour of 3 -D. The waving curtains in Kate's kitchen window are truly awe-some, and together with many shots that include a surface - reflecting windows mostly (or water surfaces in Godard) - these are precisely the moments when 3-D feels necessary.

Like Godard's active engagement with the linguistic potential of 3-D, Every Thing Will Be Fine reclaims so-called platitudes: the title, Wenders explains, conveys 'something of a fairy tale which we took for something very real." ${ }^{110}$ Etymologically derived from the French plat, meaning flat, these sentences regain their depth and meaning, literally in three-dimensionality. From this perspective, the mourning and healing process all the characters go through parallels the enigmatic space in the film's title between 'every' and 'thing':

It's my hope that our 3-D CinemaScope images won't become part of this never-ending and arbitrary avalanche, that they are self-contained, and will achieve what my favourite film philosopher of the 20s, Béla Balázs, said: 'Cinema is capable of securing the existence of things.' (This is the main reason why our title also has 'everything' written in two words: Every Thing, every single thing must be set right for Tomas, Christopher and Kate.) Despite this flood of digital photos and film, I still think we

109 Wenders, Wim. 'Every Thing Will Be Fine: An Interview with Director Wim Wenders.' The Upcoming (10/02/2015)<http://www.theupcoming.co.uk/2015/02/10/ every-thing-will-be-fine-an-interview-with-director-wim-wenders/>.

110 Wenders, Wim. 'Every Thing Will Be Fine | Press Conference Highlights | Berlinale 2015.' YouTube $(10 / 02 / 2015)<$ https://www.youtube.com/watch?v=6yI7Coegzy8\#t=45>. 
can make use of composed images and precise storytelling to achieve exactly this: illustrate and preserve the existence of things and people. Images don't have to be constantly surging waves, they can also be the firm rocks in that sea. ${ }^{11}$

If 3 -D were to be used only as a tool for spectacle disconnected from reality, Wenders argues, 'this fantastic language is about to drown in a lack of imagination'. ${ }^{112}$ Rather than taking part in a wave of meaningless images, 3 -D holds the real capacity to put meaning back into platitudes - in Bazinian terms, to 'save being by appearance'. ${ }^{113}$ While everything turns away, every thing will be fine. Having reclaimed this technique as realist grammar, cinema exists as the integration of imagination and reality.

As it is the case in Wenders and Godard, eloquence (or the lack thereof) accompanies Bazin's approach to the evolution of film. Indeed, he often oscillates between the affirmation of speech on the one hand and an acceptance of failures in direct communication on the other hand. From the perspective of speech impediments, I have elaborated on both harmony and disruption in the form-expression equation, throughout and beyond Bazin: e.g. Charles Baudelaire's aphasia as well as Bazin's own stutter, Charlie's gibberish and the Great Dictator speech, Serge Daney's critique to an amnesiac cinema of forms without body, and the 3-D poetry of Jean-Luc Godard as well as Wim Wenders' realist grammar. Bazin's understanding of form and content thus presents a radically new approach to the evolution of film language, which runs alongside his equally original conception of integral realism.

\subsection{VR: Complete Film, or Total Cinema?}

From color, to sound and 3-D: writing in the forties and fifties, Bazin knew all these techniques, and to defend their artistic potential, he resorts to the critical and theoretical pitfalls of generations before him. Let us recall Bazin's defence of sound cinema, facing critical rejection because of its low realism: 'Intellectuals don't like to be interrupted. When the screen started to talk, they kept quiet.'114 From this perspective, Bazin is anything but nostalgic when he writes:

111 Wenders, cited in The Upcoming, 2013.

112 Wenders in Roxborough, 2014, n. pag.

113 Bazin, 1945, EC p. 2555.

114 Bazin, 1943b, EC p. 76. 
Along with the influence from established art forms comes the impact of [cinema's] technical evolution [...] Within a few months the birth of sound came to annul its aesthetic victories. Today colour, tomorrow relief and television will come to jeopardise the fruits of 20 years of sound cinema. ${ }^{115}$

Virtual Reality, which was then not yet invented, in fact follows Bazin's lineage: when approached from the perspective of total cinema, its emergence today appears not as a break but potentially in line with the evolution and emancipation of film as an art form. 3-D already altered traditional film language; yet VR is here to radically overthrow canonical concepts in film practice and theory. Whenever it is addressed in contemporary film scholarship, VR is often met with considerable suspicion: as an immersive medium, it would be unfit for linear storytelling, and the viewing experience is asocial - in any case, the opposite of what one would expect in ciné-clubs or cinématheques. Furthermore, VR is associated with reprehensive practices, like gambling, pornography and addictive gaming, ${ }^{116}$ discrediting its use in a variety of pedagogical and therapeutic experiments (the so-called 'empathy device'), as well as its cinematographic potential. Once again, a side of the critical discourse seems to take on René Barjavel's sarcastic punch: 'Cut off his tongue!'117

And indeed, Virtual Reality is here to change film language at its core: what is montage, a shot-reverse-shot or a close-up in VR? What is on- and off-screen, when the screen is all-around? These major concerns for contemporary media development resonate with Bazin's realist perspective: to move from 'showing' to 'signifying' in VR demands an entirely new semantic. Is Bazin in 1953, for example, thinking of Virtual Reality, when he writes:

Should we then imagine a truly expandable screen that would bring us back around to the use of the iris to concentrate on a single point of the scene $[. .$.$] ? There are so many hypotheses, the choice among which is worth$ leaving to the impending history of cinema. It won't be much longer. ${ }^{118}$

While Bazin saw color, sound and $3-\mathrm{D}$ as unavoidable steps towards increased realism in film, others before him deemed the invention of color too popular, reminiscent of tabloid magazines. From this perspective, film scholar Rudolf

115 Bazin, 1949a, EC p. $5^{18 .}$

116 See Dixon, Wheeler Winston. 'Slaves of Vision: The Virtual Reality World of Oculus Rift.'

Quarterly Review of Film and Video, Vol.33, No.6 (2016): pp. 501-510.

117 Barjavel, 1944, p. 22.

118 Bazin, 1953a, EC p. 1164; Transl. Andrew, 2014, p. 247. 
Arnheim rejects realism in his 1933 book Film as Art, citing a rather pedantic critic by the name of $\mathrm{H}$. Baer:

Uncivilized man is not as a rule satisfied with black-and-white. Children, peasants and primitive peoples demand the highest degree of bright colouring. It is the primitives of the great cities who congregate before the film screen. Therefore, film calls in the aid of bright colours. It is a fresh stimulus. ${ }^{119}$

For similar reasons, extensively discussed in the first chapter of this book, sound, too, introduced a so-called degraded realism. Yet as the title of Arnheim's book illustrates, the stringency of his theories goes hand in hand with the defence of film as a worthy art form. Touching upon the expansion of cinema screens in the fifties, Arnheim again argues for film art by deliberately dismissing realism:

The temptation to increase the size of the screen goes with the desire for coloured, stereoscopic, and sound film. It is the wish of people who do not know that artistic effect is bound up with the limitations of the medium and who want quantity rather than quality. They want to keep on getting nearer to nature and do not realize that they thereby make it increasingly difficult for film to be art. ${ }^{120}$

Arnheim rejects precisely that which Bazin groups under 'total cinema': the 'complete film', in Arnheim's terminology, is 'the mechanical imitation of nature to an extreme.' ${ }^{121}$ Yet, even the most uppish critic today will not dare to doubt the added value of color and sound: think of Alfred Hitchcock, who emphasizes the psychological developments of his characters in Vertigo with color - or Chaplin, literally stumbling over his words in Modern Times (which, then again, hits the core of his comedy). No matter how heartfelt his comments were, the reality is that to this day the history of film has evolved towards an ever-shrinking gap between image and reality - precisely this gap from which today Virtual Reality is emerging.

Unlike Arnheim's complete film, Bazin's total cinema embraces the fact that film techniques continue to extend beyond the borders of the screen.

119 H. Baer cited in Arnheim (1933) 'The Complete Film', 1957, p. 159.

120 Arnheim (1933) 'The Making of a Film', 1957, p. 75.

121 Arnheim (1933) 'The Complete Film', 1957, p. 154; similarly, Joubert-Laurencin sees Bazin's realism as a reversal of Arnheim's tradition (2014, p. 47) as does Tom Gunning, 2011, pp. 122-123. 
Tom Gunning, for example, understands total cinema as the 'phenomenological image of the world as bounded by a horizon, and it is in the nature of a horizon to be expanded. ${ }^{122}$ Gunning here refers to a metaphysical frame of reference, yet the expansion in this case is cinematographic as well, as Bazin indirectly frames these 'truly expandable screens', reminiscent of VR, on a continuum with the development of sound aesthetics:

The evolution of cinema since sound, overall and in particular during the past decade, leans to a negation of montage and of plastic aesthetics, at least the sort of pictorial plastics based on the existence and proportions of the frame. [...] Montage itself relies indirectly on the dimensions of the screen, to the extent to which the close-up is conceivable only in a tight frame. ${ }^{123}$

From this citation follows that, given the dependence of montage on the frame, this practice slowly but surely will lose its dominance in film language. The acoustics of off-screen sound already move beyond the edges of the screen; CinemaScope and other panoramic screens incite the spectators to move their heads and choose their own focus point; and depth perception in 3-D, which breaks the surface of the screen more than the frame, is only possible when the spectator makes a mental superimposition of the left and the right image. Yet this 'truly expandable screen' goes further than CinemaScope or 3-D and reminds us of Virtual Reality where, paradoxically enough, the smallest screen is the most immersive.

While editing remains crucial in contemporary film language, Bazin sees with the increase in screen size of the fifties the necessity to at least put its position as the principal signifier in perspective: "[the interest in widescreen] has come along to definitely destroy montage as the key element in cinematic discourse'. ${ }^{124}$ Virtual Reality, too, rejects the 'existence and proportions of the frame', and so editing as we know it becomes problematic. This way, Alejandro G. Iñárritu reasons that 'VR is all that cinema is not, and vice versa; the frame is gone and the two-dimensional limits are dissolved'. ${ }^{25}$ Explaining the difficulties with composing the script for Carney Arena (2017), a 6-minute walk-around VR installation, ${ }^{126}$ Iñárritu links the disappearance of the frame to his own loss of control as a director:

\footnotetext{
122 Gunning, 2011, p. 125.

123 Bazin, 1953a, EC p. 1164; Transl. Andrew, 2014, p. 246.

124 Bazin, 1954a, EC p. 1313; Transl. Andrew, 2014, p. 292.

125 Iñárritu cited in Pomeroy, 2017.

126 Being a walk-around installation, Carne y Arena necessitates virtual imagery (e.g. the use of motion capture technology and CGI), which are in this case strikingly mixed with natural
} 
Film in a way is a bi-dimensional tiny reality that I create in $20 \%$ of your brain that you passively observe. But this is basically the end of the dictatorship of this frame: you go into, you take the space, you own the space. And I do not control: I created $20 \%$, here I create 360 degree of your universe, but you are free to do whatever you want - which is terrifying [...]. Here [in the $20 \%$ frame] it's very easy; honestly to make films is very primitive: I show you that, and you have to imagine the other reality that I don't show you. So, if two guys are in a restaurant talking, you have to imagine the waiters behind. You make your mind here [in your head] but I don't have to show it to you - I just put some sound and that's it. Here, if you turn, I have to put the waiter there. ${ }^{127}$

Essentially, VR exposes an ongoing power play between spectator and director for the simple reason that a frame makes it easier to direct the spectator's gaze: with 'normal' cinema, no one will look for a waiter in the back of a theater. Yet, if the director wants me to find him in VR, he may in fact use techniques that will most likely make me turn my head. In Carne y Arena, for example, 'off-screen' sound is used to navigate this extreme centrifugal screen: after a more-or-less uniform soundscape of immigrants talking sporadically as they continue their journey, the deafening sound of a helicopter hovering over the Mexican desert demands everyone's attention, and its blinding searchlight then enables an otherwise not-so-subtle cut to a different shot. This is what Jessica Brillhart, in-house VR filmmaker at Google, calls 'probabilistic experiential editing': 'understanding a visitor's likely interaction with the world around them'. ${ }^{128}$ Rather than completely giving up control, VR-makers need to guide spectators with cues towards so-called 'points of interest' in the scene; shot transitions work best when they abide by 'match on attention'; and pre-production decoupage is complemented with post-production 'stitching'. ${ }^{129}$ In other words, it appears as though VR recreates the most basic spectacle, everyday perception: as in

elements, like the coldness of the detention center waiting room, the desert sand on your bare feet or wind blowing in your face.

127 Iñárritu, 2018

128 Brillhart, 2016; Brillhart frames her lecture around four crucial aspects concerning VR:

'1. Wait, what happened to my frame?

2. Editing doesn't work. Oh wait, it does? I'm confused.

3. THE CAMERAS ARE MADE OUT OF PEOPLE?!

4. What about storytelling?'

From there on, she discusses her own approach to VR editing, narrative structure and identification.

129 See: Brillhart, 2015-2016. 
reality, on an infinite screen each detail or object may potentially become meaningful, provided that we pay attention to it.

This grammar of VR is destined to develop itself by wavering on the ever-shrinking gap between image and reality: a balancing act which, in any case, will not follow the logic and dimensions of the frame, i.e. editing, but necessarily seek more realist semantics. Dudley Andrew describes these semantics as initiating 'one powerful line of French theory which treats film as an art which "discovers" significance rather than "constructs" meaning,, ${ }^{130}$ and he identifies Bazin as the initiator of this 'Cahiers du cinéma line of thought, applied to questions of editing'. ${ }^{131}$ Bazin's notorious stance against editing, then, is tied to his views on the evolution of film language, which offers spectators an aesthetic to discover. 'They are no longer tethered like Plato's slaves,' Andrew writes, 'staring straight ahead "On Screen, in Frame". ${ }^{132}$ In the article to which Andrew refers here, 'On Screen, in Frame: Film and Ideology' (1976), Stephen Heath attacks the 'cinematic practice in favour of a transparent presentation of "reality" (cinema - "the art of the real"),', ${ }^{133}$ specifically targeting Bazin's centrifugal screen. ${ }^{134}$ Instead, emphasizing his semiotic position, Heath writes: 'the stake of the frame is clear [...]: the frame is the reconstitution of the scene of the signifier, of the symbolic, into that of the signified.'135 Keeping in mind that editing depends on the proportions of the frame, Bazin's centrifugal screen (which rejects the frame) inevitable leads to a different semantic process. In his own words, by rejecting the frame, wide-screen cinema 'approaches its deep vocation, which is to show even before expressing, or more precisely, to express by evidence of the real, which is to say once again: not by signifying but by revealing'. ${ }^{136}$

Discovery rather than construction, then, not only typifies post-war film aesthetics but returns today in a seemingly contradictory form. The point, however, is not to prove that Bazin knew this all along, or even that the future masterpieces will be made in VR. Instead, my purpose was to show, with Bazin, that what cinema is has been characterized by trial and error, starting with the supposedly detrimental effect of sound film on silent film theory, followed by the debate over 3-D film and now VR. If construction implies a pre-conceived plan or essence that gradually takes form, discovery

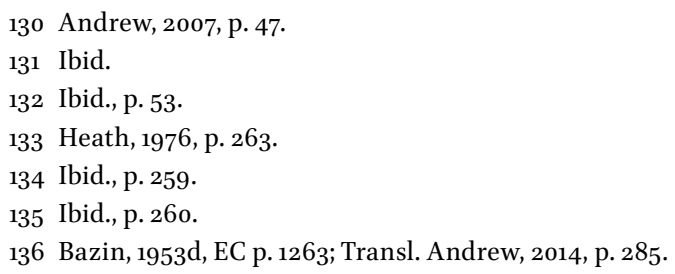




\section{leaves the development of film theory open for possibilities not previously part of the plan: not yet invented.}

\section{Bibliography}

Almendros, Nestor (1990). Días de una cámara. Madrid: Seix Barral.

Andrew, Dudley (1995). Mists of Regret: Culture and Sensibility in Classic French Film. Princeton: Princeton University Press.

--- (2007). 'A Film Aesthetic to Discover.' Cinémas:Journal of Film Studies, Vol. 17, No. 2-3: pp. 47-71.

--- (2011). 'Malraux, Bazin, and the Gesture of Picasso.' In: Opening Bazin: Postwar Film Theory and Its Aftermath. Eds. Dudley Andrew and Hervé Joubert-Laurencin. New York: Oxford University Press, pp. 153-166.

--- (2013). André Bazin. New York: Oxford University Press.

Archimedes. 'On Floating Bodies. Book I.' The Works of Archimedes. Ed. T.L. Heath. Cambridge: Cambridge University Press (1897): pp. 253-262.

Arnheim, Rudolf (1957). Film as Art. Berkeley: University of California Press.

Austin, Guy (1996). Contemporary French Cinema: An Introduction. Manchester: Manchester University Press.

Austin, L.J. (1953). 'La Genèse du “Cimetière marin”.' Cahiers de l'association internationale des études françaises, No. 3-5: pp. 253-269.

Barjavel, René. Cinéma total: essai sur les formes futurs du cinéma. Paris: Éditions Denoël (1944)

Barthes, Roland (1957). 'Operation Margarine.' Mythologies. Transl. Annette Lavers. New York: Hill \& Wang (1972): pp. 41-42.

Baudelaire, Charles (1861). 'Le Voyage.' Les Fleurs du mal. Paris: Poulet-Malassis et De Broise, pp. 305-313.

Bazin, André (1943b). 'Pour une esthétique réaliste.' L'Information universitaire, No. 1168 (6 November). EC I, 5 .

--- (1945). 'Ontologie de l'image photographique.' Qu'est-ce que le cinéma? Paris: Éditions du Cerf (2008): pp. 9-18. EC OP, 1.

--- (1946/1958). 'Le Mythe du cinéma total.' Qu'est-ce que le cinéma? Paris: Éditions du Cerf (2008): pp. 19-24. EC OP I, 2.

--- (1949a). 'Misère, servitude et grandeur de la critique de films.' Revue internationale du cinéma, No. 2 (April). EC VII, 572.

--- (1950-1955). 'L'Évolution du langage cinématographique.' Qu'est-ce que le cinéma? Paris: Éditions du Cerf (2008): pp. 63-8o. EC OP, 17.

--- (1950b). 'La "technique" et le "sujet" ne jouent pas au cinéma le même rôle que dans les autres arts: la forme et le fond.' Radio cinéma télévision, No. 45 (28 November). EC VIII, 771.

--- (1951c). 'Théâtre et cinéma.' Qu'est-ce que le cinéma? Paris: Éditions du Cerf(2008): pp. 129-178. EC IX, $797 \& 817$.

--- (1951e). 'De la forme et du fond ou la “crise” du cinéma.' Almanach du théâtre et du cinéma. EC VIII, 774 .

--- (1952c). 'Un nouveau stade du cinéma en relief: le relief en équations.' Radio cinéma télévision, No. 131 (20 July). EC X, 1087.

--- (1953a). 'La guerre de trois dimensions, aura-t-elle lieu?' L'Observateur No. 153 (2 April). EC XIII, 1305 .

--- (1953c). 'CinemaScope e neo-realismo.' Filmcritica, No. 28 (September). EC XIV, 1407. 
---(1953d). 'Le CinémaScope sauvera-t-il le cinéma?' Ésprit, No. 207-208 (10 November-December). EC XIV, 1430.

--- (1953e). 'Le langage de notre temps.' In: Regards neufs sur le cinéma. Eds. Jacques Chevallier and Max Egly. Paris: Éditions du Seuil (1963): pp. 5-17. EC XII, 1202.

--- (1954a). 'Le Cinémascope. Fin du montage.' Cahiers du cinéma, No. 31 (January). EC XIV, 1497.

--- (1956a). 'Le petit journal du cinema: Un préjugé qui me coûtait cher.' Cahiers du cinema, No. 62 (August). EC XIX, 2111.

--- (1956b). 'Le Monde du silence: Icare sous-marin.' Radio cinéma télévision, No. 319 (26 February). EC XIX, 1993.

--- (1956c). 'Le Monde du silence.' France observateur, No. 303 (1 March). EC XIX, 1997.

--- (1957b). 'De la politique des auteurs.' Cahiers du cinéma, No. 70 (April). EC XXI, 2275.

--- and Jean-Pierre Chartier (1942). 'Peut-on s'intéresser au cinéma?' Maison des lettres (December). EC I, 1.

--- and Georges Sadoul (1945-1949). 'Convergences et divergences sur la profondeur de champ et le sujet.' 1895: Revue d'histoire du cinéma, No. 67 (Summer 2012): pp. 126-143.

Chartier, Roger (2003). Dictionnaire encyclopédique du Livre. Tome I. Paris: Cercle de la Librairie.

Daney, Serge (1991). 'The Demise of Critical Thinking.' Transl. Stoffel Debuysere. Diagonal Thoughts. [Accessed 30/10/2017] <http://www.diagonalthoughts.com/? $\mathrm{p}=15^{21}>$.

--- (1993). L'exercice a été profitable, Monsieur. Eds. Jean-Claude Biette and Emmanuel Crimail. Paris: P.O.L.

Darke, Chris (1993). 'Rupture, continuity and diversification: Cahiers du cinéma in the 1980s.' Screen, Vol. 34, No. 4 (December): pp. 362-379.

Dixon, Wheeler Winston (2016). 'Slaves of Vision: The Virtual Reality World of Oculus Rift.' Quarterly Review of Film and Video, Vol. 33, No. 6: pp. 501-510.

Eisenstein, Sergei (1947). 'On Stereocinema.' In: ${ }_{3} D$ Cinema and Beyond. Eds. Dan Adler, Janine Marchessault and Sanja Obradovic. Toronto: Public 47 (2013): pp. 20-59.

Elsaesser, Thomas (2013). "The "Return" of 3-D: On Some of the Logics and Genealogies of the Image in the Twenty-First Century.' Critical Inquiry, Vol. 39 (Winter): pp. 217-246.

Gunning, Tom (2004). 'An Aesthetic of Astonishment: Early Film and the (In)credulous Spectator.' In: Film Theory: Critical Concepts in Media and Culture Studies. Volume 3. Eds. Philip Simpson, Andrew Utterson and K.J. Shepherdson. New York: Routledge, pp. 78-95.

--- (2011). 'The World In Its Own Image: The Myth of Total Cinema.' In: Opening Bazin: Postwar Film Theory and Its Aftermath. Eds. Dudley Andrew and Hervé Joubert-Laurencin. New York: Oxford University Press, pp. 119-126.

Harries, Karsten (2002). Infinity and Perspective. Cambridge: The MIT Press.

Heath, Stephen (1976). 'On Screen, In Frame: Film and Ideology.' Quarterly Review of Film Studies, Vol. 1, No. 3: pp. 251-265.

Joubert-Laurencin, Hervé (2014). Le Sommeil paradoxal: écrits sur André Bazin. Montreuil: Les Éditions de l'œil.

Loiperdinger, Martin (2004). 'Lumière's Arrival of the Train: Cinema's Founding Myth.' The Moving Image, Vol. 4, No. 1 (Spring): pp. 89-118.

Lumière, Louis (1936). 'Stereoscopy On the Screen.' Journal of the Society of Motion Picture Engineers, Vol. 27, No. 3 (September): pp. 315-320.

Merleau-Ponty, Maurice (1945). 'Cézanne's Doubt.' In: Sense and Non-Sense. Illinois: Northwestern University Press (1964): pp. 9-25.

Perec, Georges (1978). Les Choses communes:Je me souviens. Paris: Hachette.

Ross, Miriam (2015). ${ }_{3}$ D Cinema: Optical Illusion and Tactile Experiences. New York: Palgrave Macmillan. 
Sadoul, Georges (1948). 'La Métaphysique de la profondeur de champ.' 1895: Revue d'histoire du cinéma, No. 67 (Summer 2012): pp. 132-137.

Truffaut, François (1983). 'André Bazin nous manque.' Le Plaisir des yeux. Paris: Flammarion (2014): pp. 54-63.

Valéry, Paul (1920). 'Le Cimetière marin.' Charmes. Paris: Gallimard (1952): pp. 222-241.

Wagner, Jon (1988). 'Lost Aura: Benjamin, Bazin and the Realist Paradox.' Spectator, Vol. 1 (Fall): pp. 57-69.

Wenders, Wim and Mary Zournazi (2013a). Inventing Peace: A Dialogue on Perception. London: I.B. Tauris.

Wenders, Wim (2013b). 'A Film for Pina: Keynote of the Toronto International Stereoscopic $3 \mathrm{D}$ Conference.' In: ${ }_{3}$ D Cinema and Beyond. Eds. Dan Adler, Janine Marchessault and Sanja Obradovic. Toronto: Public 47, pp. 214-233.

Zone, Ray (2005). 'A Note on “Cinema's Founding Myth”.' The Moving Image, Vol. 5, No. 2 (Fall): pp. 146-147.

--- (2007). Stereoscopic Cinema and the Origins of 3-D Film, 1838-1952. Lexington: The University of Kentucky Press.

--- (2012).3-D Revolution: The History of Modern Stereoscopic Cinema. Lexington: The University of Kentucky Press.

\section{Other sources}

'Tout le mal que "Le Grand Bleu” a fait à l'apnee.' 20 minutes, 02/o6/2016. [Accessed 30/10/2017] <http://www.2ominutes.fr/marseille/1857651-2016o6o2-tout-mal-grand-bleu-fait-apnee>.

Bordwell, David (2019). 'Adieu au langage: $2+2 x_{3}$ D.' Observations on Film Art (7 September). [Accessed 25/04/2019] <http://www.davidbordwell.net/blog/2014/o9/o7/ adieu-au-langage-2-2-x-3d/>.

Brillhart, Jessica (2015-2016). 'The Language of VR.' Medium.com. [Accessed 25/04/2019] <https:// medium.com/the-language-of-vr>.

--- (2016). 'VR \& Cinema - Google I/O 2016.' Google Developers (19 May). [Accessed 25/04/2019] <https://www.technologyreview.com/lists/innovators-under-35/2017/pioneer/ jessica-brillhart/>.

Dallas, Paul (2014). '1+1=3.' Filmcomment (November/December). [Accessed 25/04/2019] <http:// www.filmcomment.com/article/fabrice-aragno-interview $>$.

Ebert, Roger (2010). 'Why I Hate 3D.' Newsweek (5 October). [Accessed 25/04/2019] < http://www. newsweek.com/roger-ebert-why-i-hate-3d-movies-70247>.

Frazer, Bryant (2014). 'Five Ways Jean-Luc Godard Breaks the 3D Rules in Farewell to Language.' StudioDaily (3 October). [Accessed 25/04/2019] <http://www.studiodaily.com/2014/10/ five-ways-jean-luc-godard-breaks-the-3d-rules-in-farewell-to-language/>.

Iñárritu, Alejandro G. \& Jenna Pirog (2018). 'Carne y Arena: Art and Technology.' The Philips Collection. 4June. [Accessed 25/04/2019] <https://www.youtube.com/watch?v=-XcvJ6lUTwI $>$.

Legato, Rob. 'Hugo and the Joy of Filmmaking.' CreativeCOW.net [Accessed 21/02/2015] < https:// library.creativecow.net/legato_rob/magazine_3o_HUGO/1>.

Lodge, Guy (2015). 'Every Thing Will Be Fine.' Variety (10 February). [Accessed 25/04/2019] <http:// variety.com/2015/film/reviews/berlin-film-review-every-thing-will-be-fine-1201429546/>.

Marsh, Calum (2014). 'The Shot of the Year.' The Dissolve (19 December). [Accessed 25/04/2019] <https://thedissolve.com/features/2014-in-review/866-the-shot-of-the-year/>. 
Pagliano, Jean-Pierre (1988). 'Profils perdus: André Bazin.' France culture (2o October). [Accessed 25/04/2019] <https://podcloud.fr/podcast/les-nuits-de-france-culture/episode/profils-perdusandre-bazin-2eme-partie-1ere-diffusion-27-slash-10-slash-1988 > [Radio program].

Pattinson, Michael (2015). 'Wim Wenders' Every Thing Will Be Fine is a Major Disappointment.' Indiewire (10 February). [Accessed 25/04/2019] <http://www.indiewire.com/article/ berlin-review-wim-wenders-every-thing-will-be-fine-is-a-major-disappointment-20150210>.

Pomeroy, Robin (2017). 'Iñárritu Puts a Boarder Guard's Gun to Your Head in VR Film at Cannes.' Reuters, (22 May). [Accessed 25/04/2019] <https://www.reuters.com/article/ us-filmfestival-cannes-inarritu-idUSKBN18I2C $>$.

Roxborough, Scott (2014). 'Wim Wenders on How 3 D Is Drowning "In a Lack of Imagination" (Q\&A).' The Hollywood Reporter (2 May). [Accessed 25/04/2019] <http://www.hollywoodreporter.com/news/berlin-wim-wenders-how-3d-677303>.

Stereographics Developers' Handbook (1997). Stereographics Corporation. [Accessed 25/04/2019] <http://www.cs.unc.edu/Research/stc/FAQs/Stereo/stereo-handbook.pdf>.

Wenders, Wim (2015). 'Every Thing Will Be Fine | Press Conference Highlights | Berlinale 2015.' YouTube (10 February). [Accessed 25/04/2019] <https://www.youtube.com/ watch? $\mathrm{v}=6 \mathrm{yI} 7 \mathrm{Coegzy} 8 \# \mathrm{t}=45>$.

--- (2015). 'Every Thing Will Be Fine: An Interview with Director Wim Wenders.' The Upcoming (10 February). [Accessed 25/04/2019] <http://www.theupcoming.co.uk/2015/02/10/ every-thing-will-be-fine-an-interview-with-director-wim-wenders/>.

\section{Used translations}

Daney, Serge (1991). 'The Demise of Critical Thinking.' Transl. Stoffel Debuysere. Diagonal Thoughts. [Accessed 30/10/2017] <http://www.diagonalthoughts.com/?p=1521>.

Baudelaire, Charles (1993). 'The Voyage.' In: The Flowers of Evil. Transl. James McGowan. Oxford: Oxford University Press.

Bazin, André. 'On the Politique des auteurs.' Transl. Peter Graham. In: Cahiers du cinéma: The 1950s Neo-Realism, Hollywood, New Wave. Vol. ı. Ed. Jim Hillier. Oxon: Routledge (2005): pp. 248-259.

---. What Is Cinema? Transl. Timothy Barnard. Montreal: Caboose (2009).

---. Bazin On Global Cinema, 1948-1959. Transl. Bert Cardullo. Texas: University of Texas Press (2014).

---. André Bazin's New Media. Transl. Dudley Andrew. Berkeley: University of California Press (2014).

\section{Filmography}

L'Entrée d'un train en gare à La Ciotat (Auguste \& Louis Lumière, 1896)

L'Entrée d'un train en gare à La Ciotat $3 D$ (Louis Lumière, 1903)

The Wheel (Abel Gance, 1923)

The Human Beast [La Bête humaine] (Jean Renoir, 1938)

Around Is Around (Norman McLaren, 1952)

Now Is the Time (Norman McLaren, 1952)

The Graduate (Mike Nichols, 1967) 
The Swimmer (Frank Perry, 1968)

Deep End (Jerry Skolimowski, 1970)

The Big Blue [Le Grand Bleu] (Luc Besson, 1988)

Red Wood Pigeon [Palombella rossa] (Nanni Moretti, 1988)

Titanic ${ }_{3} D$ (James Cameron, 1996)

Swimming Pool (François Ozon, 2003)

Welcome (Philippe Lioret, 2009)

Hugo (Martin Scorsese, 2011)

Pina (Wim Wenders, 2011)

Les Trois Désastres (Jean-Luc Godard, 2013)

The Wind Rises (Hayao Miyazaki, 2013)

Adieu au langage (Jean-Luc Godard, 2014)

Cathedrals of Culture (Wim Wenders, 2014)

Every Thing Will Be Fine (Wim Wenders, 2015)

The Beautiful Days of Aranjuez (Wim Wenders, 2016)

Submergence (Wim Wenders, 2017)

Carne y Arena (Alejandro G. Iñárritu, 2017)

\section{Illustrations}

Figure 29. Astra margarine advertisement, 'Astra rend tout meilleur: recette du beefsteak au poivre' (1952)

Figure 30-32. Diagram on parallax degrees from 'Math Equations for $3^{D}$ ' (A. Bazin, 1952), included in Dudley Andrew's André Bazin's New Media (2014): pp. 237-240 



\title{
Epilogue: Unknown Arts, New Media
}

\begin{abstract}
The epilogue is a concluding, short exploration of the myth of Icarus in relation to the evolution of the arts. It puts the emphasis on the role of imagination (rather than technology) in the evolution of media. I furthermore reflect on Bazin's realism as a hypothesis: a working method rather than a theory.
\end{abstract}

Keywords: Icarus, new media, myth of total cinema

Mankind, it is said, holds on to its dreams. Flying is one of them (from Icarus to Valentin the birdman). To register real movement, in less real time, is another. A couple of years before [the $20^{\text {th }}$ ] century, airplanes and cameras started making noise at the same time.

Serge Daney, $1983 \mathrm{~b}$

Bazin is most commonly associated with realism, and rightly so, as it undoubtedly accounts for his received position as the French post-war film critic. But it is also as a realist that he has often been considered a critic of the past. Dismissed as a stumbling block, an empty signifier or naïve ideal, his realism (ontological realism in particular) would be unable to account for the many mutations that have undeniably altered cinema from the kind Bazin knew into what it is today. Throughout this book, however, I have maintained that Bazin's repeated mention of myth along with realism (integral realism) justifies continued reinvention motivated by imagination. His usage of myth and integral realism is indeed original and ground-breaking, and its successful application in his critical work furthermore demands a contemporary reconsideration precisely because cinema has changed so much. New technologies and new media do not destroy cinema's essence (as Arnheim would have it), nor do they determine its evolution. 'If the cinema ever disappears,' 
Bazin writes, 'it will be due to a lack of imagination.' Preparing the first collected volume of his work in 1958, Bazin adds to this already extensive 'Myth' essay the comparison between the invention of film and one particular myth: the myth of Icarus. Can the story of Icarus, today, tell us something about this incessantly evolving and somehow inherently unknown art form?

\section{Icarus Is the Inventor of Film}

Imagine flying with your arms, effortlessly, like swimming but in the sky. To soar through the air, as birds do, is an age-old theme in countless dreams, stories and myths that persist in our minds today. The myth of Icarus, for instance, tells the story of a young boy on exile with his father Daedalus. Imprisoned on an island surrounded by water, Daedalus realizes their only way out is upwards: through the sky. Being a craftsman and an engineer, he sets to work and builds two pairs of wings out of feathers and wax. The Roman poet Ovid, whose treatment of the Icarus myth remains to this day the most referenced, described the father's ingenuity as follows:

And turning his mind

Toward unknown arts, he transformed nature. ${ }^{2}$

Everything goes well as Icarus and his father fly like gods over sea and land, where a fisherman, a ploughman and a shepherd stand amazed at this miracle unfolding in the sky. But against his father's advice, Icarus flies too close to the sun, which melts the wax, and, unable to keep his course, the little boy falls into the ocean. Having lost his son to 'ruinous arts', ${ }^{3}$ Daedalus will remain forever embittered about his ingenious invention, by which he joined the laws of nature with his own imagination and thereby enabled human flight. By copying nature, to use Ovid's formulation: 'imitating a real bird's wing', ${ }^{4}$ a dream transformed into reality.

Towards the end of his life, Bazin references the story of Icarus alongside the technological development of cinema. In his seminal essay, 'The Myth of Total Cinema', he writes:

2 Ovid (8 AD), 2010, p. 396.

3 Ibid., p. 398.

4 Ibid., p. 397 . 
The guiding myth of the invention of cinema is thus that it will accomplish the dominant myth of every nineteenth-century technology for reproducing reality, from photography to the phonograph: an integral realism, the recreation of the world in its own image - an image upon which the irreversibility of time and the artist's interpretation do not weigh. [...] The ancient myth of Icarus had to await the internal combustion engine before descending from Plato's higher world, but this myth had been present in every human being since we began to observe the birds. ${ }^{5}$

In this remarkable passage, Bazin first understands the origins of cinema from the perspective of a directing myth, integral realism, which he readily aligns with the Icarus myth: these technologies of mechanical reproduction are not determined solely by their invention (the internal combustion engine) but gradually accomplish a more venerable desire (human flight). Daedalus could have created the wings only by copying real birds: the feathers and wax are an invention created in imagination. This is what Ovid termed the 'unknown arts' and to which Bazin alludes when he describes the myth of total cinema as an age-old desire for recreation: to copy nature aided by technological developments and by doing so, ultimately, to transform reality.

For centuries, the combined effort of invention and imagination into 'unknown arts' underlined the aspirations of many artists and poets alike: each speaking from their own time, they reinterpreted and recreated the ancient Icarus myth well into the twentieth century. An era marked by rapid technological developments and inventions (airplanes, finally!), it also gave rise to a new art: the seventh art - cinema. Over the course of a mere 150 years, this art has been pronounced dead and born again with each technological addition that inevitably reinvented it: color, sound, new formats and a third dimension gradually joined the moving image (analogue or digital). With his myth of total cinema, Bazin instead develops an approach to the history of cinema as a continued effort towards recreating the world in its image: 'total cinema', he calls it, a dream come true. Incidentally, right before Bazin's rewritten 'Myth' essay, the French philosopher and anthropologist Edgar Morin evoked the same dream of human flight in the opening chapter of The Cinema, or the Imaginary Man (1956), subtitled 'The Airplane, the Cinema':

As the nineteenth century dies, it bequeaths us two new machines. Both of them are born on almost the same date, at almost the same place, then 
simultaneously launch themselves upon the world and spread across continents. They pass from the hands of the pioneers into those of operators, crossing a 'supersonic barrier'. The first machine realizes at last the most insane dream man has pursued since he looked at the sky: to break away from the earth. Until then, only the creatures of his imagination, of his desire - the angels - had wings. This need to fly, which arises, well before Icarus, at the same time as the first mythologies, seems to all appearances the most infantile and mad. It is also said about dreamers that they do not have their feet on the ground. Clement Adler's feet, for an instant, escaped the ground, and the dream finally came to life. ${ }^{6}$

Morin in fact cites a passage from Bazin's original essay in this very chapter, and pushes the affirmation of imagination even further: 'But is not the inventor himself possessed by his imagination before he is hailed as a great scientist? Is a science nothing but a science? Is it not always, as its inventive source, daughter of a dream? [...] The technical and the dream are linked at birth. ${ }^{7}$ Total cinema in Bazin's oeuvre functions in a similar way: always attentive to the unknown, yet-to-be-invented film, his curiosity extends from his written and oral criticism in the ciné-clubs to tentative ideas of what cinema could one day become.

\section{Bazin's Hypothesis}

In many ways, Bazin's film criticism is invested in defending the evolution of cinema from the perspective of unknown arts: it motivates his detailed and innumerable film analyses, amounting to several thousands of essays, as well as his extensive studies on the critical notion of realism in film. In this sense, total cinema functions in Bazin's oeuvre as a hypothesis, a working method more than a theory. In Gunning's words, total cinema is 'bounded by a horizon, and it is in the nature of a horizon to be expanded. ${ }^{8}$ Rather than gradually working out a preconceived essence linked to technology, or even hailing some kind of future cinema, the role of myth in Bazin's film criticism is an attempt to reconcile artistic imagination with the history

6 Morin, 1956, p. 5 .

7 Ibid., p. 9. Bazin's influence is clearly tangible here, and he in fact considered this book to be 'the most important title in French post-war bibliographies' (Bazin, 1956e, EC p. 2018). He furthermore argues that Morin lays bare the mythical appeal of cinema: 'With cinema, civilization returns to the most archaic and perhaps the most universal myth.' (Ibid.)

8 Gunning, 2011, p. 125. 
of technology. 'The function of criticism,' Bazin argued in response to the overly scientific tone of academic film scholarship in his days, 'is not to bear on a silver platter a truth that may not exist. ${ }^{9}$ From his side, Morin (a scholar) affirms that:

[...] the enigma is not in the facts, but in the uncertainty of a current that zigzags between play and research, spectacle and laboratory, the decomposition and reproduction of movement, in the Gordian knot of science and dream, illusion and reality where the new invention is taking shape. ${ }^{10}$

Art and science, imagination and invention go hand in hand. What Bazin's film criticism can show contemporary film studies is that cinema remains not yet invented because imagination (in art as well as in science) by definition reaches beyond what is known.

As much as it is in the nature of a horizon to expand, finally, a hypothesis needs to be tested. Serge Daney has done this ad absurdum, pushing total cinema to the point of its own falsification: 'for Bazin, the horizon of cinema's history is cinema's disappearance. Until then, this history is indistinguishable from that of a small difference that is the object of a constant negation." Similarly, I have tried throughout this book to test Bazin's work from a contemporary perspective, which brought me from Charlie's sound cinema, the cinema of Bruegel, Baudelaire, Valéry and even Van Gogh, to Eisenstein on 3-D and Bazin on VR. If Bazin's 'theory' has been deemed ahistorical and outdated, I hope that my emphasis on realism from the perspective of myth pays off: integral realism, as a hypothesis, cannot be but contemporary.

\section{Bibliography}

Ovid (8 AD). Metamorphoses. Transl. Stanley Lombardo. Cambridge: Hackett Publishing Company (2010).

Bazin, André (1946/1958). 'Le Mythe du cinéma total.' Qu'est-ce que le cinéma? Paris: Éditions du Cerf (2008): pp. 19-24. EC OP I, 2.

--- (1956e). 'L'Homme imaginaire et la function magique du cinema.' France observateur, No. 331 (13 September). EC XX, 2123.

--- (1958b). 'Réflexions sur la critique.' Cinéma: revue de la fédération des ciné clubs, No. $3^{2}$ (December). EC XXIV, 2681.

9 Bazin, 1958b, EC p. 2519; Transl. Cardullo, 2014, p. 59.

10 Morin, 1956, p. 11.

11 Daney, 1972, p. 34. 
Daney, Serge (1972). 'The Screen of Fantasy (Bazin and Animals).' Transl. Mark A. Cohen. In: Rites of Realism: Essays on Corporeal Cinema. Ed. Ivone Margulies. Durham: Duke University Press (2002): pp. 32-41.

Gunning, Tom (2011). 'The World In Its Own Image: The Myth of Total Cinema.' In: Opening Bazin: Postwar Film Theory and Its Aftermath. Eds. Dudley Andrew and Hervé Joubert-Laurencin. New York: Oxford University Press, pp. 119-126.

Morin, Edgar (1956). The Cinema, or The Imaginary Man. Transl. Lorraine Mortimer. Minneapolis: University of Minnesota Press (2003).

\section{Used translations}

Bazin, André. What Is Cinema? Transl. Timothy Barnard. Montreal: Caboose (2009).

---. André Bazin's New Media. Transl. Dudley Andrew. Berkeley: University of California Press (2014).

---. Bazin On Global Cinema, 1948-1959. Transl. Bert Cardullo. Texas: University of Texas Press (2014). 


\section{About the Author}

Blandine Joret is a lecturer in Media and Culture at the University of Amsterdam. In 2015, she defended her PhD thesis on the film criticism of André Bazin. Her current research looks at the intersection of realism, immersion and media literacy, with a specific emphasis on 3-D and Virtual Reality. 



\section{Index}

Advertising $10,135,138-140,146$

Alberti, Leon Battista 150

Almendros, Nestor 138

Altman, Georges $\quad 18,29$

Archimedes 143

Argento, Dario

The Stendhal Syndrome (1996) 114-116

Aristoteles 146-147,149

Arnheim, Rudolf $170-171,181$

Antonioni, Michelangelo

Blow-Up (1966) 89,104

Artaud, Antonin 90,116-122

Art documentary 92, 94, 105, 111-113, 116

Auden, W.H. 101-104, 107

Auteur theory $14-15,38-43,137,139$

Ayfre, Amédée 91

Badiou, Alain 74

Balázs, Béla $\quad 168$

Barjavel, René $\quad 24-25,27,170$

Barthes, Roland 21, 98,139

Bataille, Georges $\quad$ 90, 116-117, 121-122

Baudelaire, Charles $\quad 42-43,126,164-165,169$, 185

Bazin, Janine (Chartier) $\quad 42,127$

Benjamin, Walter $\quad 58,63$

Bergman, Ingmar

The Seventh Seal (1957) 80

Bergson, Henri $\quad 36,59,63-65,67-68,91,74,111$

Besson, Luc 161

Atlantis (1991) 145

cinéma du look 146

The Big Blue (1988) 136, 145-149

Borsoutsky, Myriam \& Pierre Braunberger Bullfight (1951) 76-77

Breton, André 103-104, 106

Bruegel the Elder, Pieter $\quad 89,99-106,113,115$, 119,185

Cahiers du cinéma $\quad$ 10-11, 14, 41, 127, 162, 174

Centrifugal screen $\quad 66,101,107-110,112-113,123$, $125,151,174$

Cézanne, Paul 151, 157

Chaplin, Charles $17-18,25-29,35-36,42,166$, 169

Modern Times (1936) 26-27, 171

The Great Dictator (1940) 26-27, 169

Chavance, Louis $\quad 159-160$

Christianity/Catholicism $\quad 81-82,91$

Cinema and other arts $29,84,91-93,95,97$, 99,136

literature 90, 94-95, 97

painting $13,90,92-95,99,106,108-109$, $111-114,118,122,124,126,168$ poetry $73,89,97-98,102,104,118,138-139$, $141-142,165$

theater $90,94,123,160,166$

cinephilia $10,19,31,33,98,145,156$

versus cinephobia $19,21,38$

Clair, René 24, 36

Clancier, Emmanuel $\quad$ 91-92

Clouzot, Henri-Georges

The Mystery of Picasso (1956) 111-113

Cocteau, Jean 109-110

The Blood of a Poet (1930) 109-110, 123

Cohen Seat, Gilbert $\quad 31,34,36$

Cousteau, Jacques-Yves \& Louis Malle The Silent World (1956) ５1, 99, 140-143, 147

Daney, Serge $\quad 9,10,13,41,54,59-64,67,72,75$, $83,98,136,145^{-149}, 169,181,185$

Degas, Edgar 95-96, 99

Delacroix, Eugène 126

Deligny, Fernand $\quad 10,117-118,126-128$

Descartes, René 35

De Sica, Vittorio

Umberto D (1952) 67-72

Dreyer, Carl Theodor 35

Duhem, Pierre 101

Dulac, Germaine 24

Edison, Thomas $\quad 96$

Editing 14, 53-54, 60, 62, 65, 67, 75-77, 155, 164, $170,172-173$

Kuleshov-effect $\quad 77$

neo-montage 77

Eisenstein, Sergei $\quad 76,159-162,166,185$

El Greco $\quad 126$

Epstein, Jean $\quad 24,58,61,63,66,68,83$ photogénie $62-64,70$

Euripides 36

Evolution of film $\quad 11,18,28,30,94,136-137,161$, $169,181-184$

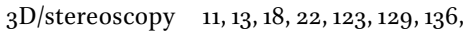
$142,149,15^{1-154}, 156-163,165-169,174,185$

CGI and digital cinema $10,18,48,51-53$, $68,83,113,163,168$

impure cinema $13,29,90-91$

sound cinema $11,18,23-28,30,34,36,37$, $136,169-170$

Virtual Reality $\quad 13,130,136,169-174,185$

Existentialism 29- 31, 34, 36, 48, 6o, 62, 79, $80-81,83-84,90-91,166$

Film criticism $\quad 11,18-19,23,34-35,37,41$, $138-139,145,161,185$ and film historiography $\quad 20-21,23,36$, 142-143 
ciné-club movement $\quad 11,35-37,40-41,137$, 184

Film language $\quad 37,90,96,126,128,144,155$, $162,164,168-170$

language of objects $\quad 127-129$

realist grammar 165,169

realist semantics $127,129,155$

Filmology 9, 28, 32-37, 40

Kirsch, Florent 33

Flaherty, Robert

Man of Aran (1934) $\quad$ 54-55

Flammarion, Camille 121

Formalism $\quad 98,130,135,138,141,144-145,151$, 162

realist formalism $136,160-161$

Form and content $\quad 111,129,135,140-143,147$, $150,161,169$

Fresnadillo, Juan Carlos Intacto (2001) $\quad 78-80$

Gance, Abel $\quad 24,155$

The Wheel (1923) 155

Gaugin, Paul 117-119

Giraudoux, Jean 39

Godard, Jean-Luc $\quad$ 162,168-169

Adieu au langage (Godard, 2014) 162-163

Les Trois Désastres (Godard, 2013) 162-163

Griffith, David Wark 35

Haesaerts, Paul \& Henri Storck

Rubens (1948) 94

Hawks, Howard 38

Heidegger, Martin 109

Hemingway, Ernest $\quad 76-78$

Heyerdahl, Thor

Kon-Tiki (1950) 48-52, 55, 149

Hitchcock, Alfred

Vertigo (1958) 171

Huston, John 38

Huygens, Christiaan 108

Iñárritu, Alejandro 173

Carne y Arena (2017) 172-173

Intertextuality / recreation (method) 98, $125^{-12} 6,128,142-143,145,156$

Isherwood, Christopher 103

Kal, Jan $\quad 89,104$

Kierkegaard, Søren $\quad 62-63$

Leenhardt, Roger $\quad 13,61,67,72,83$

ellipsis $\quad 62-65,67,70$

Léger, Guy 90

Lessing, Gotthold 71

L'Herbier, Marcel 24

Lioret, Philippe

Welcome (2009) 149

Lumière, Louis $36,96,15^{0}, 15^{2-155,157-159}$

L'Arrivée d'un train en gare de La Ciotat (1896) $153^{-1} 5^{8}$
Lynch, David

Blue Velvet (1986) 120-123, 125

Mallarmé, Stéphane $\quad 73-74,140-142$

Malraux, André $\quad 94-95,126-127$

Marcel, Gabriel $\quad 30,83-84,90-93,95$

Marey, Etienne-Jules 97

Marker, Chris $10,118,127$

Marxism 22, 82

Mauriac, Claude $\quad 59,83,91$

McLaren, Norman 154

Medium specificity / essentialism 29, 31, $58-60,62,64,66,70,74-75,83,90-91$

Méliès, Georges 36

Merleau-Ponty, Maurice $\quad 151-152,157-158$

Minnelli, Vicente Lust for Life (1956) 43, 117, 119-122, 124

Miyazaki, Hayao The Wind Rises (2013) 97, 100

Molière $\quad 36$

Moretti, Nanni Red Wood Pigeon (1988) 148-149

Morin, Edgar $183^{-185}$

Murnau, Friedrich Wilhelm 35

Myth $12-13,21,28,47,60,95-96,101,106,117$, $143,147,15^{2}, 158,166,181-183,185$

and reality $117-119,125$

of Chaplin 25, 27-29

of Icarus $89,90,96-100,102-106,113,119$, $147,165,182-184$

of Narcissus 110, 147

of total cinema $12,20-27,36,41,90,101$, $129,136,15^{2-153}, 156,171,183^{-184}$

origin myth of cinema 156

"The Myth of Total Cinema" $(1946 / 1958) \quad 12,21,28,47,96,143,154$, $15^{8}, 182-183$

Newton, Isaac $\quad 61,66-69,74,107,142-143$

Nichols, Mike The Graduate (1967) 148

Ontology $47-48,50,59,62,66,69,73,90,93$, 99-101, 107, 109, 111, 116, 122, 124, 140, 142, 146, $149-151,162$

"The Ontology of the Photographic Image" (1945) 12, 48, 49-50, 89-90, 95, 101, 142, 150,162

Ovid 100, 182-183

Ozon, François

Swimming Pool (2003) 148

Pascal, Blaise $\quad 66,73,81-83,150$

Pavlov, Ivan 33

Pazienza, Claudio Tableau avec chutes (1997) 89, 104-105

Pedagogy 9, 35, 118, 126, 128, 137

Perec, Georges $\quad$ 139-140

Perry, Frank The Swimmer (1968) $\quad 148$ 


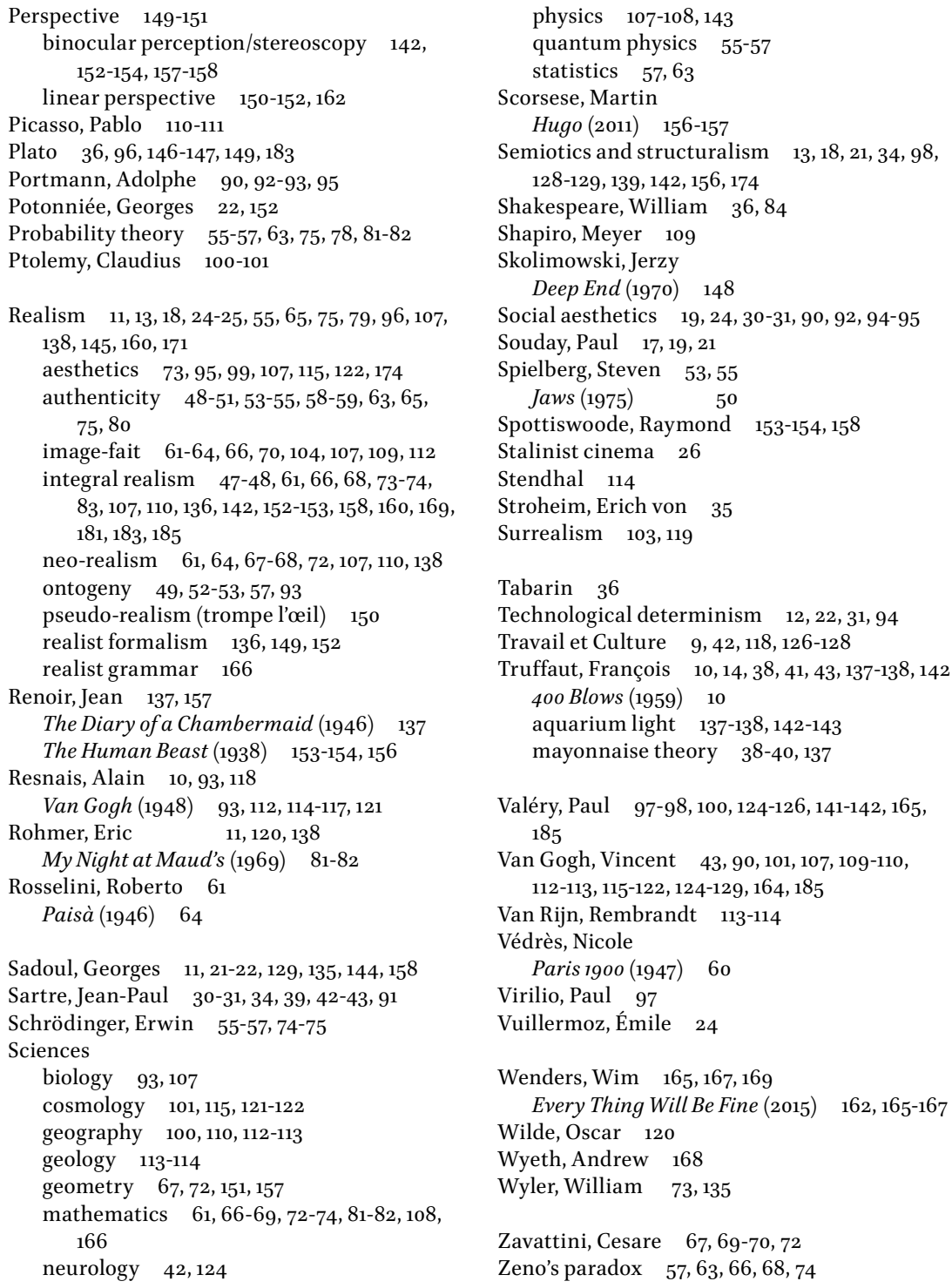


